Check for updates

Cite this: J. Mater. Chem. A, 2020, 8 , 4996

Received 5th November 2019

Accepted 5th February 2020

DOI: $10.1039 / c 9 t a 12169 b$

rsc.li/materials-a

\section{A review of phosphorus and phosphides as anode materials for advanced sodium-ion batteries}

\author{
Guoliang Chang, ${ }^{a}$ Yufeng Zhao, ${ }^{* a}$ Li Dong, ${ }^{a}$ David P. Wilkinson, ${ }^{b}$ Lei Zhang, ${ }^{\text {ac }}$ \\ Qinsi Shao, ${ }^{a}$ Wei Yan, ${ }^{a}$ Xueliang (Andy) Sun (D)*ad and Jiujun Zhang (D)*ab
}

Sodium-ion batteries (SIBs) are promising low-cost alternatives to lithium-ion batteries (LIBS) in energy storage applications because of the natural abundance of sodium as compared with lithium. However, the radius of $\mathrm{Na}^{+}$ ions is $\sim 50 \%$ larger than that of $\mathrm{Li}^{+}$ions, leading to challenging sodiation/desodiation at the anodes of SIBs and reduced performances. Therefore, the exploration of novel SIB anode materials to facilitate sodiation/ desodiation has become a leading area of research. Here, cost-effective phosphorus and metal/nonmetal phosphides, possessing high theoretical gravimetric capacities and volumetric specific capacities, have emerged as new and promising anode materials for SIBs. Based on this, this review will provide a comprehensive summary of the recent progress in the development of phosphorus and metal/nonmetal phosphide materials and corresponding composite SIB anodes in terms of material synthesis, characterization, sodium storage mechanism and performance validation in SIB apparatuses. In addition, challenges associated with the development of such advanced materials are summarized and analyzed. Finally, to facilitate the research and development of these emerging SIB anode materials, future research directions are proposed to overcome challenges toward the practical commercialization of sodium-ion batteries. anstitute for Sustainable Energy/College of Sciences, Shanghai University, Shanghai, 200444, China. E-mail: yufengzhao@shu.edu.cn; xsun9@uwo.ca; jiujun.zhang@i. shu.edu.cn

${ }^{b}$ Department of Chemical and Biochemical Engineering, University of British Columbia, Vancouver, BC, V6T 1 W5, Canada

${ }^{c}$ Energy, Mining, and Environment, National Research Council of Canada, Vancouver, BC, V6T 1W5, Canada

${ }^{d}$ Department of Mechanical and Materials Engineering, University of Western Ontario, London, Ontario, N6A 3K7, Canada

\section{Introduction}

Global demand for advanced energy storage and conversion technologies, especially electrochemical energy technologies such as batteries, is rapidly growing and among various types of batteries, Li-ion batteries (LIB) have shown success in many applications. ${ }^{1,2}$ However, although LIBs can meet the tough demands of energy storage and conversion applications, the limited abundance of lithium (only $20 \mathrm{ppm}$ ) needs to be

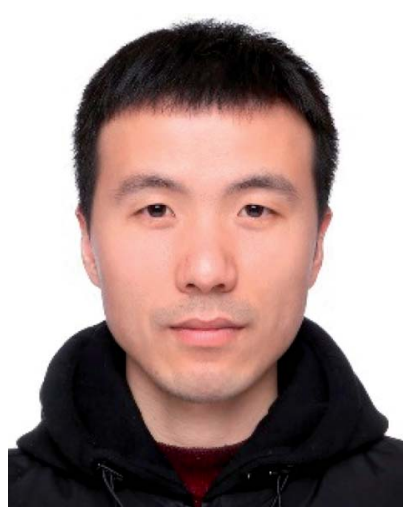

Guoliang Chang is currently a PhD candidate under the supervision of Prof. Jiujun Zhang at the College of Sciences/ Institute for Sustainable Energy, Shanghai University. His research interests include electrochemical energy storage and conversion, e.g., sodium-ion batteries and photoelectrochemical water splitting.

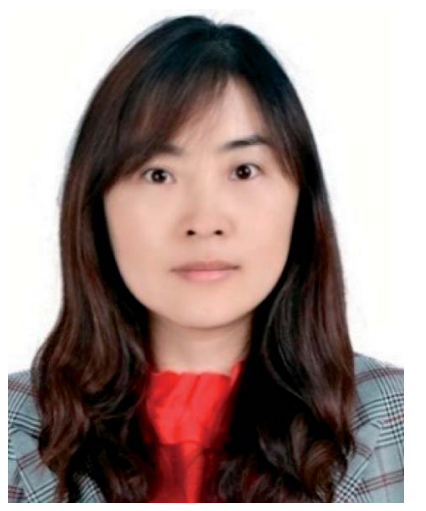

Dr Yufeng Zhao is currently working as a professor at Shanghai University. She received her B.S. and M.S. degrees from Tianjin University, China, in 2000 and 2003 respectively. She obtained her PhD from Nanyang Technological University, Singapore in 2006. Afterwards, she worked at Deakin University, Australia (2006-2008) and Phillips University Marburg, Germany (2008-2009) as a research scientist. She was also a visiting professor at Northwestern University (2014-2015). Her research mainly focuses on energy storage materials and devices, such as nanocarbon materials, supercapacitors, and electrocatalysts. 
considered in terms of sustainability. ${ }^{3}$ Therefore, the exploration of alternatives to replace lithium ion batteries is necessary. Fortunately, sodium has been identified as a suitable alternative to lithium as demonstrated by the practical feasibility of sodium-ion batteries (SIBs). ${ }^{4}$ Fig. 1a shows the comparison between lithium and sodium in terms of their atomic masses, electrode potentials, cationic radiuses, elemental abundances, and prices. It can be seen that sodium is the second-lightest and smallest alkali metal next to lithium and is one of the most abundant elements in Earth's crust with an average abundance of 28400 ppm. ${ }^{5}$ And in battery applications, sodium can provide a suitable electrochemical redox potential of $-2.71 \mathrm{~V} v s$. the standard hydrogen electrode (SHE), which is only $0.3 \mathrm{~V}$ less negative than that of lithium. Furthermore, sodium is much cheaper than lithium. Due to these promising properties, SIBS are promising alternatives to LIBs, in particular for large-scale applications such as energy storage systems for power grids. ${ }^{5}$

However, the ionic radius of $\mathrm{Na}$ is larger than that of $\mathrm{Li}(1.02 \AA$ for $\mathrm{Na}^{+} v s$. $0.76 \AA$ for $\mathrm{Li}^{+}$), which results in sluggish reaction kinetics and poor electrochemical performances in corresponding batteries. To address this, great efforts have been undertaken and in recent years, significant progress has been made for the cathodes of SIBs with a variety of materials being demonstrated as suitable cathodes for sodium ion storage. ${ }^{6-11}$ Fig. $2 \mathrm{~b}$ summarizes the main difference between lithium-ion batteries (LIBs) and sodium-ion batteries (SIBs) in terms of their cost, power density, energy density and overcharge resistibility. In general, the exploration of low-cost anodes for both LIBs and SIBs to match their corresponding cathodes as well as the corresponding synthesis strategies remain challenging. Similar to LIBs, carbonaceous materials such as hard carbon, ${ }^{12-19}$ graphitic carbon, ${ }^{20-22}$ and graphene ${ }^{23-28}$ along with novel materials such as metals, ${ }^{29-35}$ metal oxides, ${ }^{36-41}$ metal sulfides, ${ }^{42-48}$ metal selenides, ${ }^{49-54}$ metal alloys $^{55-64}$ and organic compounds ${ }^{65-69}$ have all been explored as anode materials for SIBs. Most recently, phosphorus (P) and phosphides $^{\mathbf{7 0 - 7 8}}$ have also been extensively explored for $\mathrm{Na}$ storage. Among these P-based materials, red phosphorus (RP) was the first to attract attention from researchers due to favorable properties as anode materials in SIBs, including a highest theoretical specific capacity of $\sim 2600 \mathrm{~mA} \mathrm{~h} \mathrm{~g}{ }^{-1}$ and a suitable insertion voltage of $\sim 0.4 \mathrm{~V} v s . \mathrm{Na} / \mathrm{Na}^{+} .^{79}$ The major advantages of SIBs are summarized in Fig. 1b. Particularly, RP is abundant, easily available and nontoxic, being identified as the most promising anode candidate material for practical SIBs (Fig. 1c). However, RP also possesses drawbacks such as low electrical conductivity $\left(\sim 10^{-14} \mathrm{~S} \mathrm{~cm}^{-1}\right)^{80}$ and large volume expansion after full sodiation (300-500\%), ${ }^{\mathbf{8 1}-83}$ leading to shortened cycle lifespans and poor rate performances in sodium storage applications; in addition, the sodiated product $\mathrm{Na}_{3} \mathrm{P}$ also shows a low electrical conductivity and the surface of $\mathrm{Na}_{3} \mathrm{P}$ is highly reactive which may cause a severe electrolyte decomposition. ${ }^{84}$ To overcome these issues, great efforts have been made and considerable progress has been achieved. Many composites such as amorphous $\mathrm{RP} /$ carbon, ${ }^{79,82} \mathrm{RP} /$ carbon nanotubes, ${ }^{85} \mathrm{RP} / \mathrm{Ni}-\mathrm{P}^{86}$ and hollow RP nanospheres ${ }^{87}$ have been prepared to improve the Na storage performance of RP anodes, which could buffer the volume expansion of RP during cycles and/or enhance the conductivity of electrodes. In addition to RP, black phosphorus (BP) is also gaining prominence due to a similarly high theoretical specific capacity to $\mathrm{RP}\left(\sim 2600 \mathrm{~mA} \mathrm{~h} \mathrm{~g}^{-1}\right)$ and a higher electronic conductivity $\left(\sim 300 \mathrm{~S} \mathrm{~m}^{-1}\right) .{ }^{88}$ However, large volume expansion, sluggish reaction kinetics and rigorous synthesis conditions also hinder the application of $\mathrm{BP}$ in $\mathrm{Na}$ storage devices. Phosphorene is one or few layers of BP and has also attracted much attention as a promising anode material due to its unique 2D structure (similar to a graphene).${ }^{89}$ Furthermore, metal phosphides, which usually possess higher electrical conductivities than phosphorus, ${ }^{77}$ can easily be synthesized into

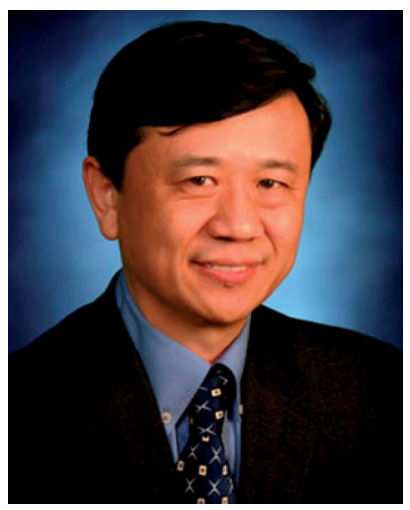

Prof. Xueliang (Andy) Sun holds a Canada Research Chair in the Development of Nanomaterials for Clean Energy, Fellow of the Royal Society of Canada and Canadian Academy of Engineering and Full Professor at the University of Western Ontario, Canada. Dr Sun received his PhD in materials chemistry in 1999 from the University of Manchester, UK, which he followed up by working as a postdoctoral fellow at the University of British Columbia, Canada and as a Research Associate at L'Institut National de la Recherche Scientifique (INRS), Canada. His current research interests are focused on advanced materials for electrochemical energy storage and conversion, including solid-state batteries and electrocatalysis in fuel cells.

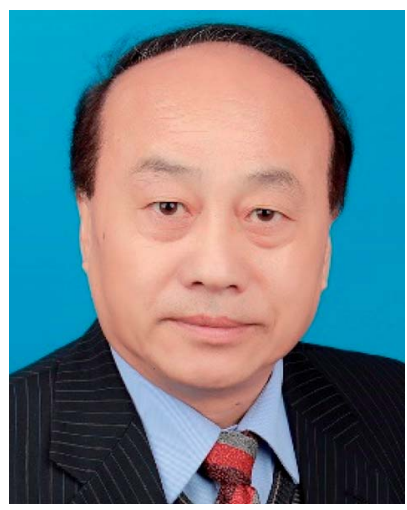

Dr Jiujun Zhang is a Professor at the College of Sciences/Institute for Sustainable Energy at Shanghai University, a former Principal Research Officer (Emeritus) at the National Research Council of Canada (NRC). Dr Zhang received his B.S. and M.Sc. in Electrochemistry from Peking University in 1982 and 1985, respectively, and his PhD in Electrochemistry from Wuhan University in 1988. Dr Zhang serves as an Editor-in-Chief of Electrochemical Energy Reviews (Springer Nature) and Associate Editor of Green Energy \& Environment (KeAi), and Editorial Board Member for several international journals as well as Editor for a book series of Electrochemical Energy Storage and Conversion (CRC). Dr Zhang's expertise areas are electrochemistry, electrocatalysis, fuel cells, batteries, supercapacitors, and water $/ \mathrm{CO}_{2}$ electrolysis. 


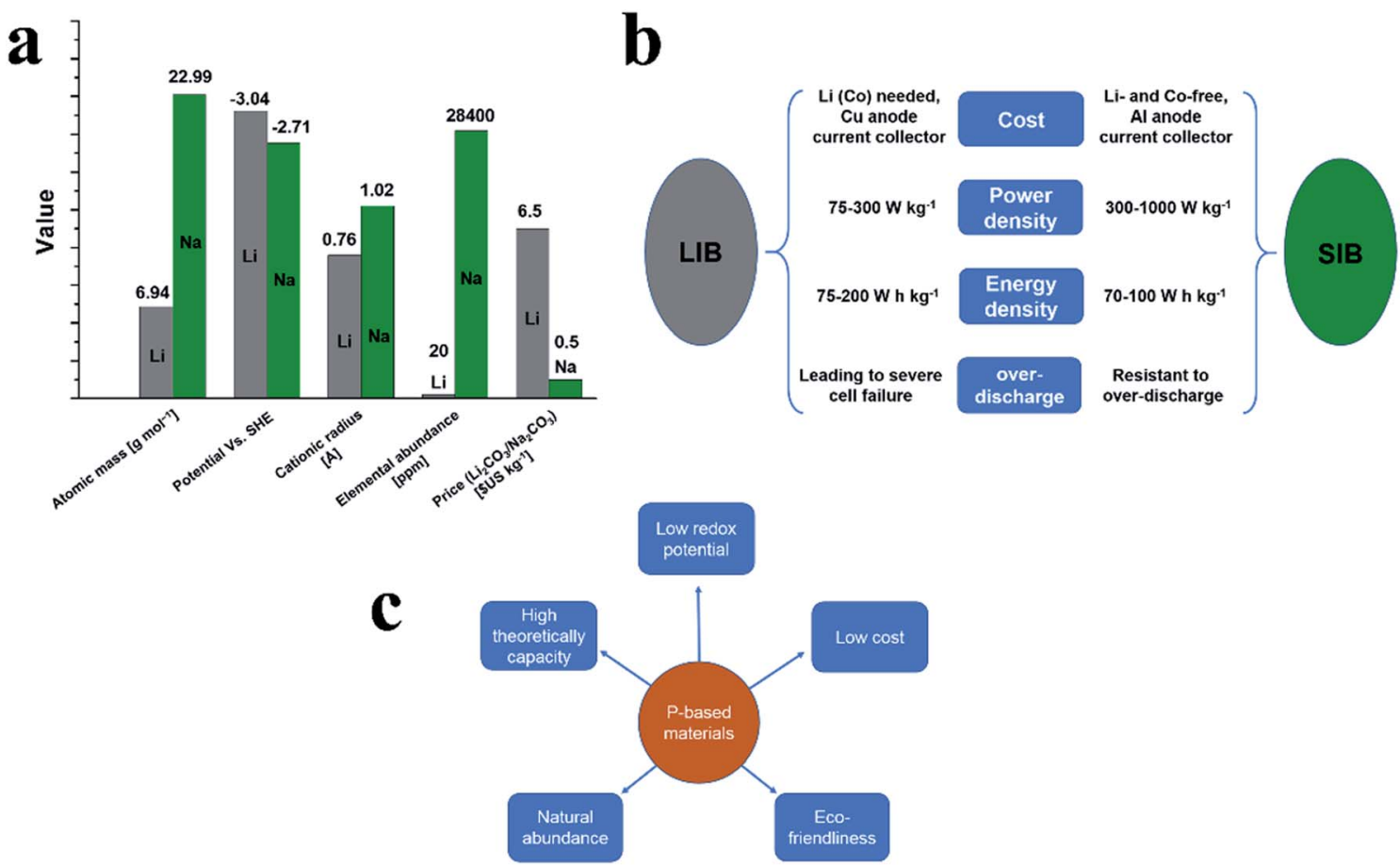

Fig. 1 (a) Major property differences between lithium and sodium; (b) main differences between lithium-ion batteries (LIBs) and sodium-ion batteries (SIBs); (c) main advantages of phosphorus/phosphides as anode materials for SIBs.

various nanostructures and are also promising anode materials for SIBs. Some unique metal phosphide nanostructures such as $\mathrm{CoP}_{4}$ nanoarrays, ${ }^{90}$ yolk-shell $\mathrm{Sn}_{4} \mathrm{P}_{3} @ \mathrm{C}$ nanospheres ${ }^{91}$ and monodisperse $\mathrm{Ni}_{2} \mathrm{P}$ nanocrystals ${ }^{92}$ have been prepared and showed excellent Na-ion storage performance as anode materials. Finally, non-metal phosphides and ternary phosphides as supplemental materials to metal phosphides have also experienced great progress for practical application in SIBs.
Because of all these advancements, this review will comprehensively summarize the recent progress in the research and development of phosphorus and phosphide composites for SIB anodes. It covers the structural properties and sodium storage mechanisms of these composites as well as the design strategies. In addition, the advantages and limitations of current synthesis methods for the preparation of phosphorus/phosphide anodes are also discussed. And to facilitate future research efforts, $\mathbf{a}$

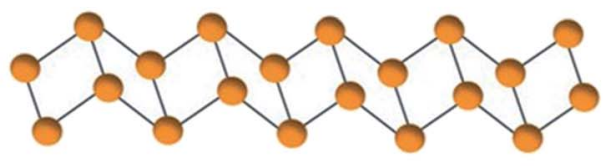

b

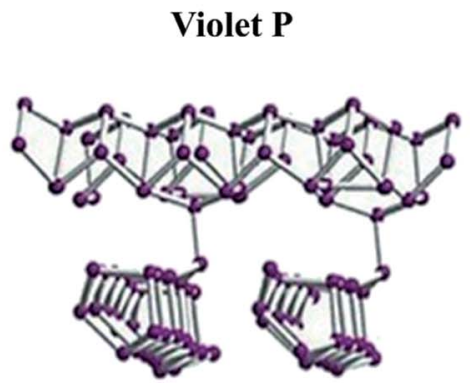

c

Fibrous P
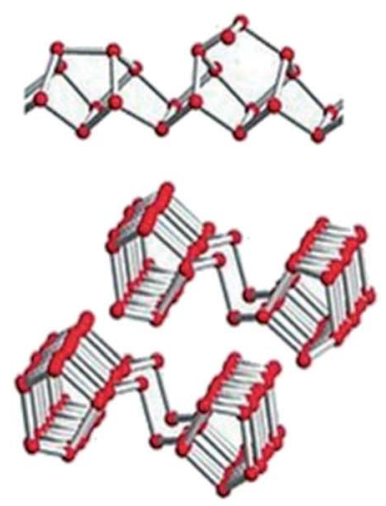

Fig. 2 Characteristic structural fragments of (a) amorphous RP; (b) violet P (Hittorf's P); (c) fibrous P. (a) Reproduced with permission. ${ }^{100}$ Copyright 2019, WILEY-VCH. (b, c) Reproduced with permission. ${ }^{113}$ Copyright 2017, Wiley-VCH. 
associated challenges are also presented and analyzed as well as possible research directions to address these challenges.

\section{Phosphorus anodes for SIBs}

In general, elemental phosphorus exists in three allotropes, namely, red, black and white phosphorus. White phosphorus is flammable and toxic, and not suitable for SIBs, whereas RP and $\mathrm{BP}$ can react with sodium to form $\mathrm{Na}_{3} \mathrm{P}$ and present high theoretical capacities of $\sim 2600 \mathrm{~mA} \mathrm{~h} \mathrm{~g}{ }^{-1}$ as electrochemical sodium storage materials. ${ }^{93}$ Compared with $\mathrm{BP}$, which is difficult to synthesize, RP is more commercially available, and thus is regarded as the most promising candidate for SIB anode materials. In addition, phosphorene (one or several layers of BP)

Table 1 Summary of recent progress of phosphorus anodes in SIBs

\begin{tabular}{|c|c|c|c|c|c|c|}
\hline Material & Synthetic method & Cycling performance & Rate capability & $\mathrm{P}$ content & $\begin{array}{l}\text { Initial coulombic } \\
\text { efficiency }\end{array}$ & Ref. \\
\hline RP/CNT & Hand grinding & $\begin{array}{l}1283 \mathrm{~mA} \mathrm{~h} \mathrm{~g}^{-1}, \\
\text { at } 143 \mathrm{~mA} \mathrm{~g}^{-1}, 10 \mathrm{th}\end{array}$ & - & $70 \%$ & $69 \%$ & 121 \\
\hline $\mathrm{RP} /$ graphene & Ball milling & $\begin{array}{l}1700 \mathrm{~mA} \mathrm{~h} \mathrm{~g}^{-1} \\
\text { at } 520 \mathrm{~mA} \mathrm{~g}^{-1}, 60 \mathrm{th}\end{array}$ & $\begin{array}{l}520 \mathrm{~mA} \mathrm{~h} \mathrm{~g}^{-1} \\
5200 \mathrm{~mA} \mathrm{~g}^{-1}\end{array}$ & $70 \%$ & $83 \%$ & 73 \\
\hline $\mathrm{RP} / \mathrm{CNT} / \mathrm{PDA}$ & Ball milling & $\begin{array}{l}470 \mathrm{~mA} \mathrm{~h} \mathrm{~g} \\
\text { at } 5200 \mathrm{~mA} \mathrm{~g}^{-1}, 5000 \text { th }\end{array}$ & $\begin{array}{l}1060 \mathrm{~mA} \mathrm{~h} \mathrm{~g}^{-1}, \\
2600 \mathrm{~mA} \mathrm{~g}^{-1}\end{array}$ & $66.04 \%$ & $\sim 60 \%$ & 122 \\
\hline $\mathrm{RP} / \mathrm{C}$ & Ball milling/spray drying & $\begin{array}{l}1408 \mathrm{~mA} \mathrm{~h}_{\mathrm{p}}^{-1} \\
\text { at } 0.1 \mathrm{~A} \mathrm{~g}^{-1}, 300 \text { th }\end{array}$ & $\begin{array}{l}986 \mathrm{~mA} \mathrm{~h} \mathrm{~g}_{\mathrm{p}}^{-1} \\
2000 \mathrm{~mA} \mathrm{~g}^{-1}\end{array}$ & $42.5 \%$ & $86.2 \%$ & 125 \\
\hline RP-graphene & Ball milling & $\begin{array}{l}2172 \mathrm{~mA} \mathrm{~h} \mathrm{~g}^{-1} \\
\text { at } 250 \mathrm{~mA} \mathrm{~g}^{-1}, 150 \text { th }\end{array}$ & $\begin{array}{l}342 \mathrm{~mA} \mathrm{~h} \mathrm{~g}^{-1} \\
2600 \mathrm{~mA} \mathrm{~g}^{-1}\end{array}$ & - & - & 126 \\
\hline $\mathrm{P}-\mathrm{TiO}_{2}-\mathrm{C}$ & Ball milling & $\begin{array}{l}632 \mathrm{~mA} \mathrm{~h} \mathrm{~g} \\
\text { at } 500 \mathrm{~mA} \mathrm{~g}^{-1}, 100 \mathrm{th}\end{array}$ & $\begin{array}{l}958.9 \mathrm{~mA} \mathrm{~h} \mathrm{~g}^{-1} \\
1000 \mathrm{~mA} \mathrm{~g}^{-1}\end{array}$ & $60 \%$ & $77 \%$ & 130 \\
\hline RP/boron nitride/Gr & Ball milling & $\begin{array}{l}947 \mathrm{~mA} \mathrm{~h} \mathrm{~g}{ }^{-1} \\
\text { at } 50 \mathrm{~mA} \mathrm{~g}^{-1}, 100 \text { th }\end{array}$ & $\begin{array}{l}776 \mathrm{~mA} \mathrm{~h} \mathrm{~g}^{-1} \\
300 \mathrm{~mA} \mathrm{~g}^{-1}\end{array}$ & $42 \%$ & $64 \%$ & 179 \\
\hline $\mathrm{Fe}_{3} \mathrm{O}_{4} / \mathrm{C} / \mathrm{RP}$ & Vaporization/condensation & $\begin{array}{l}1390 \mathrm{~mA} \mathrm{~h} \mathrm{~g} \\
\text { at } 200 \mathrm{~mA} \mathrm{~g}^{-1}, 200 \mathrm{th}\end{array}$ & $\begin{array}{l}692 \mathrm{~mA} \mathrm{~h} \mathrm{~g}^{-1} \\
2000 \mathrm{~mA} \mathrm{~g}^{-1}\end{array}$ & $25 \%$ & $80.4 \%$ & 129 \\
\hline $\mathrm{RP} / \mathrm{C}$ & Vaporization/condensation & $\begin{array}{l}700 \mathrm{~mA} \mathrm{~h} \mathrm{~g}^{-1} \\
\text { at } 2 \mathrm{~A} \mathrm{~g}^{-1}, 920 \text { th }\end{array}$ & $\begin{array}{l}500 \mathrm{~mA} \mathrm{~h} \mathrm{~g}^{-1} \\
10 \mathrm{~A} \mathrm{~g}^{-1}\end{array}$ & $\sim 60 \%$ & $69.9 \%$ & 134 \\
\hline P@RGO & Vaporization/condensation & $\begin{array}{l}914 \mathrm{~mA} \mathrm{~h} \mathrm{~g} \\
\text { at } 1594 \mathrm{~mA} \mathrm{~g}^{-1}, \text { 300th }\end{array}$ & $\begin{array}{l}519 \mathrm{~mA} \mathrm{~h} \mathrm{~g}^{-1} \\
31.88 \mathrm{~A} \mathrm{~g}^{-1}\end{array}$ & $61.4 \%$ & $75.2 \%$ & 132 \\
\hline $\mathrm{RP} / \mathrm{C}$ & Vaporization/condensation & $\begin{array}{l}580 \mathrm{~mA} \mathrm{~h} \mathrm{~g}{ }^{-1}, \\
\text { at } 2500 \mathrm{~mA} \mathrm{~g}^{-1}, 800 \text { th }\end{array}$ & $\begin{array}{l}430 \mathrm{~mA} \mathrm{~h} \mathrm{~g}^{-1} \\
8000 \mathrm{~mA} \mathrm{~g}^{-1}\end{array}$ & $\sim 40 \%$ & $69.8 \%$ & 117 \\
\hline RP@RGO & Vaporization/condensation & $\begin{array}{l}1625 \mathrm{~mA} \mathrm{~h} \mathrm{~g}^{-1}, \\
\text { at } 1000 \mathrm{~mA} \mathrm{~g}^{-1}, 200 \mathrm{th}\end{array}$ & $\begin{array}{l}679 \mathrm{~mA} \mathrm{~h} \mathrm{~g}^{-1} \\
6000 \mathrm{~mA} \mathrm{~g}^{-1}\end{array}$ & $57.9 \%$ & $73.2 \%$ & 133 \\
\hline RP@YP & Vaporization/condensation & $\begin{array}{l}1064 \mathrm{~mA} \mathrm{~h} \mathrm{~g}_{\mathrm{p}}^{-1}, \\
\text { at } 420 \mathrm{~mA} \mathrm{~g}^{-1}, 100 \text { th } \\
533 \mathrm{~mA} \mathrm{~h} \mathrm{~g}_{\mathrm{p}}^{-1}, \\
\text { at } 420 \mathrm{~mA} \mathrm{~g}^{-1}, 1000 \text { th }\end{array}$ & $\begin{array}{l}601 \mathrm{~mA} \mathrm{~h} \mathrm{~g}^{-1} \\
6780 \mathrm{~mA} \mathrm{~g}_{\mathrm{p}}^{-1}\end{array}$ & $48 \%$ & $68 \%$ & 136 \\
\hline Hollow P sphere & Solvothermal & $\begin{array}{l}1500 \mathrm{~mA} \mathrm{~h} \mathrm{~g}^{-1}, \\
\text { at } 1300 \mathrm{~mA} \mathrm{~g}^{-1}, 80 \mathrm{th} \\
970 \mathrm{~mA} \mathrm{~h} \mathrm{~g}{ }^{-1}, \\
\text { at } 2600 \mathrm{~mA} \mathrm{~g}^{-1}, 600 \text { th }\end{array}$ & $\begin{array}{l}278 \mathrm{~mA} \mathrm{~h} \mathrm{~g}^{-1} \\
10.4 \mathrm{~A} \mathrm{~g}^{-1}\end{array}$ & $99.9 \%$ & $77.3 \%$ & 87 \\
\hline Porous RP/GO & Boiling method & $\begin{array}{l}1250 \mathrm{~mA} \mathrm{~h} \mathrm{~g}^{-1} \\
\text { at } 173 \mathrm{~mA} \mathrm{~g}^{-1}, 150 \mathrm{th}\end{array}$ & $\begin{array}{l}657 \mathrm{~mA} \mathrm{~h} \mathrm{~g}^{-1} \\
3465 \mathrm{~mA} \mathrm{~g}^{-1}\end{array}$ & $67.6 \%$ & $78.5 \%$ & 144 \\
\hline I-Doped hollow porous RP & $\begin{array}{l}\text { Redox reaction } \\
\text { Boiling process }\end{array}$ & $\begin{array}{l}1658 \mathrm{~mA} \mathrm{~h} \mathrm{~g}^{-1}, \\
\text { at } 260 \mathrm{~mA} \mathrm{~g}^{-1}, 100 \mathrm{th}\end{array}$ & $\begin{array}{l}760 \mathrm{~mA} \mathrm{~h} \mathrm{~g}^{-1} \\
5200 \mathrm{~mA} \mathrm{~g}^{-1}\end{array}$ & $\sim 100 \%$ & $75.6 \%$ & 145 \\
\hline RPQDs/rGO & Hydrothermal & $\begin{array}{l}900 \mathrm{~mA} \mathrm{~h} \mathrm{~g} \\
\text { at } 250 \mathrm{~mA} \mathrm{~g}^{-1}, 250 \mathrm{th}\end{array}$ & $\begin{array}{l}193 \mathrm{~mA} \mathrm{~h} \mathrm{~g}^{-1} \\
4000 \mathrm{~mA} \mathrm{~g}^{-1}\end{array}$ & $55.7 \%$ & $55.5 \%$ & 146 \\
\hline RP@C & $\begin{array}{l}\text { Shear emulsifying } \\
\text { electrospinning }\end{array}$ & $\begin{array}{l}821 \mathrm{~mA} \mathrm{~h} \mathrm{~g}{ }^{-1}, \\
\text { at } 1000 \mathrm{~mA} \mathrm{~g}^{-1}, 300 \mathrm{th}\end{array}$ & $\begin{array}{l}676 \mathrm{~mA} \mathrm{~h} \mathrm{~g}^{-1} \\
5000 \mathrm{~mA} \mathrm{~g}^{-1}\end{array}$ & $51 \%$ & $75 \%$ & 127 \\
\hline NTO/C-BP & Ball milling & $\begin{array}{l}225 \mathrm{~mA} \mathrm{~h} \mathrm{~g}{ }^{-1} \\
\text { at } 20 \mathrm{~mA} \mathrm{~g}^{-1}, 55 \mathrm{th}\end{array}$ & - & $20 \%$ & $42 \%$ & 177 \\
\hline BP-CNT & Ball milling & $\begin{array}{l}1092 \mathrm{~mA} \mathrm{~h} \mathrm{~g}^{-1}, \\
\text { at } 520 \mathrm{~mA} \mathrm{~g}^{-1}, 200 \mathrm{th}\end{array}$ & $\begin{array}{l}441 \mathrm{~mA} \mathrm{~h} \mathrm{~g}^{-1} \\
11.7 \mathrm{~A} \mathrm{~g}^{-1}\end{array}$ & $74.5 \%$ & $87.7 \%$ & 174 \\
\hline $\mathrm{BP} / \mathrm{G}$ & $\begin{array}{l}\text { Sonication } \\
\text { Electrophoretic deposition }\end{array}$ & $\begin{array}{l}1297 \mathrm{~mA} \mathrm{~h} \mathrm{~g}^{-1} \\
\text { at } 100 \mathrm{~mA} \mathrm{~g}^{-1}, 100 \text { th }\end{array}$ & $\begin{array}{l}623 \mathrm{~mA} \mathrm{~h} \mathrm{~g}^{-1} \\
500 \mathrm{~mA} \mathrm{~g}^{-1}\end{array}$ & $50 \%$ & $75.6 \%$ & 175 \\
\hline BP/C-MWNT & Ball milling & $\begin{array}{l}1700 \mathrm{~mA} \mathrm{~h} \mathrm{~g}{ }^{-1}, \\
\text { at } 1300 \mathrm{~mA} \mathrm{~g}^{-1}, 100 \text { th (for BP) }\end{array}$ & $\begin{array}{l}928 \mathrm{~mA} \mathrm{~h} \mathrm{~g}^{-1} \\
3000 \mathrm{~mA} \mathrm{~g}^{-1}\end{array}$ & $70 \%$ & $91.1 \%$ & 173 \\
\hline Phosphorene-C & Liquid-phase exfoliation & $\begin{array}{l}2080 \mathrm{~mA} \mathrm{~h} \mathrm{~g}^{-1} \\
\text { at } 50 \mathrm{~mA} \mathrm{~g}^{-1}, 100 \mathrm{th}\end{array}$ & $\begin{array}{l}645 \mathrm{~mA} \mathrm{~h} \mathrm{~g}^{-1} \\
26 \mathrm{~A} \mathrm{~g}^{-1}\end{array}$ & $48.3 \%$ & $80 \%$ & 72 \\
\hline Phosphorene & Electrochemical exfoliation & $\begin{array}{l}\sim 1190 \mathrm{~mA} \mathrm{~h} \mathrm{~g}^{-1}, \\
\text { at } 100 \mathrm{~mA} \mathrm{~g}^{-1}, 50 \mathrm{th}\end{array}$ & $\begin{array}{l}591 \mathrm{~mA} \mathrm{~h} \mathrm{~g}^{-1} \\
1500 \mathrm{~mA} \mathrm{~g}^{-1}\end{array}$ & $100 \%$ & $\sim 50 \%$ & 188 \\
\hline
\end{tabular}


has also attracted great interest for Na-ion storage because of its unique 2D structure, high electronic conductivity, and other advantages. Recently, some new allotropic modifications of $\mathrm{P}$ have been experimentally produced, such as blue phosphorus ${ }^{\mathbf{9 4}}$ and ring-shaped phosphorus within carbon nanotube nanoreactors $;^{95}$ nevertheless, these allotropes have not been experimentally applied in batteries yet. ${ }^{96}$ So in this section, we will present recent advances in RP, BP and phosphorene anodes for SIBs. And Table 1 summarizes these recent developments.

\subsection{Red phosphorus}

$\mathrm{RP}$ is the most abundant and easily available allotrope of elemental phosphorus, ${ }^{97,98}$ and is chemically stable and nontoxic to the environment. ${ }^{99}$ Commercial RP exhibits an amorphous form or an intermediate state between amorphous and crystalline. ${ }^{79,100,101}$ RP has been widely used in our daily life and industry, such as safety matches, ${ }^{\mathbf{1 0 2}}$ flame retardants ${ }^{\mathbf{1 0 3}}$ and chemical analysis. ${ }^{\mathbf{1 0 4}}$ Recently, the application of RP has extended to the field of semiconductors, ${ }^{105}$ rechargeable batteries $^{\mathbf{8 2}}$ and photocatalysts ${ }^{\mathbf{1 0 6}}$ with the progress of nanotechnology. And it is necessary to understand the structural information of RP for further research. Roth et al. ${ }^{107}$ proposed five distinct allotropes of RP, four crystalline (Types II to V) and one amorphous (Type I). The exact structures of these four crystalline types can be determined by X-ray diffraction (XRD) or other methods. For example, Type IV (fibrous RP) and Type V (violet P or Hittorf's P) were confirmed to consist of tubes with a pentagonal cross section, which in turn are a regular sequence of three different building units (Fig. 2b and c). ${ }^{\mathbf{1 0 0 , 1 0 8 - 1 1 0 , 1 1 3}}$ As for amorphous RP, the exact structure remained unclear until Zhang et al. ${ }^{\mathbf{1 0 0}}$ investigated some of its basic properties by several experimental methods, including scanning tunneling microscopy (STM), gel permeation chromatography (GPC) and single-molecule atomic-force microscopy (AFM). Based on the results, they proposed that amorphous RP should be a linear inorganic polymer with a broad molecular weight distribution (mainly at $31000 \pm 20000 \mathrm{Da}$ ) and with a zig-zag ladder chain structure (85 $\pm 55 \mathrm{~nm}$ ), as shown in Fig. 2a. ${ }^{100}$ Compared with crystalline RP, amorphous RP seems more advantageous in accommodating the volumetric expansion during $\mathrm{Li}^{+} / \mathrm{Na}^{+}$ insertion-extraction cycles. In fact, most RP anodes for $\mathrm{Li} / \mathrm{Na}$ ion batteries in the literature are in the amorphous form, especially for Na-ion batteries. ${ }^{\mathbf{8 2 , 1 1 1}}$ However, because RP anodes usually exhibit an amorphous form and most of the sodiated RP phases are also amorphous, ${ }^{82}$ they are difficult to investigate in terms of sodiation and desodiation mechanisms. ${ }^{82}$ Nevertheless, it is acknowledged that the sodiation of RP mainly occurs between $0.5 \mathrm{~V}$ and $0 \mathrm{~V}$ to form $\mathrm{Na}_{3} \mathrm{P}$, while the desodiation process involves a stepwise sodium extraction from $\mathrm{Na}_{3} \mathrm{P}$ with possible intermediates such as $\mathrm{Na}_{2} \mathrm{P}, \mathrm{NaP}$ and $\mathrm{NaP}_{7} .^{76,79,87}$

Although RP possesses great potential for practical application in SIBs due to high theoretical capacity, low redox potential $(<0.4 \mathrm{~V}){ }^{82}$ natural abundance and eco-friendliness, major drawbacks such as low electronic conductivity $\left(\sim 10^{-14} \mathrm{~S} \mathrm{~cm}^{-1}\right),,^{80}$ large volume expansion during sodiation $(300-500 \%)^{81,82,112}$ and low initial coulombic efficiency hinder its application. There are several approaches to overcome these drawbacks: one is to combine RP nanostructures with electronic conductive materials and supporting matrices including carbon-based materials, conductive polymers, metals, metal oxides or metal phosphides; another one is to synthesize novel or self-supported RP nanostructures, and particle surface modification may also be a potential method to address these issues.

2.1.1 Combination with carbon-based materials or conductive polymers. Various carbon-based materials possess high electronic conductivity and/or mechanical robustness, such as Super $P ®$ carbon, carbon nanotubes and graphene. These materials can be used to enhance the conductivity of RP based anodes and mitigate the expansion of RP during charge/ discharge cycles, leading to an enhanced $\mathrm{Na}$ storage performance. Recently, conductive polymers such as polyacrylonitrile (PAN) and poly-pyrrole (PPy) have also been used as host materials or a protective layer for RP.

As for the synthesis of RP anode composites, two conventional methods are mainly used, including ball milling (or other mechanical milling methods) and vaporization/condensation methods. Ball milling (high energy) is a mechanochemical process that is facile and cost-effective to produce a wide range of nano-powders from bulk raw materials. During a high energy and long-term ball milling process, chemical reactions and structural changes can occur and allow for the formation of new phases or complex composites. ${ }^{\mathbf{1 1 4}}$ The vaporization-condensation method is also an effective approach to prepare $\mathrm{RP} /$ carbon composites. ${ }^{115}$ In a typical process, RP is first sublimated by heating and the gaseous $\mathrm{P}$ subsequently diffused into the pores or on the surface of the carbon matrix through capillary forces and pressure differences, and then the $\mathrm{P}$ is adsorbed and deposited onto the internal surface to form solid RP as the temperature drops down. ${ }^{\mathbf{8 1 1 6}}$ Compared with mechanical strategies, the vaporization-condensation method can ensure the uniform dispersal or adsorption of RP into carbon matrices and facilitate intimate contact between RP and host materials. ${ }^{\mathbf{1 1 6}}$ However, the RP content in the composite synthesized by this method was usually not high. Some other methods such as solvothermal and hydrothermal have also been applied to prepare RP nanostructure/nanocomposite, which will be fully discussed in latter sections. Among these various synthesis methods, the high energy ball milling method is the most widely used approach to prepare RP-based anodes for both LIBs and SIBs.

RP was used as the anode material in LIBs earlier than in SIBs, ${ }^{115,118,119}$ and researchers found that the lithium ion storage capacity of RP depended dramatically on its crystalline structure and morphology, and a better lithium ion storage performance could be obtained when the crystalline and large-size RP was transformed into amorphous RP nanoparticles. ${ }^{\mathbf{1 2 0}}$ Soon after these reports, Qian et al. and Kim et al. ${ }^{79,82}$ first introduced RP into SIBs, and respectively prepared an amorphous $\mathrm{RP} /$ carbon nanocomposite as an anode by simply ball milling commercially available amorphous RP and Super P $(7: 3)$. They found that the micro-sized commercially available RP could not react with $\mathrm{Na}$ reversibly in spite of a large initial specific capacity 
obtained, while the ball-milled RP nanoparticles show a much better Na-ion storage performance. During this long-term and high-energy ball milling process, bulk commercial phosphorus particles were crushed into amorphous nanoparticles under a strong mechanical force, dispersing into the conductive carbon matrix. Due to the short electron/ion transfer route and the amorphous form of RP, these $\mathrm{P} / \mathrm{C}$ nanocomposites exhibited high reversible capacity and high rate capability, for example, a rate capability of $1540 \mathrm{~mA} \mathrm{~h} \mathrm{~g} \mathrm{~g}^{-1}$ at a current density of $2.86 \mathrm{~A} \mathrm{~g}^{-1}$ could be obtained. ${ }^{82}$ Interestingly, Li et al. ${ }^{\mathbf{2 1}}$ demonstrated that commercial micro-sized RP could also deliver a high reversible capacity after being mixed with carbon nanotubes (CNTs) by simple hand milling. And the authors proposed that a good electronic conductivity is essential for RP to reversibly react with $\mathrm{Na}$. This indicates that increasing the electronic conductivity of RP is an effective way to improve the Na storage performance of RP anodes in terms of either the rate capability and the specific capacity. As the combination of RP with CNTs shows noticeable success, predictably, ball milling of $\mathrm{RP}$ and carbon materials with high mechanical strength such as
CNTs or graphene may produce amazing results. Song et al. ${ }^{73}$ found that after a ball milling process of RP and graphene stacks, the graphene stacks were mechanically exfoliated to nanosheets, and more importantly, these nanosheets were chemically bonded with the surfaces of RP particles. Benefiting from this robust and intimate contact, the graphene at the particle surfaces could help to maintain electrical contact and stabilize the solid electrolyte interphase upon the large volume change of RP during cycling, leading to an improved cycling stability.

However, these simply ball milled RP anodes often suffered from insufficient rate capability and long-term stability, mainly caused by the large and rough particle size for this method, as the larger particle size means a longer diffusion length for electrons/ions, leading to unsatisfactory rate performance. And it also causes severe pulverization of RP after repeated large volume changes between $\mathrm{P}$ and $\mathrm{Na}_{3} \mathrm{P}$, and as a result, lots of pulverized RP particles are electrically isolated in the anode, ${ }^{83}$ and a continuous solid electrolyte interphase (SEI) growth occurs, leading to fast capacity decay. To address these issues,
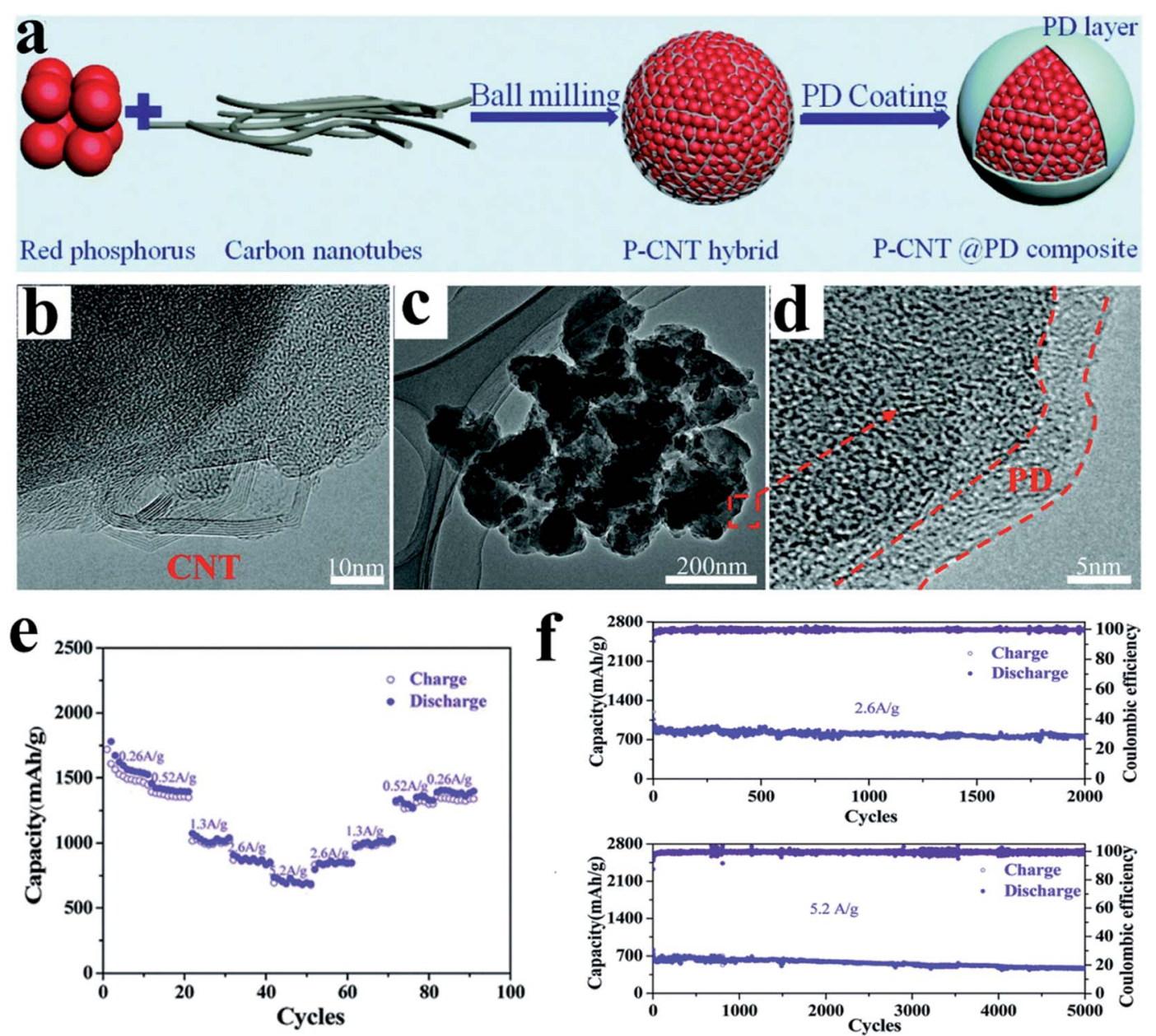

Fig. 3 (a) Schematic of the synthesis of the P-CNTaPD composite. (b) HRTEM image of the P-CNT hybrid. (c) TEM and (d) HRTEM images of the P-CNT@PD composite. (e) Rate performances at various current densities from $0.26 \mathrm{~A} \mathrm{~g}^{-1}$ to $5.2 \mathrm{~A} \mathrm{~g}^{-1}$ of the P-CNT@PD composite between 0.001 and $2.0 \mathrm{~V}$ (vs. $\mathrm{Na}^{+} / \mathrm{Na}$ ). (f) Long-term cycling performances of the P-CNT@PD composite at $2.6 \mathrm{~A} \mathrm{~g}^{-1}$ and $5.2 \mathrm{~A} \mathrm{~g}^{-1}$ between 0.001 and $2.0 \mathrm{~V}$ (vs. $\mathrm{Na}^{+} / \mathrm{Na}$ ). Reproduced with permission. ${ }^{122}$ Copyright 2018, The Royal Society of Chemistry. 
combination with conductive polymers is an effective strategy. For example, Liu et al. ${ }^{122}$ recently designed a strategy to in situ coat ball milled $\mathrm{P} / \mathrm{C}$ hybrids (phosphorus-carbon nanotube, $\mathrm{P}$ CNT) with a polydopamine layer (Fig. 3a-d). They proposed that the coating layer could provide an elastic buffer to accommodate active material volume change and prevent their direct contact with electrolytes. As a result, the P-CNT@PD (PD, polydopamine) composite anode presented high rate capacities of $1060 \mathrm{~mA} \mathrm{~h} \mathrm{~g}^{-1}$ in the second discharge and $730 \mathrm{~mA} \mathrm{~h} \mathrm{~g}$ after 2000 cycles at $2.6 \mathrm{~A} \mathrm{~g}^{-1}$ and high cycling stabilities with $470 \mathrm{~mA} \mathrm{~h} \mathrm{~g}{ }^{-1}$ capacity retained after 5000 cycles at $5.2 \mathrm{~A} \mathrm{~g}^{-1}$ (Fig. 3e and f), and this is the longest cycle lifespan that has ever been reported for RP-based materials.

In another exmaple, ${ }^{123}$ a conductive polymer of sulfurized polyacrylonitrile (SPAN) was ball milled with RP, forming a chemically bonded RP/SPAN hybrid. The functional conductive matrix with robust $\mathrm{P}-\mathrm{S}$ bonds linked to RP could accommodate the large volume change during cycles and enhance the conductivity of the anode. Consequently, this hybrid anode delivered a capacity of $\sim 1300 \mathrm{~mA} \mathrm{~h} \mathrm{~g}^{-1}$ at $520 \mathrm{~mA} \mathrm{~g}^{-1}$ and good cycling performance ( $91 \%$ capacity retention after 100 cycles).

Song et al. ${ }^{124}$ developed a novel cross-linked polymer binder and found that it could effectively maintain the structural stability of RP anodes during cycling. They first prepared a chemically bonded RP-carbon nanotube hybrid (P-CNT) as an active material through ball milling, and then, this cross-linked sodium carboxymethyl cellulose-citric acid was used as a binder to fabricate a robust RP electrode, in which citric acid functioned as a cross-linker to form a 3D network when drying the electrode at $150{ }^{\circ} \mathrm{C}$ for $2 \mathrm{~h}$. As a result, a high reversible capacity of $2134 \mathrm{~mA} \mathrm{~h} \mathrm{~g}^{-1}$ and good cycling stability ( $\sim 91 \%$ capacity retention after 100 cycles) were achieved, with a high initial coulombic efficiency of $84.7 \%$. Similarly, Xu et al. ${ }^{125}$ used sodium alginate as a binder to synthesize an affordable phosphorus/carbon (APC) anode and obtained an improved electrochemical performance. APC nano/microspheres were prepared by ball milling of RP, flake graphite, CNTs, Super $\mathrm{P}{ }^{\circledR}$ carbon and sodium alginate (SA, a biomass binder), followed by a closed spray drying process (Fig. 4a). The researchers proposed that this binder-filled phosphorus/carbon structure could maintain the structural integrity after repetitive volume variation and enhance the overall electrical conductivity of the RP anode due to its porous structure and strong surface interactions (Fig. 4b). As a result, this anode delivered a high reversible capacity of $1408 \mathrm{~mA} \mathrm{~h} \mathrm{~g}_{\mathrm{P}}{ }^{-1}$ at $100 \mathrm{~mA} \mathrm{~g}^{-1}$ with a capacity retention of $82.6 \%$ for over 300 cycles and showed superior rate capabilities, demonstrating that this industrially adaptable process and the application of sodium alginate binders are promising methods for RP-based practical SIBS (Fig. 4c). However, the low RP content in this anode $(\sim 42.5 \%)$ and the massive usage of carbon-based materials may cause issues with respect to gravimetric/volumetric capacity for practical application.

To investigate whether the carbon defects of the carbon scaffold in a anode have an effect on the electrochemical performance, Li et al. ${ }^{\mathbf{1 2 6}}$ designed a carbon scaffold containing controlled single-walled carbon nano-horn (SWCNH) and single-walled carbon nanotube (SWCNT) compositions, and combined this carbon scaffold with RP by hand milling. The researcher chose these two kinds of carbon for the reason that SWCNHs exhibit a significant presence of $\mathrm{sp}^{3}$ hybridized carbon defects embedded into the $\mathrm{sp}^{2}$ hybridized carbon matrix while SWCNTs are fully based on defect-free $\mathrm{sp}^{2}$ hybridized carbon species, and thus carefully controlled defect density composites can be obtained. Here, they reported that the stable alloy region in which $\mathrm{NaP}$ and $\mathrm{Na}_{5} \mathrm{P}_{4}$ were formed between 0.40 and $0.15 \mathrm{~V}$ versus $\mathrm{Na} / \mathrm{Na}^{+}$was mostly independent of carbon composite matrix chemistry and that an unstable alloying region $(0-0.15 \mathrm{~V})$
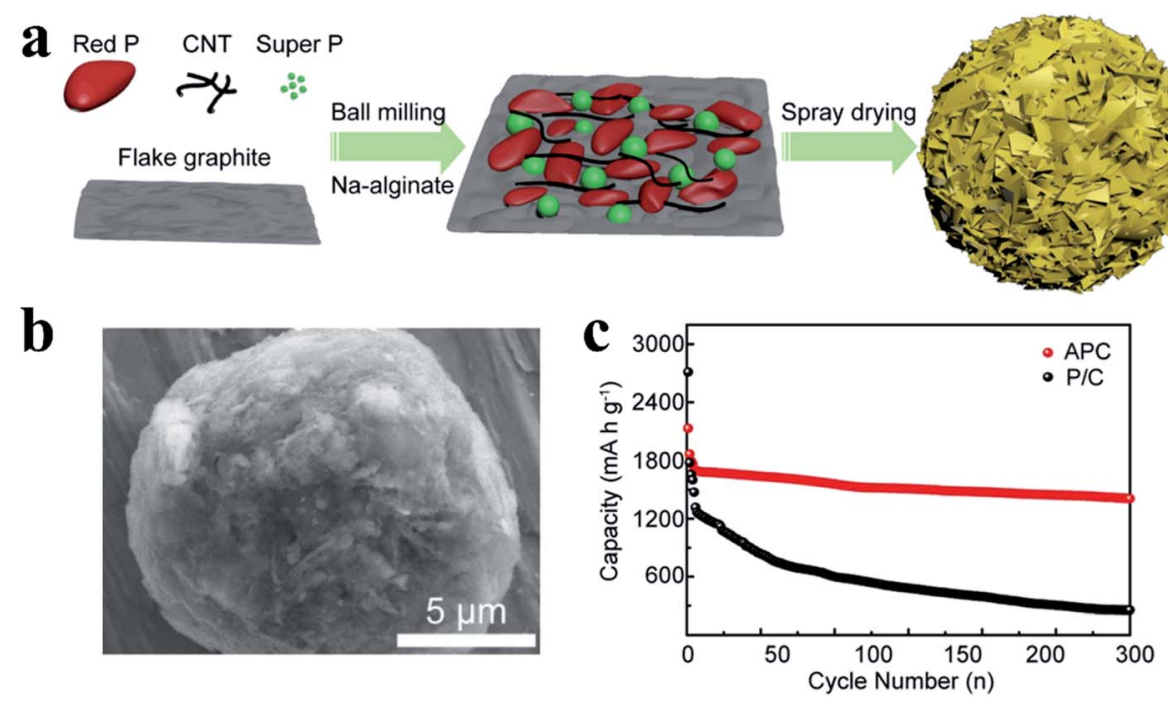

Fig. 4 (a) Schematic of the synthetic process of phosphorus/carbon (APC) nano/microspheres. (b) SEM image of the typical morphology of the APC nano/microspheres. (c) Cycling performance of the anode at a constant current density of $100 \mathrm{~mA} \mathrm{~g}^{-1}$. P/C refers to the control material without SA binders. Reproduced with permission. ${ }^{125}$ Copyright 2018, American Chemical Society. 
where defects could facilitate the continuous formation of irreversible $\mathrm{Na}_{3} \mathrm{P}$ products over the carbon surface. This work elucidates the mechanism why $\mathrm{sp}^{2}$ hybridized carbon is better suited as a reversible host material for RP anodes, and suggests that future effort can leverage surface engineering routes to further improve performance in this unstable alloying regime.

Interestingly, besides this ball milling method, Liu et al. ${ }^{\mathbf{1 2 7}}$ broke RP particles into smaller clusters by using a high-shear emulsifying machine, and embedded these RP nanoparticles ( $\sim 97 \mathrm{~nm}$ ) homogeneously in porous nitrogen-doped carbon nanofibers (RP@C) by a electrospinning technique (Fig. 5a). They first ball milled commercial RP into RP particles, and then these RP particles were broken into smaller clusters under a high energy shear force during the emulsifying process. After standing, the RP with small sizes $(\sim 97 \mathrm{~nm})$ in the upper liquid were collected and were homogeneously embedded in porous nitrogen-doped carbon nanofibers via a electrospinning process and a heat treatment (Fig. 5b and c). Although the yield of these small RP particles may be low as they only exist in the upper liquid, this method is still interesting because of its uniform particle size, and the larger RP particles in the sediment can be recycled for further preparation. In addition, these RP embedded nanofibers could be fabricated as a binder- and current collector-free anode, which could not only increase the $P$ content in the anode, but also reduce the fabrication cost for practical application. The anode showed a high reversible Na storage capacity of $1308 \mathrm{~mA} \mathrm{~h} \mathrm{~g}^{-1}$ at $200 \mathrm{~mA} \mathrm{~g}^{-1}$, exceptionally high rate capabilities of $637 \mathrm{~mA} \mathrm{~h} \mathrm{~g}^{-1}$ at $5000 \mathrm{~mA} \mathrm{~g}^{-1}$ and $343 \mathrm{~mA} \mathrm{~h} \mathrm{~g}^{-1}$ at $10000 \mathrm{~mA} \mathrm{~g}^{-1}$ and long cycling stabilities of $\sim 81 \%$ capacity retention over 1000 cycles (Fig. 5d and e). Moreover, researchers also assembled a soft package Na-ion full battery using RP@C as the anode and $\mathrm{Na}_{3} \mathrm{~V}_{2}\left(\mathrm{PO}_{4}\right)_{2} \mathrm{~F}_{3} / \mathrm{C}$ as the cathode and obtained an operational voltage of $\sim 3.65 \mathrm{~V}$ and a SIB energy density of $161.8 \mathrm{~W} \mathrm{~h} \mathrm{~kg}^{-1}$.

Aside from ball milling or other mechanical force methods, the vaporization-condensation method is also an effective approach to prepare $\mathrm{RP} /$ carbon composites. ${ }^{115}$ In a typical process of this method, RP is first sublimated by heating and subsequently diffused into the pores or surface of a carbon matrix through capillary forces and pressure differences, and then the gaseous $\mathrm{P}$ is adsorbed and deposited onto the internal surface. ${ }^{\mathbf{8 1 , 1 1 6}}$ As compared with the mechanical strategy, the vaporization-condensation method can ensure the uniform dispersal or adsorption of RP into carbon matrices and can obtain nanosized RP. ${ }^{76,116}$ As a result, the P/C composite fabricated by this method usually shows better long-term stability than that by the ball milling method. For the first time, Marino et al. ${ }^{\mathbf{1 1 5}}$ prepared a carbon-phosphorus composite using this method for application in LIBs. Subsequently, this method was widely applied in SIBs, for example, Zhu et al. ${ }^{85}$ prepared a RP/ single-walled carbon nanotube composite (P/SWCNT) as an anode, in which RP was uniformly distributed between tangled SWCNT bundles with an average particle size of $\sim 5 \mu \mathrm{m}$ and a P content of $\sim 40 \%$. Benefiting from this mild and nondestructive

\section{a}
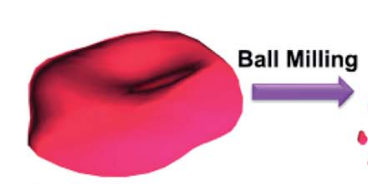

Bulk Phosphorus
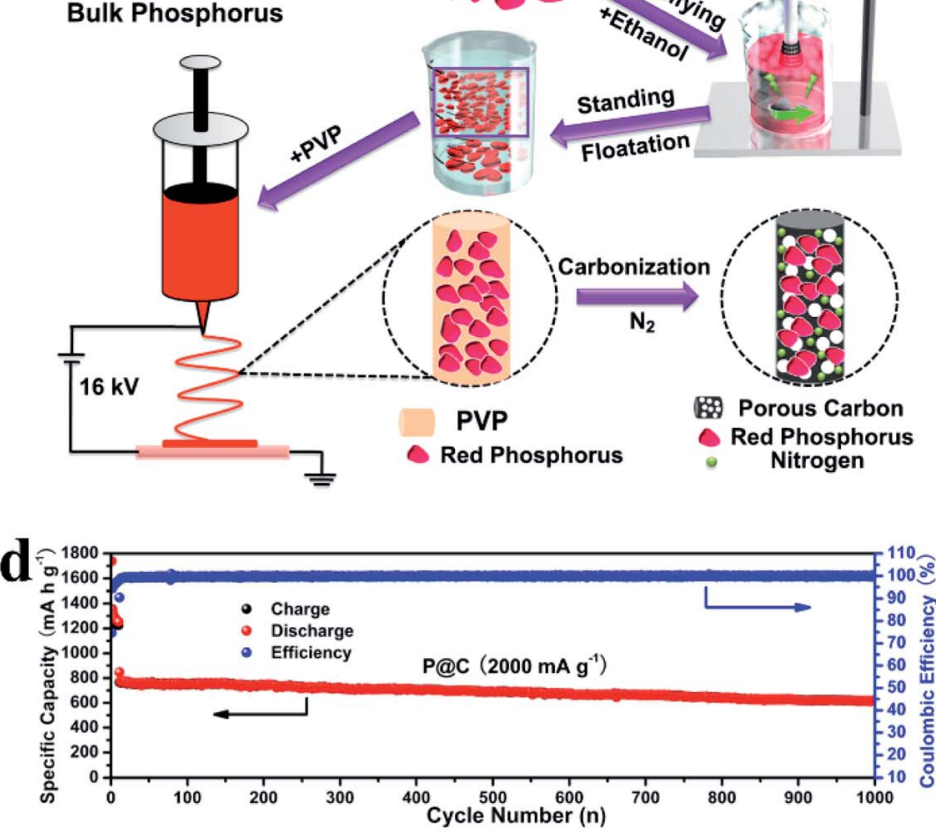

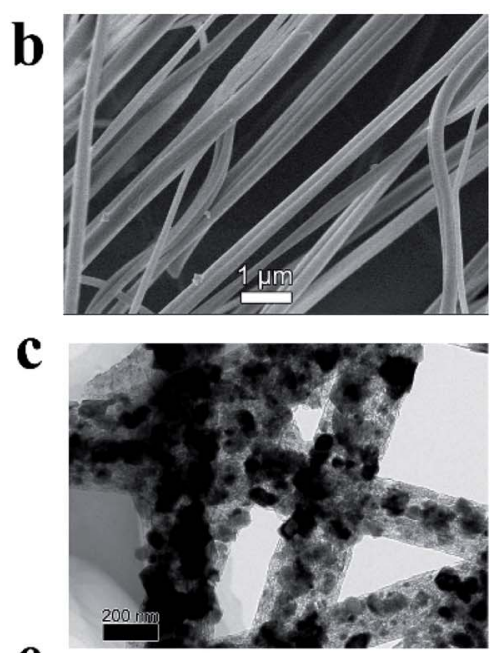

Q

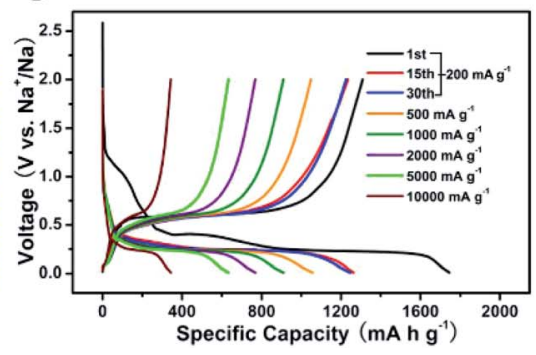

Fig. 5 (a) Schematic illustration of the preparation process for RP@C nanofibers. (b, c) SEM and TEM images of red P@C nanofibers. (d) Longterm cycling stability of the $\mathrm{P}\left(\mathrm{C}\right.$ e electrode at a current density of $2000 \mathrm{~mA} \mathrm{~g}^{-1}$. (e) Charge/discharge profiles obtained at various rates of the P@C electrode in the voltage range of 0.01-2 V vs. $\mathrm{Na}^{+} / \mathrm{Na}$. Reproduced with permission. ${ }^{127}$ Copyright 2017, Elsevier B.V. 
preparation process, uniform mixing and intimate contact between RP and SWCNTs could be achieved, and the mechanically strong SWCNT network was preserved, which enhanced the conductivity of the composite, helped to maintain the integrality of the anode, and stabilized the solid electrolyte interphase, leading to a stable long-term cycling performance with $80 \%$ capacity retention after 2000 cycles. However, because the particle size was quite large $(\sim 5 \mu \mathrm{m})$, the rate capability of the anode was not sufficient $\left(\sim 300 \mathrm{~mA} \mathrm{~h} \mathrm{~g}^{-1}\right.$ at $\left.2000 \mathrm{~mA} \mathrm{~g}^{-1}\right)$, and the high cost of SWCNTs is also a concern for practical application. In another study, ordered mesoporous carbon (commercial CMK-3) with a pore size of $\sim 4 \mathrm{~nm}$ was also used as a carbon host material to load RP. In this RP/CMK-3 composite, the nanoscale of RP and the interconnected pores of the CMK-3 matrix provide many advantages for $\mathrm{Na}$ storage, such as accommodating the volume change of RP during cycling, reducing the diffusion length of $\mathrm{Na}^{+} / \mathrm{e}^{-}$and leading to an enhanced Na storage performance. ${ }^{\mathbf{1 2 8}}$ However, the P content of this RP/CMK-3 composite was not high ( $31 \%)$, and the other $\mathrm{RP} / \mathrm{C}$ composites prepared by this method in the literature also suffered from this same issue. ${ }^{\mathbf{1 1 7}, \mathbf{1 2 9}}$ The large amount of carbon in the composite is also a concern, which may lead to low volumetric capacity, low coulombic efficiency and other negative effects. ${ }^{130}$ Gao et al. ${ }^{131}$ developed a novel strategy and designed a unique structure: coating a 3D porous graphenehydrogel/RP precursor with a poly-pyrrole layer, and thus the $P$ content in the composite could be effectively maintained during the following vaporization-condensation-redistribution process. This coated composite showed a $\mathrm{P}$ content of $\sim 47.2 \%$, which was more than twice that of the sample without a carbon layer $(22.8 \%)$. In addition, the researchers proposed that the unique nanostructure of this $3 \mathrm{D}$ porous carbon matrix with RP particles (10-20 nm) uniformly distributed and firmly sealed in it was an ideal design for an anode material in SIBs. ${ }^{\mathbf{1 3 1}}$

Recently, Liu et al. ${ }^{132}$ developed a method to densely and uniformly deposit RP nanodots onto reduced graphene oxide sheets (P@RGO) with RP nanodot sizes ranging from tens to several hundred nanometers (Fig. 6a-c). Here, the researchers suggested that this unique size and structure could minimize sodium ion diffusion lengths and sodiation/desodiation stress whereas the RGO network could serve as an efficient pathway for electron transfer and accommodate the volume variations of phosphorus particles. As a result, the P@RGO flexible anode reportedly achieved specific charge capacities of 1165.4, 510.6 and $135.3 \mathrm{~mA} \mathrm{~h} \mathrm{~g}^{-1}$ at 159.4, 31878.9 , and $47818.3 \mathrm{~mA} \mathrm{~g}^{-1}$ respectively along with a $914 \mathrm{~mA} \mathrm{~h} \mathrm{~g}^{-1}$ capacity after 300 deep cycles at a current density of $1593.9 \mathrm{~mA} \mathrm{~g}^{-1}$, which was much better than that of conventional RP anodes for SIBs (Fig. 6d-f).

Furthermore, Zhou et al. ${ }^{133}$ developed a facile single-step flash-heat treatment to obtain reduced graphene oxide and deposit RP onto the rGO sheets simultaneously. This single-step method is energy-saving and is beneficial to preparation on a large scale. The resulting RP/rGO flexible film anode for SIBs produced an average capacity of $1625 \mathrm{~mA} \mathrm{~h} \mathrm{~g}^{-1}$ after 200 cycles at a charge/discharge current density of $1 \mathrm{Ag}^{-1}$ and also showed an excellent rate capability with average charge capacities of 1786, 1597, 1324 and $679 \mathrm{~mA} \mathrm{~h} \mathrm{~g}^{-1}$ at 1, 2, 4 and $6 \mathrm{~A} \mathrm{~g}^{-1}$ current densities respectively.

In addition to the application of these traditional carbon materials, the design and fabrication of novel carbon hosts with high electronic conductivity, high mechanical strength and porous morphology to load RP is an important topic for this
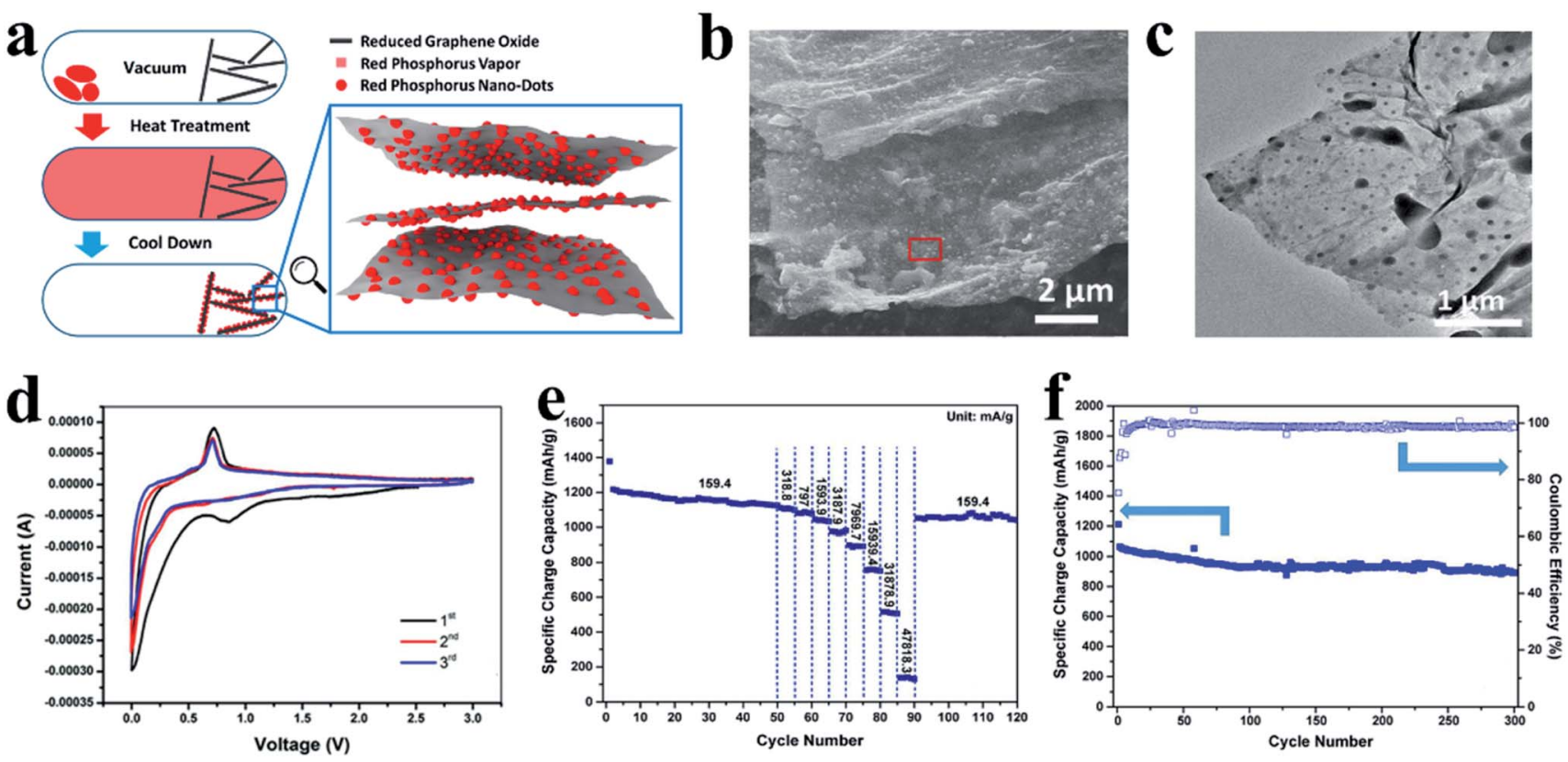

Fig. 6 (a) Schematic of the P@RGO synthesis. (b, c) SEM and TEM images of the P@RGO composite. (d) Cyclic voltammetry of the P@RGO anode at a scan rate of $0.1 \mathrm{mV} \mathrm{s}^{-1}$ between 0 and $3.0 \mathrm{Vvs}$. Na/Na+. (e) Rate performance of the P@RGO anode. (f) Cycling performance of the P@RGO anode at a charge/discharge current density of $1593.9 \mathrm{~mA} \mathrm{~g}^{-1}$. Reproduced with permission. ${ }^{132}$ Copyright 2017, American Chemical Society. 
vaporization-condensation method to further improve the $\mathrm{Na}$ storage performance. Based on this, Sun et al. ${ }^{\mathbf{1 3 4}}$ used this approach to prepare composites of RP encapsulated into porous multichannel carbon nanofibers as a flexible anode material for SIBs and reported a rate capability of $500 \mathrm{~mA} \mathrm{~h} \mathrm{~g}^{-1}$ at $10 \mathrm{~A} \mathrm{~g}^{-1}$ and long cycle lifespans with $700 \mathrm{~mA} \mathrm{~h} \mathrm{~g}^{-1}$ capacity retention at $2 \mathrm{~A} \mathrm{~g}^{-1}$ after 920 cycles. The researchers suggested that the novel structure of the synthesized composite could reduce ion and electron diffusion barriers, accommodate volume variations during sodiation/desodiation, improve electrode mechanical strength, and thus lead to excellent rate capabilities and cycling performances. Liu et al. ${ }^{117}$ designed a carbon nanotube-backboned mesoporous carbon (TBMC) material as a matrix for RP (Fig. 7a). In their preparation process, resorcinol-formaldehyde resin/ $/ \mathrm{SiO}_{2}$ was first grown onto carbon nanotubes, with tetraethyl orthosilicate (TEOS) used as the $\mathrm{SiO}_{2}$ precursor and resorcinol-formaldehyde (RF) resin as the carbon source, and then the resin was carbonized and the $\mathrm{SiO}_{2}$ was removed to obtain TBMC. The researchers reported that the competitive growth of $\mathrm{SiO}_{2}$ and $\mathrm{RF}$ resin during the synthesis process could lead to various $\mathrm{SiO}_{2}$ distributions and thus different final structures. Consequently, TBMC, hollow TBMC and deflated TBMC could be obtained based on high, medium and low dosages of RF respectively (Fig. 7a). These various TBMCs were subsequently infiltered with RP using the vaporization/condensation method to form P@TBMC composites. The researchers found that the TBMC with a high dosage of RF showed the best Na storage performance, providing a high reversible specific capacity of $\sim 1000 \mathrm{~mA} \mathrm{~h} \mathrm{~g}^{-1}$ at $0.05 \mathrm{~A} \mathrm{~g}^{-1}$, a superior rate performance of $\sim 430 \mathrm{~mA} \mathrm{~h} \mathrm{~g}^{-1}$ at $8 \mathrm{~A} \mathrm{~g}^{-1}$ and a long cycle lifespan with no capacity decay for 800 cycles at $2.5 \mathrm{~A} \mathrm{~g}^{-1}$ (Fig. 7b-d). They proposed that the multi-walled carbon nanotubes could facilitate electron transfer due to the high content of $\mathrm{sp}^{2}$ carbon whereas the mesoporous carbon layers provide voids to load $\mathrm{P}$ and ensure adequate spacing to accommodate large volume variations of $\mathrm{P}$ during cycles, leading to an excellent Na storage performance.

Yao et al. ${ }^{135}$ also designed novel hollow porous carbon nanospheres (HPCNSs) as host structures for the vaporization/ condensation synthesis of $\mathrm{P} / \mathrm{C}$ composites. Through the methods of molecular dynamic simulations and density functional theory calculations, they found that the morphology of polymeric $\mathrm{P}_{4}$ and the $\mathrm{P}$ loading in the $\mathrm{P} / \mathrm{C}$ composite were mainly dependent on the pore size and surface conditions of the carbon support. The micropores of 1-2 $\mathrm{nm}$ in diameter and oxygenated functional groups attached on the carbon surface were essential for achieving high P loadings and high structural stability. This HPCNS/amorphous RP composite with enhanced structural/functional features presented a low volume expansion of $\sim 67.3 \%$ during anode cycles, much smaller than that of the theoretical value of commercial RP $(\approx 400 \%)$, and showed remarkable long-life cycling stabilities with a capacity retention of over $76 \%$ after 1000 cycles. This study signified the importance of the rational design of electrode materials to obtain cost-effective $\mathrm{P} / \mathrm{C}$ composite anodes for SIBs. Furthermore, $\mathrm{Li}$ et $a .^{76}$ reported that a composite of confined amorphous RP with particle sizes of less than $1 \mathrm{~nm}$ in MOF-derived N-doped microporous carbon also produced promising performances.
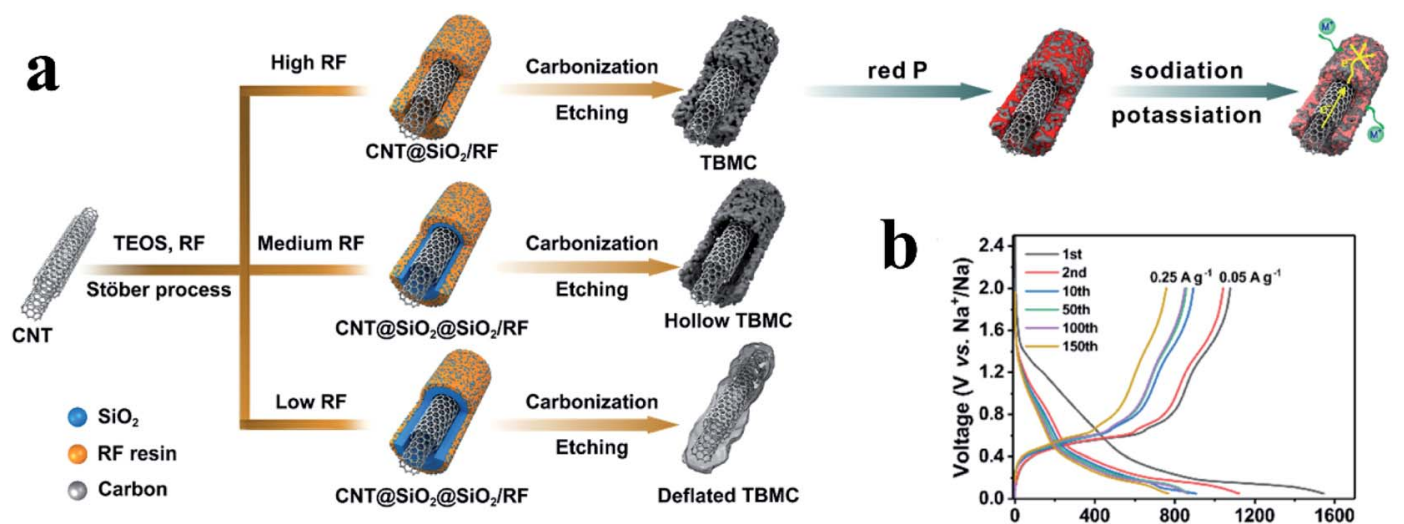

b
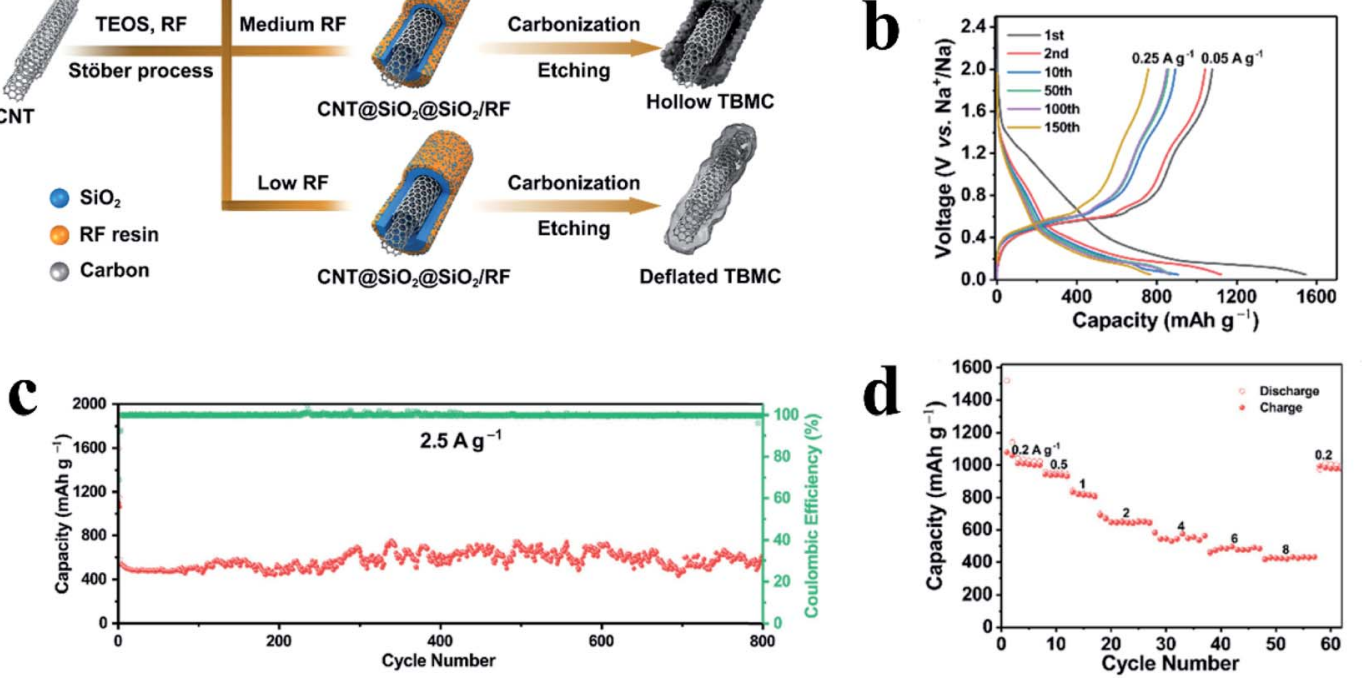

Fig. 7 (a) Schematic of the synthesis of nanotube-backboned mesoporous carbon (TBMC), hollow TBMC and deflated TBMC and the sodiation/ potassiation of the PATBMC composite. (b) Representative galvanostatic discharge/charge voltage profiles of the PaTBMC electrode at $0.25 \mathrm{~A} \mathrm{~g}^{-1}$ after the initial two-cycle activation at $0.05 \mathrm{~A} \mathrm{~g}^{-1}$. (c) Long-term cycling performance of P@TBMC at $2.5 \mathrm{~A} \mathrm{~g}^{-1}$ and (d) rate capability of PaTBMC. Reproduced with permission. ${ }^{117}$ Copyright 2018, Elsevier Ltd. 
These studies indicate that the design of favorable carbon hosts for RP is an effective approach for improving the $\mathrm{Na}$ storage performance. In addition, facile preparation methods for these materials are also necessary for practical applications.

Compared with the ball milling method, the vaporization/ condensation method is a mild and nondestructive process; however, the phase-transformation process of $\mathrm{P}$ will inevitably generate white phosphorus, which is toxic and highly active. ${ }^{\mathbf{1 1 6}}$ To address this, Yu et al. ${ }^{136}$ developed a modified vaporizationdeposition-conversion method in which a multi-step heating/ cooling process was used to avoid the generation of white phosphorus. By using this refined strategy, RP nanoparticles were adsorbed and confined within the nanopores of commercial microporous carbon YP-80F (P@YP) (Fig. 8a), ensuring high reversible capacity, excellent rate capability and long-term cycling stability with a superior capacity retention of 92\% after 100 cycles and $46 \%$ after 1000 cycles (Fig. 8b-d). And as compared with P@YP, a P@CNT composite without confined $\mathrm{P}$ was deposited onto the surface of carbon nanotubes and presented rapid capacity decay with a capacity retention of only $\sim 40.6 \%$ after 100 cycles. Here, the researchers suggested that the nanostructure of the $\mathrm{P}-\mathrm{C}$ composite with $\mathrm{P}$ confined in the porous carbon is key to enhanced electrochemical performances and long-term cycling stabilities. ${ }^{\mathbf{1 3 6}}$

2.1.2 Combination with other materials. Although $\mathrm{RP} / \mathrm{C}$ composite approaches appear to be promising, the performance of the $\mathrm{RP} / \mathrm{C}$ composites is found to be dependent on several factors such as fabrication methods. ${ }^{81}$ The large amount of carbon in the $\mathrm{RP} / \mathrm{C}$ composite is also a concern, as the low density $\left(\sim 2.16 \mathrm{~g} \mathrm{~cm}^{-3}\right),{ }^{137}$ high specific area, poor air stability and low operating voltage $\left(<0.1 \mathrm{~V} v s \text {. } \mathrm{Na} / \mathrm{Na}^{+}\right)^{138}$ of these carbonaceous materials usually result in low volumetric capacity, low coulombic efficiency, autoignition, and possible sodium plating. ${ }^{\mathbf{8 6 , 1 3 0 , 1 3 8 - 1 4 1}}$ The higher the carbon content, the more significant these problems are. In addition, the limited carbon coverage on RP and uncontrollability of carbon layer thickness may also hinder the electrochemical performance of $\mathrm{RP} / \mathrm{C}$ based electrodes. In this regard, the search for noncarbonaceous materials that function similarly to those carbon materials is needed. ${ }^{\mathbf{1 3 0}}$

In fact, the combination of RP with other non-carbon materials, such as metals, metal oxides or metal phosphides also demonstrates improved $\mathrm{Na}$ storage performance. For example, Chin et al. ${ }^{\mathbf{1 4 2}}$ mixed commercial RP with appropriate amounts of iron using high-energy ball milling to obtain a RP/ Fe composite. As a result, they found that the RP/Fe anode showed a higher sodium diffusion coefficient than pure RP anodes, and improved electrochemical performance of 1582, 1419, 884 and $676 \mathrm{~mA} \mathrm{~h} \mathrm{~g}^{-1}$ specific desodiation capacities at $0.2,0.6,6$ and $10 \mathrm{~A} \mathrm{~g}^{-1}$ current densities respectively were obtained for the $9.1 \%$ Fe-containing RP composite. Although the cycle lifespan of this anode may not be long because of the pulverization of RP during charge/discharge processes, the addition of low cost iron is still a novel and effective approach to improve the electrochemical performance of RP. Based on the idea that the functional synergy of higher capacity of $\mathrm{P}$ with high-rate capability and high cyclability of $\mathrm{Sb}$ may obtain a compelling electrochemical performance, Walter et al. ${ }^{\mathbf{1 4 3}}$ reported a $\mathrm{P} / \mathrm{Sb} / \mathrm{Cu}$ composite anode synthesized by simple mechanic mixing of monodisperse $\mathrm{Sb}$ nanocrystals with $\mathrm{RP}$ particles and $\mathrm{Cu}$ nanowires. Benefiting from the good electronic conductivity of $\mathrm{Sb}$ and $\mathrm{Cu}$ and the mechanical strength of $\mathrm{Cu}$ nanowires, this $\mathrm{P} / \mathrm{Sb} / \mathrm{Cu}$ anode showed much greater cycling stability than pure RP anodes, providing a capacity of above
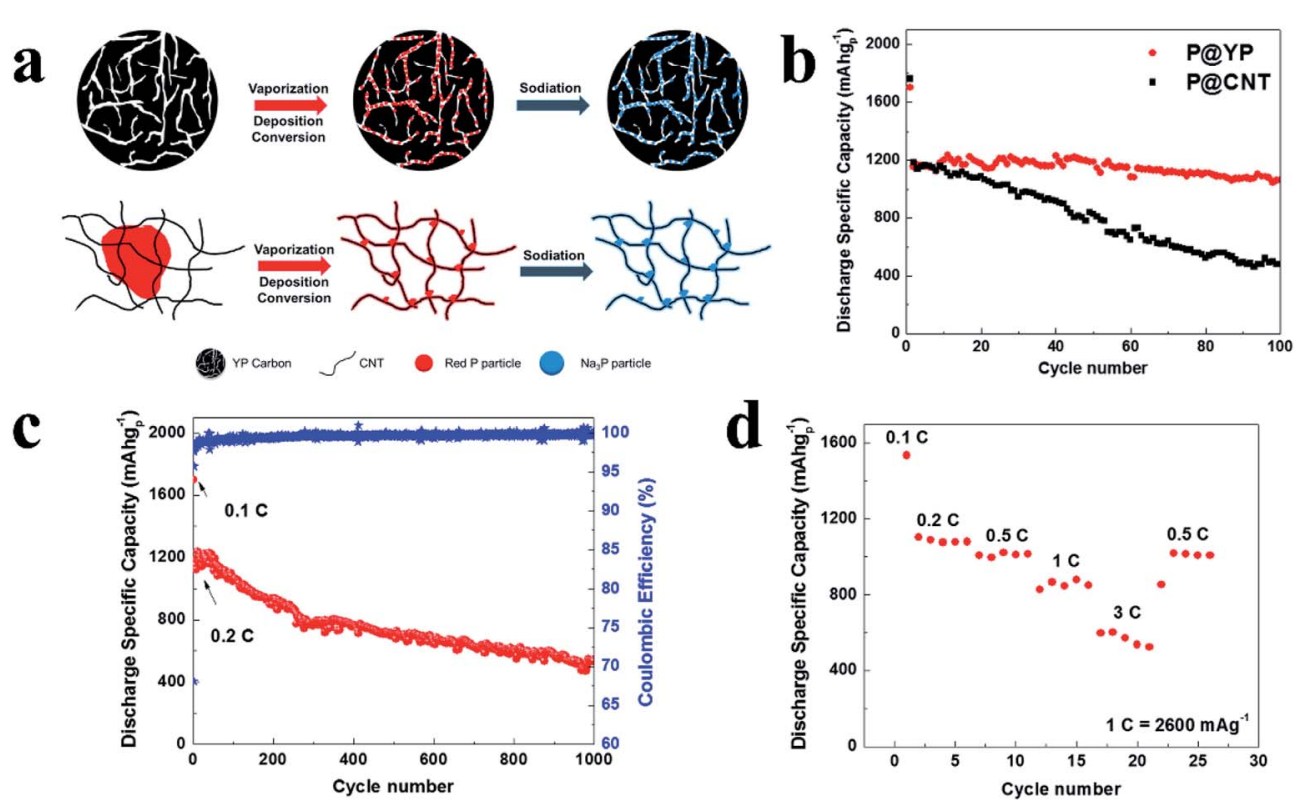

Fig. 8 (a) Schematics of the preparation and sodiation of P@YP and P@CNT composites. (b) Cycling performances of PaYP and P@CNT composites within 100 cycles. (c) Long term cycling performance of the P@YP composite. (d) Rate performance of the P@YP composite at Crates between $0.1 \mathrm{C}$ and $3 \mathrm{C}\left(1 \mathrm{C}=2600 \mathrm{~mA} \mathrm{~g}^{-1}\right)$. Reproduced with permission. ${ }^{136}$ Copyright 2017, Elsevier Ltd. 
$1100 \mathrm{~mA} \mathrm{~h} \mathrm{~g}^{-1}$ after 50 cycles at a current density of $125 \mathrm{~mA} \mathrm{~g}^{-1}$, and an excellent rate capability of more than $900 \mathrm{~mA} \mathrm{~h} \mathrm{~g}^{-1}$ at a high current density of $2000 \mathrm{~mA} \mathrm{~g}^{-1}$. Compared with the addition of $\mathrm{Fe}$ within $\mathrm{RP}$, the use of $\mathrm{Sb}$ and $\mathrm{Cu}$ in this study may increase the cost for practical application, as the $\mathrm{P}$ content in this $\mathrm{P} / \mathrm{Sb} / \mathrm{Cu}$ anode is low (40\%). Nevertheless, the mechanical strength of $\mathrm{Cu}$ nanowires along with the matrix of $\mathrm{Sb}$ can ensure a longer cycle lifespan for this $\mathrm{P} / \mathrm{Sb} / \mathrm{Cu}$ anode.

Lan et al. ${ }^{130}$ prepared a phosphorus-titania-carbon $\left(\mathrm{P}-\mathrm{TiO}_{2}-\right.$ C) composite as an anode for SIBs by ball milling of RP, titanium oxide and carbon powder. The researchers suggested that the $\mathrm{P}-\mathrm{TiO}_{2}-\mathrm{C}$ composites could alter local chemistries in both titanium oxide and phosphorus such as the doping of $\mathrm{TiO}_{2}$ by $\mathrm{P}$ and/or $\mathrm{C}$, as well as stabilization of $\mathrm{P}$ by the Ti-O-P and/or $\mathrm{P}-\mathrm{C}$ chemical environment, and thus lead to an improved electronic conductivity and enhanced stability during repeated charge/ discharge cycles. The resulting composite anode delivered a high reversible capacity of $1147 \mathrm{~mA} \mathrm{~h} \mathrm{~g}^{-1}$ at a current density of $100 \mathrm{~mA} \mathrm{~g}^{-1}$ with good cyclability and a high rate performance with $81.5 \%$ of its original capacity being maintained as discharge rates increased from 100 to $1000 \mathrm{~mA} \mathrm{~g}^{-1}$. In addition, a chain-like $\mathrm{Fe}_{3} \mathrm{O}_{4} / \mathrm{C} / \mathrm{RP}$ (C means carbon) composite was also prepared by introducing a magnetic stimulus source during the vaporization/condensation process and also demonstrated high cycling performances and superior rate capabilities. ${ }^{129}$ Interestingly, this assisted magnetic field could cause a high pressure driven force to uniformly deposit $\mathrm{RP}$ onto the $\mathrm{Fe}_{3} \mathrm{O}_{4} / \mathrm{C}$ surface, and consequently increase the $\mathrm{P}$ loading and enhance the contact between $\mathrm{Fe}_{3} \mathrm{O}_{4} / \mathrm{C}$ and RP. Although the content of $\mathrm{RP}$ in this anode is quite low (25\%) and the RP is only loaded on the surface of the conductive carbon chain, the addition of RP can obviously increase the specific capacity and shows little negative effects on the cycling stability. This indicates that the combination of low-cost metal oxides and RP may be an effective approach to apply in practical SIBs; however, the low electronic conductive of metal oxides is still a concern and more effort should be dedicated to addressing this issue.

Liu et al. ${ }^{86}$ designed RP@Ni-P core-shell nanostructures as anodes for SIBs through a two-step approach: electroless deposition of Ni on RP particles and then chemical dealloying of this RP@Ni compound, in which the Ni-P shell thicknesses could be controlled by regulating the dealloying time (Fig. 9a). Here, Liu et al. ${ }^{86}$ suggested that in situ generated $\mathrm{Ni}_{2} \mathrm{P}$ on $\mathrm{RP}$ particle surfaces could facilitate intimate contact between RP

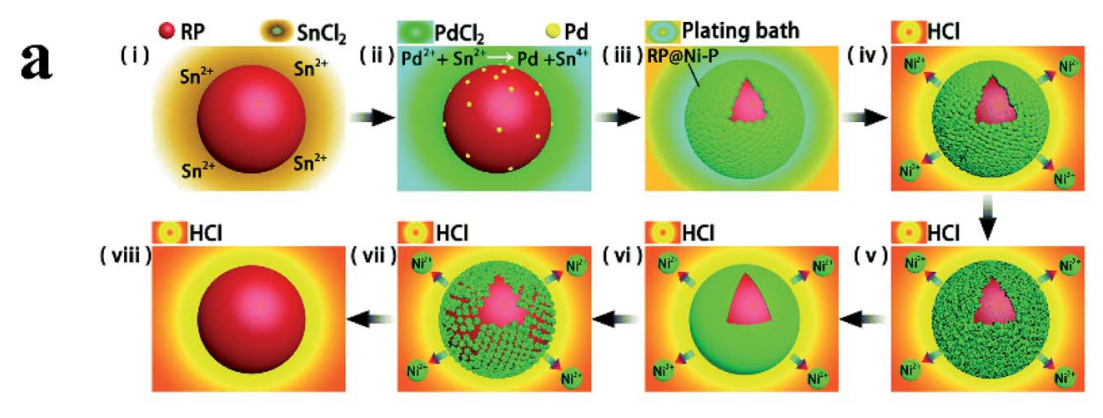

b
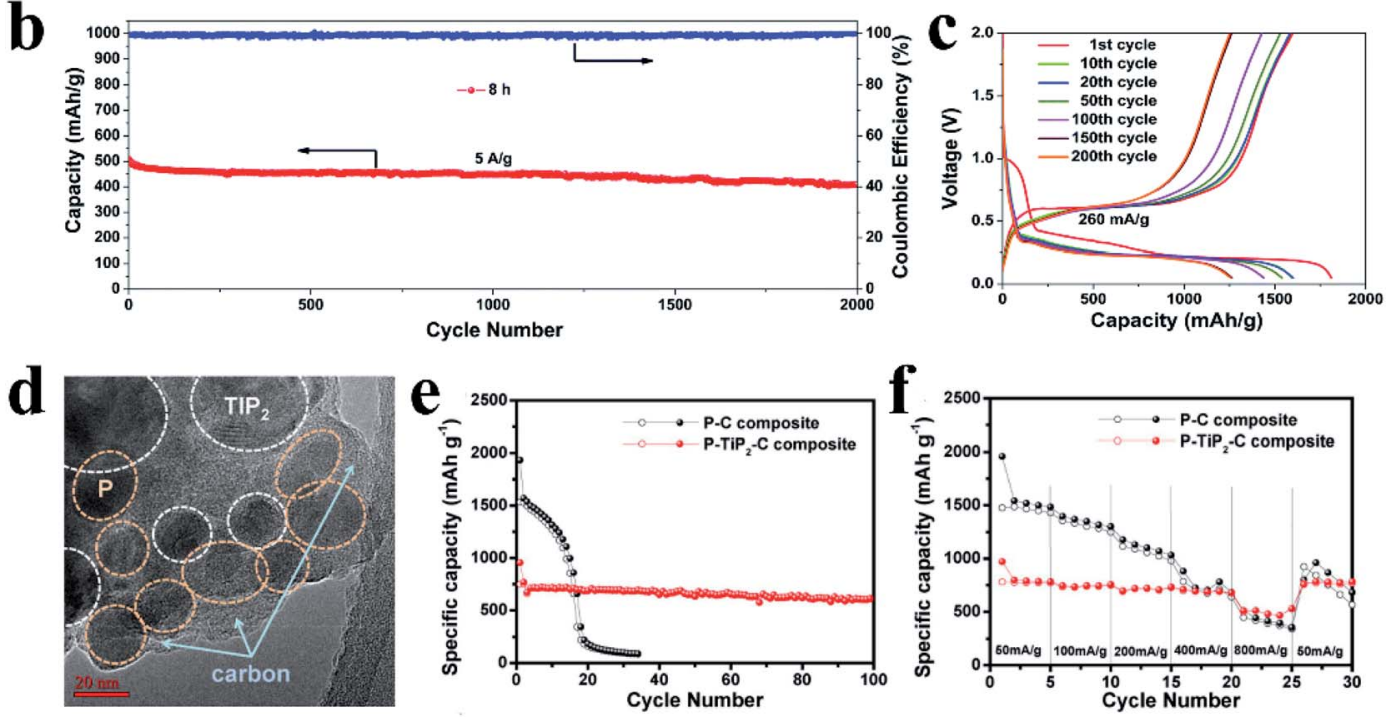

Fig. 9 (a) Schematics of the electroless deposition of Ni on RP nanoparticles (i-iii) and the evolution of the RP@Ni-P core@ashell nanostructure through chemical dealloying (iv-viii). (b) Long-term cycling performance of the $8 \mathrm{~h}$ RPaNi-P electrode at $5 \mathrm{~A} \mathrm{~g}^{-1}$ between 0.05 and $2.0 \mathrm{~V}$. (c) Galvanostatic charge-discharge voltage profiles of the $8 \mathrm{~h} \mathrm{RP@Ni-P}$ anode between 0.05 and $2.0 \mathrm{~V}$ at a current density of $260 \mathrm{~mA} \mathrm{~g}^{-1}$. Reproduced with permission. ${ }^{86}$ Copyright 2017, The Royal Society of Chemistry. (d) Low magnification TEM image of the P-TiP $2-C$ composite, (e) cycle performances and (f) rate capabilities of the $\mathrm{P}-\mathrm{C}$ and $\mathrm{P}-\mathrm{TiP}_{2}-\mathrm{C}$ composite electrodes in sodium half cells. The specific capacity was calculated based on the total mass of the composite materials. Reproduced with permission. ${ }^{139}$ Copyright 2016, American Chemical Society. 
and the amorphous Ni-P outer shell which was mechanically strong and highly electron conductive, thus ensuring strong electrode structural integrity, stable solid electrolyte interphases and fast electronic transport. As a result, the RP@Ni-P composite with a dealloying time of $8 \mathrm{~h}$ displayed a super high capacity of $1256.2 \mathrm{~mA} \mathrm{~h} \mathrm{~g}^{-1}$ after 200 cycles at $260 \mathrm{~mA} \mathrm{~g}^{-1}$, a superior rate capability of $491 \mathrm{~mA} \mathrm{~h} \mathrm{~g}^{-1}$ at $5200 \mathrm{~mA} \mathrm{~g}^{-1}$ and an long cycle lifespan with a capacity of $409.1 \mathrm{~mA} \mathrm{~h} \mathrm{~g}^{-1}$ retained after 2000 cycles at $5000 \mathrm{~mA} \mathrm{~g}^{-1}$ (Fig. 9b and c). When the RP particle size is below $200 \mathrm{~nm}$, the outer protective shell is a key factor in obtaining long cycle stability, which can effectively prevent the pulverization of RP during cycles. In addition, the facile process of in situ growth and the low-cost of Ni make it a promising strategy for practical SIBs. In another study, Kim et al. ${ }^{139}$ synthesized a $\mathrm{P}-\mathrm{TiP}_{2}-\mathrm{C}$ nanocomposite as an anode material for SIBs using a facile and simple one-step high energy mechanical milling process in which the resulting composite anode (Fig. 9d-f) displayed an initial desodiation capacity of $755 \mathrm{~mA} \mathrm{~h} \mathrm{~g}^{-1}$ with a coulombic efficiency of $80 \%$ and a good capacity retention of $80 \%$ after 100 cycles. Here, the researchers suggested that the greatly improved electrochemical performances could be ascribed to the unique nanostructure in which $\mathrm{RP}$ and crystalline $\mathrm{TiP}_{2}$ were homogeneously embedded into a conductive carbon network. They also suggested that in this phosphorus-based composite, the conductive $\mathrm{TiP}_{2}$ could provide structural stability as well as high conductivity during cycling, leading to better SIB cycling stabilities and rate capabilities as compared with nanocomposites without $\operatorname{TiP}_{2}$.

2.1.3 Morphology and/or size-controlled RP nanostructure. Although ball-milling and vaporization-condensation methods possess many advantages and are the most commonly used methods to prepare RP-based anodes, the uneven and large particle sizes of RP and the low $\mathrm{P}$ content in the ball-milled RP composite and the uncontrollable distribution and the low loading ratio of RP in the vaporization/condensation RP anode consequently cause poor rate performance, reduced long-term stability, and decreased energy density. In addition, the toxic white $\mathrm{P}$ remnants produced by the vaporization/condensation method make it unfit for the popularization of SIBs. ${ }^{79,87,121,132,134}$ In view of this, synthesizing a morphology/size controlled RP nanostructure by novel preparation methods is an effective approach. For example, Zhou et $a l^{87}$ recently successfully fabricated hollow $\mathrm{P}$ nanospheres (HPNs) with porous shells by a solvothermal method (Fig. 10a). The synthesis progress could be summarized and expressed by the following equation:

$$
10 \mathrm{NaN}_{3}+2 \mathrm{PCl}_{5} \stackrel{\text { toluene }}{\longrightarrow} 2 \mathrm{P}+10 \mathrm{NaCl}+15 \mathrm{~N}_{2}
$$

Here, a gas-bubble-directed formation mechanism during the solvothermal process works to produce hollow $\mathrm{P}$ nanosphere with the produced $\mathrm{P}$ nuclei covering the surface of $\mathrm{NaN}_{3}$ during the initial reaction stage. And with increasing gas-bubble sizes, $\mathrm{P}$ nuclei are continuously supplied at the interface between $\mathrm{NaN}_{3}$ and the gas bubbles and gradually assemble around the surface of the gas bubbles. These bubbles eventually detach from the surface of $\mathrm{NaN}_{3}$ and form hollow phosphorus nanospheres. And with subsequent cooling and system pressure reduction, the gases confined by the $\mathrm{P}$ shells are released and thus help to form porous shells. Here, the researchers reported that different average diameters ranging from $150 \mathrm{~nm}$ to $1 \mu \mathrm{m}$ could be obtained for these hollow phosphorus nanospheres through tuning the $\mathrm{NaN}_{3}$ concentration, and found that $300 \mathrm{~nm}$ hollow nanospheres (shell thickness: $\sim 40 \mathrm{~nm}$ ) exhibited optimal electrochemical performances as an anode for a SIB, delivering a high capacity of $1364.7 \mathrm{~mA} \mathrm{~h} \mathrm{~g}^{-1}$ at $0.2 \mathrm{C}$ (with $60 \%$ loading of $\mathrm{P}, 2274.5 \mathrm{~mA} \mathrm{~h} \mathrm{~g}^{-1}$ for $\mathrm{RP}$, and $1 \mathrm{C}=2.6 \mathrm{~A} \mathrm{~g}^{-1}$ ) and long-term cycling performances. ${ }^{87}$

However, this pure phase RP nanostructure may suffer from insufficient electronic conductivity. Furthermore, the use of toxic and explosive $\mathrm{NaN}_{3}$ in the preparation process is also a concern. In another study, iodine-doped RP nanoparticles with size ranging from 100 to $200 \mathrm{~nm}$ have also been
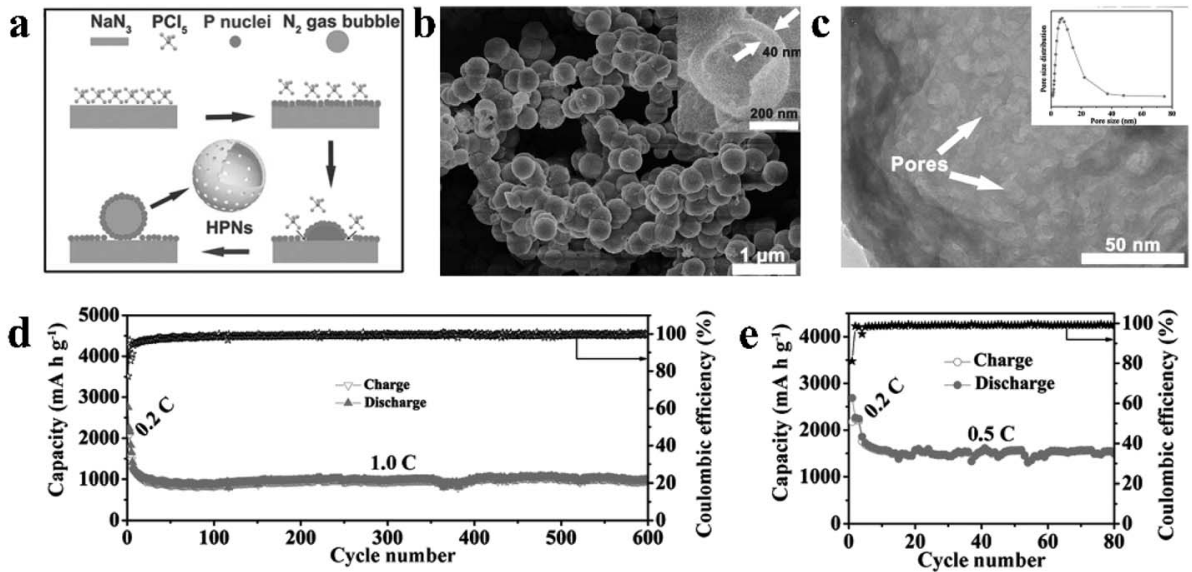

Fig. 10 (a) Schematic of the proposed formation mechanism of hollow phosphorus nanospheres (HPNs). (b) SEM image of the prepared HPNs; inset shows the SEM image of a broken nanosphere. (c) TEM image of the HPNs under higher magnification; inset shows the pore-size distribution of the HPNs. Cycling stability and coulombic efficiency of the HPNs at (d) $1.0 \mathrm{C}$ for 600 cycles and (e) at $0.5 \mathrm{C}$ for 80 cycles. $1 \mathrm{C}=$ $2.6 \mathrm{~A} \mathrm{~g}^{-1}$. Reproduced with permission. ${ }^{87}$ Copyright 2017, WILEY-VCH. 
synthesized by a simple and large-scale solution phase method. ${ }^{140}$ During the reaction process, the $\mathrm{PI}_{3}$ precursor was reduced with ethylene glycol and simultaneously RP nanoparticles (RPNPs) were formed in the presence of CTAB under an ambient environment. The conductivity of these I-doped RPNPs was measured to be between $2.62 \times 10^{-3}$ and $1.81 \times$ $10^{-2} \mathrm{~S} \mathrm{~m}^{-1}$, which is close to that of semiconductor germanium $\left(1.02 \times 10^{-2} \mathrm{~S} \mathrm{~m}^{-1}\right)$. Although the authors only investigated the Li-ion storage performance of these RPNPs, the unique morphology/nanostructure and the novel synthesis method are all progressive for the application of RP.

Based on this novel solution phase method, Liu et al. ${ }^{\mathbf{1 4 4}}$ synthesized nanoporous RP on reduced graphene oxide as a SIB anode (NPRP@RGO) by a boiling method. In brief, the RP@RGO precursor was first synthesized involving several steps, including the reduction of phosphorus triiodide $\left(\mathrm{PI}_{3}\right)$ to produce RP, the uniform mixing of the as-prepared RP with GO in a solution, and a further reduction of RP@GO to RP@RGO. Then this reduced RP@RGO was subsequently subjected to centrifugation and the concentrated RP@RGO solution was heated in a vacuum drying chamber at $200{ }^{\circ} \mathrm{C}$ to allow the RP to assemble around gas bubbles. And with the growth of these bubbles, increasing amounts of disordered RP particles became dispersed onto the surface of the gas bubbles and the final NPRP@RGO was obtained after the gas bubbles were detached (Fig. 11a). Here, the researchers reported that the unique nanostructure of the nanoporous RP with sizes mainly in the range of 20-100 nm (Fig. 11b) was able to accommodate volume change and minimize ion diffusion lengths and that the highly conductive RGO network sheets could facilitate fast electron and ion transportation. As a result, this anode exhibited a high capacity of $1249.7 \mathrm{~mA} \mathrm{~h} \mathrm{~g}^{-1}$ after 150 cycles at $173.26 \mathrm{~mA} \mathrm{~g}^{-1}$,

\section{a eRP Solution 2 GO 2 RGO Bubble}
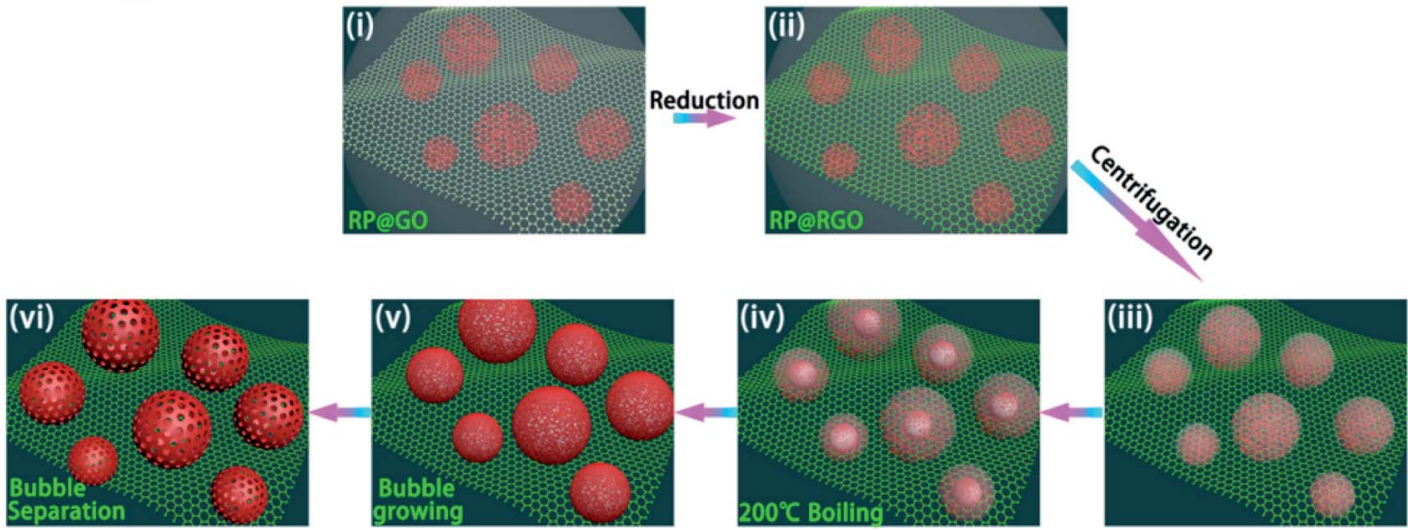

b
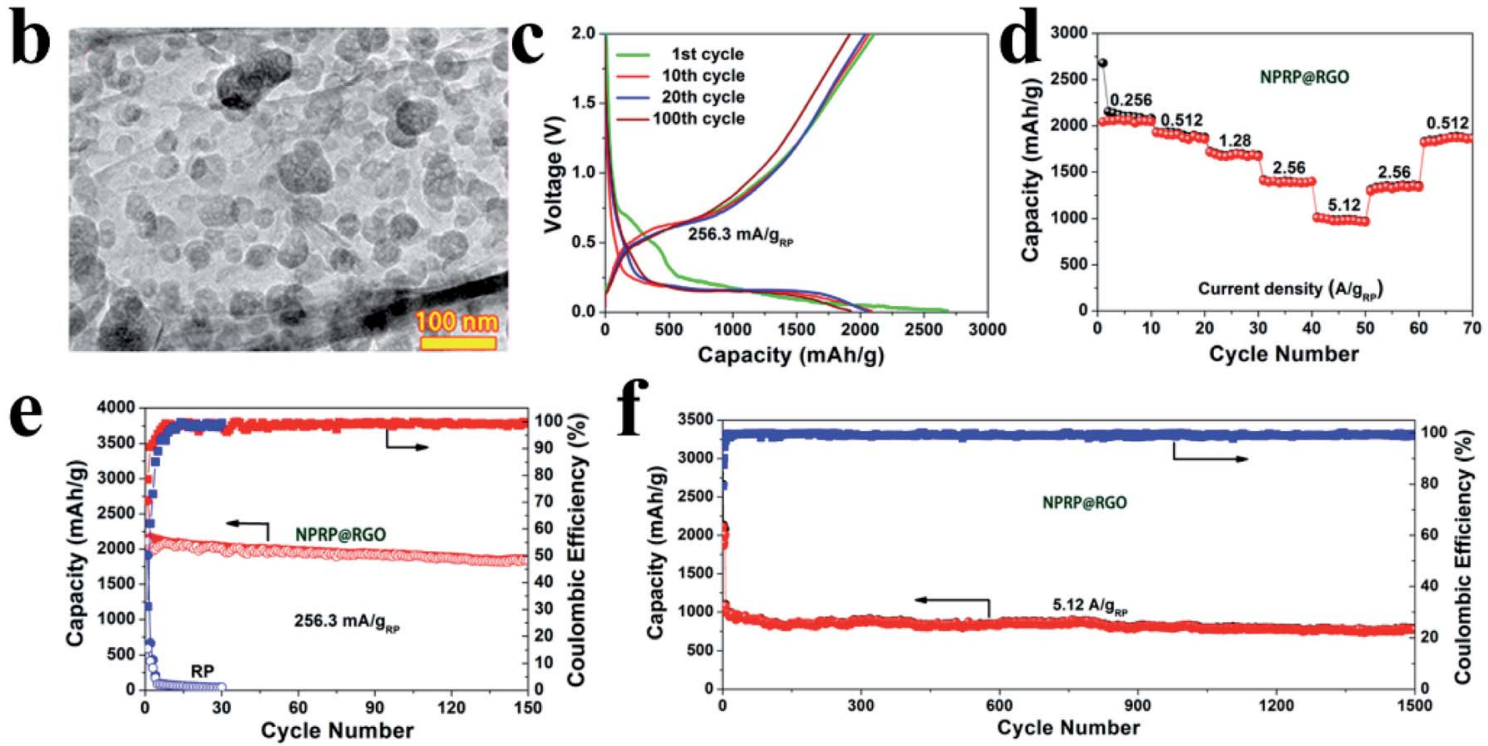

Fig. 11 (a) Schematic of the preparation of NPRP@RGO. (b) TEM image of NPRP@RGO. (c) Galvanostatic charge/discharge curves of the NPRP@RGO electrode at $256.3 \mathrm{~mA} \mathrm{~g}_{\mathrm{RP}}^{-1}$ (173.26 mA g composite $^{-1}$ ) within a voltage range of $0.01-2 \mathrm{~V}$. (d) Rate capability of the NPRP@RGO electrode from 0.256 to $5.12 \mathrm{~A} \mathrm{~g} \mathrm{gPP}^{-1}$. (e) Cycling performances of NPRP@RGO and commercial RP electrodes at $256.3 \mathrm{~mA} \mathrm{~g}_{\mathrm{RP}}{ }^{-1}$ within the voltage range of $0.01-2 \mathrm{~V}$. (f) Long-term cycling performance of the NPRP@RGO electrode at $5.12 \mathrm{~A} \mathrm{~g}_{\mathrm{RP}}{ }^{-1}\left(3465.28 \mathrm{~mA} \mathrm{~g}_{\mathrm{composite}}{ }^{-1}\right)$ between 0.01 and 2.0 V. Current density and specific capacity were calculated based on the mass of NPRP. Reproduced with permission. ${ }^{144}$ Copyright 2018, American Chemical Society. 
a superior rate capability of $656.9 \mathrm{~mA} \mathrm{~h}^{-1}$ at $3465.28 \mathrm{~mA} \mathrm{~g}^{-1}$ based on the anode composite and a long cycle lifespan of 1500 cycles with a capacity of $775.3 \mathrm{~mA} \mathrm{~h} \mathrm{~g}^{-1}$ at $5.12 \mathrm{~A} \mathrm{~g}^{-1}$ based on the RP mass (Fig. 11c and d). ${ }^{\mathbf{1 4 4}}$ In addition, in their another study, ${ }^{145}$ iodine-doped hollow nanoporous RP (HNPRP) was prepared by a similar preparation method. When tested as an anode for SIBs, ${ }^{\mathbf{1 4 0}}$ this HNPRP exhibited a high capacity of $1658.2 \mathrm{~mA} \mathrm{~h} \mathrm{~g}^{-1}$ after 100 cycles at $0.26 \mathrm{~A} \mathrm{~g}^{-1}$, superior rate capability (759.6 $\mathrm{mA} \mathrm{h} \mathrm{g}^{-1}$ at $5.2 \mathrm{~A} \mathrm{~g}^{-1}$ ) and ultralong cycle-life (857.3 $\mathrm{mA} \mathrm{h} \mathrm{g}^{-1}$ after 1000 cycles at $2.6 \mathrm{~A} \mathrm{~g}^{-1}$ ).

Sun et al. ${ }^{101}$ further fabricated ultrafine RP particles with an average size of $\sim 10 \mathrm{~nm}$ embedded in a 3D carbon framework through the carbothermic reduction of $\mathrm{P}_{2} \mathrm{O}_{5}$ and reported that these small sized phosphorus particles could accommodate large stress without cracking, decrease electron/ion diffusion lengths and connect strongly with the carbon framework. And as a result, their SIB anode provided a reversible specific capacity of $1027 \mathrm{~mA} \mathrm{~h} \mathrm{~g}^{-1}$ and a high capacity retention of $88 \%$ over 160 cycles. RP quantum dots (RPQDs) were also prepared using a reliable hydrothermal method with commercial RP as the only phosphorus source. ${ }^{\mathbf{1 4 6}}$ Although the yield of RPQDs in this synthesis process was low, this method was quite simple, and the size of these quantum dots was at the nano-level with an average size of $4.0 \mathrm{~nm}$. And a hybrid of these dots with rGO (RPQDs/rGO) delivered an initial specific capacity of $1161 \mathrm{~mA} \mathrm{~h} \mathrm{~g}^{-1}$ and a low capacity deterioration rate of less than $0.12 \%$ per cycle after 250 cycles at $200 \mathrm{~mA} \mathrm{~g}^{-1}$.

\subsection{Black phosphorus and phosphorene}

BP is another important allotrope of phosphorus and is most thermodynamically stable among these allotropes..$^{\mathbf{8 , 1 4 7 , 1 4 8}}$ Due to its layered structure and other properties, BP attracts much attention and shows great potential for many applications such as batteries, ${ }^{72,149}$ field-effect transistors, ${ }^{\mathbf{1 5 0}}$ and photodetectors. ${ }^{149}$ BP possesses three crystalline modifications induced by different temperature and pressure,${ }^{\mathbf{1 5 1}}$ including orthorhombic, rhombohedral, and cubic, and also can present an amorphous form. ${ }^{152,153}$ Under normal temperature and pressure, BP usually shows an orthorhombic crystallinity with a layered structure, as shown in Fig. 12a and $d .^{89}$ Here, phosphorus atoms are covalently bonded with three adjacent phosphorus atoms to form a puckered honeycomb structure in a single layer of $\mathrm{BP},{ }^{\mathbf{8 9 , 1 5 0}}$ and these individual atomic layers are stacked together by van der Waals interactions, similar to graphite (Fig. 12a), ${ }^{\mathbf{1 4 8 , 1 5 0 , 1 5 4}}$ giving a calculated density of $\sim 2.69 \mathrm{~g} \mathrm{~cm}^{-3}$. The layer-to-layer spacing is about $5.3 \AA$, and there are no contacts shorter than $3.59 \AA$ for atoms between successive layers. ${ }^{154} \mathrm{BP}$ shows good electronic conductivities $\left(\sim 66-300 \mathrm{~S} \mathrm{~m}^{-1} \text { vs. } \sim 10^{-12} \mathrm{~S} \mathrm{~m}^{-1} \text { for RP }\right)^{155,156}$ and has a suitable operating potential $\left(\approx 0.45 \mathrm{~V} v s . \mathrm{Na} / \mathrm{Na}^{+}\right)$for Na storage. ${ }^{157}$ In addition, the interlayer channel size of BP is $\sim 3.08 \AA$, which is suitable for the storage of both lithium (1.52 $\AA)$ and sodium (2.04 $\AA$ ) ions in the channels (Fig. 12a). ${ }^{\mathbf{1 4 8 , 1 5 8}}$ However, sluggish reaction kinetics and large volume changes (300-500\%) during desodiation/sodiation hinder its application as a SIB anode. ${ }^{158,159}$ Furthermore, the lack of effective, low-cost
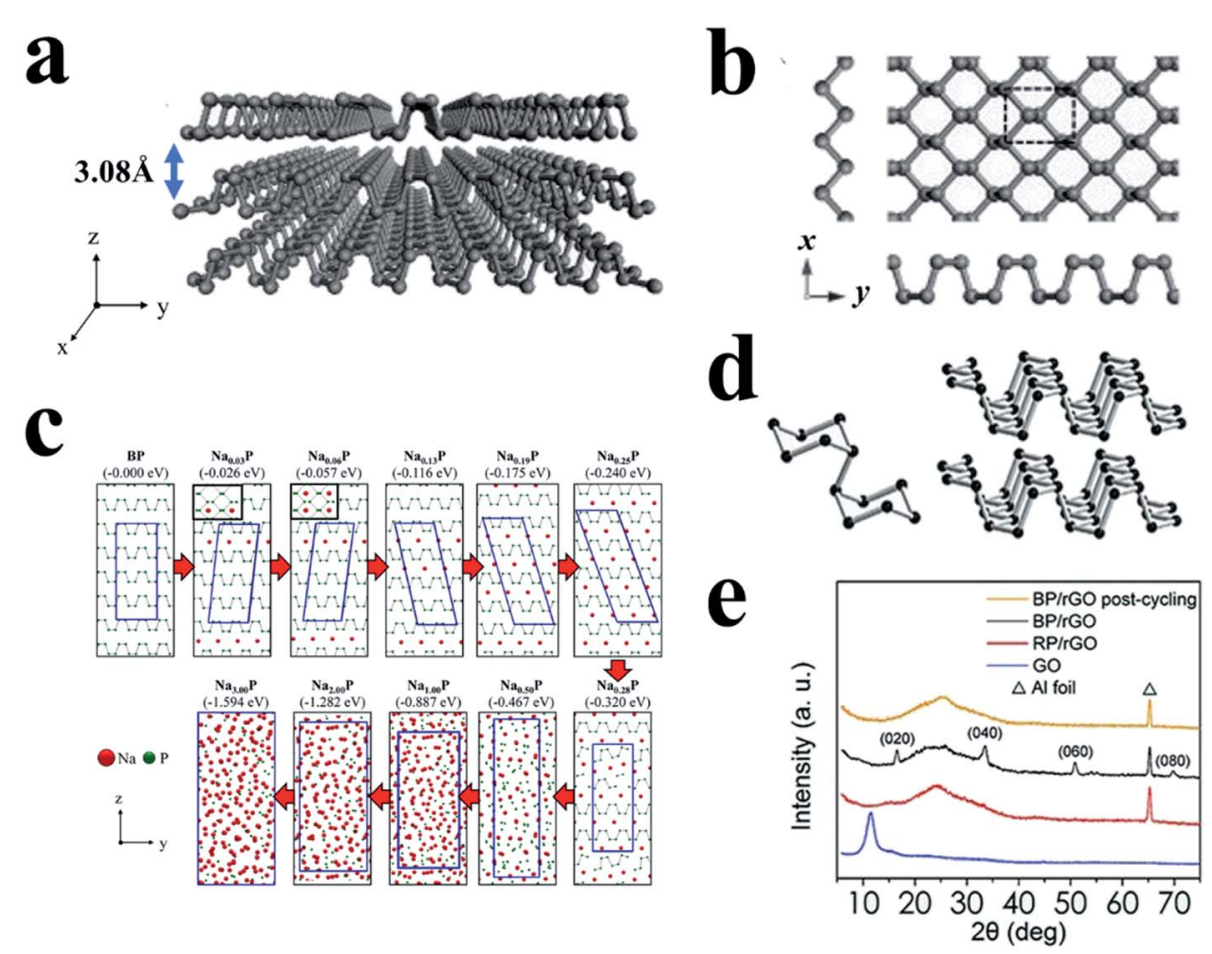

Fig. 12 (a) The puckered structure of a few-layer BP sheet. (b) Top view of monolayer BP. The $x$ and $y$ axes are along zigzag and armchair directions, respectively. Reproduced with permission. ${ }^{89}$ Copyright 2015, Wiley-VCH. (c) Sodiation mechanism of black phosphorus. The numbers in parentheses indicate calculated formation energies of $\mathrm{Na}_{x} \mathrm{P}$ structures. Reproduced with permission. ${ }^{167}$ Copyright 2015 , American Chemical Society. (d) Characteristic structural fragments of BP. Reproduced with permission. ${ }^{113}$ Copyright 2017, Wiley-VCH. (e) XRD patterns of the GO, RP/rGO precursor, as-prepared and post-cycling BP/rGO samples. Reproduced with permission. ${ }^{162}$ Copyright 2018, American Chemical Society. 
synthesis methods to produce BP on a large scale is a major concern for its practical application. Currently, the main strategies for preparing BP include high-energy mechanical milling, ${ }^{\mathbf{1 4 7}}$ mineralizer-assisted gas-phase transformation ${ }^{\mathbf{1 6 0}}$ and high-pressure (or with high-temperature) conversion from RP. ${ }^{161,162}$ All of these methods are critically dependent on the preparative conditions. With respect to this, some progress for novel methods to synthesize BP has been made recently. ${ }^{163-166}$

Compared with RP, the electrochemical mechanism of BP to store $\mathrm{Na}$ is easier to unravel due to its crystalline structure. And a thorough understanding of the chemistry that occurs in sodiation and desodiation can elucidate the structure-performance relationships responsible for high capacities and help to devise strategies to mitigate the performance degradation. ${ }^{\mathbf{1 6 8}}$ Many theoretical calculations have been carried out to understand the process of sodiation for BP. ${ }^{167,169-171}$ Based on these investigations, sodiation of BP includes two steps: (1) an intercalation process occurring in the interlayer channels of $\mathrm{BP}$ (along the $\mathrm{x}$-axial) until forming the composition of $\mathrm{Na}_{0.25} \mathrm{P}$ (diffusion barrier of $0.18 \mathrm{eV}$ ); and (2) an alloying process to form a layered $\mathrm{Na}_{x} \mathrm{P}$ structure and eventually an $\mathrm{Na}_{3} \mathrm{P}$ phase. After the intercalation process (step 1) was completed, one $\mathrm{Na}$ atom tended to bind with four $\mathrm{P}$ atoms, resulting in sliding of the phosphorene layers (Fig. 12c). At $\mathrm{Na}$ levels beyond $\mathrm{Na}_{0.25} \mathrm{P}$, alloying with $\mathrm{P}$ could lead to the breaking of $\mathrm{P}-\mathrm{P}$ bonds, in which the staggered $\mathrm{P}-\mathrm{P}$ bonds were preferentially broken rather than the planar $\mathrm{P}-\mathrm{P}$ bonds, generating $\mathrm{P}_{2}$ dumbbells. As sodiation proceeded further, most of the $\mathrm{P}_{2}$ dumbbells became isolated $\mathrm{P}$ atoms. Thus, after full sodiation to form the amorphous $\mathrm{Na}_{3} \mathrm{P}$ phase, only low-coordinate $\mathrm{P}$ components such as isolated atoms (primarily) and dumbbells could be found.

However, the mechanism of the desodiation process was little reported in the literature. In addition, it seems that the crystalline BP was converted into an amorphous form during cycling, and this has been experimentally evidenced. In a study, Liu et al. ${ }^{\mathbf{1 6 2}}$ found that the XRD characteristic peaks of BP disappeared after repeated charge and discharge (Fig. 12e), suggesting that the BP did not recover to its crystalline phase after desodiation, which was consistent with the results of Raman patterns, TEM and fast Fourier transform (FFT) images. If the BP was amorphized during cycling, it was difficult to explain why the cycling performance of anodes prepared from BP could continue to exceed that of anodes prepared from RP. To answer this question, researchers speculated that phosphorus (like $\mathrm{C}$, $\mathrm{H}_{2} \mathrm{O}$, and silicate glasses) might be polyamorphous and that amorphous $\mathrm{P}$ formed from BP could retain both structural and electronic advantages over RP or amorphous products formed from RP, and BP-graphite/graphene composites might play a role in maintaining the layered structures of $\mathrm{BP} .^{72,162}$ In addition, it was proposed that during the charge-discharge process, the electrolyte molecules could intercalate into the layer spaces and then lead to exfoliation of the layered structures and thus BP-graphite/graphene composites or pillared BP might be good options to improve the stability of the layered structure of BP during sodiation. ${ }^{167,169-171}$

Recently, Marbella et al. ${ }^{\mathbf{1 6 8}}$ investigated phosphorus intermediates in BP anodes during the sodiation and desodiation process on a molecular level by a combined experimental and theoretical approach, involving techniques such as solid-state NMR (sSNMR), powder X-ray diffraction (XRD), and DFT and NMR calculations. Specifically, individual $P$ binding sites within the amorphous $\mathrm{Na}_{x} \mathrm{P}$ phases that were formed during cycling can be probed with $2 \mathrm{D}{ }^{31} \mathrm{P}$ phase-adjusted spinning sideband (PASS) ssNMR experiments, thus providing information on the geometry of chemical bonding environments and structures of molecular fragments. In their study, ex situ ${ }^{31} \mathrm{P}$ magic-angle spinning (MAS) NMR spectra were acquired at different stages of (de)sodiation to probe the structural features of various $\mathrm{Na}_{x} \mathrm{P}$ phases in BP anodes (Fig. 13a). During the first sodiation, ${ }^{31} \mathrm{P}$ NMR shifts consistent with $\mathrm{P}$ helices/zig-zags were present as early as $0.60 \mathrm{~V}\left(\mathrm{Na}_{0.52} \mathrm{P}\right)$, suggesting that $\mathrm{P}-\mathrm{P}$ cleavage began at this composition. The ex situ XRD results also indicated that an amorphous or highly disordered phase was present in this stage in addition to residual BP. $\mathrm{P}$ helices were the predominant structural motifs that were subsequently formed after this stage. In addition, $\mathrm{P}$ helices and zig-zags (which are likely truncated helices) might allow some of the original alternating planar/ staggered $\mathrm{P}-\mathrm{P}$ bonds found in pristine $\mathrm{BP}$ to persist while also forming an energetically favorable $\mathrm{Na}_{x} \mathrm{P}$ phase. As $\mathrm{BP}$ was further sodiated to $0.38 \mathrm{~V}$, the amorphous $\mathrm{Na}_{x} \mathrm{P}$ phase (780 $\mathrm{mA} \mathrm{h} \mathrm{g}^{-1}$, approximate composition of $\mathrm{NaP}$ ) showed ${ }^{31} \mathrm{P}$ sites consistent with $\mathrm{P}$ helices and terminal $\mathrm{P}$ units from short $\mathrm{P}$ chains (four-membered P zig-zags), as shown in Fig. 13b-e. The corresponding ex situ XRD results also indicated that this phase was amorphous $\left(\mathrm{a}-\mathrm{Na}_{x} \mathrm{P}\right)$. In addition, the researchers proposed that dumbbell-containing structures previously predicted by others did not form in a measurable quantity in these SIBs during cycling. Once the potential dropped below $0.22 \mathrm{~V}$, the formation of a lower energy crystalline $\mathrm{Na}_{3} \mathrm{P}-\mathrm{P}_{3} \mathrm{~cm}$ structure occurred. And a plateau at $0.21 \mathrm{~V}$ (ranging from 1358$2340 \mathrm{~mA} \mathrm{~h} \mathrm{~g}^{-1}$, corresponding $x$ to 1.57-2.70) was observed and could be attributed to the formation of $\mathrm{c}-\mathrm{Na}_{3} \mathrm{P}-\mathrm{P}_{3} \mathrm{~cm}$, which is the most stable crystal structure of crystalline $\mathrm{Na}_{3} \mathrm{P}$ upon sodiation based on DFT calculations. During desodiation, the c$\mathrm{Na}_{3} \mathrm{P}-\mathrm{P}_{3} \mathrm{~cm}^{31} \mathrm{P}$ resonance at $-207 \mathrm{ppm}$ persisted until $>0.60 \mathrm{~V}$ $\left(>1490 \mathrm{~mA} \mathrm{~h} \mathrm{~g}{ }^{-1}\right.$, approximately $\mathrm{Na}_{1.28} \mathrm{P}$ ), as shown in Fig. 13a. At $0.8 \mathrm{~V}$ (1730 $\mathrm{mA} \mathrm{h} \mathrm{g}^{-1}$, approximately NaP), P motifs of helices could again be observed in a-NaP, but with longer average Na-P interatomic distances (Fig. $13 \mathrm{~g}$ and $\mathrm{h}$ ). Increased structural disorder was also observed and might be due to a larger range of clusters that were formed from the isolated $\mathrm{P}$ ions in $\mathrm{Na}_{3} \mathrm{P}$, as opposed to the original $\mathrm{P}-\mathrm{P}$ bonded BP phase. At the end of desodiation, the researchers found that BP was not re-formed, which might contribute to the poor capacity retention observed in the Na-P system. And the results of NMR also indicated that the $\mathrm{Na}$ ions were not completely removed during desodiation and/or were consumed in deleterious side reactions.

Compared with pure theoretical calculations, the use of experimental methods can make it more authentic and concrete for understanding the mechanism of $\mathrm{Na}$ storage, and more leveraging of advanced and suitable detecting instruments to study the behavior of active materials in SIBs is necessary. 


\section{a}

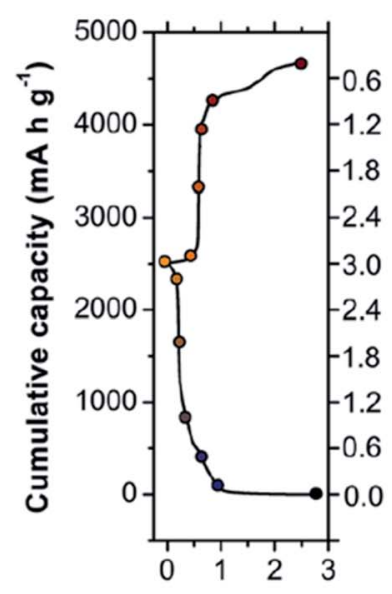

Voltage ( $\mathrm{V}$ vs $\left.\mathrm{Na}^{+} / \mathrm{Na}\right)$

c
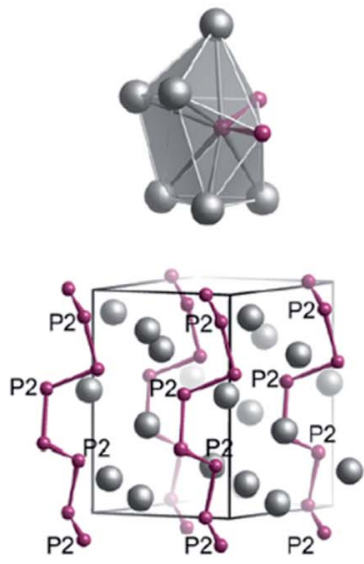

f

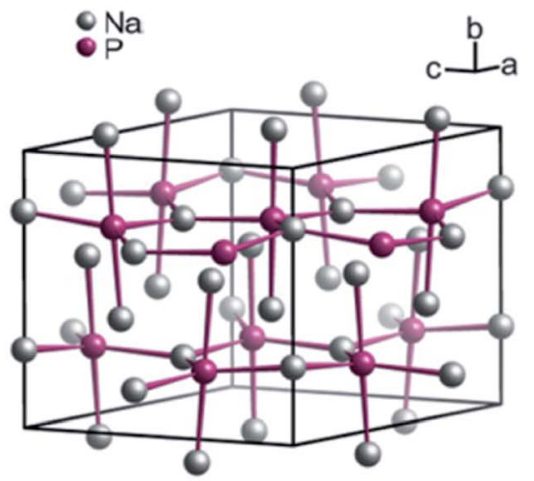

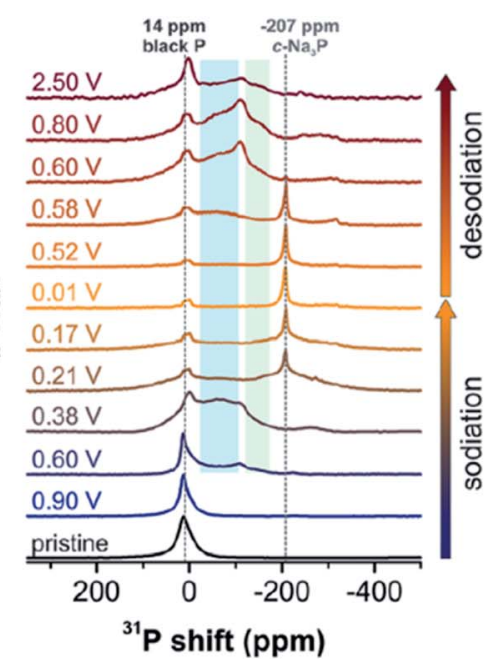

d
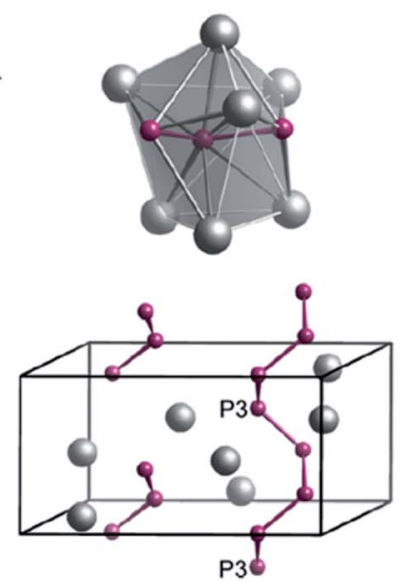

b

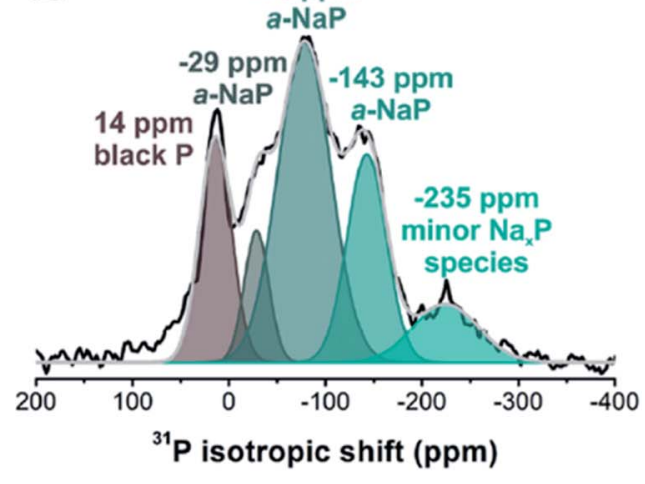

e
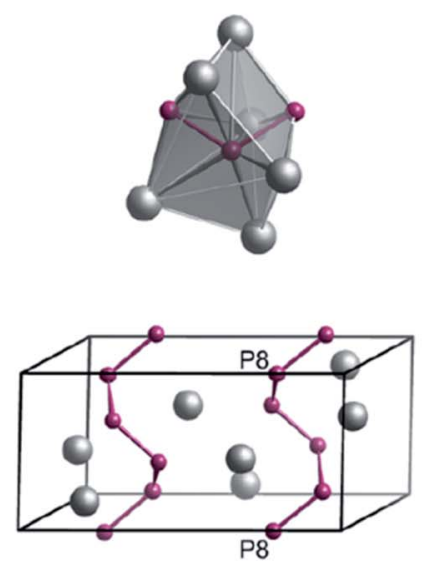

g

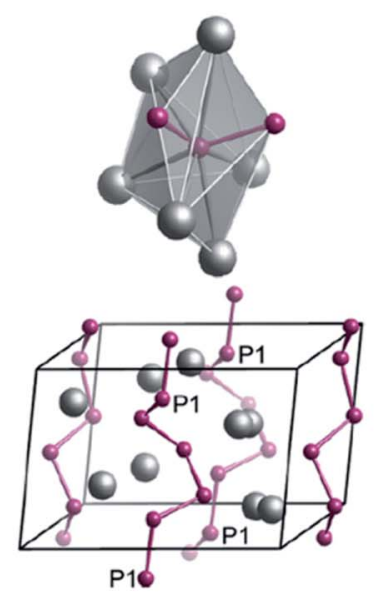

h
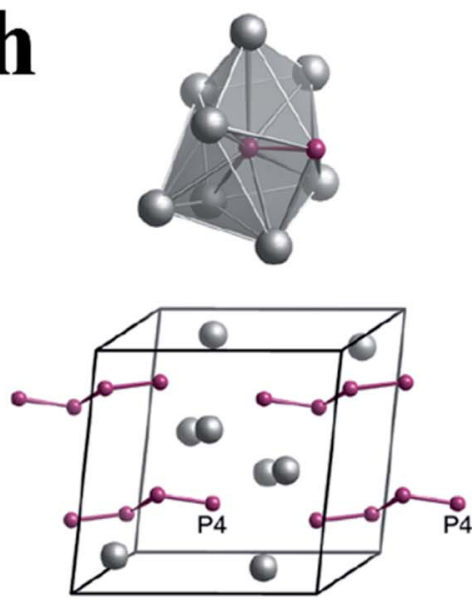

Fig. 13 (a) Ex situ ${ }^{31}$ P MAS NMR spectra of BP recorded at various stages of sodiation/desodiation (right) and the corresponding electrochemistry (left). ${ }^{31} \mathrm{P}$ chemical shift regions corresponding to $\mathrm{P}$ helical motifs and $\mathrm{P}$ near the end of chains are shaded in blue and green respectively. (b) Deconvolution of the ${ }^{31} \mathrm{P}$ isotropic projection from 2D ${ }^{31} \mathrm{P}$ phase-adjusted spinning sideband (PASS) experiments (black line) performed on a sample of approximate composition NaP, extracted from a SIB at $0.38 \mathrm{~V}\left(780 \mathrm{~mA} \mathrm{~h} \mathrm{~g}^{-1}\right)$ during sodiation. Five regions with centers-of-mass at 14 (BP), $-29,-78,-143$, and -235 ppm are observed. (c-e) The corresponding P sites (top) and extended P structures (bottom) of sideband patterns (calculated) for different isotropic chemical shifts, $\delta_{\text {iso }}=-29$ (c), -78 (d), and $-143 \mathrm{ppm}(\mathrm{e})$, extracted from a SIB at $0.38 \mathrm{~V}\left(780 \mathrm{~mA}\right.$ h $\mathrm{g}^{-1}$ ) during sodiation. (f) Crystal structures of $\mathrm{Na}_{3} \mathrm{P}-\mathrm{P} 6_{3} \mathrm{~cm}$ (calculated). (g, h) The corresponding $\mathrm{P}$ sites (top) and extended $\mathrm{P}$ structures (bottom) of sideband patterns (calculated) for $\delta_{\text {iso }}=-29(\mathrm{~g})$ and $-78(\mathrm{~h})$, extracted from a SIB at $0.80 \mathrm{~V}\left(1730 \mathrm{~mA} \mathrm{~h}^{-1}\right)$ during desodiation. The symbol of $\mathrm{P}_{x}$, $x=2,3,8,1,4$ (c-e, g and h), denotes individual ${ }^{31} \mathrm{P}$ sites in certain structural models. Reproduced with permission. ${ }^{168}$ Copyright 2018 , American Chemical Society. 
To solve the issue of sluggish reaction kinetics, Dou et al. ${ }^{159}$ utilized nanoscale surface engineering to homogeneously deposit highly electron conductive poly(3,4ethylenedioxythiophene) (PEDOT) nanofibers onto special surface-modified BP nanosheets (Fig. 14a) and reported that this design could enhance charge transfer kinetics and super surface wettability with electrolytes, leading to enhancement in the reaction kinetics of sodium storage (Fig. 14b and c). In another study, Wang et al. ${ }^{172}$ used 4-nitrobenzenediazonium (4NBD) to modify BP and further made it chemically bond with reduced graphene oxide to prepare a hybrid as an anode material. The researchers reported that due to enhanced interactions between the chemically functionalized BP and graphene, the cycling performance of the resulting SIB anode was significantly improved, exhibiting a specific capacity of $1472 \mathrm{~mA} \mathrm{~h} \mathrm{~g}^{-1}$ at $0.1 \mathrm{Ag}^{-1}$ in the 50 th cycle and $650 \mathrm{~mA} \mathrm{~h} \mathrm{~g}^{-1}$ at $1 \mathrm{~A} \mathrm{~g}^{-1}$ after 200 cycles. The results further indicated that these interactions could improve BP stability during long term cycling, reduce surface energies and increase BP thicknesses, all of which enabled the enlargement of channels between BP nanosheets and graphene, allowing more sodium ions to be stored for improved cycling performances. According to these studies, it can be seen that surface engineering is an effective way to improve the reaction kinetics of BP and thus can enhance the rate capability.

Similar to RP, direct combination with carbon-based materials is an effective approach to overcome the drawbacks of BP for $\mathrm{Na}$ storage. For example, $\mathrm{Xu}$ et al. ${ }^{173}$ reported that a composite of ball milled $\mathrm{BP} /$ Ketjen-black/multiwalled carbon nanotubes (BPC) could exhibit high performances: a first-cycle reversible capacity of $2011.1 \mathrm{~mA} \mathrm{~h} \mathrm{~g}^{-1}$, with an initial coulombic efficiency of $91.1 \%$ and a capacity of $1700 \mathrm{~mA} \mathrm{~h} \mathrm{~g}^{-1}$ over 100 cycles at a current of $1.3 \mathrm{~A} \mathrm{~g}^{-1}$. Similarly, HaghighatShishavan et al. ${ }^{\mathbf{1 7 4}}$ also prepared a composite of BP and multiwalled carbon nanotubes (BP-CNTs) through ball milling process; in addition, they found that appropriate air exposure could successfully alter BP powder from a naturally hydrophobic form to a desired hydrophilic form, which is essential to the formation of stable bonds between BP and functionalized CNTs during ball milling. In this study, a binary polymeric binder of sodium carboxyl methyl cellulose-poly acrylic acid (NaCMC-PAA) was used to fabricate an anode; as a result, the resulting anode delivered a first discharge capacity of $2073 \mathrm{~mA} \mathrm{~h} \mathrm{~g}^{-1}$ at $0.2 \mathrm{C}$ for SIBs, with a high capacity retention of $75.3 \%$ after 200 cycles, and a rate capacity of $609 \mathrm{~mA} \mathrm{~h} \mathrm{~g}^{-1}$ at $2 \mathrm{C}$ was obtained. Here, the researchers suggested the strong bonds between BP and the hydroxyl groups of NaCMC and carboxylic acid groups of PAA played an important role for the improved $\mathrm{Na}$ storage performance of $\mathrm{BP} .{ }^{174}$ In another study, Li et al. ${ }^{\mathbf{1 7 5}}$ reported a $\mathrm{BP} /$ graphene $(\mathrm{BP} / \mathrm{G}) 2 \mathrm{D}$ macroscopic heterostructure prepared by a co-exfoliation/electrophoretic deposition process. When used as a binder- and additive-free anode for SIBs, this composite demonstrated superior specific capacities of 2365 $\mathrm{mA} \mathrm{h} \mathrm{g}_{\mathrm{P}}{ }^{-1}, 1894 \mathrm{~mA} \mathrm{~h} \mathrm{~g}_{\mathrm{P}}{ }^{-1}$ and $1456 \mathrm{~mA} \mathrm{~h} \mathrm{~g}_{\mathrm{P}}{ }^{-1}$ at 100, 200 and $500 \mathrm{~mA} \mathrm{~g}_{\mathrm{P}}^{-1}$ rates respectively and showed a stable cycling performance. This novel preparation method ensures the intimate contact of BP and graphene, and thus a binder- and additive-free anode can be obtained, not only increasing the specific capacity but also reducing the cost for practical application. Recently, a BP-graphene layered structure was synthesized directly from a RP-graphene precursor by a low-cost and scalable pressurization (8 GP) process at room temperature (Fig. 14d). ${ }^{162}$ These hybrids could also be directly used as anode materials without a conductive additive and binder for SIBs and showed excellent rate capabilities and cycling stabilities $\left(\sim 1250 \mathrm{~mA} \mathrm{~h} \mathrm{~g}^{-1}\right.$ at $1 \mathrm{~A} \mathrm{~g}^{-1}$ and $\sim 640 \mathrm{~mA} \mathrm{~h} \mathrm{~g}^{-1}$ at $40 \mathrm{Ag}^{-1}$ after 600 cycles) (Fig. 14e). This study combines the synthesis of BP and the preparation of a BP-graphene hybrid anode in one step, offering excellent possibility for scalable production of composites for practical SIBs.

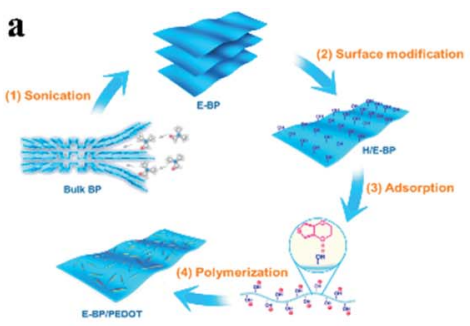

b
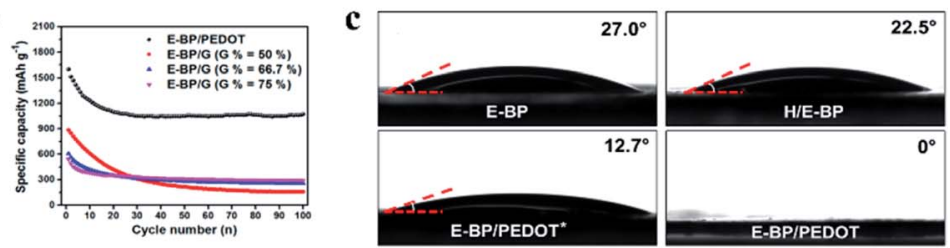

d

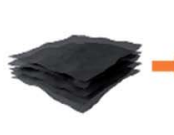

60
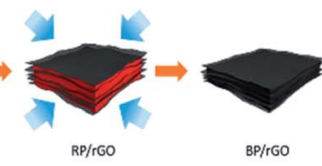

BP/rGo

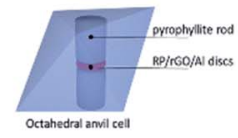

e

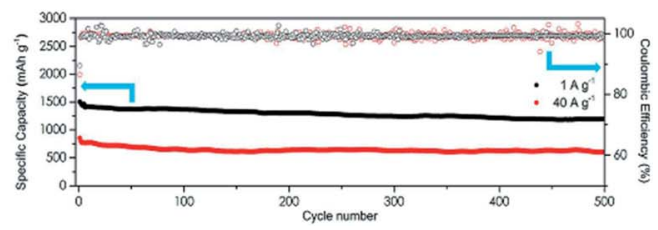

Fig. 14 (a) Schematic of the preparation of the E-BP/PEDOT architecture. (b) Cycling life of E-BP/PEDOT and E-BP/graphene hybrid electrodes with different ratios at $100 \mathrm{~mA} \mathrm{~g}^{-1}$. (c) Characterization of wetting properties and optical images of contact angles between electrolytes and EBP, H/E-BP, E-BP/PEDOT * (less PEDOT grown on BP nanosheets) and E-BP/PEDOT electrodes. (a-c) Reproduced with permission. ${ }^{159}$ Copyright 2017, Elsevier Ltd. (d) Schematic description of the BP/rGO synthesis. (e) Cycling performance of the BP/rGO anodes at charge and discharge current densities of 1 and $40 \mathrm{~A} \mathrm{~g}^{-1}$ in black and red, respectively. (d, e) Reproduced with permission. ${ }^{162}$ Copyright 2018, American Chemical Society. 
Besides carbon materials to be combined with BP, researchers have also explored composites with other types of materials. For example, Meng et al. ${ }^{176}$ prepared a composite of BP quantum dots (BPQDs) anchored onto $\mathrm{Ti}_{3} \mathrm{C}_{2}$ nanosheets (TNSs) as an anode material for SIBs by a assembling process with the assistance of sonication and long-term stirring. They reported that due to the addition of TNSs, the BPQDs were endowed with improved conductivity and reduced stress during cycling, allowing for a high initial discharge capacity of $\sim 723 \mathrm{~mA} \mathrm{~h} \mathrm{~g}^{-1}$ and outstanding long-term cycling stabilities up to 1000 cycles with a capacity retention of nearly $100 \%$. In another study, Song et al. ${ }^{177}$ employed a simple high-energy mechanical milling approach to fabricate a novel and stable sodium titanate/carbon-BP $\left(\mathrm{Na}_{2} \mathrm{Ti}_{3} \mathrm{O}_{7} / \mathrm{C}-\mathrm{BP}\right)$ hybrid as a SIB anode material and found that the $\mathrm{BP}$ nanoparticles could interconnect with bare NTO through $\mathrm{P}-\mathrm{O}-\mathrm{Ti}$ bonds and/or P-C bonds. As a result, the NTO/C-BP hybrid delivered specific capacities of $\sim 225 \mathrm{~mA} \mathrm{~h} \mathrm{~g}^{-1}$ at $20 \mathrm{~mA} \mathrm{~g}^{-1}$ after 55 cycles and $\sim 183 \mathrm{~mA} \mathrm{~h} \mathrm{~g}^{-1}$ after 100 cycles at $100 \mathrm{~mA} \mathrm{~g}^{-1}$. The researchers also suggested that the formation of stable $\mathrm{P}-\mathrm{C}$ bonds and $\mathrm{P}-\mathrm{O}-$ Ti bonds was a promising strategy to fabricate other Ti-based and P-based electrode materials for practical application in SIBs. However, the BP content in this composite is quite low $(20 \%)$ which results in a reduced special capacity, and the large specific surface area of these ball milled hybrids causes a low initial coulombic efficiency (42\%), which is not suitable for practical applications. Xia's group ${ }^{\mathbf{1 7 8}}$ synthesized a composite of sulfur-doped $\mathrm{BP}-\mathrm{TiO}_{2}\left(\mathrm{TiO}_{2}\right.$-BP-S) as an anode material for SIBS using a feasible and large-scale high energy ball milling method and obtained a discharge specific capacity of up to $490 \mathrm{~mA} \mathrm{~h}^{-1}$ after 100 cycles at $50 \mathrm{~mA} \mathrm{~g}^{-1}$ and good cycling stabilities with $290 \mathrm{~mA} \mathrm{~h} \mathrm{~g}^{-1}$ capacity retention after 600 cycles at $500 \mathrm{~mA} \mathrm{~g}^{-1}$. In another study, Ding et al. ${ }^{179}$ also designed a strategy to produce BP composites in which they first ball milled amorphous RP with cubic boron nitride to obtain a $\mathrm{BP} / \mathrm{c}-\mathrm{BN}$ composite, and then wrapped this composite by nanoporous graphene networks via a sonication method. In this composite, the super hard c-BN could not only reduce the size of RP during ball milling, but also act as a mechanical skeleton to suppress and buffer the large volume expansion of BP during the sodiation process. As a result, this $\mathrm{BP} / \mathrm{c}-\mathrm{BN} / \mathrm{Gr}$ composite anode demonstrated high cyclability with a stable specific capacity of $947 \mathrm{~mA} \mathrm{~h} \mathrm{~g}^{-1}$ and a $\sim 90 \%$ capacity retention after 100 cycles at a current density of $50 \mathrm{~mA} \mathrm{~g}^{-1}$. This is the first time that a super hard material was introduced into P-based anodes for SIBs; however, the high electron resistance of such c-BN may cause insufficient rate capability, and finding materials that possess both high mechanical strength and high electronic conductivity to host BP is a promising strategy for practical SIBs.

Phosphorene is a new 2D material that contains one or few layers of BP (Fig. 12a and b) ${ }^{89}$ and can be obtained from bulk BP through various methods ${ }^{\mathbf{1 8 0 - 1 8 3}}$ or even from white phosphorus. ${ }^{164}$ These 2D phosphorene materials possess unique properties such as enlarged specific surface areas, increased interlayer distances, ${ }^{72}$ and fast electron transfer and $\mathrm{Na}$ diffusivity (energy barrier of only $0.04 \mathrm{eV}$ for monolayer BP), ${ }^{\mathbf{1 8 4}, \mathbf{1 8 5}}$ and have attracted significant attention and witnessed development in SIB applications. For example, Sun et $a l . .^{72}$ synthesized a hybrid with several layers of phosphorene sandwiched between graphene layers and obtained a specific capacity of $2440 \mathrm{~mA} \mathrm{~h} \mathrm{~g}{ }^{-1}$ (based on phosphorus) at a current density of $50 \mathrm{~mA} \mathrm{~g}^{-1}$ and a $83 \%$ capacity retention after 100 cycles. The results of in situ TEM and ex situ XRD indicated a dual Na storage mechanism involving the intercalation of sodium ions along the $x$-axis of phosphorene and the formation of $\mathrm{Na}_{3} \mathrm{P}$, which is consistent with the theoretical calculations carried out by other researchers. ${ }^{167}$ Furthermore, the graphene layers in this hybrid were found to serve as a mechanical backbone and an electrical highway to accommodate the anisotropic expansion of phosphorene layers along the $y$ - and $z$-axial directions for stable cycling operations, leading to excellent stability. ${ }^{72}$

The lack of large-scale and low-cost methods to prepare phosphorene hinders its practical applications; however, developments have been made after continuous efforts, such as mechanical exfoliation and liquid-phase peeling. ${ }^{\mathbf{1 8 0 , 1 8 2 , 1 8 3 , 1 8 6 , 1 8 7}}$ Recently, Huang et al. ${ }^{\mathbf{1 8 8}}$ developed a electrochemical cationic intercalation method to prepare phosphorene from BP crystals and applied it as an anode material for SIBs (Fig. 15a). Here, tetraalkylammonium cations were used to intercalate BP, and FL-P-5 meant that a potential of $-5 \mathrm{~V}$ was applied to exfoliate bulk BP; similarly, FL-P-10 and FL-P-15 correspond to potentials of -10 and -15 , respectively. The researchers found that the number of BP layers (from 2 to 11 layers) could be manipulated by changing the applied potential and that the BP layers were free of surface functional groups (Fig. 15b-d). As a result, this phosphorene anode showed excellent performances for SIBs, delivering a capacity of $1968 \mathrm{~mA} \mathrm{~h} \mathrm{~g}^{-1}$ after 15 cycles and $\sim 1190 \mathrm{~mA} \mathrm{~h} \mathrm{~g}^{-1}$ after 50 cycles at a current density of $100 \mathrm{~mA} \mathrm{~g}^{-1}$ (Fig. 15f and g).

\section{Metal phosphides}

Metal phosphides (MPs) are also promising anode materials for SIBs due to their noticeably high gravimetric and volumetric specific capacities, appropriate redox potentials and higher electrical conductivities as compared with pure phosphorus. ${ }^{77,189}$ The higher performance of MPs as SIB anodes can mainly be attributed to the presence of metal atoms acting as electronic pathways that drastically enhance the electronic conductivity. ${ }^{190}$ In addition, conductive metal particles can be formed in MP anodes during battery cycling which further increases the conductivity of electrodes. ${ }^{91,189}$ Furthermore, in some MPs, metal nanocrystals are embedded in phosphorus matrices during cycling and thus inhibit the agglomeration of metals and improve the cycling performance of MP anodes. However, there are also drawbacks of MP anodes, including large volume variations and poor diffusion kinetics during cycling which is similar to phosphorus. To overcome these disadvantages and allow MPs to become more practical for SIBs, extensive investigations have been conducted and various MP nanostructures have been prepared, such as yolk-shell $\mathrm{Sn}_{4} \mathrm{P}_{3} @ \mathrm{C}$ nanospheres, ${ }^{91} \mathrm{CoP}$ nanowires, ${ }^{191}$ monodisperse $\mathrm{Ni}_{2} \mathrm{P}$ particles $^{92}$ and hollow FeP@carbon nanocomposites, ${ }^{192}$ all of which possess unique nanostructures or conductive matrices 


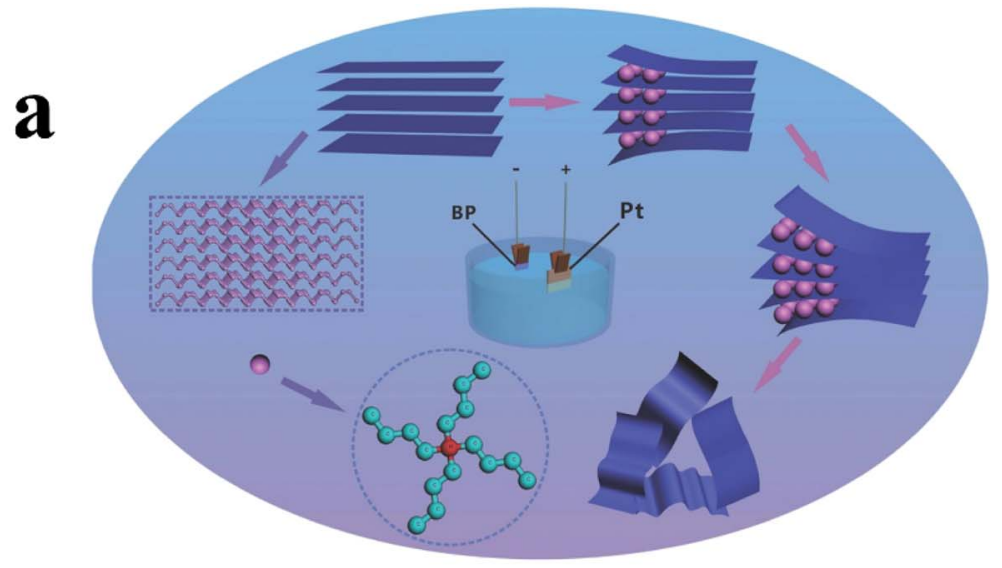

b

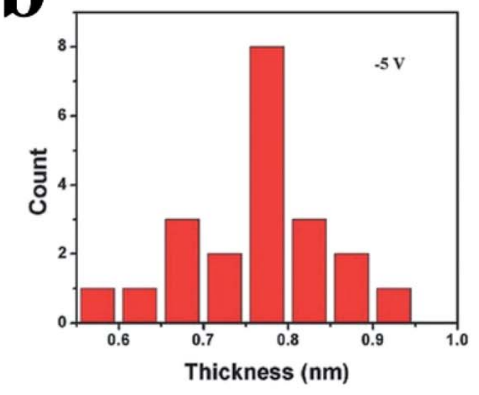

e

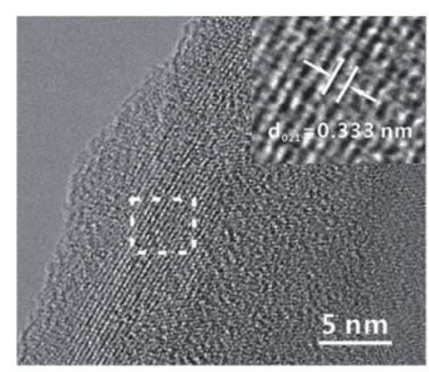

c

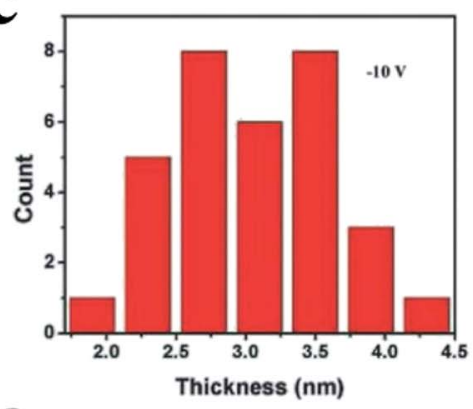

f

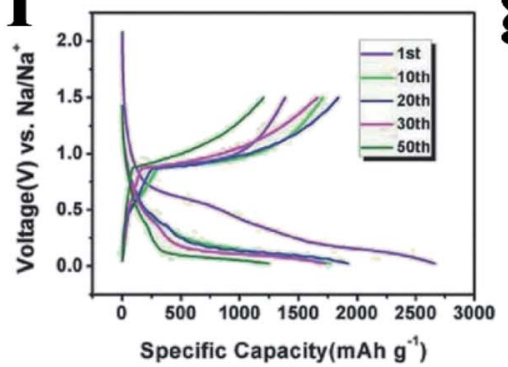

d
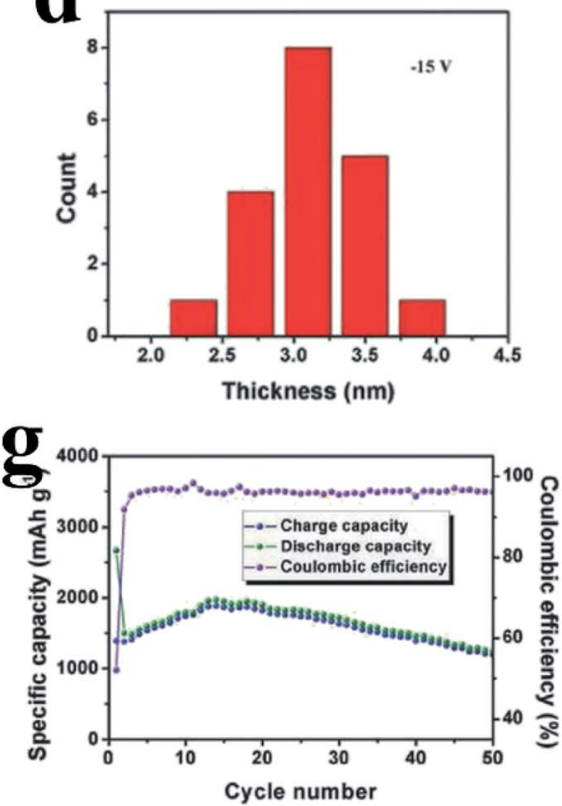

Fig. 15 (a) Schematic of the electrochemical exfoliation process of phosphorene. (b-d) The corresponding thickness distribution charts of FL-P5. FL-P-10, and FL-P-15, respectively. (e) HRTEM image of FL-P-5. (f) Charge and discharge profiles of different cycles at $100 \mathrm{~mA} \mathrm{~g}^{-1}$. (g) Cycling performances and coulombic efficiencies at $100 \mathrm{~mA} \mathrm{~g}^{-1}$. Reproduced with permission. ${ }^{188}$ Copyright 2017, WILEY-VCH.

that could accommodate volume expansion and offer more active sites for $\mathrm{Na}$ insertion/extraction and thus high electrochemical performances.

In general, the reaction mechanisms of MPs are more complex than those of pure phosphorus. Based on whether the metal elements in MPs can electrochemically react with sodium, MPs can be divided into metal-active phosphides and metal-inactive phosphides. For metal-active phosphides, both the metal element and $\mathrm{P}$ phase can react with $\mathrm{Na}$, and in a typical reaction process, crystalline metal and $\mathrm{P}$ phases are formed after the first cycle through a conversion process and react with sodium during the subsequent cycles through a reversible alloying process respectively, as expressed as follows: $:^{74,77,91,193,194}$

$$
\mathrm{MP}_{x}+(3 x+y) \mathrm{Na}^{+}+(3 x+y) \mathrm{e}^{-} \rightarrow \mathrm{Na}_{y} \mathrm{M}+x \mathrm{Na}_{3} \mathrm{P}
$$

$$
\begin{aligned}
& \mathrm{Na}_{y} \mathrm{M} \leftrightarrow \mathrm{M}+y \mathrm{Na}^{+}+y \mathrm{e}^{-} \\
& \mathrm{Na}_{3} \mathrm{P} \leftrightarrow 3 \mathrm{Na}^{+}+\mathrm{P}+3 \mathrm{e}^{-}
\end{aligned}
$$

Examples of metal-active phosphides include $\mathrm{Sn}_{4} \mathrm{P}_{3}$ (ref. 91 and 195) and $\mathrm{GeP}_{5} \cdot{ }^{193}$

For another kind of metal-active phosphide, crystalline metal and P phases can reform the original phase of MPs after desodiation, such as $\mathrm{GeP}_{3}$ (ref. 196) and $\mathrm{GeP},{ }^{197}$ and the process can be expressed as follows:

$$
\mathrm{MP}_{x}+(3 x+y) \mathrm{Na}^{+}+(3 x+y) \mathrm{e}^{-} \leftrightarrow \mathrm{Na}_{y} \mathrm{M}+x \mathrm{Na}_{3} \mathrm{P}
$$

Similarly, metal-inactive phosphides also proceed through two main types of reactions: one allows for the reconversion to the original MP phase after desodiation whereas the other one cannot. In the former reaction, metallic and $\mathrm{Na}_{x} \mathrm{P}$ phases are 
formed after sodiation and the metal and $\mathrm{P}$ atoms can re-bond to form MPs during desodiation. Examples of this type of material include $\mathrm{CuP}_{2},{ }^{189} \mathrm{Cu}_{3} \mathrm{P},{ }^{198} \mathrm{NiP}_{3}$ (ref. 199) and $\mathrm{CoP}_{3}$ (ref. 200) and the reaction process can be presented as eqn (5):

$$
\mathrm{MP}_{x}+3 x \mathrm{Na}^{+}+3 x \mathrm{e}^{-} \leftrightarrow x \mathrm{Na}_{3} \mathrm{P}+\mathrm{M}
$$

As for the latter reaction, nanosized metallic nanocrystals and $\mathrm{Na}_{x} \mathrm{P}$ phases are formed after metal-P bonds break during the first sodiation process. In the following desodiation process, a pure $\mathrm{P}$ phase is formed after Na-extraction and undergoes a reversible conversion reaction with $\mathrm{Na}$ in the subsequent cycles. Examples of this type of material include $\mathrm{FeP}^{\mathbf{2 0 1}, 202}$ and $\mathrm{CoP}^{203,204}$ and the reaction process can be expressed as follows:

$$
\begin{gathered}
\mathrm{MP}_{x}+3 x \mathrm{Na}^{+}+3 x \mathrm{e}^{-} \rightarrow x \mathrm{Na}_{3} \mathrm{P}+\mathrm{M} \\
\mathrm{Na}_{3} \mathrm{P} \leftrightarrow 3 \mathrm{Na}^{+}+\mathrm{P}+3 \mathrm{e}^{-}
\end{gathered}
$$

Overall, details of Na-storage mechanisms for MPs have yet to be fully understood and more efforts and new advanced characterization methods are needed.

\subsection{Tin phosphides}

Tin phosphides such as $\mathrm{Sn}_{4} \mathrm{P}_{3}$ and SnP have attracted considerable attention because of their high theoretical volumetric specific capacity $\left(6650 \mathrm{~mA} \mathrm{~h} \mathrm{~cm}{ }^{-3}\right.$ for $\mathrm{Sn}_{4} \mathrm{P}_{3} v s .5710 \mathrm{~mA} \mathrm{~h} \mathrm{~cm} \mathrm{~cm}^{-3}$ for $\mathrm{P})^{77}$ and high electronic conductivity $\left(30.7 \mathrm{~S} \mathrm{~cm}^{-1}\right.$ for $\mathrm{Sn}_{4} \mathrm{P}_{3}$ vs. $\sim 10^{-14} \mathrm{~S} \mathrm{~cm}^{-1}$ for $\left.\mathrm{RP}\right) .{ }^{77,80} \mathrm{Sn}_{4} \mathrm{P}_{3}$ exhibits a rhombohedral lattice (JCPDS No. 71-2221) with a layered structure consisting of Sn layers and P layers packed alternately (Fig. 16a). ${ }^{205,206} \mathrm{Kim}$ et $a{ }^{.77}$ for the first time studied the electrochemical performance of $\mathrm{Sn}_{4} \mathrm{P}_{3}$ as a SIB anode obtained through ball milling and reported a high reversible capacity of $718 \mathrm{~mA} \mathrm{~h} \mathrm{~g} \mathrm{~g}^{-1}$ and a high stability with negligible capacity fading over 100 cycles. In addition, the $\mathrm{Sn}_{4} \mathrm{P}_{3}$ sample in this study also showed an appropriately low redox potential of $\sim 0.3 \mathrm{~V} v s . \mathrm{Na} / \mathrm{Na}^{+}$, allowing the anode to achieve high energy densities in full cells. According to the reported literature ${ }^{\mathbf{7 4 , 9 1 , 1 9 5}}$ researchers suggested that the better cycle performance of $\mathrm{Sn}_{4} \mathrm{P}_{3}$ compared with Sn could be attributed to the confinement effect of Sn nanocrystallites in the amorphous phosphorus matrix during cycling. And the $\mathrm{Na}$ storage mechanism of $\mathrm{Sn}_{4} \mathrm{P}_{3}$ could be summarized based on their results, ${ }^{74,91,195}$ as expressed as follows:

$$
\begin{gathered}
\mathrm{Sn}_{4} \mathrm{P}_{3}+24 \mathrm{Na}^{+}+24 \mathrm{e}^{-} \rightarrow \mathrm{Na}_{15} \mathrm{Sn}_{4}+3 \mathrm{Na}_{3} \mathrm{P} \\
\mathrm{Na}_{15} \mathrm{Sn}_{4} \leftrightarrow 4 \mathrm{Sn}+15 \mathrm{Na}+15 \mathrm{e}^{-} \\
\mathrm{Na}_{3} \mathrm{P} \leftrightarrow 3 \mathrm{Na}^{+}+\mathrm{P}+3 \mathrm{e}^{-}
\end{gathered}
$$

According to the literature reported by Jung et al. ${ }^{207}$ the sodiation/desodiation processes of $\mathrm{Sn}_{4} \mathrm{P}_{3}$ can be depicted as follows: in the initial stage of sodiation, the $\mathrm{Na}$ ions break the Sn-P bonds of $\mathrm{Sn}_{4} \mathrm{P}_{3}$ and react with $\mathrm{P}$ to form $\mathrm{Na}_{x} \mathrm{P}$ due to the strong preference of $\mathrm{Na}$ for $\mathrm{P}$ over $\mathrm{Sn}$; meanwhile, the Sn atoms are separated from $\mathrm{P}$ atoms and then join together to form local $\mathrm{Sn}$ particles. The $\mathrm{Na}_{x} \mathrm{P}$ phase can surround the $\mathrm{Sn}$ particles because of its volume expansion with $\mathrm{Na}$ alloying, or Sn nanoparticles are dispersed in the amorphous-like $\mathrm{P}$ matrix. As sodiation continues, the $\mathrm{Na}_{x} \mathrm{P}$ phase evolves into $\mathrm{Na}_{3} \mathrm{P}$, and the $\mathrm{Sn}$ particles evolve into $\mathrm{Na}_{y} \mathrm{Sn}$ by reacting with $\mathrm{Na}$ ions and eventually into $\mathrm{Na}_{15} \mathrm{Sn}_{4} \cdot{ }^{74}$ After full sodiation, $\mathrm{Sn}_{4} \mathrm{P}_{3}$ is changed to a morphology where $\mathrm{Na}_{15} \mathrm{Sn}_{4}$ particles are confined in a $\mathrm{Na}_{3} \mathrm{P}$ matrix. After Na-extraction of these products, low crystallinity Sn nanoparticles are formed and highly dispersed in the
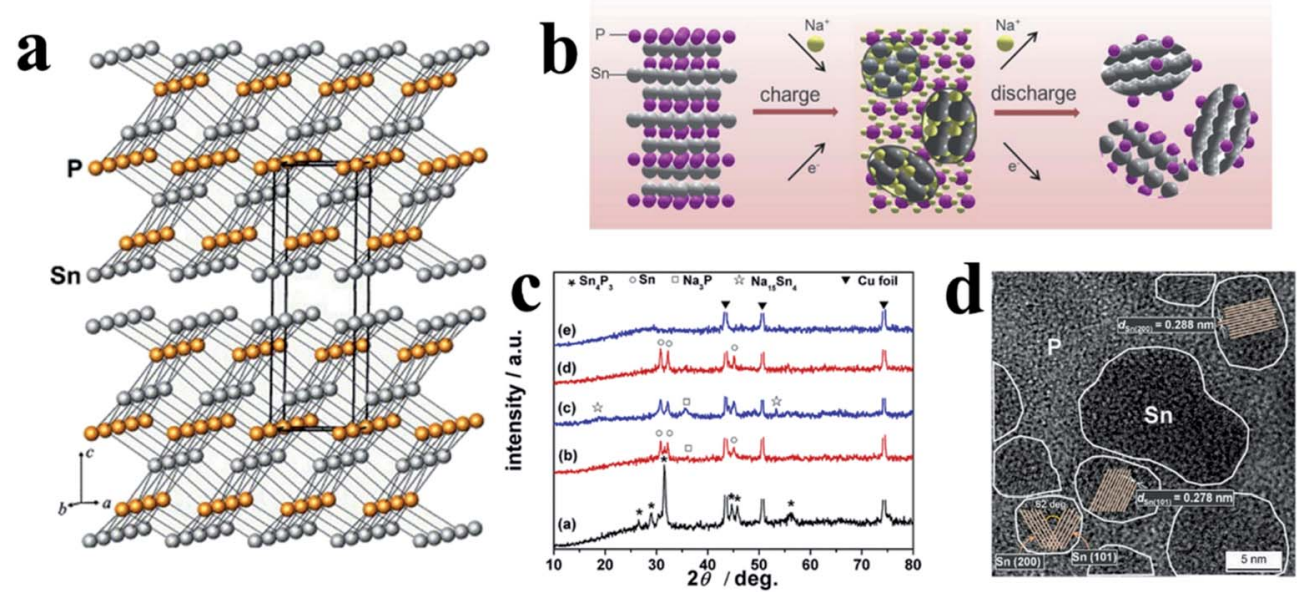

Fig. 16 (a) Optimized structure of hexagonal crystalline $\mathrm{Sn}_{4} \mathrm{P}_{3}$; orange and gray balls represent the $\mathrm{Sn}$ and $\mathrm{P}$ atoms, respectively. Reproduced with permission. ${ }^{206}$ Copyright 2006, Elsevier Inc. (b) Schematic illustration of the Na storage mechanism in the $\mathrm{Sn}_{4} \mathrm{P}_{3}$ electrode. Phase transformation of $\mathrm{Sn}_{4} \mathrm{P}_{3}$ by sodiation and desodiation (discharge) reactions. (c) Ex situ XRD patterns of the $\mathrm{Sn}_{4} \mathrm{P}_{3} / C$ electrode in different charge and discharge states: (a) fresh electrode; (b) after the 1st charge to $0.25 \mathrm{~V}$; (c) after completion of the 1 st charge to $0.01 \mathrm{~V}$; (d) after the 1 st discharge to $0.5 \mathrm{~V}$; and (e) full discharge to $2.0 \mathrm{~V}$. Here the charge process represents sodiation. (c, d) Reproduced with permission. ${ }^{74}$ Copyright 2014 , American Chemical Society. (d) High magnification TEM image of $\mathrm{Sn}_{4} \mathrm{P}_{3}$ after the first desodiation (in an ionic liquid electrolyte). Reproduced with permission. ${ }^{208}$ Copyright 2017, American Chemical Society. 
amorphous $\mathrm{P}$ host matrix. In the subsequent sodiation/ desodiation cycles, $\mathrm{P}$ and Sn undergo reversible alloying and de-alloying reactions, respectively. This is well consistent with the experimental results (Fig. 16c and d). In addition, this $\mathrm{Na}$ storage mechanism can well explain the excellent cycle performance of $\mathrm{Sn}_{4} \mathrm{P}_{3}$. The core $\left(\mathrm{Na}_{15} \mathrm{Sn}_{4}\right) /$ matrix $\left(\mathrm{Na}_{3} \mathrm{P}\right)$ morphology formed by initial sodiation has high structural integrity because the bulk modulus of $\mathrm{Na}_{3} \mathrm{P}$ is $71 \%$ higher than that of $\mathrm{Na}_{15} \mathrm{Sn}_{4}$. Thus, $\mathrm{Na}_{3} \mathrm{P}$ is much better able to withstand deformation than $\mathrm{Na}_{15} \mathrm{Sn}_{4}$, and effectively prevent the aggregation of the $\mathrm{Sn}$ particles in the next charge-discharge cycle, and this is largely responsible for the excellent cycle performance and high coulombic efficiency of $\operatorname{Sn}_{4} \mathrm{P}_{3} \cdot{ }^{74,77,208}$ Furthermore, the Sn phase can change its morphology during sodiation-desodiation in response to P's volume changes; consequently, the void spaces could be filled by their morphological changes, preventing the electrical isolation of the active material layer. ${ }^{209}$ The structure of crystalline $\mathrm{Sn}_{4} \mathrm{P}_{3}$, the schematic illustration of the Na storage mechanism, and the experimental results are shown in Fig. 16a and $\mathrm{b}$.

However, in the study carried out by Kim et al. ${ }^{77}$ the results of ex situ TEM and XRD analyses indicated that the conversion reaction of $\mathrm{Sn}_{4} \mathrm{P}_{3}$ to $\mathrm{Na}_{x} \mathrm{P}$ and $\mathrm{Na}_{15} \mathrm{Sn}_{4}$ was reversible (Fig. 17). It is possible that the conversion reaction may be partially reversible, similar to the electrochemical behavior of $\mathrm{Sn}_{4} \mathrm{P}_{3}$ in LIBs. ${ }^{210}$

In addition to the better cycle performance, $\mathrm{Sn}_{4} \mathrm{P}_{3}$ could also show excellent rate performance, due to not only its intrinsic high electronic conductivity, but also the Sn phase formed during the sodiation/desodiation processes, which could compensate for the poor electronic conductivity of the $\mathrm{Na}_{3} \mathrm{P}$ phase. ${ }^{7,207,211}$ Moreover, $\operatorname{Sn}_{4} \mathrm{P}_{3}$ allows fast $\mathrm{Na}$ ion transport. The $\mathrm{Na}$ diffusivities in the intermediate product of amorphous
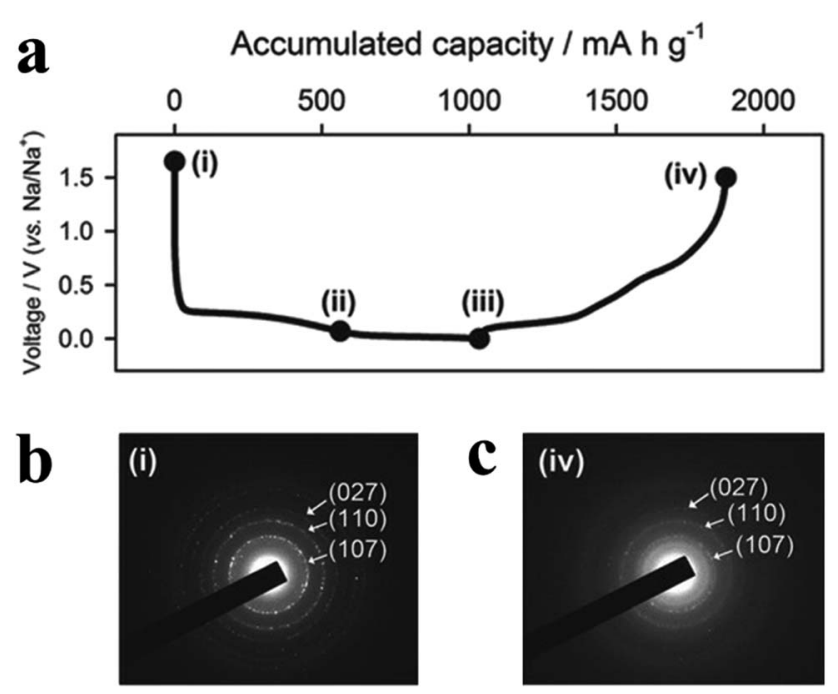

Fig. 17 (a) First galvanostatic charge and discharge profiles of the $\mathrm{Sn}_{4} \mathrm{P}_{3}$ electrode obtained without an FEC additive. The different points indicate (i) pristine, (ii) $0.07 \mathrm{~V}$, (iii) $0 \mathrm{~V}$ and (iv) $1.5 \mathrm{~V}$. (b, c) Electron diffraction (ED) patterns at the points (i) and (iv) in (a), respectively. Reproduced with permission. ${ }^{77}$ Copyright 2014, WILEY-VCH.
$\mathrm{Na}_{x} \mathrm{Sn}_{4} \mathrm{P}_{3}(x=1.33-24)$ were found to be between $3.0 \times 10^{-8}$ and $1.0 \times 10^{-7} \mathrm{~cm}^{2} \mathrm{~s}^{-1}$, and for amorphous $\mathrm{Na}_{15} \mathrm{Sn}_{4}$ and $\mathrm{Na}_{3} \mathrm{P}$, they are $1.1 \times 10^{-7}$ and $1.6 \times 10^{-8} \mathrm{~cm}^{2} \mathrm{~s}^{-1}$, respectively. ${ }^{207} \mathrm{It}$ was indicated that the Sn-rich environment around $\mathrm{Na}$ could effectively enhance the $\mathrm{Na}$ ion conductivity in $\mathrm{Sn}_{4} \mathrm{P}_{3}$ because $\mathrm{Na}$ ions could more easily break the weak $\mathrm{Na}-\mathrm{Sn}$ bonds than the strong $\mathrm{Na}-\mathrm{P}$ bonds during their transport. ${ }^{207}$ As a result, the fast electron/Na-ion transport could enable an excellent rate performance of $\mathrm{Sn}_{4} \mathrm{P}_{3}$.

After Kim's pioneering study, a two phase nanocomposite of $\mathrm{Sn}_{4+x} \mathrm{P}_{3} @ S n-\mathrm{P}$ comprised of $\mathrm{Sn}_{4+x} \mathrm{P}_{3}$ crystals (size, $\sim 30 \mathrm{~nm}$ ) with an amorphous $\mathrm{Sn}-\mathrm{P}$ coating layer (thickness, $\sim 3 \mathrm{~nm}$ ) has also been prepared by this ball milling method and showed an excellent $\mathrm{Na}$ storage performance. ${ }^{195}$ In another study, Wang et al. ${ }^{212}$ found that $\mathrm{Sn}$ agglomeration in pristine $\mathrm{Sn}_{4} \mathrm{P}_{3}$ particles during anode sodiation/desodiation was the major cause of performance fading. And they found that Sn agglomeration could be effectively suppressed through the introduction of TiC into $\mathrm{Sn}_{4} \mathrm{P}_{3}$ by a ball milling method. As a result, a significantly improved cycling stability has been obtained, delivering a capacity of $300 \mathrm{~mA} \mathrm{~h} \mathrm{~g}^{-1}$ over 100 cycles at a current density of $100 \mathrm{~mA} \mathrm{~g}^{-1}$ (with $30 \mathrm{wt} \% \mathrm{TiC}$ ). It is noticeable that the performance of $\mathrm{Sn}_{4} \mathrm{P}_{3}$ in this study was different from that reported by Kim's group, ${ }^{77}$ which was probably caused by the different preparation conditions such as the molar ratio of precursors (Sn: $\mathrm{P}, 4: 3$ vs. $6: 4$ ) and the ball milling time (1 hour vs. 30 hours) and other reasons. Xu et al. ${ }^{213}$ also prepared a $\mathrm{Sn}_{4} \mathrm{P}_{3}-$ $\mathrm{P} @$ graphene nanocomposite ( $\mathrm{Sn}: \mathrm{P}=1: 3)$ using ball milling and reported high rate capability retentions of $>550$ and $371 \mathrm{~mA} \mathrm{~h} \mathrm{~g}^{-1}$ at current densities of 1 and $2 \mathrm{~A} \mathrm{~g}^{-1}$ respectively over 1000 cycles as well as high rate capacities of $>815, \sim 585$ and $\sim 315 \mathrm{~mA} \mathrm{~h} \mathrm{~g}^{-1}$ at $0.1,2$ and $10 \mathrm{~A} \mathrm{~g}^{-1}$ respectively. In this study, the ball milling process involved two steps: the mixing and milling of tin and RP powders under Ar atmosphere followed by the mixing and milling of the as-synthesized $\mathrm{SnP}_{3}$ with graphene stacks under the same conditions to obtain the final $\mathrm{Sn}_{4} \mathrm{P}_{3}-\mathrm{P} @$ graphene nanocomposite.

However, similar to the preparation of RP, it is hard to obtain a desired small-size morphology or refined nanostructure for $\mathrm{Sn}_{4} \mathrm{P}_{3}$ via this mechanical approach. Nevertheless, many new nanostructured $\mathrm{Sn}_{4} \mathrm{P}_{3}$ samples have been reported by various preparation methods recently. For example, in situ phosphidation is often used to obtain a $\mathrm{Sn}_{4} \mathrm{P}_{3}$ nanostructure with $\mathrm{Sn}$ or $\mathrm{SnO}_{2}$ as precursors. In most of the phosphidation processes for synthesizing metal phosphides (MPs), $\mathrm{PH}_{3}$ or gaseous RP is often used which can be generated from $\mathrm{NaH}_{2} \mathrm{PO}_{2}\left(\mathrm{NaH}_{2} \mathrm{PO}_{2} \cdot \mathrm{H}_{2} \mathrm{O}\right)$ or solid RP under an inert atmosphere and high temperature conditions. ${ }^{\mathbf{9 0 , 2 0 2 , 2 1 4}}$ Interestingly, researchers found that Sn could be phosphorized at low temperature by a solvothermal method. For instance, RP powder could be soluble in ethylenediamine during a solvothermal treatment, and then, the dissolved $\mathrm{P}$ species reacted with solid $\mathrm{Sn}$ and diffused towards the interior of the Sn particles to form Sn-P alloys. ${ }^{\mathbf{2 0 6}, 215}$ This mild preparation method avoids the toxic $\mathrm{PH}_{3}$ product or the white $\mathrm{P}$ by-product, during which lower temperature is needed. However, this solvothermal method could only be used to phosphorize the Sn precursor, and a traditional phosphorization approach with 
$\mathrm{NaH}_{2} \mathrm{PO}_{2}\left(\mathrm{NaH}_{2} \mathrm{PO}_{2} \cdot \mathrm{H}_{2} \mathrm{O}\right)$ as the $\mathrm{P}$ source was often used for a $\mathrm{SnO}_{2}$ precursor. For example, Liu et al. ${ }^{91}$ synthesized uniform yolk-shell $\mathrm{Sn}_{4} \mathrm{P}_{3} @ \mathrm{C}$ nanospheres as anode materials for SIBs by a stepwise preparation approach, involving a hydrothermal method to obtain a $\mathrm{SnO}_{2}$ template, a reduction process to obtain $\mathrm{Sn}$, and a phosphorization process to transform $\mathrm{Sn}$ into $\mathrm{Sn}_{4} \mathrm{P}_{3}$ (Fig. 18a). During the reduction and phosphorization process, the hollow $\mathrm{SnO}_{2}$ template transformed into one big nanoparticle and several small nanoparticles of $\mathrm{Sn}$ which were encapsulated in each carbon nanocage, and evenly formed a yolk-shell $\mathrm{Sn}_{4} \mathrm{P}_{3} @ \mathrm{C}$ nanostructure. Due to the unique nanostructure, this $\mathrm{Sn}_{4} \mathrm{P}_{3} @ \mathrm{C}$ anode exhibited a high reversible capacity of $790 \mathrm{~mA} \mathrm{~h} \mathrm{~g}{ }^{-1}$ at $100 \mathrm{~mA} \mathrm{~g}^{-1}$, superior rate capacities of 720, 651, 581, 505 and $421 \mathrm{~mA} \mathrm{~h} \mathrm{~g}^{-1}$ at $0.2 \mathrm{C}, 0.4 \mathrm{C}, 0.8 \mathrm{C}, 1.5 \mathrm{C}$ and $3 \mathrm{C}$ respectively $(1 \mathrm{C}=$ $1000 \mathrm{~mA} \mathrm{~g}^{-1}$ ) and stable cycling performances with a high capacity of $360 \mathrm{~mA} \mathrm{~h} \mathrm{~g}{ }^{-1}$ at $1.5 \mathrm{C}$ after 400 cycles. Similarly, Ma et al. ${ }^{216}$ designed an integrated anode material of $\mathrm{Sn}_{4} \mathrm{P}_{3} @ \mathrm{C}$ with a yolk-shell nanocube structure for SIBs by phosphorization of a $\mathrm{Sn}$ precursor and found that the voids and spaces between
$\mathrm{Sn}_{4} \mathrm{P}_{3}$ and carbon nanocubes could effectively buffer volume expansion during charge/discharge and that the highly conductive carbon material could promote fast electron transfer. As a result, this SIB anode exhibited a high discharge capacity of $701 \mathrm{~mA} \mathrm{~h} \mathrm{~g}^{-1}$ at $0.1 \mathrm{~A} \mathrm{~g}^{-1}$ after 50 cycles, remarkable rate capability of $508 \mathrm{~mA} \mathrm{~h} \mathrm{~g}^{-1}$ even at $2.0 \mathrm{~A} \mathrm{~g}^{-1}$ and highly stable cycling performances with 516 and $368 \mathrm{~mA} \mathrm{~h}^{-1}$ capacity retention after 500 cycles at 1.0 and $2.0 \mathrm{~A} \mathrm{~g}^{-1}$ respectively. Furthermore, Choi et $a .^{217}$ fabricated size-adjustable core-shell $\mathrm{Sn}_{4} \mathrm{P}_{3}-\mathrm{C}$ nanospheres using a carbonization/reduction and phosphorization process and reported that among the different sizes of $\mathrm{Sn}_{4} \mathrm{P}_{3}-\mathrm{C}$ nanospheres, the $140 \mathrm{~nm} \quad \mathrm{Sn}_{4} \mathrm{P}_{3}-\mathrm{C}$ nanosphere electrode demonstrated the highest reversible capacity and rate capability, with an ultra-long cycle stability with $420 \mathrm{~mA} \mathrm{~h} \mathrm{~g}{ }^{-1}$ capacity retention after 2000 cycles at a current density of $2000 \mathrm{~mA} \mathrm{~g}^{-1}$. In addition, researchers have also reported that the cycling life of $\mathrm{Sn}_{4} \mathrm{P}_{3} / \mathrm{C}$ could be largely extended through the reduction of particle size to the nanoscale which could reduce the pulverization of anodes. ${ }^{217}$

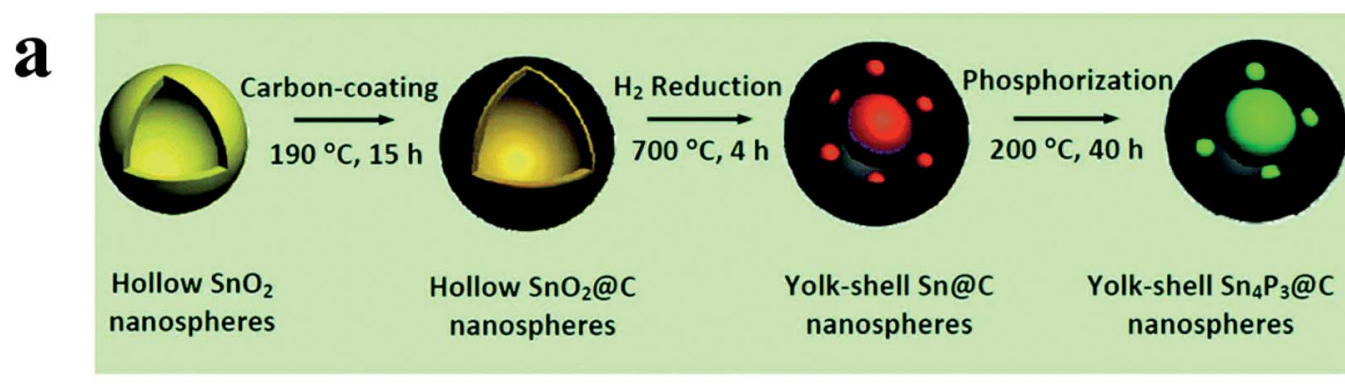

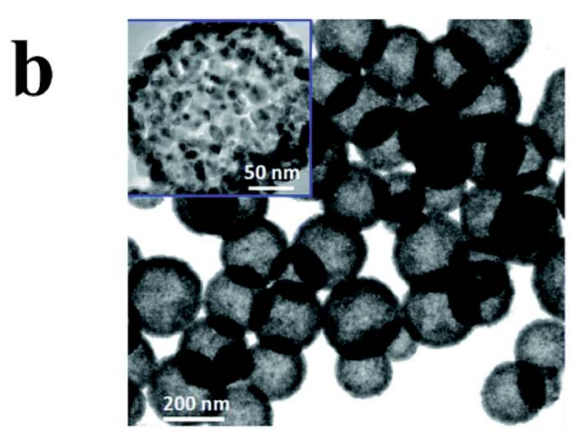

d

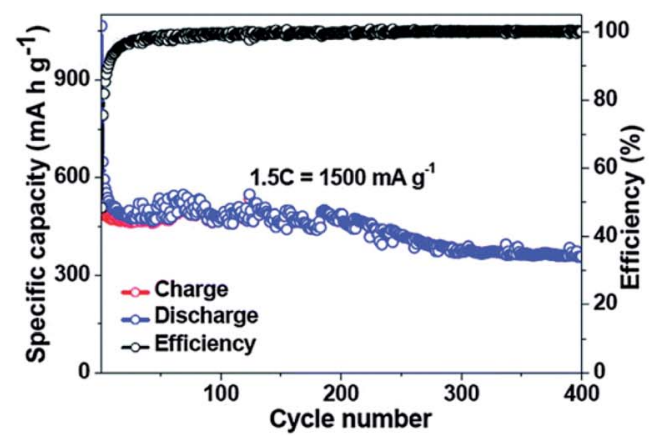

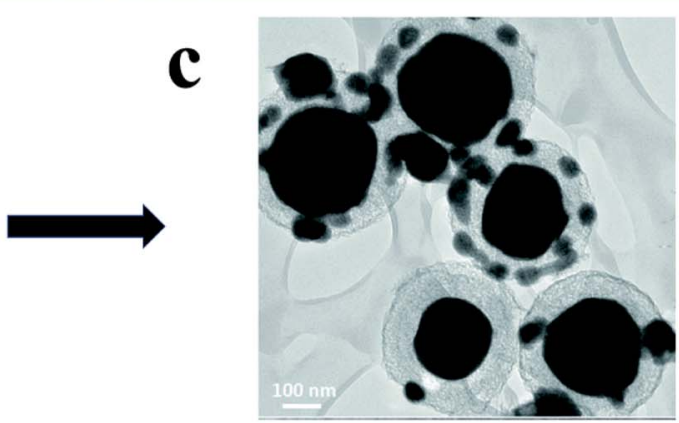

e

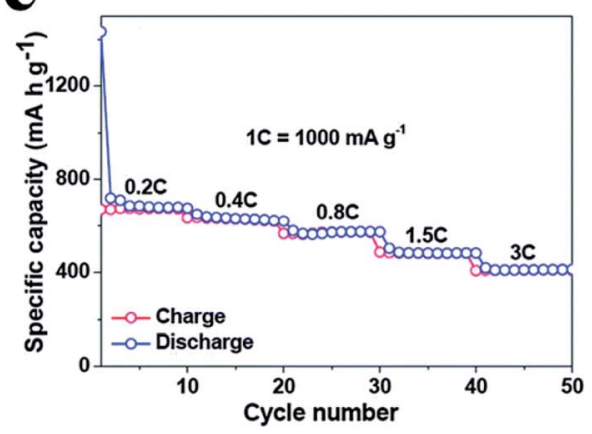

Fig. 18 (a) Schematic of the fabrication of uniform yolk-shell $\mathrm{Sn}_{4} \mathrm{P}_{3} \mathrm{aC}$ nanosphere anodes. (b) TEM image of uniform $\mathrm{SnO}_{2}$ hollow nanosphere templates; the inset shows a typical $\mathrm{SnO}_{2}$ hollow nanosphere with a shell thickness of about $\sim 25 \mathrm{~nm}$. (c) TEM images of a uniform yolk-shell SnaC nanosphere; (d) Long cycling performance of yolk-shell Sn $\mathrm{P}_{3} @ \mathrm{CC}$ nanospheres at 1.5C. (e) Rate capability at different rates (increased from $0.2 \mathrm{C}$ to $3 \mathrm{C}) .1 \mathrm{C}=1000 \mathrm{~mA} \mathrm{~g}^{-1}$. Reproduced with permission. ${ }^{91}$ Copyright 2015 , The Royal Society of Chemistry. 
These studies indicate that the combination of $\mathrm{Sn}_{4} \mathrm{P}_{3}$ with carbon materials is also an effective strategy to improve the performance of Na storage, and the refined nanostructures can give significant advantages for practical SIBs.

Shin et al. ${ }^{213}$ also prepared $\mathrm{Sn}-\mathrm{P}$ compounds $\left(\mathrm{Sn}_{4} \mathrm{P}_{3}, \mathrm{Sn}_{4-x} \mathrm{P}_{3}\right.$ or $\operatorname{Sn}_{4} \mathrm{P}_{3+x}$ ) as anode materials for SIBs by this simple solvothermal method and found that the temperature and time period used for solvothermal treatment played a critical role in determining the phase and composition of the $\mathrm{Sn}-\mathrm{P}$ compound and thus its electrochemical behavior. When solvothermal synthesis was conducted at lower or higher temperatures than a certain critical value $\left(e . g ., 200{ }^{\circ} \mathrm{C}\right)$, the resulting compound contained unreacted (residual) Sn or excess $\mathrm{P}$ species. The $\mathrm{Sn}_{4} \mathrm{P}_{3}$ compounds $\left(\mathrm{Sn}_{4} \mathrm{P}_{3}\right.$ mixed with $\left.\sim 1.7 \% \mathrm{Sn}\right)$ prepared with the optimized solvothermal parameters $\left(T=200{ }^{\circ} \mathrm{C}\right.$ and $\left.t=40 \mathrm{~h}\right)$ showed the best electrochemical $\mathrm{Na}$ storage performance. Yin et $a .^{218}$ designed a $\mathrm{Sn}_{4} \mathrm{P}_{3} /$ reduced graphene oxide nanohybrid $\left(\mathrm{Sn}_{4} \mathrm{P}_{3} / \mathrm{RGO}\right)$ similarly by this low-temperature solution-based phosphorization reaction route. In the preparation process, $\mathrm{NaBH}_{4}$ was used as the reducing agent to reduce $\mathrm{Sn}^{2+}$ and GO, with a Sn/RGO nanohybrid formed, and then the Sn/RGO nanostructures were used as the precursor and RP as the $\mathrm{P}$ source to synthesize $\mathrm{Sn}_{4} \mathrm{P}_{3} / \mathrm{RGO}$ by a solvothermal approach at $200{ }^{\circ} \mathrm{C}$. Due to the hybrid structure and the high electronic conductivity of RGO, this nanohybrid SIB anode exhibited a high reversible capacity, an enhanced rate capability, and a superior long cycling life $\left(362 \mathrm{~mA} \mathrm{~h} \mathrm{~g}^{-1}\right.$ after 1500 cycles at a current density of $1.0 \mathrm{~A} \mathrm{~g}^{-1}$ ). In another study, a novel morphology of pure phase and size-controllable $\mathrm{Sn}_{4} \mathrm{P}_{3}$ nanotops was developed through a novel facile solution chemical method using Sn and trioctylphosphine (TOP) as raw materials. ${ }^{219}$ This $\mathrm{Sn}_{4} \mathrm{P}_{3}$ nanotop anode showed a good electrochemical performance for SIBs, providing an initial capacity of $719.8 \mathrm{~mA} \mathrm{~h} \mathrm{~g}^{-1}$ at a current density of $50 \mathrm{~mA} \mathrm{~g}^{-1}$, an initial coulombic efficiency of $\sim 72.7 \%$, and good cyclability and stability (543 $\mathrm{mA} \mathrm{h} \mathrm{g}^{-1}$ at $200 \mathrm{~mA} \mathrm{~g}^{-1}$ for 80 cycles).

Alternatively, a high temperature atmosphere phosphidation approach with $\mathrm{SnO}_{2}$ as the precursor is another effective way to prepare $\mathrm{Sn}_{4} \mathrm{P}_{3}$ nanostructures. Compared with the solvothermal method, which often involves low temperature but a long process time $\left(T=200{ }^{\circ} \mathrm{C}\right.$ and $\left.t=40 \mathrm{~h}\right)$, the atmosphere phosphidation approach usually needs higher temperature but a shorter process time $\left(\sim 300{ }^{\circ} \mathrm{C}\right.$, less than a few hours $)$ with $\mathrm{NaH}_{2} \mathrm{PO}_{2}\left(\mathrm{NaH}_{2} \mathrm{PO}_{2} \cdot \mathrm{H}_{2} \mathrm{O}\right)$ as the $\mathrm{P}$ source.

As the initial coulombic efficiency (CE) of $\mathrm{Sn}_{4} \mathrm{P}_{3} / \mathrm{C}$ nanocomposites was found to be inefficient $(40-50 \%)^{91}$ and it is challenging to achieve both long cycle life and high CE for high capacity tin phosphide anodes, Fan et al. ${ }^{205}$ reported an anode composed of pomegranate-structured $\mathrm{Sn}_{4} \mathrm{P}_{3} @ \mathrm{C}$ spheres synthesized using a facile aerosol spray-pyrolysisphosphidation method. In brief for this process, the transparent precursor containing $\mathrm{SnSO}_{4}$ and sucrose was atomized into microsized droplets $(0.1-2 \mu \mathrm{m})$ and then these droplets were pyrolyzed in a $600{ }^{\circ} \mathrm{C}$ furnace and transformed into $\mathrm{SnO}_{2} / \mathrm{C}$ spheres (0.1-2 $\mu \mathrm{m})$; finally, pomegranate-structured $\mathrm{Sn}_{4} \mathrm{P}_{3} @ \mathrm{C}$ spheres were obtained after a phosphidation process with $\mathrm{NaH}_{2} \mathrm{PO}_{2}$ as the $\mathrm{P}$ source (Fig. 19a and c). It can be seen from the TEM images (Fig. 19b) that $\mathrm{Sn}_{4} \mathrm{P}_{3}$ nanoparticles with a size of 20-40 $\mathrm{nm}$ were encapsulated by thin carbon layers. The $\mathrm{Sn}_{4} \mathrm{P}_{3}$ @C anode was able to provide a reversible capacity of $\sim 800 \mathrm{~mA} \mathrm{~h} \mathrm{~g}^{-1}$ with a record-high initial CE (>90\%) and high cycle CE $(\sim 99.9 \%)$ for over 120 cycles at a current of $100 \mathrm{~mA} \mathrm{~g}^{-1}$ in an ether-based electrolyte (Fig. 19d). Here, the researchers suggested that to achieve both long cycling life and high CE, a
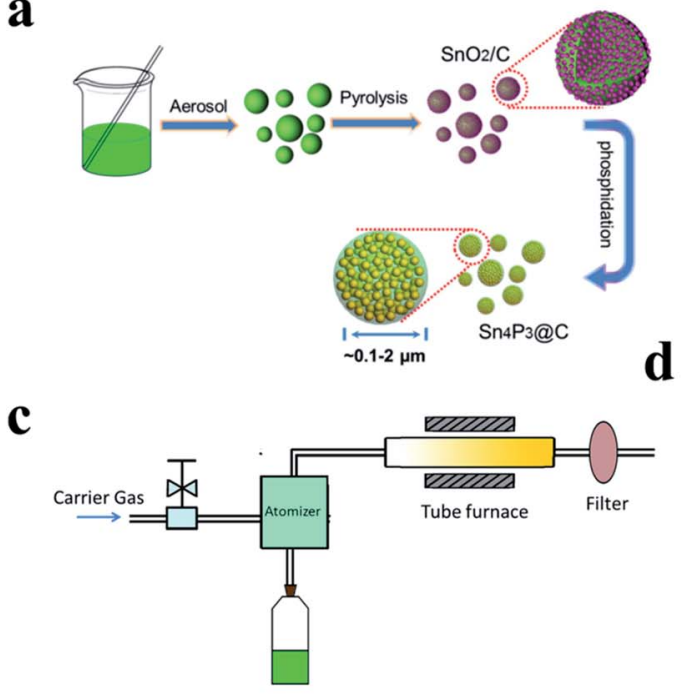

b
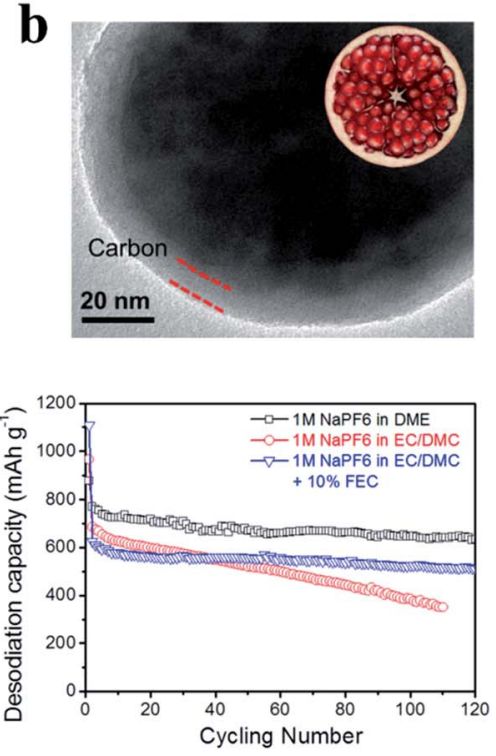

Fig. 19 (a) Schematic illustration of the fabrication process for $\mathrm{Sn}_{4} \mathrm{P}_{3} \mathrm{aC}$ pomegranates. (b) TEM image of the as-synthesized pomegranatestructured $\mathrm{Sn}_{4} \mathrm{P}_{3} \mathrm{aC}$ sphere; inset of (b) shows the ideal pomegranate structure. (c) Schematic illustration of the fabrication of the $\mathrm{SnO} \mathrm{O}_{2} / \mathrm{C}$ spherical composite using the aerosol-spray-pyrolysis method. (d) Cycling performances of the pomegranate-structured $\mathrm{Sn}_{4} \mathrm{P}_{3} \mathrm{CC}_{\mathrm{C}}$ nanosphere at $100 \mathrm{~mA}$ using different electrolytes. Reproduced with permission. ${ }^{205}$ Copyright 2017, Elsevier Ltd. 
ideal anode materials should possess microsized primary particles consisting of nanosized secondary high capacity active materials and nanopores in a carbon matrix, allowing for the formation of a SEI on only the primary particle surface and the maintenance of the electronically conductive nanoporous composite integrity during charge/discharge cycles. Based on this, the pomegranate-structured $\mathrm{Sn}_{4} \mathrm{P}_{3} @ \mathrm{C}$ spheres synthesized in this study were in accordance with the ideal anode they referred to.

Recently, $\mathrm{Sn}_{4} \mathrm{P}_{3}$ microspheres encapsulated in hollow carbon spheres $\left(\mathrm{Sn}_{4} \mathrm{P}_{3} @ \mathrm{C}\right)$ were prepared by this phosphorization route using $\mathrm{SnO}_{2} @ \mathrm{C}$ as the precursor and $\mathrm{NaH}_{2} \mathrm{PO}_{2}$ as the $\mathrm{P}$ source. The void volume of this nanostructure and the elasticity of the protective carbon spherical shell could efficiently mitigate the volume change of active $\mathrm{Sn}_{4} \mathrm{P}_{3}$ microspheres $(200 \mathrm{~nm})$ during charge/discharge processes and form a stable solid electrolyte interface film on the surface of the carbon shell. As a result, the $\mathrm{Sn}_{4} \mathrm{P}_{3}$ @C anode for SIBs showed a stable specific capacity of $420 \mathrm{~mA} \mathrm{~h} \mathrm{~g}^{-1}$ after 300 cycles at a current density of $0.2 \mathrm{~A} \mathrm{~g}^{-1}$, as well as excellent rate capabilities of $253,175,111,78$, and $50 \mathrm{~mA} \mathrm{~h} \mathrm{~g}^{-1}$ at densities of 1, 2, 5, 10, and $20 \mathrm{~A} \mathrm{~g}^{-1}$, respectively. More importantly, this anode also showed an ultralong cycling performance, delivering stable capacities of 205 and $103 \mathrm{~mA} \mathrm{~h} \mathrm{~g}^{-1}$ at large current densities of 2 and $5 \mathrm{~A} \mathrm{~g}^{-1}$ after 4000 cycles, respectively.

In addition to $\operatorname{Sn}_{4} \mathrm{P}_{3}$, tin monophosphide ( $\mathrm{SnP}$ ) also shows promise as anode materials for SIBs, possessing a high theoretical capacity of $1209 \mathrm{~mA} \mathrm{~h} \mathrm{~g}{ }^{-1}$ due to its high $\mathrm{P}$ ratio. SnP exhibits a trigonal crystallographic phase and shows a layered structure consisting of Sn-P-P-Sn sandwiches that are stacked on top of each other. ${ }^{220}$ However, SnP has not yet been extensively explored in energy storage devices due to its challenging synthesis conditions. To address this, Liu et al. ${ }^{\mathbf{1 9 0}}$ synthesized spherical SnP nanocrystals (NCs) with a size of $34 \pm 5 \mathrm{~nm}$ through a liquid phase synthesis method. And a SIB based on the SnP NC anode with sodium(I) bis(fluorosulfonyl)imide (NaFSI) as the electrolyte exhibited a high reversible capacity of $600 \mathrm{~mA} \mathrm{~h} \mathrm{~g}^{-1}$ at $100 \mathrm{~mA} \mathrm{~g}^{-1}$ and enhanced cycling stabilities for over 200 cycles. Here, the researchers suggested that the high cycling performance was associated with both the small size of the crystal domain and the particular composition and phase of SnP, which could prevent mechanical disintegration and major phase separation during charge/discharge.

Another tin phosphide material $\mathrm{SnP}_{3}$, which has the highest $\mathrm{P}$ mass ratio among tin phosphides such as $\mathrm{Sn}_{4} \mathrm{P}_{3}$ and $\mathrm{SnP}$, exhibits the highest theoretical capacity of $1616 \mathrm{~mA} \mathrm{~h} \mathrm{~g}{ }^{-1} \cdot{ }^{194}$ Fan et al. ${ }^{194}$ prepared a composite of $\mathrm{SnP}_{3} / \mathrm{C}$ by a simple ball milling method and demonstrated that $\mathrm{SnP}_{3} / \mathrm{C}$ could reversibly react with $\mathrm{Na}$ through conversion and alloy reaction processes as SIB anodes. The corresponding anode could provide a high capacity of $\sim 810 \mathrm{~mA} \mathrm{~h} \mathrm{~g}^{-1}$ at a current density of $150 \mathrm{~mA} \mathrm{~g}^{-1}$ without capacity fading after 150 cycles and was also able to retain $400 \mathrm{~mA} \mathrm{~h} \mathrm{~g}^{-1}$ even at $2560 \mathrm{~mA} \mathrm{~g}^{-1}$. Furthermore, detailed analysis using SEM, TEM and XPS revealed that the strong bonding interaction between Sn and P could successfully mitigate the pulverization and aggregation of Sn and P, allowing for the partial self-healing of the $\mathrm{SnP}_{3} / \mathrm{C}$ composite structure and enhanced cycling stabilities.

\subsection{Cobalt phosphides}

Cobalt phosphides can also electrochemically react with $\mathrm{Na}{ }^{90,203}$ Although metallic Co is inactive with Na, researchers reported that it can act as a conductive matrix to buffer volume expansion and enhance electron transfer. CoP is the most commonly used cobalt phosphide for SIBs and usually exhibits an orthorhombic phase, as shown in Fig. 20a. ${ }^{221,222}$ Liu et al. ${ }^{203}$ synthesized nanosized CoP particles as an anode for SIBs through ball milling metal Co and commercial RP. The anode delivered a high initial specific capacity of $770 \mathrm{~mA} \mathrm{~h} \mathrm{~g}{ }^{-1}$ and high rate capabilities, demonstrating that CoP is a promising anode candidate for sodium ion storage. In addition, ex situ XPS and STEM were carried out to investigate the sodium storage mechanism of CoP in this study and revealed that the sodium storage of CoP was based on a reaction between $\mathrm{P}$ and $\mathrm{Na}$ and can be summarized as follows:

$$
\begin{gathered}
\mathrm{CoP}+3 \mathrm{Na}^{+}+3 \mathrm{e}^{-} \rightarrow \mathrm{Co}+\mathrm{Na}_{3} \mathrm{P} \text { (first discharge) } \\
\mathrm{Na}_{3} \mathrm{P} \leftrightarrow 3 \mathrm{Na}^{+}+\mathrm{P}+3 \mathrm{e}^{-} \text {(subsequent cycles) }
\end{gathered}
$$

It means that CoP decomposed into Co and $\mathrm{P}$ after the initial charge-discharge process and in the next cycles, element $\mathrm{P}$ reversibly reacts with $\mathrm{Na}$ to form $\mathrm{Na}_{3} \mathrm{P}$ with intermediate phases $\left(\mathrm{Na}_{2} \mathrm{P}, \mathrm{NaP}\right.$ and $\left.\mathrm{NaP}_{7}\right)$, being consistent with other literature. ${ }^{204}$ Table 2 summarizes the recent progress of phosphides used as an anode for SIBs.

Similar to RP, CoPs obtained from ball milling methods often suffered from fast capacity fading during cycling and inferior rate performance due to the large and uneven particle size; however, complex and ultrafine nanostructures could be synthesized by methods such as hydrothermal reactions and solution phase processes for CoP, giving an effective approach to solve these issues. For example, Ge et al. ${ }^{\mathbf{2 0 4}}$ developed a strategy to synthesize MOF derived core/shell structured CoP@C polyhedrons anchored onto 3D reduced graphene oxide (RGO) on nickel foam (NF) as a binder-free SIB anode. Here, the unique core/shell CoP@C polyhedral structure was obtained through an in situ low-temperature phosphidation process derived from ZIF-67 and was further combined with RGO/NF which could efficiently act as a binder and electrical conductor. As a result, the corresponding anode exhibited remarkable electrochemical performances and delivered a specific capacity of $473.1 \mathrm{~mA} \mathrm{~h} \mathrm{~g}^{-1}$ at a current density of $100 \mathrm{~mA} \mathrm{~g}^{-1}$ after 100 cycles. In another example, Kang et al. ${ }^{223}$ designed a nanostructure of small size CoP nanoparticles uniformly embedded in N-doped $\mathrm{C}$ nanosheets (CNSs) by a simple one-step calcination process with a Co-based MOF and $\mathrm{RP}$ as precursors. Due to the small CoP particles $(\sim 11.3 \mathrm{~nm})$, the strong $\mathrm{P}-\mathrm{C}$ bonds and the high conductivity of the CNSs, a resulting anode using this composite delivered a Na-storage capacity of $598 \mathrm{~mA} \mathrm{~h} \mathrm{~g} \mathrm{~g}^{-1}$ at $100 \mathrm{~mA} \mathrm{~g}^{-1}$ (pure CoP, $831 \mathrm{~mA} \mathrm{~h} \mathrm{~g}^{-1}$ ), a high rate capability of $174 \mathrm{~mA} \mathrm{~h} \mathrm{~g}^{-1}$ at $20 \mathrm{~A} \mathrm{~g}^{-1}$ and a long-term cyclability of $98.5 \%$ capacity retention after 900 cycles at $1 \mathrm{~A} \mathrm{~g}^{-1}$. Furthermore, Zhang et al. ${ }^{191}$ introduced a conducting polymer (poly-pyrrole, PPy) coating layer to protect 
a

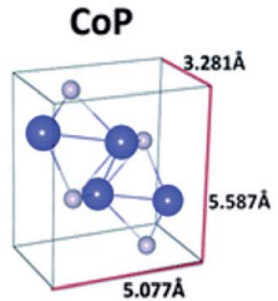

b

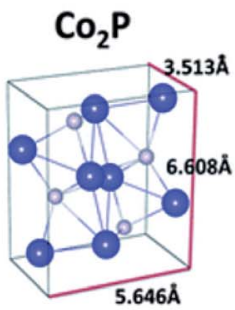

c

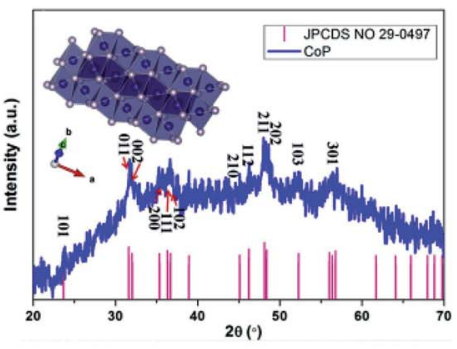

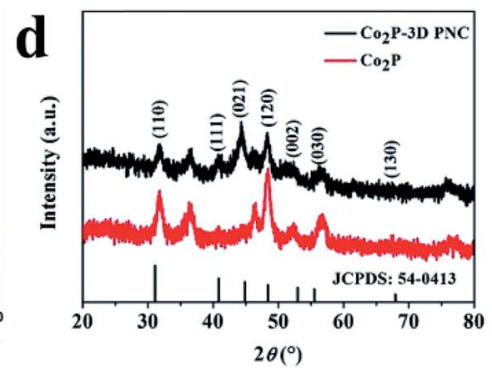

f

e

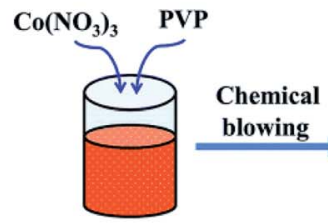

$\mathrm{Co}\left(\mathrm{NO}_{3}\right)_{3}+\mathrm{PVP}+\mathrm{H}_{2} \mathrm{O}$

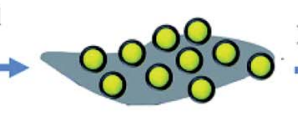

Co-3D PC
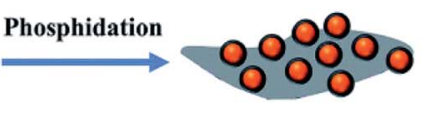

$\mathrm{Co}_{2}$ P-3D PC
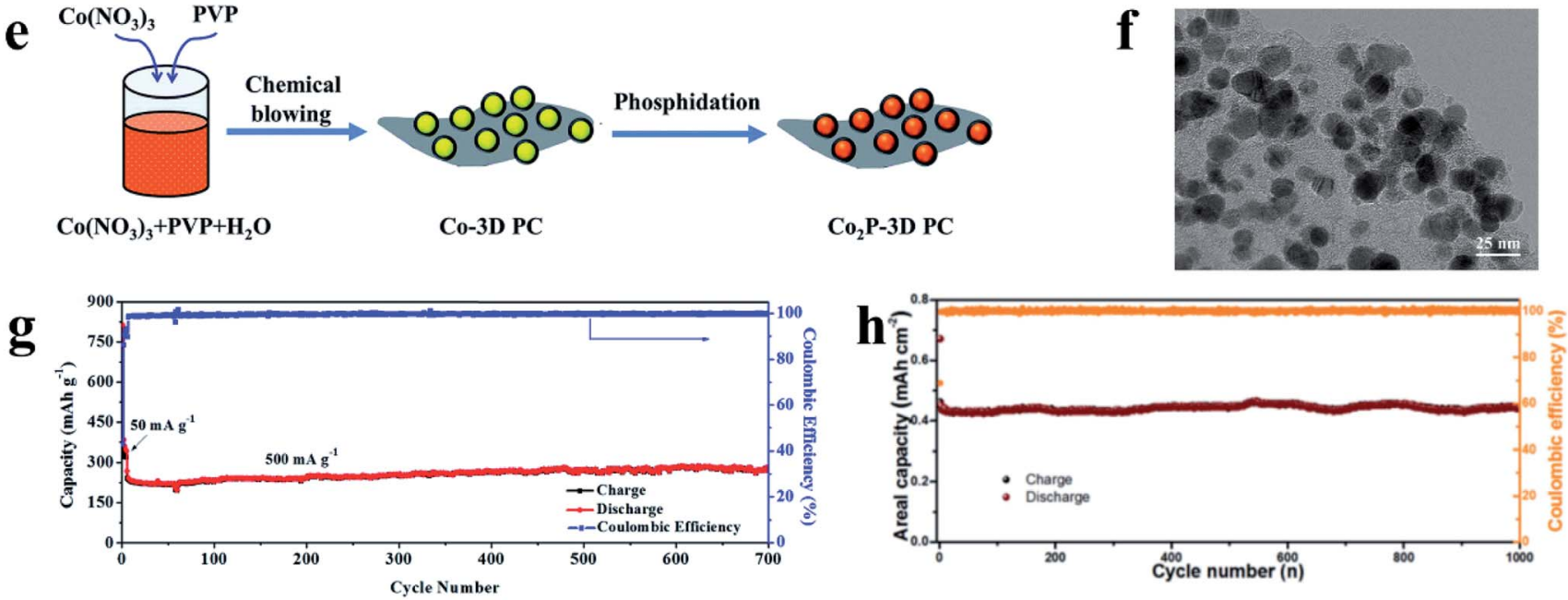

i
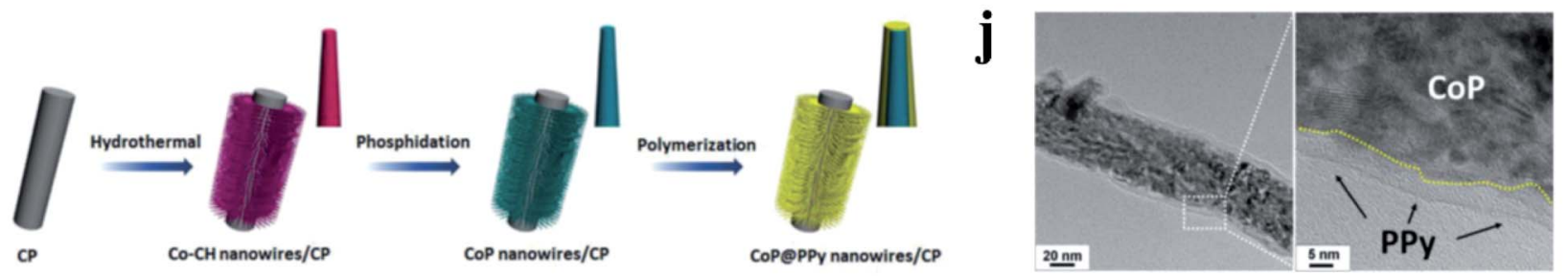

Fig. 20 (a, b) Crystal structures of orthorhombic CoP and $\mathrm{Co}_{2} \mathrm{P}$. (c, d) XRD pattern of crystalline CoP and $\mathrm{Co}_{2} \mathrm{P}$. (e) Schematic representation of the synthesis process of the $\mathrm{CO}_{2} \mathrm{P}-3 \mathrm{D}$ PNC composite. (f) TEM image of the $\mathrm{CO}_{2} \mathrm{P}-3 \mathrm{D}$ PNC composite. (g) Long-term cycling performance of the $\mathrm{CO}_{2} \mathrm{P}-3 \mathrm{D}$ PNC composite at $500 \mathrm{~mA} \mathrm{~g}^{-1}$. (h) Long-term cycling stability of the CoP(aPPy NWs/CP electrode at $1.5 \mathrm{~mA} \mathrm{~cm}^{-2}$. (i) $\mathrm{Schematic}$ diagram of the fabrication process of the CoPaPPy nanowires/CP electrode. (j) TEM images of CoP(APPy NWs. (a, b) Reproduced with permission. ${ }^{221}$ Copyright 2011, The Royal Society of Chemistry. (c) Reproduced with permission. ${ }^{203}$ Copyright 2015, Elsevier B.V. (d-g) Reproduced with permission. ${ }^{224}$ Copyright 2018, The Royal Society of Chemistry. (h-j) Reproduced with permission. ${ }^{191}$ Copyright 2018 , WILEY-VCH.

1D nanostructured CoP nanowires and fabricated a freestanding binder free SIB anode. Here, the synthesis process involved three steps, including the initial growth of $1 \mathrm{D} \mathrm{Co}-$ based precursors on carbon paper using a hydrothermal method, a phosphidation process to obtain CoP nanowires and then a coating of the polymer PPy onto the surface of the CoP nanowires through polymerization and oxidation of pyrrole monomers (Fig. 20i and j). The researchers proposed that the obtained 1D core-shell CoP@PPy NWs/CP not only enhanced charge transfer and ion diffusion but also buffered volume expansion during cycling. As a result, these anodes exhibited superb electrochemical performance, delivering a high areal capacity of $0.521 \mathrm{~mA} \mathrm{~h} \mathrm{~cm} \mathrm{~cm}^{-2}$ at $0.15 \mathrm{~mA} \mathrm{~cm}^{-2}$ after 100 cycles and $0.443 \mathrm{~mA} \mathrm{~h} \mathrm{~cm}{ }^{-2}$ at $1.5 \mathrm{~mA} \mathrm{~cm}^{-2}$ even after 1000 cycles (Fig. 20h), and a significant areal discharge capacity of $0.285 \mathrm{~mA} \mathrm{~h} \mathrm{~cm} \mathrm{~cm}^{-2}$ even at a high current density of $3 \mathrm{~mA} \mathrm{~cm}^{-2}$.
Other cobalt phosphides such as Co-rich phase $\mathrm{Co}_{2} \mathrm{P}$ (Fig. 20b) and phosphorus rich phases $\mathrm{CoP}_{3}$ and $\mathrm{CoP}_{4}$ have also been reported as viable anode materials for SIBs. For example, Zhou et al. ${ }^{224}$ prepared a composite of $\mathrm{Co}_{2} \mathrm{P}$ nanoparticle encapsulated 3D porous $\mathrm{N}$-doped carbon nanosheet networks (3D-PNC) using a blowing method and an in situ phosphidation process (Fig. 20e). This unique $\mathrm{Co}_{2} \mathrm{P} / 3 \mathrm{D}-\mathrm{PNC}$ nanostructure exhibited enhanced cycling stability and rate capability with a high initial discharge capacity of $827 \mathrm{~mA} \mathrm{~h} \mathrm{~g}^{-1}$ at $50 \mathrm{~mA} \mathrm{~g}^{-1}$ and $271 \mathrm{~mA} \mathrm{~h} \mathrm{~g}^{-1}$ after 700 cycles at $500 \mathrm{~mA} \mathrm{~g}^{-1}$ (Fig. 20g). Jin et al. ${ }^{240}$ utilized a cobalt-based metal organic framework (ZIF-67) as a self-template to obtain a nanostructure of $\mathrm{Co}_{2} \mathrm{P}$ nanoparticles hybridized with $\mathrm{N}$-doped carbon matrices $\left(\mathrm{Co}_{2} \mathrm{P} @ \mathrm{~N}-\right.$ $\mathrm{C})$. For the preparation process, they first prepared a $\mathrm{CoP} @ \mathrm{~N}-\mathrm{C}$ nanostructure, and then combined this CoP@N-C with reduced graphene oxide by a simple hydrothermal method to form 
Table 2 Summary of MPs and other phosphide anodes for SIBs

\begin{tabular}{|c|c|c|c|c|c|}
\hline Materials & Synthetic method & Cycling performance & Rate capability & $\begin{array}{l}\text { Initial coulombic } \\
\text { efficiency }\end{array}$ & Ref. \\
\hline $\mathrm{Sn}_{4} \mathrm{P}_{3}$ powder & Ball milling & $\begin{array}{l}\sim 718 \mathrm{~mA} \mathrm{~h} \mathrm{~g}^{-1} \text {, at } 100 \mathrm{~mA} \mathrm{~g}^{-1} \text {, } \\
100 \mathrm{th}\end{array}$ & 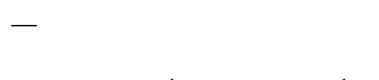 & $\sim 78 \%$ & 77 \\
\hline $\mathrm{Sn}_{4} \mathrm{P}_{3} @ \mathrm{C}$ & $\begin{array}{l}\text { Hydrothermal/ } \\
\text { phosphorization }\end{array}$ & $\begin{array}{l}360 \mathrm{~mA} \mathrm{~h} \mathrm{~g}{ }^{-1} \text {, at } 1000 \mathrm{~mA} \mathrm{~g}^{-1} \text {, } \\
400 \mathrm{th}\end{array}$ & $360 \mathrm{~mA} \mathrm{~h} \mathrm{~g}^{-1}, 3000 \mathrm{~mA} \mathrm{~g}^{-1}$ & - & 91 \\
\hline $\mathrm{Sn}_{4} \mathrm{P}_{3} / \mathrm{TiC}$ & Ball milling & $\begin{array}{l}300 \mathrm{~mA} \mathrm{~h} \mathrm{~g}^{-1} \text {, at } 100 \mathrm{~mA} \mathrm{~g}^{-1} \text {, } \\
\text { 100th }\end{array}$ & - & $85.5 \%$ & 212 \\
\hline $\begin{array}{l}\mathrm{Sn}_{4} \mathrm{P}_{3}- \\
\text { P@graphene }\end{array}$ & Ball milling & $\begin{array}{l}607 \mathrm{~mA} \mathrm{~h} \mathrm{~g}^{-1} \text {, at } 1000 \mathrm{~mA} \mathrm{~g}^{-1} \text {, } \\
\text { 800th }\end{array}$ & $371 \mathrm{~mA} \mathrm{~h} \mathrm{~g}^{-1}, 1000 \mathrm{~mA} \mathrm{~g}^{-1}$ & $73 \%$ & 213 \\
\hline $\mathrm{Sn}_{4} \mathrm{P}_{3}$ nanotop & $\begin{array}{l}\text { Solution chemistry } \\
\text { method }\end{array}$ & $\begin{array}{l}543 \mathrm{~mA} \mathrm{~h} \mathrm{~g}^{-1} \text {, at } 200 \mathrm{~mA} \mathrm{~g}^{-1} \text {, } \\
\text { 80th }\end{array}$ & $399 \mathrm{~mA} \mathrm{~h} \mathrm{~g}^{-1}, 1000 \mathrm{~mA} \mathrm{~g}^{-1}$ & $72.7 \%$ & 219 \\
\hline $\mathrm{Sn}_{4} \mathrm{P}_{3}-\mathrm{C}$ sphere & $\begin{array}{l}\text { Hydrothermal/ } \\
\text { phosphorization }\end{array}$ & $\begin{array}{l}420 \mathrm{~mA} \mathrm{~h} \mathrm{~g}^{-1} \text {, at } 2000 \mathrm{~mA} \mathrm{~g}^{-1} \text {, } \\
\text { 2000th }\end{array}$ & $260 \mathrm{~mA} \mathrm{~h} \mathrm{~g}{ }^{-1}, 4000 \mathrm{~mA} \mathrm{~g}^{-1}$ & $60 \%$ & 217 \\
\hline $\mathrm{Sn}_{4} \mathrm{P}_{3} @ \mathrm{C}$ sphere & Aerosol spray-pyrolysis & $\begin{array}{l}700 \mathrm{~mA} \mathrm{~h} \mathrm{~g}^{-1} \text {, at } 100 \mathrm{~mA} \mathrm{~g}^{-1} \text {, } \\
\text { 120th }\end{array}$ & $\sim 500 \mathrm{~mA} \mathrm{~h} \mathrm{~g}{ }^{-1}, 800 \mathrm{~mA} \mathrm{~g}^{-1}$ & $90.7 \%$ & 205 \\
\hline $\begin{array}{l}\mathrm{Sn}_{4} \mathrm{P}_{3} @ \mathrm{C} \text { yolk- } \\
\text { shell }\end{array}$ & $\begin{array}{l}\text { Liquid phase/sintering/ } \\
\text { solvothermal }\end{array}$ & $\begin{array}{l}701 \mathrm{~mA} \mathrm{~h} \mathrm{~g}{ }^{-1} \text {, at } 100 \mathrm{~mA} \mathrm{~g}^{-1} \text {, } \\
\text { 50th }\end{array}$ & $508 \mathrm{~mA} \mathrm{~h} \mathrm{~g}^{-1}, 2000 \mathrm{~mA} \mathrm{~g}^{-1}$ & $63.7 \%$ & 216 \\
\hline $\mathrm{SnP}_{3} @ \mathrm{C}$ & Ball milling & $\begin{array}{l}810 \mathrm{~mA} \mathrm{~h} \mathrm{~g}^{-1} \text {, at } 150 \mathrm{~mA} \mathrm{~g}^{-1} \text {, } \\
\text { 150th }\end{array}$ & $\sim 400 \mathrm{~mA} \mathrm{~h} \mathrm{~g}^{-1}, 2560 \mathrm{~mA} \mathrm{~g}^{-1}$ & $71.2 \%$ & 194 \\
\hline SnP nanocrystal & Liquid phase synthesis & $\begin{array}{l}600 \mathrm{~mA} \mathrm{~h} \mathrm{~g}^{-1} \text {, at } 100 \mathrm{~mA} \mathrm{~g}^{-1} \text {, } \\
\text { 200th }\end{array}$ & $396 \mathrm{~mA} \mathrm{~h} \mathrm{~g}^{-1}, 2500 \mathrm{~mA} \mathrm{~g}^{-1}$ & - & 190 \\
\hline $\mathrm{CoP}$ & Ball milling & $\begin{array}{l}315 \mathrm{~mA} \mathrm{~h} \mathrm{~g}^{-1} \text {, at } 100 \mathrm{~mA} \mathrm{~g}^{-1} \text {, } \\
25 \mathrm{th}\end{array}$ & $80 \mathrm{~mA} \mathrm{~h} \mathrm{~g}^{-1}, 2000 \mathrm{~mA} \mathrm{~g}^{-1}$ & $65.2 \%$ & 203 \\
\hline $\mathrm{CoP}_{3} @ \mathrm{C}$ & Ball milling & $\begin{array}{l}144 \mathrm{~mA} \mathrm{~h} \mathrm{~g}^{-1} \text {, at } 100 \mathrm{~mA} \mathrm{~g}^{-1} \text {, } \\
\text { 320th }\end{array}$ & $136.4 \mathrm{~mA} \mathrm{~h} \mathrm{~g}^{-1}, 250 \mathrm{~mA} \mathrm{~g}^{-1}$ & $87 \%$ & 200 \\
\hline $\begin{array}{l}\text { CoP@C } \\
\text { polyhedron }\end{array}$ & $\begin{array}{l}\text { Calcination/ } \\
\text { phosphidation }\end{array}$ & $\begin{array}{l}473 \mathrm{~mA} \mathrm{~h} \mathrm{~g}^{-1} \text {, at } 100 \mathrm{~mA} \mathrm{~g}^{-1} \text {, } \\
100 \text { th }\end{array}$ & $253.6 \mathrm{~mA} \mathrm{~h} \mathrm{~g}^{-1}, 800 \mathrm{~mA} \mathrm{~g}^{-1}$ & $47.3 \%$ & 204 \\
\hline $\mathrm{CoP} / \mathrm{CNS}$ & Calcination & $\begin{array}{l}386 \mathrm{~mA} \mathrm{~h} \mathrm{~g}^{-1} \text {, at } 1000 \mathrm{~mA} \mathrm{~g}^{-1} \text {, } \\
\text { 900th }\end{array}$ & $174 \mathrm{~mA} \mathrm{~h} \mathrm{~g}^{-1}, 20 \mathrm{~A} \mathrm{~g}^{-1}$ & $64.6 \%$ & 223 \\
\hline $\mathrm{Co}_{2} \mathrm{P}-3 \mathrm{D} \mathrm{PNC}$ & $\begin{array}{l}\text { Blowing method/ } \\
\text { phosphidation }\end{array}$ & $\begin{array}{l}271 \mathrm{~mA} \mathrm{~h} \mathrm{~g}^{-1} \text {, at } 500 \mathrm{~mA} \mathrm{~g}^{-1} \text {, } \\
\text { 700th }\end{array}$ & $179 \mathrm{~mA} \mathrm{~h} \mathrm{~g}^{-1}, 3000 \mathrm{~mA} \mathrm{~g}^{-1}$ & $41 \%$ & 224 \\
\hline $\mathrm{CoP}_{4} / \mathrm{CF}$ & $\begin{array}{l}\text { Hydrothermal/ } \\
\text { phosphidation }\end{array}$ & $\begin{array}{l}851 \mathrm{~mA} \mathrm{~h} \mathrm{~g}^{-1} \text {, at } 300 \mathrm{~mA} \mathrm{~g}^{-1} \text {, } \\
\text { 300th }\end{array}$ & $535 \mathrm{~mA} \mathrm{~h} \mathrm{~g}^{-1}, 4000 \mathrm{~mA} \mathrm{~g}^{-1}$ & $53 \%$ & 90 \\
\hline FeP nanoparticle & Ball milling & $\begin{array}{l}321 \mathrm{~mA} \mathrm{~h} \mathrm{~g}^{-1} \text {, at } 50 \mathrm{~mA} \mathrm{~g}^{-1} \text {, } \\
60 \text { th }\end{array}$ & $60 \mathrm{~mA} \mathrm{~h} \mathrm{~g}{ }^{-1}, 500 \mathrm{~mA} \mathrm{~g}^{-1}$ & $60.2 \%$ & 201 \\
\hline FeP nanoarray & $\begin{array}{l}\text { Hydrothermal/ } \\
\text { phosphidation }\end{array}$ & $\begin{array}{l}548 \mathrm{~mA} \mathrm{~h} \mathrm{~g}^{-1} \text {, at } 200 \mathrm{~mA} \mathrm{~g}^{-1} \text {, } \\
\text { 100th }\end{array}$ & $184 \mathrm{~mA} \mathrm{~h} \mathrm{~g}^{-1}, 2000 \mathrm{~mA} \mathrm{~g}^{-1}$ & $55.7 \%$ & 202 \\
\hline CNT@FeP@C & Solution phase & $\begin{array}{l}415 \mathrm{~mA} \mathrm{~h} \mathrm{~g}^{-1} \text {, at } 100 \mathrm{~mA} \mathrm{~g}^{-1} \text {, } \\
\text { 100th }\end{array}$ & $268 \mathrm{~mA} \mathrm{~h} \mathrm{~g}^{-1}, 1500 \mathrm{~mA} \mathrm{~g}^{-1}$ & $59 \%$ & 214 \\
\hline $\mathrm{FeP}_{4}$ & Ball milling & $\begin{array}{l}1000 \mathrm{~mA} \mathrm{~h} \mathrm{~g}^{-1} \text {, at } 89 \mathrm{~mA} \mathrm{~g}^{-1} \text {, } \\
\text { 30th }\end{array}$ & $900 \mathrm{~mA} \mathrm{~h} \mathrm{~g}^{-1}, 3578 \mathrm{~mA} \mathrm{~g}^{-1}$ & $84 \%$ & 70 \\
\hline H-FeP@C@GR & $\begin{array}{l}\text { Solvothermal/ } \\
\text { phosphidation }\end{array}$ & $\begin{array}{l}446 \mathrm{~mA} \mathrm{~h} \mathrm{~g}^{-1} \text {, at } 100 \mathrm{~mA} \mathrm{~g}^{-1} \text {, } \\
\text { 100th }\end{array}$ & $237 \mathrm{~mA} \mathrm{~h} \mathrm{~g}^{-1}, 1600 \mathrm{~mA} \mathrm{~g}^{-1}$ & $74 \%$ & 192 \\
\hline $\mathrm{NiP}_{3}$ & Ball milling & $\begin{array}{l}1079 \mathrm{~mA} \mathrm{~h} \mathrm{~g}^{-1} \text {, at } 176 \mathrm{~mA} \mathrm{~g}^{-1} \text {, } \\
\text { 15th }\end{array}$ & $720 \mathrm{~mA} \mathrm{~h} \mathrm{~g}^{-1}, 1760 \mathrm{~mA} \mathrm{~g}^{-1}$ & - & 199 \\
\hline Yolk-shell $\mathrm{Ni}_{2} \mathrm{P}$ & $\begin{array}{l}\text { Hydrothermal/ } \\
\text { phosphidation }\end{array}$ & $\begin{array}{l}181 \mathrm{~mA} \mathrm{~h} \mathrm{~g}^{-1} \text {, at } 200 \mathrm{~mA} \mathrm{~g}^{-1} \text {, } \\
100 \text { th }\end{array}$ & $101 \mathrm{~mA} \mathrm{~h} \mathrm{~g}^{-1}, 2000 \mathrm{~mA} \mathrm{~g}^{-1}$ & $52 \%$ & 225 \\
\hline $\mathrm{NiP}_{3}-\mathrm{CNT}$ & Ball milling & $\begin{array}{l}668 \mathrm{~mA} \mathrm{~h} \mathrm{~g}^{-1} \text {, at } 200 \mathrm{~mA} \mathrm{~g}^{-1} \text {, } \\
\text { 120th }\end{array}$ & $494 \mathrm{~mA} \mathrm{~h} \mathrm{~g}^{-1}, 3200 \mathrm{~mA} \mathrm{~g}^{-1}$ & $71.3 \%$ & 226 \\
\hline $\mathrm{Ni}_{2} \mathrm{P} / \mathrm{C}$ & $\begin{array}{l}\text { Solution phase/heat } \\
\text { treatment }\end{array}$ & $\begin{array}{l}361 \mathrm{~mA} \mathrm{~h} \mathrm{~g}^{-1} \text {, at } 100 \mathrm{~mA} \mathrm{~g}^{-1} \text {, } \\
\text { 300th }\end{array}$ & $100 \mathrm{~mA} \mathrm{~h} \mathrm{~g}^{-1}, 5000 \mathrm{~mA} \mathrm{~g}^{-1}$ & $76.7 \%$ & 92 \\
\hline $\begin{array}{l}\mathrm{Ni}_{2} \mathrm{P} / \text { graphene/ } \\
\mathrm{Ni}_{2} \mathrm{P}\end{array}$ & $\begin{array}{l}\text { Hydrothermal/ } \\
\text { phosphidation }\end{array}$ & $\begin{array}{l}188 \mathrm{~mA} \mathrm{~h} \mathrm{~g}^{-1} \text {, at } 500 \mathrm{~mA} \mathrm{~g}^{-1} \text {, } \\
\text { 300th }\end{array}$ & $152 \mathrm{~mA} \mathrm{~h} \mathrm{~g}^{-1}, 2000 \mathrm{~mA} \mathrm{~g}^{-1}$ & $69 \%$ & 227 \\
\hline $\mathrm{CuP}_{2} / \mathrm{C}$ & Ball milling & $\begin{array}{l}\sim 450 \mathrm{~mA} \mathrm{~h} \mathrm{~g}^{-1} \text {, at } 50 \mathrm{~mA} \mathrm{~g}^{-1} \text {, } \\
\text { 30th }\end{array}$ & $178 \mathrm{~mA} \mathrm{~h} \mathrm{~g}^{-1}, 2000 \mathrm{~mA} \mathrm{~g}^{-1}$ & $\sim 62 \%$ & 189 \\
\hline $\begin{array}{l}\text { Carbon sheet- } \\
\mathrm{CuP}_{2}\end{array}$ & $\begin{array}{l}\text { Solution phase/ } \\
\text { phosphidation }\end{array}$ & $\begin{array}{l}410 \mathrm{~mA} \mathrm{~h} \mathrm{~g}{ }^{-1} \text {, at } 80 \mathrm{~mA} \mathrm{~g}^{-1} \text {, } \\
\text { 200th }\end{array}$ & $152 \mathrm{~mA} \mathrm{~h} \mathrm{~g}^{-1}, 2560 \mathrm{~mA} \mathrm{~g}^{-1}$ & $87 \%$ & 228 \\
\hline $\mathrm{Cu}_{3} \mathrm{P} / \mathrm{C}$ & $\begin{array}{l}\text { Solution phase/ } \\
\text { annealing }\end{array}$ & $\begin{array}{l}221 \mathrm{~mA} \mathrm{~h} \mathrm{~g}^{-1} \text {, at } 100 \mathrm{~mA} \mathrm{~g}^{-1} \text {, } \\
\text { 100th }\end{array}$ & $142 \mathrm{~mA} \mathrm{~h} \mathrm{~g}^{-1}, 2000 \mathrm{~mA} \mathrm{~g}^{-1}$ & $73 \%$ & 198 \\
\hline $\mathrm{GeP}_{5} / \mathrm{C}$ & Ball milling & $\begin{array}{l}1220 \mathrm{~mA} \mathrm{~h} \mathrm{~g}^{-1} \text {, at } 100 \mathrm{~mA} \mathrm{~g}^{-1} \text {, } \\
60 \mathrm{th}\end{array}$ & $900 \mathrm{~mA} \mathrm{~h} \mathrm{~g}^{-1}, 1500 \mathrm{~mA} \mathrm{~g}^{-1}$ & $92 \%$ & 193 \\
\hline $\mathrm{GeP}_{5} / \mathrm{AB} / \mathrm{p}-\mathrm{rGO}$ & Ball milling & $\begin{array}{l}400 \mathrm{~mA} \mathrm{~h} \mathrm{~g}^{-1} \text {, at } 500 \mathrm{~mA} \mathrm{~g}^{-1} \text {, } \\
50 \mathrm{th}\end{array}$ & $175 \mathrm{~mA} \mathrm{~h} \mathrm{~g}^{-1}, 5000 \mathrm{~mA} \mathrm{~g}^{-1}$ & $60 \%$ & 229 \\
\hline
\end{tabular}


Table 2 (Contd.)

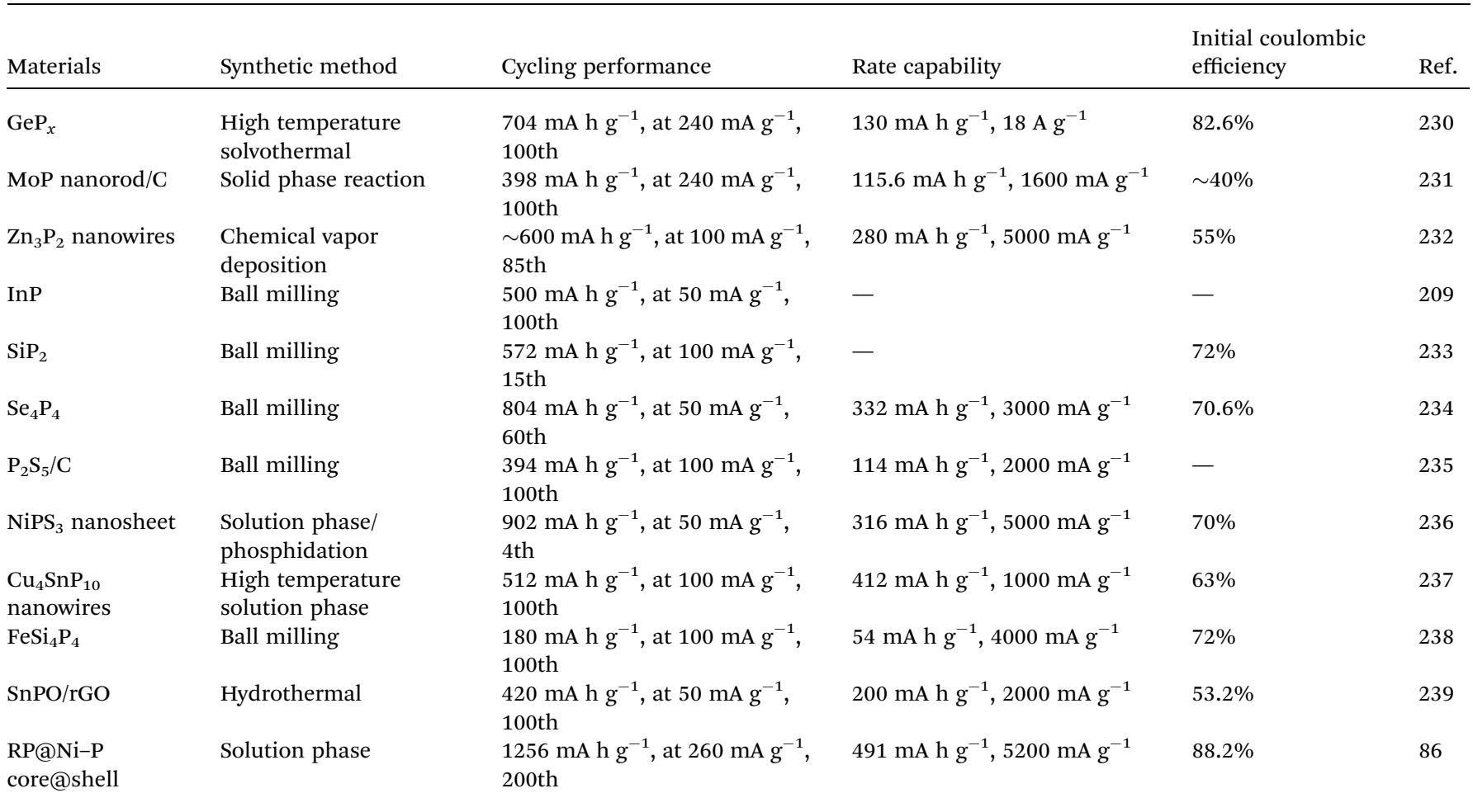

a $\mathrm{Co}_{2} \mathrm{P} @ \mathrm{~N}-\mathrm{C} @ \mathrm{rGO}$ composite. The anode of this composite exhibited an excellent sodium storage performance with a high reversible capacity of $225 \mathrm{~mA} \mathrm{~h} \mathrm{~g}^{-1}$ at $50 \mathrm{~mA} \mathrm{~g}^{-1}$ after 100 cycles. In addition, they proposed that $\mathrm{Co}_{2} \mathrm{P}$ underwent a $\mathrm{Na}$ storage mechanism similar to that of CoP, and decomposed into Co and $\mathrm{P}$ after the first discharge process, and then the $\mathrm{P}$ reversibly reacted with $\mathrm{Na}$ during the subsequent charge/discharge processes. In another study, Zhang et al. ${ }^{\mathbf{2 0 0}}$ synthesized carbon-coated $\mathrm{CoP}_{3}\left(\mathrm{CoP}_{3}\right.$ @C) nanocomposites as anodes for SIBs using a high energy mechanical milling method. Compared with plain $\mathrm{CoP}_{3}$, this carbon-coated $\mathrm{CoP}_{3}$ exhibited larger discharge capacities, enhanced cycling lifespans and better rate capabilities with a capacity of $212 \mathrm{~mA} \mathrm{~h} \mathrm{~g}^{-1}$ after 80 cycles at a current of $40 \mathrm{~mA} \mathrm{~h} \mathrm{~g}{ }^{-1}$. Sun et al. ${ }^{90}$ fabricated a binder-free anode for SIBs by growing mesoporous $\mathrm{CoP}_{4}$ nanoarrays onto carbon felt by a hydrothermal and a phosphidation process and reported that this unique mesoporous nanoarray contained a secondary structure of $\sim 10 \mathrm{~nm}$ ultrasmall primary particles. With the $3 \mathrm{D}$ carbon felt as a conductive network, this nanostructure demonstrated a capacity of $851 \mathrm{~mA} \mathrm{~h} \mathrm{~g}^{-1}$ after 300 cycles with an average coulombic efficiency of above $98 \%$, a long cycling lifespan of up to 1000 cycles ( $>90 \%$ retention rate) and a high rate capability of $535 \mathrm{~mA} \mathrm{~h} \mathrm{~g}^{-1}$ at a current density of $4 \mathrm{~A} \mathrm{~g}^{-1}$. This $\mathrm{CoP}_{4} / \mathrm{CF}$ anode was also used in a full SIB with a $\mathrm{Na}_{3} \mathrm{~V}_{2}\left(\mathrm{PO}_{4}\right)_{2} \mathrm{~F}_{3}$ cathode and an average operating voltage of $\approx 3.0 \mathrm{~V}$, a reversible capacity of $553 \mathrm{~mA} \mathrm{~h} \mathrm{~g}^{-1}$ and a high energy density of $\approx 280 \mathrm{~W} \mathrm{~h} \mathrm{~kg}^{-1}$ were achieved.

In summary, these studies have shown the possible application of cobalt phosphides as anodes in SIBs, and refined Co-P nanostructures such as polyhedrons, nanowires, and nanoarrays often exhibit better Na storage performance than ball milled Co-P particles. However, the high cost of Co may hinder their practical application, especially for large-scale energy storage systems.

\subsection{Iron phosphides}

Iron phosphides such as $\mathrm{FeP}, \mathrm{FeP}_{2}$ and $\mathrm{FeP}_{4}$ are also considered as promising anode materials for SIBs because of their high abundance, low-cost and environmentally friendly characteristics. Although $\mathrm{Fe}$ in $\mathrm{FeP}_{x}$ is electrochemically nonreactive towards $\mathrm{Na}$, it can be used as a conductive matrix to relieve the volumetric expansion of $\mathrm{P}^{\mathbf{2 1 4}}$ Because of this, great efforts have been devoted to the exploration of $\mathrm{FeP}_{x}$ as SIB anode materials. Among these various iron phosphides, FeP is most commonly used in SIBs and exhibits an orthorhombic phase (Fig. 21a) $)^{241,242}$ and possesses a theoretical capacity of $924 \mathrm{~mA} \mathrm{~h} \mathrm{~g}^{-1}$. Li et al. ${ }^{201}$ for the first time synthesized a low-cost FeP anode for SIBs with a high initial capacity of $764.7 \mathrm{~mA} \mathrm{~h}^{-1}$ through simple ball milling. The result of ex situ XRD and TEM indicated that the sodium storage mechanism of FeP was based on a conversion reaction, which can be expressed as follows:

$$
\begin{gathered}
\mathrm{FeP}+3 \mathrm{Na}^{+}+3 \mathrm{e}^{-} \rightarrow \mathrm{Fe}+\mathrm{Na}_{3} \mathrm{P} \\
\mathrm{Na}_{3} \mathrm{P} \leftrightarrow 3 \mathrm{Na}^{+}+\mathrm{P}+3 \mathrm{e}^{-}
\end{gathered}
$$

The Na storage mechanism of FeP is similar to that of CoP: after the initial discharge process, $\mathrm{FeP}$ is converted into Co and 
$\mathbf{a}$
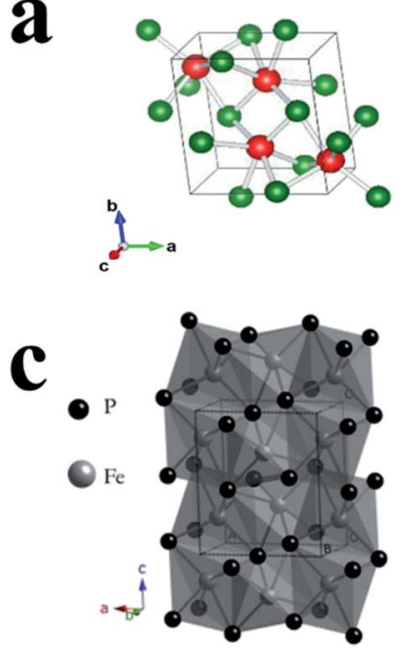

Fig. 21 (a, b) FeP crystal structure has an orthorhombic structure, and the iron atom in FeP has only one type of coordination: six. Red and orange atoms represent Fe and green atoms indicate P. Reproduced with permission. ${ }^{241}$ Copyright 2018, Elsevier Ltd. (c) Crystal structure of orthorhombic FeP in another form. (d) $\mathrm{FeP}_{6}$ polyhedron in orthorhombic FeP. The grey and black spheres represent Fe and P atoms, respectively. Reproduced with permission. ${ }^{242}$ Copyright 2015, Elsevier B.V.

$\mathrm{P}$, and then element $\mathrm{P}$ reversibly reacts with $\mathrm{Na}$ to form $\mathrm{Na}_{3} \mathrm{P}$ in the subsequent charge/discharge processes.

In another study, Wang et al. ${ }^{202}$ reported a SIB anode composed of FeP nanorod arrays on carbon cloth (FeP NAs/CC) (Fig. 22a), which delivered a high capacity of $829 \mathrm{~mA} \mathrm{~h} \mathrm{~g}^{-1}$ at $0.1 \mathrm{~A} \mathrm{~g}^{-1}$ and a high stability of $548 \mathrm{~mA} \mathrm{~h} \mathrm{~g}^{-1}$ at $0.2 \mathrm{~A} \mathrm{~g}^{-1}$ after 100 cycles with a capacity retention of $99.8 \%$, and an excellent rate and cycle performance (Fig. 22b and c). The synthesis process was simple, involving growth of $\mathrm{Fe}_{2} \mathrm{O}_{3}$ nanorod arrays onto carbon cloth through a hydrothermal method followed by a phosphidation process to transform $\mathrm{Fe}_{2} \mathrm{O}_{3}$ into $\mathrm{FeP}$ (Fig. 22a). In another study, Han et al. ${ }^{214}$ developed a synthetic strategy to construct carbon-coated FeP with an amorphous and mesoporous framework anchored onto carbon nanotubes as a SIB anode. The synthesis process involved a silica coating as a sacrificial internal spacer, which appeared to be key in the formation of a mesoporous framework. As a result, this FePbased anode demonstrated a reversible capacity of $415 \mathrm{~mA} \mathrm{~h} \mathrm{~g}^{-1}$ after 100 cycles at $100 \mathrm{~mA} \mathrm{~g}^{-1}$ and a long-life cycling capability of $295 \mathrm{~mA} \mathrm{~h} \mathrm{~g}{ }^{-1}$ after 500 cycles at $500 \mathrm{~mA} \mathrm{~g}^{-1}$. Furthermore, Wang et al. ${ }^{192}$ fabricated graphene encapsulated with a hollow FeP@carbon nanocomposite $(\mathrm{H}-$ FeP@C@GR) through a combination of solvothermal and hydrothermal methods with carbothermic reactions and phosphidation treatments (Fig. 22d) and reported that the synthesized $\mathrm{H}-\mathrm{FeP}$ nanospheres were highly uniform with an average diameter of $300-400 \mathrm{~nm}$ and that the thickness of the carbon layer was $\sim 4 \mathrm{~nm}$ (Fig. 22e). Here, the researchers also reported that such a 3D hierarchical architecture could exhibit high electrochemical performances where a reversible capacity of
$446 \mathrm{~mA} \mathrm{~h} \mathrm{~g}{ }^{-1}$ after 100 cycles and high rate capacities and stabilities were achieved (Fig. 22f and g), suggesting that the 3D conductive network of the GR skeleton and the carbon coating of $\mathrm{FeP}$ were key factors in the enhancement of Na storage performances, which could not only provide open pathways for electron/ion transport, but also prevent the continual reforming of a SEI on the surface of hollow FeP.

$\mathrm{FeP}_{4}$ exhibits a monoclinic structure and also can be used as an anode for SIBs. Zhang et al. ${ }^{70}$ synthesized iron phosphides of $\mathrm{FeP}_{2}$ and $\mathrm{FeP}_{4}$ as SIB anodes by a simple ball milling method and found that the $\mathrm{FeP}_{4}$ anode demonstrated a highly reversible sodiation capacity of $1137 \mathrm{~mA} \mathrm{~h} \mathrm{~g}^{-1}$ with a coulombic efficiency of $84.0 \%$ during the first cycle at $89 \mathrm{~mA} \mathrm{~g}^{-1}$ and high stability with a capacity of $\sim 1000 \mathrm{~mA} \mathrm{~h} \mathrm{~g}{ }^{-1}$ after 30 cycles along with good rate capabilities. However, the researchers also reported that $\mathrm{FeP}_{2}$ showed no significant electrochemical reactivities as a SIB anode possibly because of its low operating potential $\left(\leq 0 \mathrm{~V} v s . \mathrm{Na} / \mathrm{Na}^{+}\right) .{ }^{243}$

Overall, iron phosphides can show great potential as anodes for practical SIBs due to their low-cost and the facile synthesis of these ultrafine Fe-P nanostructures. However, FeP composites often exhibit low initial Coulomb efficiency (55-75\%) and insufficient cycle life-span, which is a concern for practical application. Although ball milled $\mathrm{FeP}_{4}$ possesses a higher $\mathrm{P}$ content and has shown the highest gravimetric specific capacity as well as the highest initial coulombic efficiency (84\%) among those Fe-P composites, the same issue of insufficient cycle stability hiders its application. In addition, its low electronic conductivity $\left(\sim 3 \times 10^{-3} \mathrm{~S} \mathrm{~m}^{-1}\right.$ for $\mathrm{FeP}_{4} v s . \sim 1.3 \times 10^{6} \mathrm{~S} \mathrm{~m}^{-1}$ for $\mathrm{FeP}$ ) is also a concern. It's presumed that $\mathrm{FeP}_{4}$ may undergo a similar capacity fading mechanism to amorphous RP because of its high $\mathrm{P}$ content. Furthermore, as ball milled $\mathrm{FeP}_{4}$ shows a large particle size $(1-10 \mu \mathrm{m})$, it is more likely to be pulverized, leading to insufficient cycle stability. With respect to this, more detailed and concrete $\mathrm{Na}$ storage mechanisms should be investigated, and the synthesis of novel ultrafine Fe-P nanostructures/composites especially for $\mathrm{FeP}_{4}$ is also necessary for their practical application.

\subsection{Nickel phosphides}

Nickel phosphides also have many advantages in Na storage, such as high electronic conductivity $\left(\sim 10^{6} \mathrm{~S} \mathrm{~m}^{-1}\right.$ for $\mathrm{Ni}_{2} \mathrm{P}$ and $\left.\mathrm{Ni}_{3} \mathrm{P}\right)^{244,245}$ and low cost. In addition, various morphologies or refined nanostructures can be obtained for nickel phosphides. For example, $\mathrm{Ni}_{2} \mathrm{P}$ nanoarrays, ${ }^{227}$ nanosheets, ${ }^{246}$ nanorods ${ }^{247}$ nanocrystals, ${ }^{92}$ and $\mathrm{Ni}_{3} \mathrm{P}$ films ${ }^{248}$ and particles ${ }^{226}$ were reported as anodes for Na-ion or Li-ion batteries. The crystal structures of cubic $\mathrm{Ni}_{3} \mathrm{P}$ and hexagonal $\mathrm{Ni}_{2} \mathrm{P}$ are shown in Fig. 23a. A nickel phosphide as a SIB anode material was first reported by Fullenwarth et al. ${ }^{199}$ in 2014 when they demonstrated the great potential of $\mathrm{NiP}_{3}$ in the Na storage field. In their study, two kinds of $\mathrm{NiP}_{3}$ compounds were synthesized via high temperature treatment or ball milling methods, respectively, both with metal $\mathrm{Ni}$ and commercial RP as raw materials. And the Nastorage mechanism of $\mathrm{NiP}_{3}$ was also investigated, and proposed as follows: 
$\mathbf{a}$
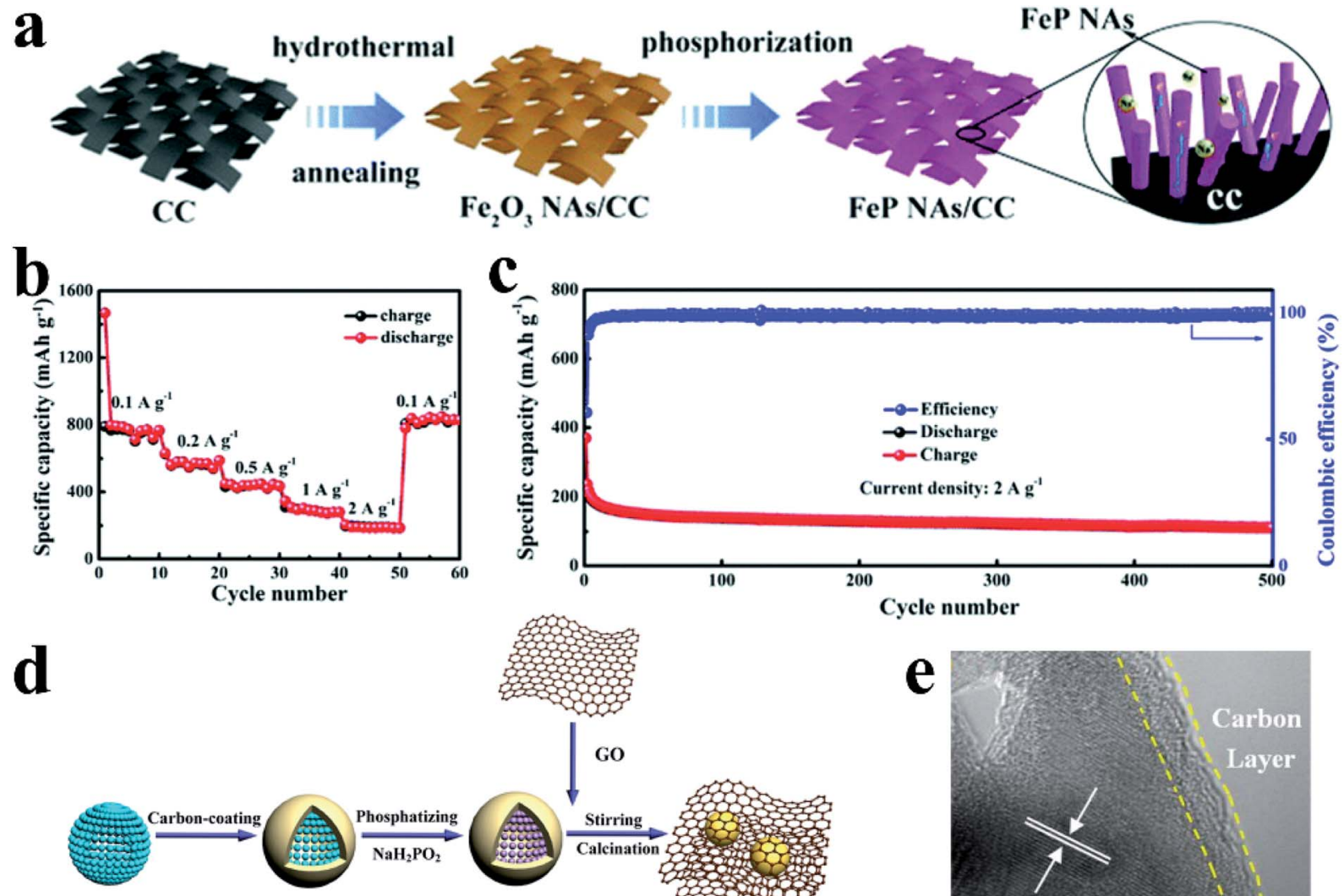

$\mathrm{H}_{-} \mathrm{Fe}_{3} \mathrm{O}_{4}$

$\mathrm{H}_{-} \mathrm{Fe}_{3} \mathrm{O}_{4} @ \mathrm{C}$

H-FeP@C

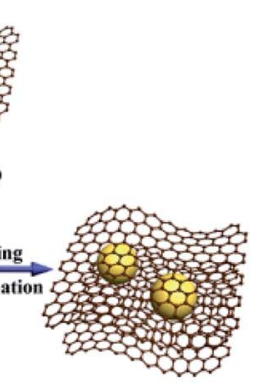

e

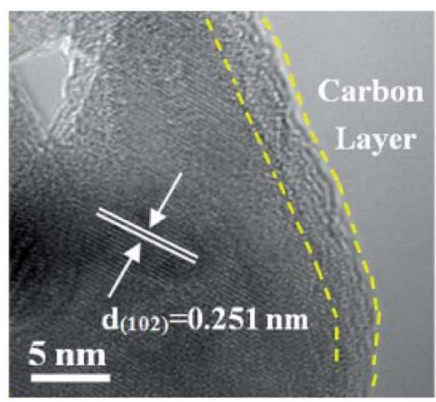

f
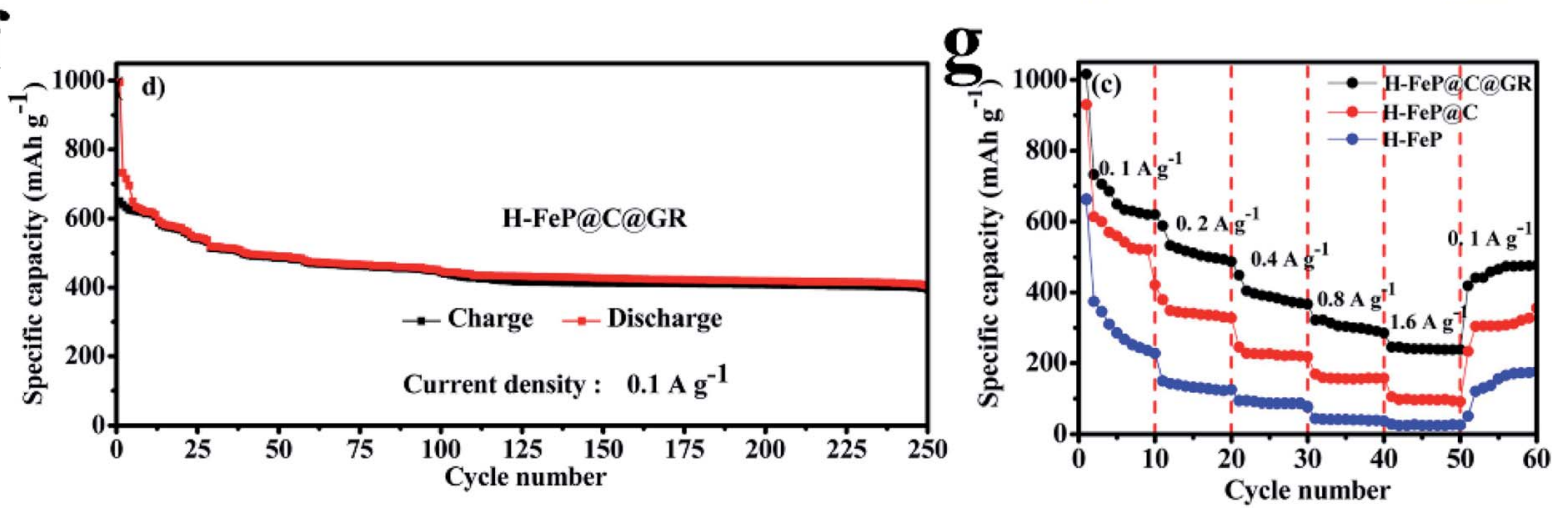

Fig. 22 (a) Schematic of the preparation of FeP NAs/CC. (b) Rate performance of the FeP NAs/CC electrode for SIBs. (c) Long-term cycling at $2 \mathrm{~A} \mathrm{~g}^{-1}$. Reproduced with permission. ${ }^{202}$ Copyright 2016, The Royal Society of Chemistry. (d) Schematic of the synthesis of H-FeP@C@GR nanocomposites. (e) HRTEM image of the H-FeP nanospheres. (f) Long-term cycling and (g) rate performance of a H-FeP(aC(aGR anode at a current density of $0.1 \mathrm{~A} \mathrm{~g}^{-1}$. Reproduced with permission. ${ }^{192}$ Copyright 2017, American Chemical Society.

$$
\begin{gathered}
\mathrm{NiP}_{3}+9 \mathrm{Na}^{+}+9 \mathrm{e}^{-} \rightarrow \mathrm{Ni}+\mathrm{Na}_{3} \mathrm{P} \text { (first discharge) } \\
\mathrm{Na}_{3} \mathrm{P} \leftrightarrow 3 \mathrm{Na}^{+}+\mathrm{P}+3 \mathrm{e}^{-} \text {(subsequent cycles) }
\end{gathered}
$$

Here, cubic phase $\mathrm{Ni}_{3} \mathrm{P}$ was directly transformed into $\mathrm{Na}_{3} \mathrm{P}$ and nanosized metallic Ni particles in the discharge process, with no possible intermediate phases such as $\mathrm{NaP}$ and $\mathrm{Na}_{3} \mathrm{P}_{11}$ evidenced. In the charge process, Na-extraction caused $\mathrm{Na}_{3} \mathrm{P}$ transformation into amorphous $\mathrm{P}$, and then the amorphous $\mathrm{P}$ underwent an alloying-dealloying process in the next cycles (amorphous $\mathrm{Ni}_{3} \mathrm{P}$ or $\mathrm{Ni}-\mathrm{P}$ compounds may also be part of the charged product). The as-prepared $\mathrm{NiP}_{3}$ anode showed a relatively low redox potential of $\sim 0.2 \mathrm{~V} v s$. Na/Na ${ }^{+}$and the $\mathrm{NiP}_{3}$ synthesized by high temperature treatment exhibited a better $\mathrm{Na}$ storage performance than that synthesized from the ball milling method, delivering a discharge capacity of $1079 \mathrm{~mA} \mathrm{~h} \mathrm{~g}^{-1}$ at 15 th cycle.

Later, Kim et al. ${ }^{226}$ proposed an approach to synthesize $\mathrm{NiP}_{3}$ particles to allow for chemical bonding with functionalized CNTs through a ball milling process (Fig. 24a). The 

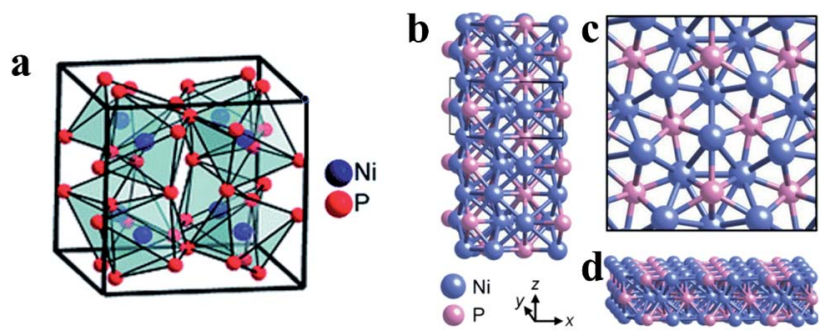

Fig. 23 (a) Crystal structure of cubic $\mathrm{Ni}_{3} \mathrm{P}$. Reproduced with permission. ${ }^{199}$ Copyright 2014, The Royal Society of Chemistry. (b) Crystal structure of hexagonal $\mathrm{Ni}_{2} \mathrm{P}$ : four unit cells stacked on top of one another, with a single unit cell outlined. (c) Top-down view of the $\mathrm{Ni}_{2} \mathrm{P}$ (001) surface. (d) A two-dimensional slice of $\mathrm{Ni}_{2} \mathrm{P}$, showing the (001) surface on top. Reproduced with permission. ${ }^{249}$ Copyright 2013, American Chemical Society.

corresponding anode delivered a high initial reversible capacity of $853 \mathrm{~mA} \mathrm{~h} \mathrm{~g}^{-1}$ with more than $80 \%$ capacity retention after 120 cycles at $200 \mathrm{~mA} \mathrm{~g}^{-1}$ and a high rate capacity of $363.8 \mathrm{~mA} \mathrm{~h} \mathrm{~g}^{-1}$ after 200 cycles at $1600 \mathrm{~mA} \mathrm{~g}^{-1}$ (Fig. 24b). The results of physical characterization indicated that the $\mathrm{P}-\mathrm{C}$ and $\mathrm{P}-\mathrm{O}-\mathrm{C}$ bonds between $\mathrm{NiP}_{3}$ and the functional groups on CNTs were generated during the ball milling process and played an important role in the enhancement of $\mathrm{NiP}_{3}$ anode performances in SIBs. Wu et al. ${ }^{225}$ also developed an assembly and selftemplate strategy for the synthesis of a 3D yolk-shell-like nanostructure in which $\mathrm{Ni}_{2} \mathrm{P}$ nanoparticles with a size of $\sim 24 \mathrm{~nm}$ were embedded into porous graphene networks. The overall fabrication process involved two main steps, an assembly step of $\mathrm{NiNH}_{4} \mathrm{PO}_{4} \cdot \mathrm{H}_{2} \mathrm{O}$ nanorods with graphene oxide (GO), and a following annealing step under a reducing atmosphere $\left(\mathrm{H}_{2}\right)$. Here, the researchers reported that the $\mathrm{Ni}_{2} \mathrm{P}$ anode for SIBs delivered a reversible initial capacity of $181 \mathrm{~mA} \mathrm{~h} \mathrm{~g}^{-1}$ at $0.2 \mathrm{~A} \mathrm{~g}^{-1}$ and maintained a capacity retention of $89 \%$ over 100 cycles. In addition, Dong et al. ${ }^{227}$ designed a sandwich-like nanoarchitecture hybrid of $\mathrm{Ni}_{2} \mathrm{P}$ nanoarrays and nitrogendoped graphene $\left(\mathrm{Ni}_{2} \mathrm{P} / \mathrm{NG} / \mathrm{Ni}_{2} \mathrm{P}\right)$ as a SIB anode and reported that the as-prepared anode delivered a high capacity of $188 \mathrm{~mA} \mathrm{~h} \mathrm{~g}^{-1}$ (57\% of initial capacity) at $0.5 \mathrm{~A} \mathrm{~g}^{-1}$ over 300 cycles. Shi et al..$^{92}$ also designed a covalent heterostructure of monodisperse $\mathrm{Ni}_{2} \mathrm{P}$ nanocrystals with sizes of 10-30 nm immobilized on N, P co-doped carbon nanosheets as a SIB anode (Fig. 24c-e) and reported that the anode showed enhanced cycling stabilities and high rate performances, maintaining $361 \mathrm{~mA} \mathrm{~h} \mathrm{~g}^{-1}$ at $100 \mathrm{~mA} \mathrm{~g}^{-1}$ after 300 cycles and $181 \mathrm{~mA} \mathrm{~h} \mathrm{~g}^{-1}$ at $500 \mathrm{~mA} \mathrm{~g}^{-1}$ after 1200 cycles (Fig. 24f and g). It is acknowledged that serious agglomeration during sodiation/ desodiation of transition metal phosphides (TMPs) leads to challenging kinetic issues and rapid capacity fading. Here, the researchers reported that an agglomeration free $\mathrm{Na}$ storage process was achieved and could be visualized using in situ TEM. In addition, the strong bonding between $\mathrm{Ni}_{2} \mathrm{P}$ and NPC was evidenced through DFT calculations, which could stabilize $\mathrm{Ni}_{2} \mathrm{P}$ nanocrystals and simultaneously enable synergistically enhanced charge storage by providing exponentially increased electronic states around the Fermi level.
Recently, a microporous structure of $\mathrm{Ni}_{2} \mathrm{P} @ \mathrm{C}-\mathrm{N}$ polyhedrons embedding in highly rough carbon fiber was designed as a selfsupporting anode material for SIBs. ${ }^{250}$ Due to the ultra-small size of $\mathrm{Ni}_{2} \mathrm{P}$ particles $(\sim 5 \mathrm{~nm})$ and the unique host nanostructure, the corresponding anode delivered a long-term cycling stability (196.8 $\mathrm{mA} \mathrm{h} \mathrm{g}^{-1}$ at $1000 \mathrm{~mA} \mathrm{~g}^{-1}$ over 1000 cycles with a capacity fading of $0.04 \%$ per cycle) and superior rate capability (197.1 $\mathrm{mA} \mathrm{h} \mathrm{g}^{-1}$ at $2000 \mathrm{~mA} \mathrm{~g}^{-1}$, and returned to $752.5 \mathrm{~mA} \mathrm{~h} \mathrm{~g}^{-1}$ at $100 \mathrm{~mA} \mathrm{~g}^{-1}$ ). Moreover, a flexible half-cell and a full cell based on this electrode could also give an excellent $\mathrm{Na}$ storage performance.

Guo et al. ${ }^{251}$ synthesized tailored carbon-coated hollow $\mathrm{Ni}_{12} \mathrm{P}_{5}$ nanocrystals with an average size of $35 \mathrm{~nm}$ that were in situ grown on reduced graphene oxide nanosheets $\left(\mathrm{Ni}_{12} \mathrm{P}_{5} @ \mathrm{C} /\right.$ GNS) using a template-free refluxing method. The corresponding composite anode showed good Na storage performances due to the finely designed dual carbon shell nanostructure and was found to be able to accommodate volume expansion, enhance ion/electron transfer, prevent $\mathrm{Ni}_{12} \mathrm{P}_{5}$ nanocrystal aggregation and thus deliver a reversible capacity of $235 \mathrm{~mA} \mathrm{~h} \mathrm{~g}^{-1}$ at $100 \mathrm{~mA} \mathrm{~g}^{-1}$.

To sum up, nickel phosphides such as $\mathrm{NiP}_{3}, \mathrm{Ni}_{2} \mathrm{P}$, and $\mathrm{Ni}_{12} \mathrm{P}_{5}$ can show great potential as anodes for practical SIBs, among which $\mathrm{NiP}_{3}$ possesses the highest $\mathrm{P}$ content as well as the highest theoretical gravimetric specific capacity. Although the pure $\mathrm{NiP}_{3}$ anode can give a high specific capacity, the insufficient cycle stability hinders its application. In contrast, the $\mathrm{NiP}_{3}$-CNT anode enables longer cycle lifespan, but a concern that the use of CNTs may increase the fabrication cost may be noticed. The high content of $\mathrm{Ni}$ in $\mathrm{Ni}_{2} \mathrm{P}$ or $\mathrm{Ni}_{12} \mathrm{P}_{5}$ leads to smaller theoretical gravimetric specific capacity than that of $\mathrm{NiP}_{3}$. Nevertheless, the high content of Ni may play an important role in achieving long cycle stability. For all these Ni-P anodes, the initial coulombic efficiency is not high (50-80\%), and the specific capacities are also very low, far from the theoretical values (1591 $\mathrm{mA} \mathrm{h} \mathrm{g}^{-1}$ for $\mathrm{NiP}_{3}$ and $1333 \mathrm{~mA} \mathrm{~h} \mathrm{~g}^{-1}$ for $\mathrm{Ni}_{2} \mathrm{P}$ ). With respect to this, more effort should be made, including design and synthesis of novel nanostructures/ composites and exploration of facile and large-scale preparation methods (especially for $\mathrm{NiP}_{3}$, which has only been prepared by ball milling or high temperature methods).

\subsection{Copper phosphides}

Copper phosphides also possess various advantages in electrochemical Na storage applications. Among these copper phosphides, $\mathrm{CuP}_{2}$ and $\mathrm{Cu}_{3} \mathrm{P}$ are often used as anodes for Na-ion batteries. $\mathrm{CuP}_{2}$ can exhibit a monoclinic structure while $\mathrm{Cu}_{3} \mathrm{P}$ usually has a hexagonal structure. In the early stage of the study of these copper phosphides, ball milling is the most commonly used method to prepare anode materials. For example, Zhao et al. ${ }^{189}$ synthesized a composite consisting of crystalline $\mathrm{CuP}_{2}$ cores coated with carbon black nanoparticles $\left(\mathrm{CuP}_{2} / \mathrm{C}\right)$ through two steps of ball milling processes, and reported that this structure could enable fast and reversible sodiation/ desodiation, allowing a capacity of more than $500 \mathrm{~mA} \mathrm{~h} \mathrm{~g}{ }^{-1}$ at $50 \mathrm{~mA} \mathrm{~g}^{-1}$, a high rate capacity of $178 \mathrm{~mA} \mathrm{~h} \mathrm{~g}^{-1}$ at $2000 \mathrm{~mA} \mathrm{~g}^{-1}$ 
a
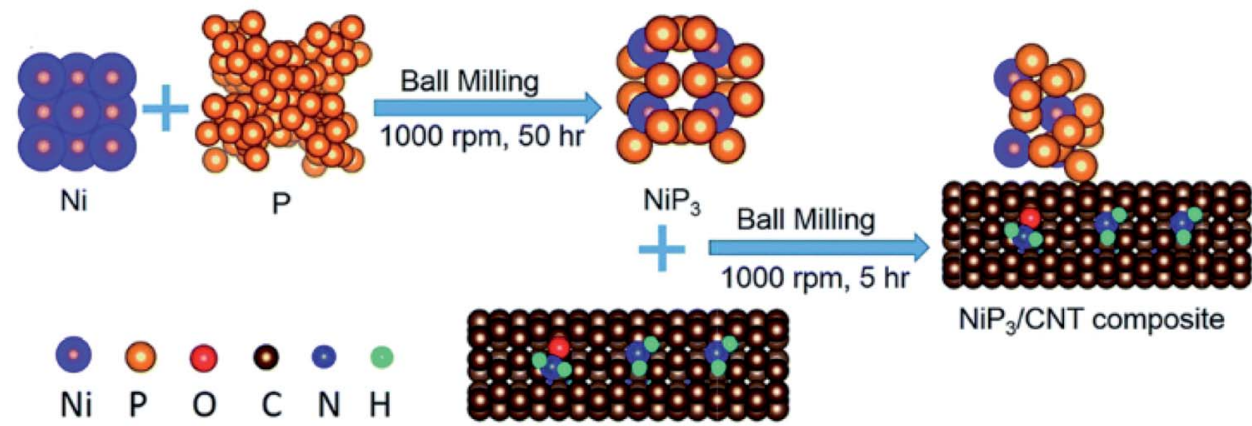

$\mathrm{NiP}_{3} / \mathrm{CNT}$ composite

CNT

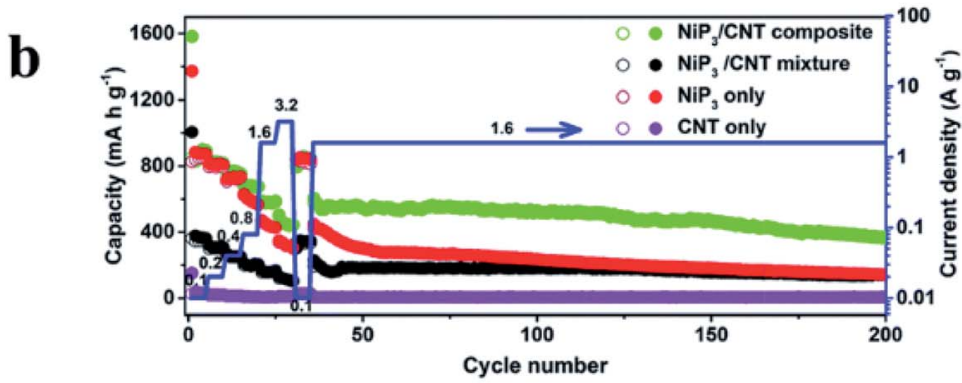

C
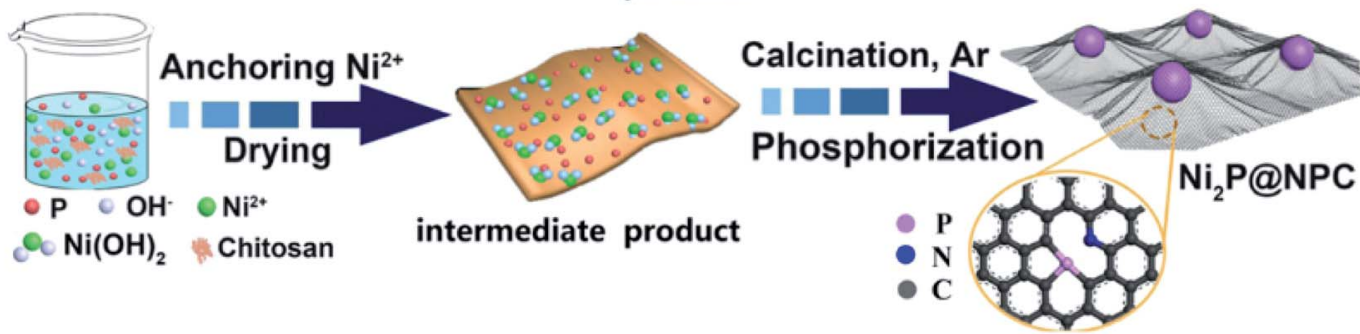

d

e
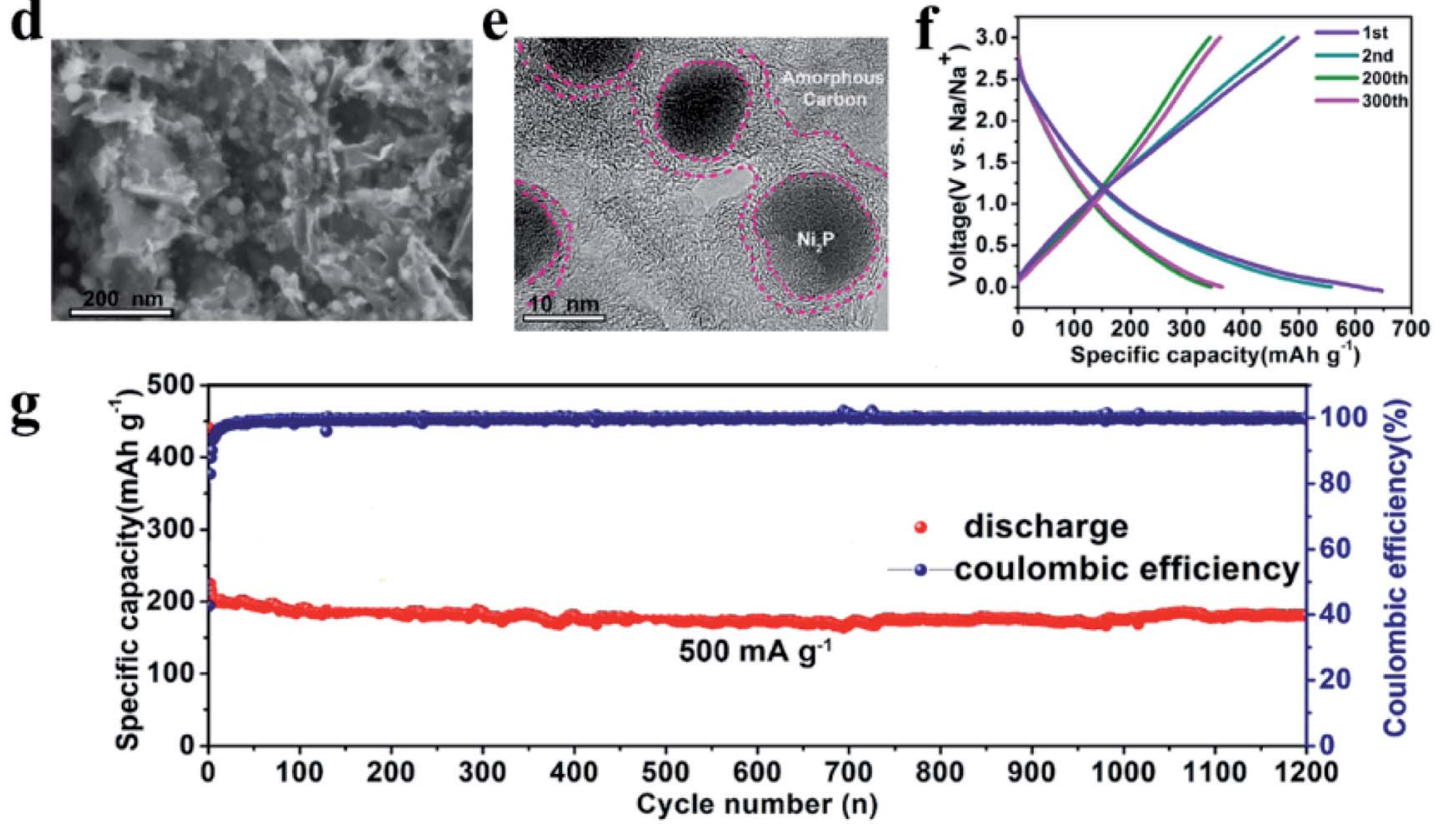

Fig. 24 (a) Schematic of the synthesis of the $\mathrm{NiP}_{3} / \mathrm{CNT}$ composite. (b) Comparison of the cycling performances of $\mathrm{CNT}_{1} \mathrm{NiP}_{3}, \mathrm{NiP}_{3} / \mathrm{CNT}$ mixture and $\mathrm{NiP}_{3} / \mathrm{CNT}$ composite electrodes. Reproduced with permission. ${ }^{226}$ Copyright 2018, The Royal Society of Chemistry. (c) Schematic of the synthesis of $\mathrm{Ni}_{2} \mathrm{P} @ N P C$. (d) SEM and TEM images of $\mathrm{Ni}_{2} \mathrm{P} @ \mathrm{~N} P C S$. (e) HR-TEM image of $\mathrm{Ni}_{2} \mathrm{P} @ \mathrm{aNPC}$. (f) Galvanostatic charge/discharge profiles of the $\mathrm{Ni}_{2} \mathrm{P} @ \mathrm{~N} P C \mathrm{SIB}$ anode for the 1st, 2nd, 200th and 300th cycles respectively. (g) Long-term cycling stability and coulombic efficiency of the $\mathrm{Ni}_{2} \mathrm{P} @ N P C$ composite at $500 \mathrm{~mA} \mathrm{~g}{ }^{-1}$. Reproduced with permission. ${ }^{92}$ Copyright 2018, Elsevier Ltd. 
and decent short-term cycling stability. Then a chemically bonded $\mathrm{CuP}_{2} / \mathrm{C}$ hybrid was also prepared by a one-step ball milling method, ${ }^{252}$ and the strong $\mathrm{P}-\mathrm{O}-\mathrm{C}$ bond and the stable nanoscale conducting framework in this hybrid offered an enhanced Na storage performance. According to these studies and other literature, ${ }^{189,228,252}$ the electrochemical reaction mechanism of $\mathrm{CuP}_{2}$ can be expressed as follows:

$$
\mathrm{CuP}_{2}+6 \mathrm{Na}^{+}+6 \mathrm{e}^{-} \leftrightarrow \mathrm{Cu}+2 \mathrm{Na}_{3} \mathrm{P}
$$

It means that crystalline $\mathrm{CuP}_{2}$ can be recovered after one discharge/charge cycle and shows a high theoretical capacity of $1282 \mathrm{~mA} \mathrm{~h} \mathrm{~g}^{-1}$ based on this conversion and alloy reaction.

Recently, other methods to prepare $\mathrm{CuP}_{2}$ anodes such as the solution phase method coupled with a heat treatment have been developed. ${ }^{198,228}$ For example, Yu et al. ${ }^{228}$ designed a nanocomposite of cross-linked hollow carbon sheet encapsulated $\mathrm{CuP}_{2}$ nanoparticles $\left(\mathrm{CHCS}-\mathrm{CuP}_{2}\right.$ ) prepared in several steps including surfactant-assisted wet-chemical precipitation, carbon coating and in situ phosphorization (Fig. 25a). Here, the researchers reported that the hollow structure and carbon shells could mitigate large volume change, prevent $\mathrm{CuP}_{2}$ nanoparticle aggregation and significantly enhance electron/ion transport (Fig. 25b-d). In addition, the connectivity of the cross-linked nanocomposite could enhance structural stability and resist inner stress, allowing for longer lifespans during cycling. As a result, the corresponding SIB anode delivered a high reversible capacity of $451 \mathrm{~mA} \mathrm{~h} \mathrm{~g}{ }^{-1}$ at a current density of $80 \mathrm{~mA} \mathrm{~g}^{-1}$ with a retention of $91 \%$ after 200 cycles, and an excellent rate performance was also obtained (Fig. 25e and f). Furthermore, a full cell made based on this anode also provided an excellent Na storage performance, showing great potential for practical SIBs. Similarly, Duan et al. ${ }^{253}$ reported a $\mathrm{CuCl}_{2} / \mathrm{chitosan}_{\text {mono- }}$ lith derived $\mathrm{CuP}_{2} / \mathrm{C}$ composite where $\mathrm{CuP}_{2}$ nanoparticles were uniformly embedded in the carbon matrix. The strong chemical bonding between electron rich groups in chitosan and the heavy metal ion $\left(\mathrm{Cu}^{2+}\right)$ played a key role in the synthesis of this homogeneous monolithic composite. In addition, the chitosan derived carbon could prevent $\mathrm{Cu}$ and $\mathrm{CuP}_{2}$ particles from aggregation upon the subsequent thermal reduction and
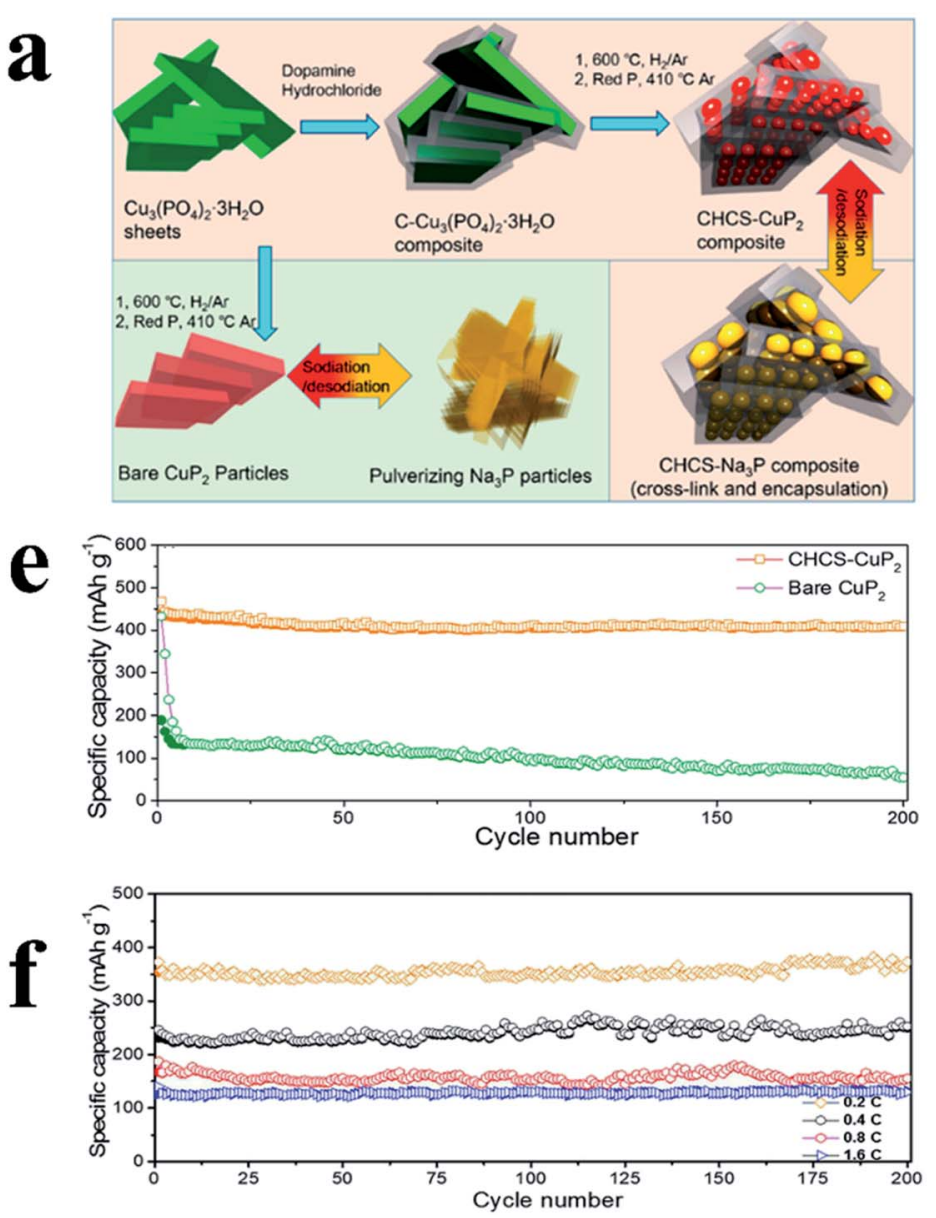
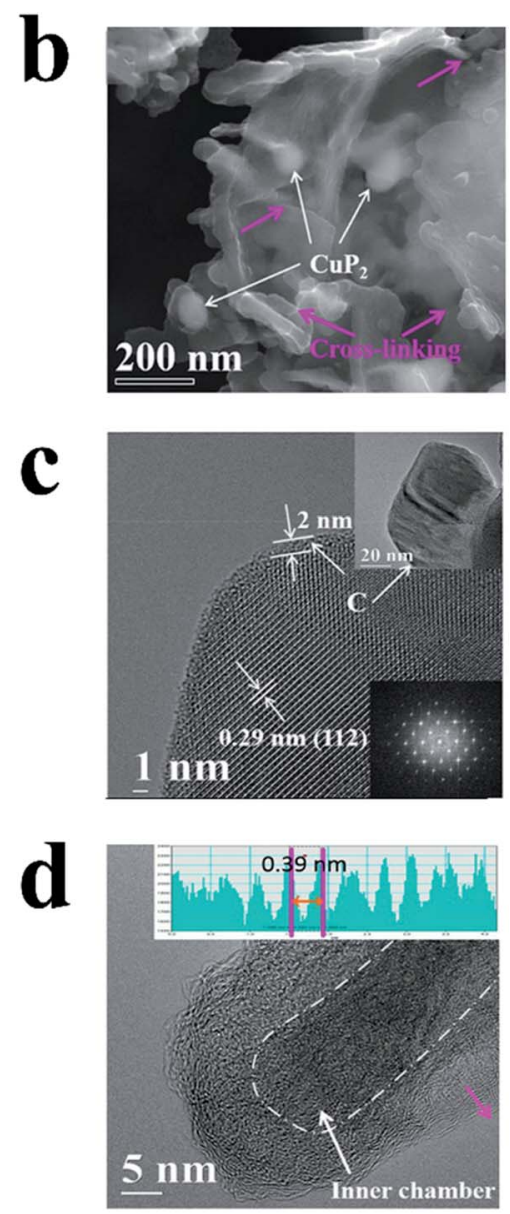

Fig. 25 (a) Schematic image of the preparation of the $\mathrm{CHCS}-\mathrm{CuP}_{2}$ composite and bare $\mathrm{CuP}_{2}$ particles, as well as the reversible reactions with $\mathrm{Na}^{+}$ions of these anodes. (b) SEM images of CHCS-CuP 2 composites. (c) HRTEM image of the CHCS-CuP 2 composite and its corresponding Fourier transformation in the inset, showing a thin carbon layer $(\sim 2 \mathrm{~nm})$ and the (110) planes of $\mathrm{CuP}_{2}$. (d) HRTEM image of a hollow carbon sheet with a wide interlayer distance $(\sim 0.39 \mathrm{~nm})$, showing an apparent inner chamber allowing for volume changes of CuP $\mathrm{P}_{2}$ during cycling. (e) Cycling performance of bare $\mathrm{CuP}_{2}$ and $\mathrm{CHCS}-\mathrm{CuP}_{2}$ composites at $80 \mathrm{~mA} \mathrm{~g}^{-1}$. (f) Cycling performance of CHCS-CuP 2 composites at $0.2,0.4,0.8$, and $1.6 \mathrm{C}\left(1 \mathrm{C}=800 \mathrm{~mA} \mathrm{~g}^{-1}\right)$. Reproduced with permission. ${ }^{228}$ Copyright 2018 , American Chemical Society. 
phosphorization. Benefiting from the synergistic effect of the small particle size and conductive carbon matrix, the $\mathrm{CuP}_{2} / \mathrm{C}$ composite anode for a SIB could deliver a high reversible capacity of $630 \mathrm{~mA} \mathrm{~h} \mathrm{~g}^{-1}$ at a current density of $100 \mathrm{~mA} \mathrm{~g}^{-1}$ and a capacity retention ratio of $91 \%$ after 200 cycles, while bare $\mathrm{CuP}_{2}$ showed a rapid capacity decay within 50 cycles.

$\mathrm{Cu}_{3} \mathrm{P}$ is also often used as an anode material for SIBs. Although $\mathrm{Cu}$ is inactive with $\mathrm{Na}^{+}$and thus shows a relatively low theoretical capacity of $363 \mathrm{~mA} \mathrm{~h} \mathrm{~g}^{-1}$ (similar to that of graphite), other advantages make it suitable as an anode for SIBs, such as air stability, high electronic conductivity, safe intercalation potential, and a high theoretical volumetric capacity of 4732 $\mathrm{mA} \mathrm{h} \mathrm{cm}{ }^{-3}$ (830 $\mathrm{mA} \mathrm{h} \mathrm{cm}{ }^{-3}$ for graphite).$^{254}$ Fan et al. ${ }^{78}$ reported an additive-free $\mathrm{Cu}_{3} \mathrm{P}$ nanowire (CPNW) anode directly grown on a copper current collector via an in situ growth and a subsequent phosphidation process. Due to its structure features, the CPNW anode demonstrated highly stable cycling ability with an $\sim 70 \%$ retention in capacity after 260 cycles. According to the literature, a reversible sodiation/desodiation of $\mathrm{Cu}_{3} \mathrm{P}$ proceeds via a conversion mechanism, which is similar to that of $\mathrm{CuP}_{2}$, and can be expressed as follows:

$$
\mathrm{Cu}_{3} \mathrm{P}+3 \mathrm{Na}^{+}+3 \mathrm{e}^{-} \leftrightarrow 3 \mathrm{Cu}+\mathrm{Na}_{3} \mathrm{P}
$$

After this study, many $\mathrm{Cu}_{3} \mathrm{P}$ composites have been successfully prepared by various methods. Inspired by metal-organic framework (MOF) derived strategies to synthesize metal phosphides/carbon (MP@C) nanostructures, Kong et al. ${ }^{198}$ designed a nanostructure of $\mathrm{Cu}_{3} \mathrm{P}$ nanoparticles $(\sim 50 \mathrm{~nm})$ coated with $\mathrm{N}$, P-codoped carbon matrices using a metalorganophosphine framework (MOPF) derived strategy (Fig. 26ad), where PTA represents 1,3,5-triaza-7-phospha-adamantane. This approach is relatively eco-friendly with no need for an additional $\mathrm{P}$ source, thus avoiding the release of harmful $\mathrm{PH}_{3}$ which is inevitably produced in the phosphorization process for most MOF-derived MP@C nanostructures. ${ }^{204,255,256}$ Due to this unique nanostructure, the corresponding SIB anode of this composite exhibited a high initial reversible capacity of $332 \mathrm{~mA} \mathrm{~h} \mathrm{~g}^{-1}$ at $50 \mathrm{~mA} \mathrm{~g}^{-1}$, a rate capacity of $142.5 \mathrm{~mA} \mathrm{~h} \mathrm{~g}^{-1}$ at
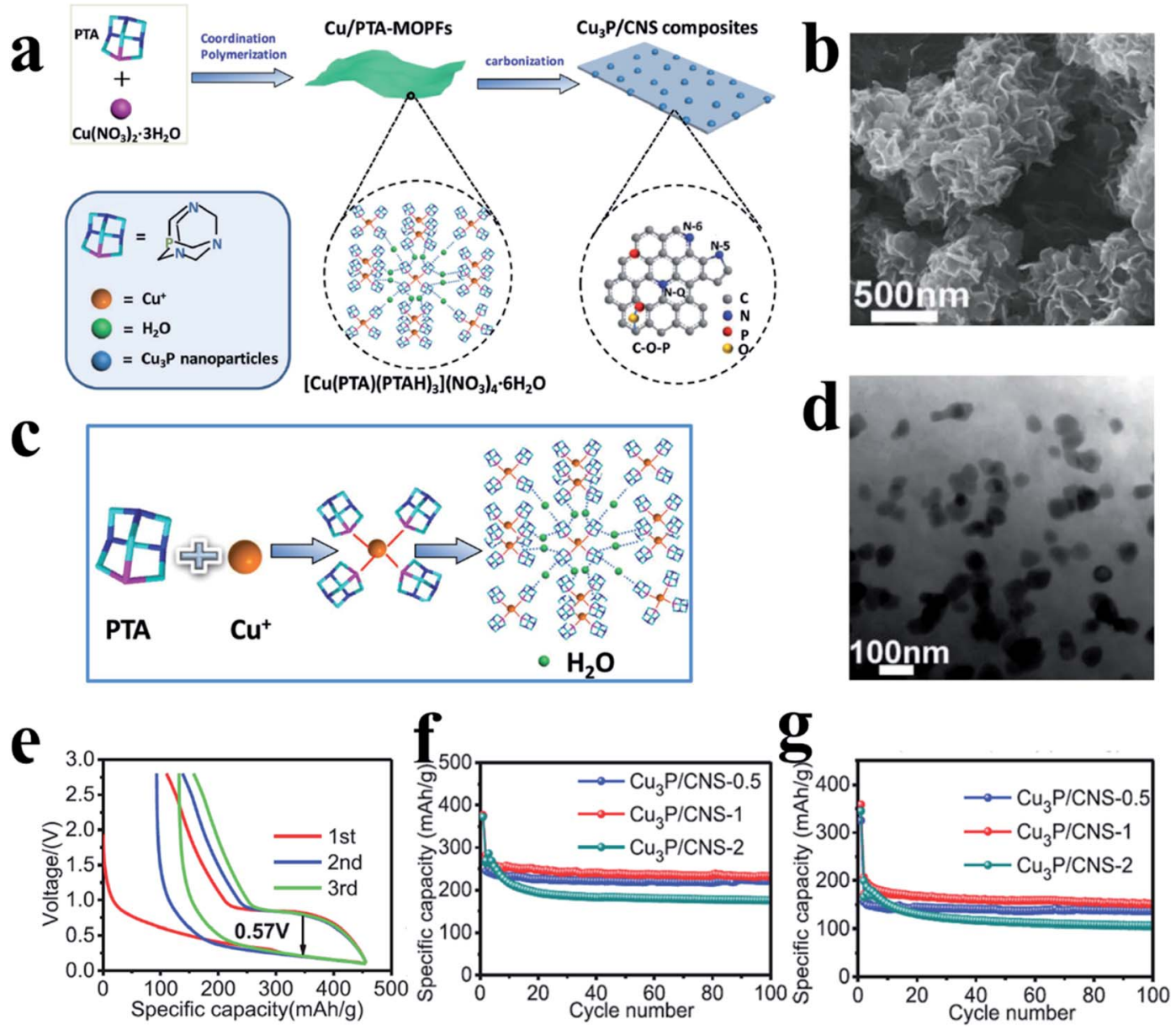

Fig. 26 (a) Schematic illustration of the evolution process from Cu/PTA-MOPFs to CuzP/CNS composites. (b) SEM images of Cu/PTA-MOPF-1 (molar ratio of PTA and $\mathrm{Cu}\left(\mathrm{NO}_{3}\right)_{2}$ is $1: 1$ ). (c) Schematic illustration of the coordination between PTA molecules and Cu ions in the precursors. (d) TEM images of the $\mathrm{Cu}_{3} \mathrm{P} / \mathrm{CNS}-1$ composite. (e) The initial three charge/discharge curves of the $\mathrm{Cu}_{3} \mathrm{P} / \mathrm{CNS}-1 \mathrm{composite}$ at $50 \mathrm{~mA} \mathrm{~g}^{-1}$. (f, $\mathrm{g}$ ) Cycling performances of three $\mathrm{Cu}_{3} \mathrm{P} / \mathrm{CNS}$ composites at 100 and $1000 \mathrm{~mA} \mathrm{~g}{ }^{-1}$, respectively (CNS-0.5, CNS-1, and CNS-2 represent the molar ratio of PTA and $\mathrm{Cu}\left(\mathrm{NO}_{3}\right)_{2}$ of $0.5,1$, and 2, respectively). Reproduced with permission. ${ }^{198}$ Copyright 2018 , WILEY-VCH. 
$2000 \mathrm{~mA} \mathrm{~g}^{-1}$ and good cycling performances with a retention of $85 \%$ after 100 cycles (Fig. 26e-g). Zhu et al. ${ }^{257}$ reported a composite of $3 \mathrm{D} \mathrm{Cu}_{3} \mathrm{P} @ \mathrm{C}$ nanosheets synthesized by heating a mixture of copper foam and phosphorus-containing resin. During the heat treatment, an epitaxial phosphidation growth coupled with a carbon deposition process occurred on the surface of copper foam, and the $3 \mathrm{D} \mathrm{Cu}_{3} \mathrm{P} @ \mathrm{C}$ nanosheets were formed. In each individual nanosheet, the thin carbon shell could serve as an electron conductor and accommodate the volume change of the $\mathrm{Cu}_{3} \mathrm{P}$ single-crystalline nanosheet. Due to its unique 3D nanoarchitecture, the $\mathrm{Cu}_{3} \mathrm{P} @ \mathrm{C}$ anode delivered a high capacity retention of $286 \mathrm{~mA} \mathrm{~h} \mathrm{~g}^{-1}$ after 300 cycles at $0.1 \mathrm{~A} \mathrm{~g}^{-1}$ and $156 \mathrm{~mA} \mathrm{~h} \mathrm{~g}^{-1}$ after 1000 cycles at $1 \mathrm{~A} \mathrm{~g}^{-1}$.

Recently, $\mathrm{Cu}_{2} \mathrm{P}_{7}$ as an anode material for SIBs has also been reported and showed excellent electrochemical performance. For example, Li et al. ${ }^{258}$ successfully prepared a $\mathrm{Cu}_{2} \mathrm{P}_{7} / \mathrm{CuP}_{2} /$ graphite composite by a facile ball milling method and used it as an anode material for SIBs. Benefiting from a synergistic effect of the high $\mathrm{P}$ concentration, the layered structure and heterointerfaces between the different phases, the corresponding anode could provide capacities of $1254 \mathrm{~mA} \mathrm{~h} \mathrm{~g}^{-1}$ after 100 cycles at $200 \mathrm{~mA} \mathrm{~g}^{-1}$ and $200 \mathrm{~mA} \mathrm{~h} \mathrm{~g}^{-1}$ at $5 \mathrm{~A} \mathrm{~g}^{-1}$ in a rate capability test. Similarly, a composite of $\mathrm{Cu}_{2} \mathrm{P}_{7}$-BP-MWCNT (MWCNT, multiwalled carbon nanotube) was also prepared by a mechanical milling method. ${ }^{259}$ When used as an anode for Naion batteries, the composite delivered high comprehensive performances: initial coulombic efficiency up to $84 \%$, $1170 \mathrm{~mA} \mathrm{~h} \mathrm{~g}^{-1}$ after 200 cycles, and $580 \mathrm{~mA} \mathrm{~h} \mathrm{~g}^{-1}$ at $5 \mathrm{~A} \mathrm{~g}^{-1}$.

In summary, copper phosphides, including $\mathrm{CuP}_{2}, \mathrm{Cu}_{3} \mathrm{P}$ and $\mathrm{Cu}_{2} \mathrm{P}_{7}$, have also attracted much attention because of their lowcost, high electronic conductivity and other advantages. Although the ball milling method to prepare $\mathrm{CuP}_{2}$ composites is facile, the insufficient cycle life-span of these anodes is a concern for practical application. In contrast, $\mathrm{CuP}_{2} / \mathrm{C}$ nanoparticles prepared by the solution phase method (assisted by other processes) show better cycle stability. However, these $\mathrm{CuP}_{2}$ anodes all suffer from insufficient gravimetric specific capacity and long-cycle lifespan, which need to be addressed in future research. Various $\mathrm{Cu}_{3} \mathrm{P}$ nanostructures/composites such as nanowires, nanoparticles, and nanosheets have been prepared, and some high sodium storage performances are achieved in terms of rate capability and long-cycle stability. However, the low theoretical specific capacity may hinder their application, especially for electric vehicles or even large-scale energy storage systems. The $\mathrm{Cu}_{2} \mathrm{P}_{7}$ composite has been recently reported as an anode for SIBs and exhibited high specific capacities due to the high $\mathrm{P}$ content of $\mathrm{Cu}_{2} \mathrm{P}_{7}$. In addition, $\mathrm{Cu}_{2} \mathrm{P}_{7}$ promises high rate capability due to its layered structure and high electronic conductivity, which favor $\mathrm{Na}^{+} / \mathrm{e}^{-}$ transportation. All of this makes $\mathrm{Cu}_{2} \mathrm{P}_{7}$ a promising candidate as an anode material for practical SIBs.

\subsection{Germanium phosphides}

Germanium phosphides $\left(\mathrm{GeP}_{x}\right)$ such as $\mathrm{GeP}_{5}$ and $\mathrm{GeP}_{3}$ have recently been extensively investigated as anode materials for SIBs. $\mathrm{GeP}_{5}$ possesses a large theoretical specific gravimetric capacity of $1888 \mathrm{~mA} \mathrm{~h} \mathrm{\textrm {g } ^ { - 1 }}$ due to the highest $\mathrm{P}$ atomic percentage among all the binary phosphides, and a high theoretical volumetric capacity of $6891 \mathrm{~mA} \mathrm{~h} \mathrm{~cm}^{-3}$ which is the best record in anodes for SIBs. In addition, rhombohedral $\mathrm{GeP}_{5}$ exhibits a layered structure similar to those of black $\mathrm{P}$ and graphite (Fig. 27a), with a high electrical conductivity of $\sim 10^{6} \mathrm{~S}$ $\mathrm{m}^{-1}, 4$ orders of magnitude higher than that of black $\mathrm{P}$ and similar to that of graphite (XRD pattern is shown in Fig. 27b). All of this indicates that $\mathrm{GeP}_{5}$ is another promising candidate as an anode material for SIBs. Li et al. ${ }^{193}$ synthesized a $\mathrm{GeP}_{5} / \mathrm{C}$ composite by ball milling $\mathrm{GeP}_{5}$ and commercial graphite and reported a low potential of $\sim 0.4 \mathrm{~V} v s$. $\mathrm{Na}^{+} / \mathrm{Na}$ with a smooth charge/discharge profile. This $\mathrm{GeP}_{5} / \mathrm{C}$ anode showed an excellent $\mathrm{Na}$ storage performance, delivering a large reversible capacity of $1250 \mathrm{~mA} \mathrm{~h} \mathrm{~g}^{-1}$ with an initial coulombic efficiency of $93 \%$ and considerable cycling stabilities with $98 \%$ capacity retention after 60 cycles (Fig. 27d). Here, the synergetic effects between the sodiation of Ge and P reportedly leveled multistep plateaus smoothly and effectively reduced polarization between charge and discharge, leading to high coulombic efficiencies. Moreover, a full SIB cell using this anode coupled with a $\mathrm{Na}_{3} \mathrm{~V}_{2}\left(\mathrm{PO}_{4}\right)_{3} / \mathrm{C}$ cathode provided a large capacity of $800 \mathrm{~mA} \mathrm{~h} \mathrm{~g}^{-1}$ with a high average output voltage of $2.65 \mathrm{~V}$. The researchers also investigated the electrochemical $\mathrm{Na}$ storage mechanism of $\mathrm{GeP}_{5}$, which can be described by equations as shown in the following:

$$
\begin{gathered}
\mathrm{GeP}_{5}+16 \mathrm{Na}^{+}+16 \mathrm{e}^{-} \rightarrow 5 \mathrm{Na}_{3} \mathrm{P}+\mathrm{NaGe} \text { (first discharge) } \\
\mathrm{Na}_{3} \mathrm{P} \leftrightarrow 3 \mathrm{Na}^{+}+\mathrm{P}+3 \mathrm{e}^{-} \text {(subsequent cycles) } \\
\mathrm{NaGe} \leftrightarrow \mathrm{Ge}+\mathrm{Na}^{+}+3 \mathrm{e}^{-}
\end{gathered}
$$

It was confirmed that $\mathrm{GeP}_{5}$ experienced conversion-alloying type sodium storage during an electrochemical reduction process. $\mathrm{GeP}_{5}$ was converted into $\mathrm{Na}_{3} \mathrm{P}$ and $\mathrm{NaGe}$ after the initial discharge process, and $\mathrm{Na}_{3} \mathrm{P}$ and $\mathrm{NaGe}$ respectively underwent desodiation/sodiation processes during the next cycles. This mechanism could be evidenced by the TEM images of the sodiated and desodiated states of $\mathrm{GeP}_{5}$ (Fig. 27c and d). Actually, in the theoretical capacity of $\mathrm{GeP}_{5}\left(1888 \mathrm{~mA} \mathrm{~h} \mathrm{~g}{ }^{-1}\right)$, Ge element can contribute $118 \mathrm{~mA} \mathrm{~h} \mathrm{~g}^{-1}$ and $5 \mathrm{P}$ atoms donate the remaining $1770 \mathrm{~mA} \mathrm{~h} \mathrm{~g}^{-1}$.

$\mathrm{GeP}_{5}$ could also be obtained through the ball milling of highpurity Ge powder and commercial RP, and the composite of this $\mathrm{GeP}_{5}$ with carbon $\left(\mathrm{GeP}_{5} / \mathrm{C}\right)$ also demonstrated good Na storage performances. ${ }^{260}$ Ning et al. ${ }^{229}$ also prepared this $\mathrm{GeP}_{5}$ by ball milling Ge powder and RP, and further designed a dual-carbon conductive network enhanced $\mathrm{GeP}_{5}$ composite by a ball milling method $\left(\mathrm{GeP}_{5} / \mathrm{AB} / \mathrm{p}-\mathrm{rGO}\right.$; $\mathrm{AB}$ represented acetylene black, and prGO was partially reduced graphene oxide). They suggested that the dual carbon network not only provided more electron transport pathways but also relaxed the huge volume change during charge/discharge. As a result, this composite anode delivered a high reversible capacity of 597.5 and $175 \mathrm{~mA} \mathrm{~h} \mathrm{~g}^{-1}$ at current densities of 0.1 and $5.0 \mathrm{~A} \mathrm{~g}^{-1}$ respectively and high 
a

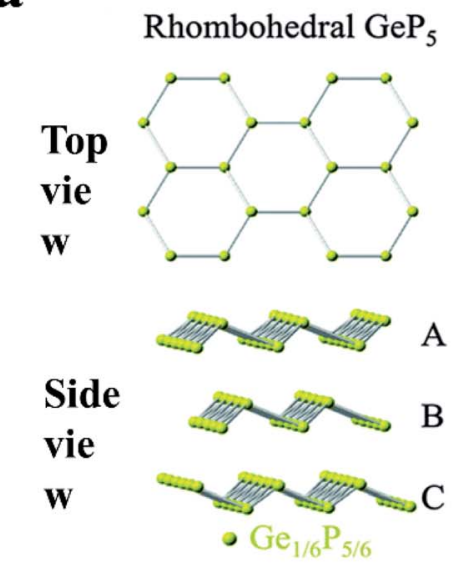

b

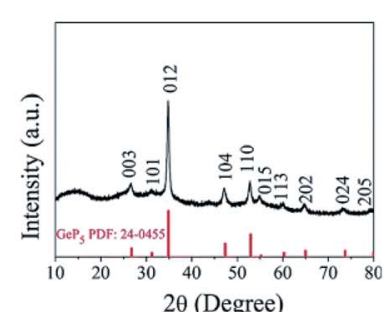

d

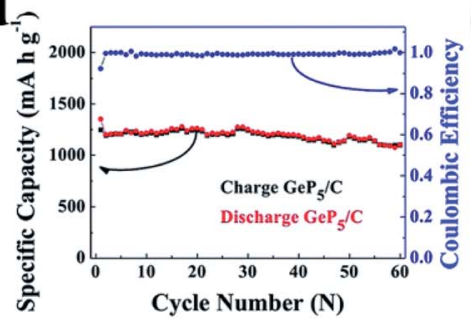

c

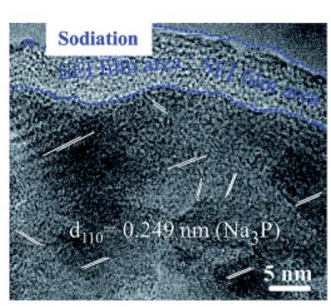

e

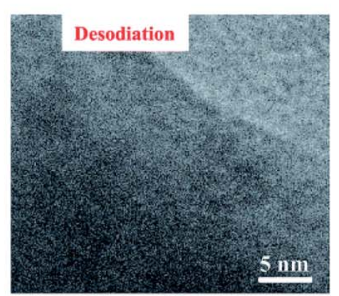

f

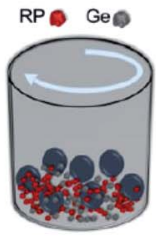

g

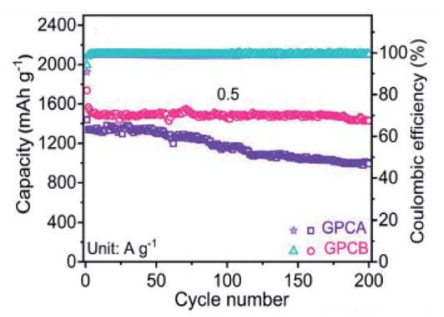

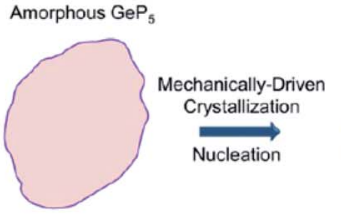

h

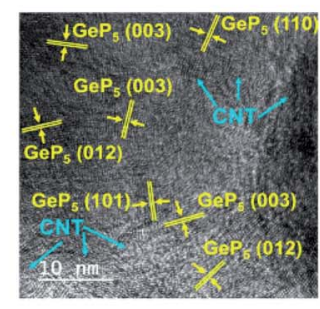

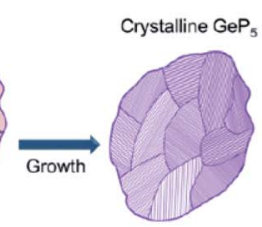

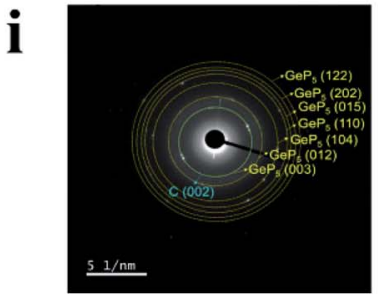

Fig. 27 (a) Crystal structure of rhombohedral $\mathrm{GeP}_{5}$. Reproduced with permission. ${ }^{261}$ Copyright 2015, The Royal Society of Chemistry. (b) XRD patterns of the as-synthesized $\mathrm{GeP}_{5} / \mathrm{C}$ composite. (c, e) HRTEM of the $\mathrm{GeP}_{5} / \mathrm{C}$ electrode in the full sodiation state (discharged to $0.005 \mathrm{~V}$ ), and in the full desodiation state (charged to $3.0 \mathrm{~V}$ ), respectively. (d) The cycle performance and corresponding coulombic efficiency of the assynthesized $\mathrm{GeP}_{5} / \mathrm{C}$ composite. (b-e) Reproduced with permission. ${ }^{193}$ Copyright 2017, The Royal Society of Chemistry. (f) Schematic explanation of mechanically induced crystallization that occurs during the milling of Ge and RP elemental powders. (g) Comparison of the cycling stability of GPCA and GPCB electrodes in the voltage range of $0.01-2.00 \mathrm{~V}$ at a current density of $0.50 \mathrm{~A} \mathrm{~g}^{-1}$ for 200 cycles (GPCA and GPCB represent the amorphous and crystalline $\mathrm{GeP}_{5}$-based composites, respectively). (h, i) HRTEM micrographs and SAED patterns of GPCB after the 50th cycle in the charged state. (f-i) Reproduced with permission. ${ }^{262}$ Copyright 2019. American Chemical Society.

stability with $400 \mathrm{~mA} \mathrm{~h} \mathrm{~g}^{-1}$ capacity retention at $0.5 \mathrm{~A} \mathrm{~g}^{-1}$ after 50 cycles. Furthermore, Tseng et al..$^{230}$ prepared mesoporous germanium phosphide $\left(\mathrm{MGeP}_{x}\right)$ microspheres as a SIB anode material through a high-temperature solvothermal method. These $\mathrm{MGeP}_{x}$ microspheres with diameters ranging from 0.5 to $1.5 \mu \mathrm{m}$ were composed of $10 \mathrm{~nm}$ nanoparticles with a narrow pore size distribution of $\sim 4 \mathrm{~nm}$ and possessed an amorphous structure with a weight ratio of $\mathrm{P}$ to Ge of 38.3 to 61.7. This unique porous nanostructure demonstrated high performance in sodium storage including high energy density, ultrahigh rate capability, and superior cyclability, showing a high reversible capacity of $704 \mathrm{~mA} \mathrm{~h} \mathrm{~g}^{-1}$ after 100 cycles at $240 \mathrm{~mA} \mathrm{~g}^{-1}$ and stable cycling performances of $278 \mathrm{~mA} \mathrm{~g}^{-1}$ at $1200 \mathrm{~mA} \mathrm{~g}^{-1}$ after 200 cycles.

Very recently, Cho et al. ${ }^{260}$ synthesized two kinds of $\mathrm{GeP}_{5}$, crystalline $\mathrm{GeP}_{5}$ (the $\mathrm{GeP}_{5}$ anodes reported by others were all of this type) and amorphous $\mathrm{GeP}_{5}$ (Fig. 27f); furthermore, the authors also prepared hybrids of $\mathrm{GeP}_{5}$ and multiwalled carbon nanotubes $\left(\mathrm{GeP}_{5} / \mathrm{CNT}\right)$. The researchers found that the crystalline $\mathrm{GeP}_{5}$ exhibited better Na storage performance than the amorphous one and proposed that the crystalline $\mathrm{GeP}_{5}$ exhibited a higher electronic conductivity, more facility for the insertion of $\mathrm{Na}^{+}$, and smaller volume expansion after sodiation. As a result, this crystalline $\mathrm{GeP}_{5} / \mathrm{CNT}$ anode showed a high initial CE of $94.13 \%$ and a high capacity of $1430 \mathrm{~mA} \mathrm{~h} \mathrm{~g}^{-1}$ after 200 cycles at $0.5 \mathrm{~A} \mathrm{~g}^{-1}$, corresponding to a capacity retention of 91.43\% from the second cycle (Fig. 27g). Interestingly, the authors suggested that $\mathrm{GeP}_{5}$ could recover to its crystalline phase after desodiation, as evidenced by the TEM images (Fig. 27h and i), which was contradictory to other reported literature. ${ }^{193,260}$ Therefore, further investigation about this issue is needed. 
Kim et al. ${ }^{263}$ introduced $\mathrm{GeP}_{3}$ as a promising anode material for SIBs and carried out a comparative investigation of $\mathrm{GeP}_{3}$ and $\mathrm{GeP}_{5}$. In their study, $\mathrm{GeP}_{3}$ was obtained by ball milling of Ge and $\mathrm{RP}$, and then the $\mathrm{GeP}_{3} / \mathrm{C}$ compound was obtained by further ball milling of $\mathrm{GeP}_{3}$ and carbon (super $\mathrm{P}$ ) for electrochemical measurements. The $\mathrm{GeP}_{5} / \mathrm{C}$ composite was synthesized by a similarly procedure. It was confirmed that $\mathrm{GeP}_{3}$ could give a rhombohedral crystal phase similar to $\mathrm{GeP}_{5}$ (Fig. 28a), but with a larger cell volume and average bonding distance compared with $\mathrm{GeP}_{5}$. Based on theoretical calculations, they also found that the bonding strength of $\mathrm{P}-\mathrm{P}$ was higher than that of $\mathrm{P}-\mathrm{Ge}$, and the elastic modulus of $\mathrm{GeP}_{3}$ showed significantly softer features than that of $\mathrm{GeP}_{5}$, indicating that the softer feature of Ge-P bonding could enable more effective accommodation for mechanical stress and deformation during charge/discharge cycles than $\mathrm{P}-\mathrm{P}$ bonding. This insight could be experimentally confirmed: the synthesized $\mathrm{GeP}_{3}$ compound maintained a high discharge capacity of $1274 \mathrm{~mA} \mathrm{~h} \mathrm{~g}^{-1}$ after 150
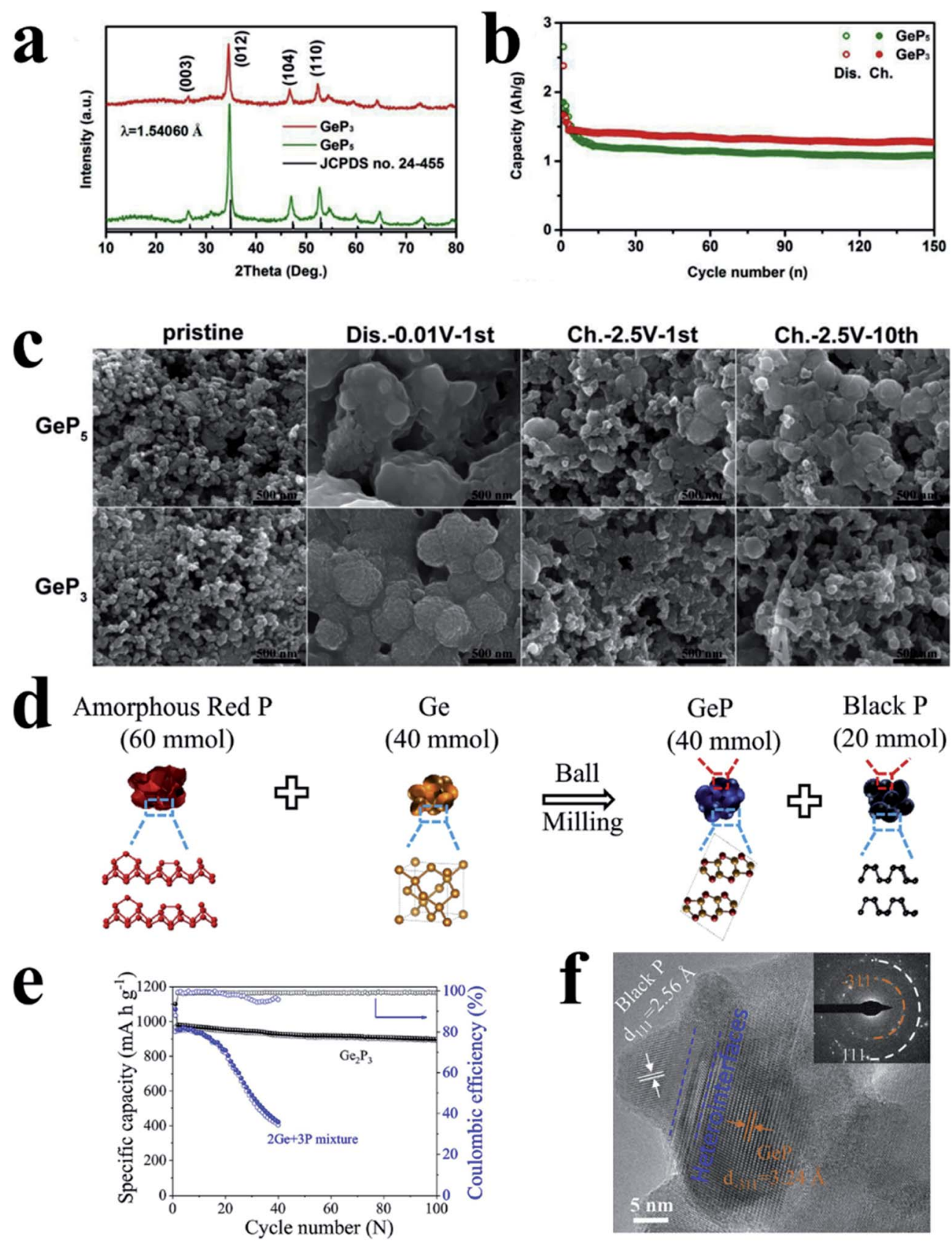

Fig. 28 (a) XRD patterns of the as-prepared $\mathrm{GeP}_{3}$ and $\mathrm{GeP}_{5}$ samples. (b) Cycling performance of $\mathrm{GeP}_{3}$ and $\mathrm{GeP}_{5}$. (c) $\mathrm{A}$ comparison of morphological changes for $\mathrm{GeP}_{5}$ (up) and $\mathrm{GeP}_{3}$ (down) compounds during the first 10 cycles. Reproduced with permission. ${ }^{263}$ Copyright 2018 , Elsevier Ltd. (d) Illustrated preparation process of the layered GeP-black P composite $\left(\mathrm{Ge}_{2} \mathrm{P}_{3}\right)$. (e) Cycle stability of the Ge $\mathrm{e}_{2} \mathrm{P}_{3}$ composite. (f) Highresolution transmission electron microscopy (HR-TEM) image and the inset shows the selected area electron diffraction of the Ge $\mathrm{P}_{3} \mathrm{Composite}$ Reproduced with permission. ${ }^{264}$ Copyright 2019, Elsevier Ltd. 
cycles, while the $\mathrm{GeP}_{5}$ compound with more $\mathrm{P}-\mathrm{P}$ bonding displayed an inferior cycling stability (Fig. 28b). Furthermore, the morphology and volume change of the $\mathrm{GeP}_{5}$ electrode seemed more serious compared to those of the $\mathrm{GeP}_{3}$ electrode during charge/discharge (Fig. 28c).

In another study, Nam et al. ${ }^{196}$ used commercial Ge and synthesized black $\mathrm{P}$ as raw materials to synthesize crystalline $\mathrm{GeP}_{3}$ through a high-power ball-milling (HPBM) method, and further prepared a $\mathrm{GeP}_{3} /$ carbon $\left(\mathrm{GeP}_{3} / \mathrm{C}\right)$ nanocomposite by ball milling this $\mathrm{GeP}_{3}$ with Super $\mathrm{P}$. The $\mathrm{GeP}_{3} / \mathrm{C}$ anode showed a highly reversible initial capacity of $984 \mathrm{~mA} \mathrm{~h} \mathrm{~g}^{-1}$ with a high initial CE of $81.3 \%$, a very stable capacity retention of $94.9 \%$ after 30 cycles, and a high rate capacity of $520 \mathrm{~mA} \mathrm{~h} \mathrm{~g}{ }^{-1}$ at $2 \mathrm{C}$ (Fig. 29e and f). Furthermore, the researchers investigated the $\mathrm{Na}$ storage mechanism of $\mathrm{GeP}_{3}$ by using various techniques, such as extended X-ray absorption fine structure (EXAFS) (Fig. 29b and c), X-ray diffraction (XRD), high-resolution transmission electron microscopy (HR-TEM) (Fig. 29d), and differential capacity $(\mathrm{d} Q / \mathrm{d} V)$ and cyclic voltammetry $(\mathrm{CV})$. It was indicated that the reaction mechanism involved one-step conversion during Na-insertion and two-step recombination/ topotactic-transition during Na-extraction, as shown by the following equations:

Na-insertion:

$$
\mathrm{GeP}_{3} \rightarrow \mathrm{NaGe}+\mathrm{Na}_{3} \mathrm{P}
$$

Na-extraction:

$$
\mathrm{NaGe}+\mathrm{Na}_{3} \mathrm{P} \rightarrow \mathrm{Na}_{x} \mathrm{GeP}_{3}+(x \leq 2.4) \rightarrow \mathrm{GeP}_{3}
$$
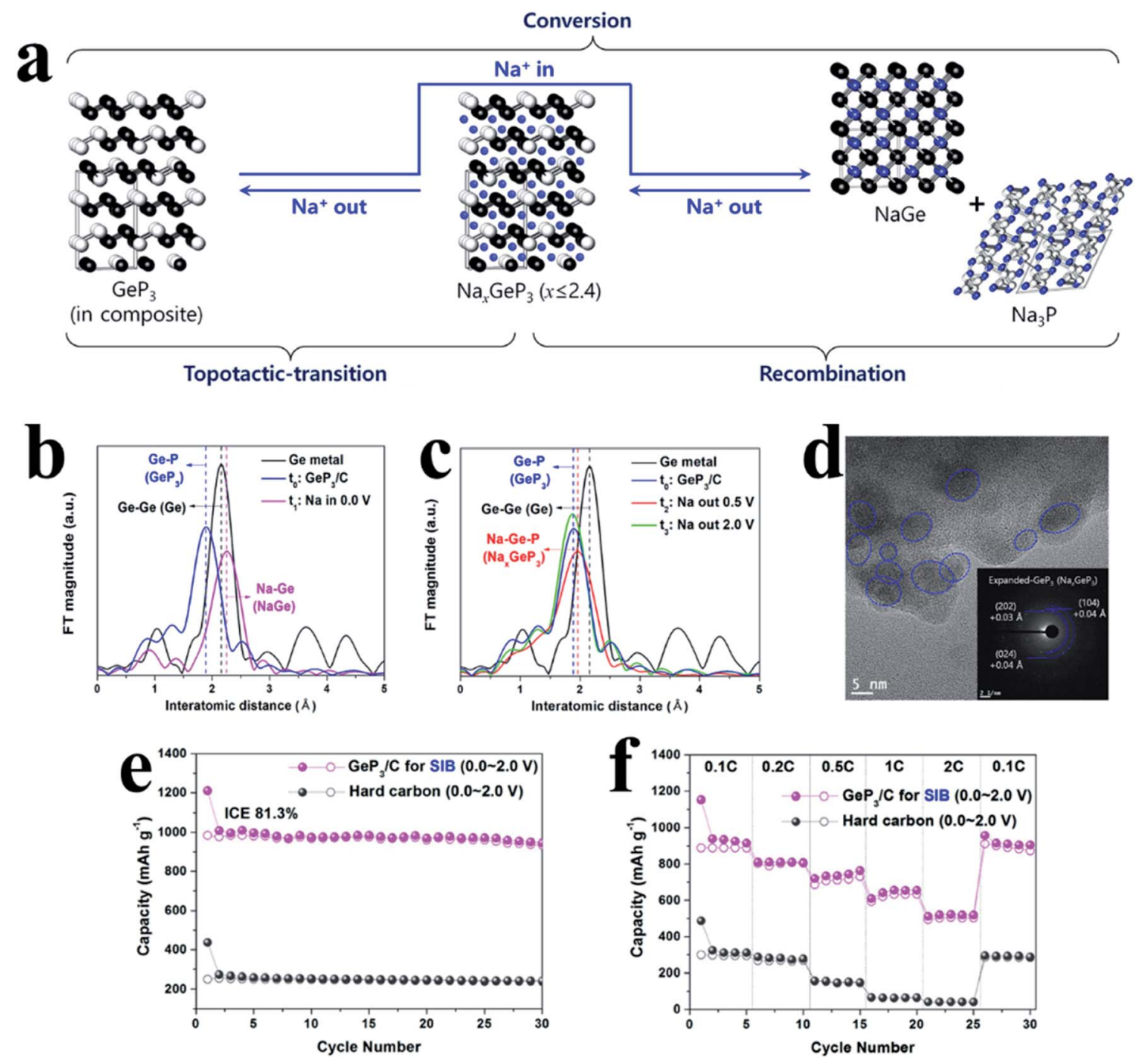

Fig. 29 (a) Schematic diagram of the electrochemically driven crystallographic phase-change mechanism of GeP3 during Na-insertion/ extraction. (b, c) Ex situ EXAFS spectra of the $\mathrm{GeP}_{3}$-based nanocomposite electrode during first Na insertion and first Na-extraction, respectively.

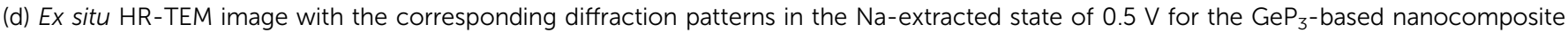
electrode. (e) Cycling performance of the $\mathrm{GeP}_{3}$-based nanocomposite and hard carbon (cycling rate: $50 \mathrm{~mA} \mathrm{~g}^{-1}$ ). (f) Rate capabilities of the $\mathrm{GeP}_{3}$-based nanocomposite $\left(1 \mathrm{C}=950 \mathrm{~mA} \mathrm{~h} \mathrm{~g}^{-1}\right)$ and hard carbon $\left(1 \mathrm{C}=250 \mathrm{~mA} \mathrm{~h} \mathrm{~g}^{-1}\right)$ for the SIB. Reproduced with permission. ${ }^{196}$ Copyright 2018, Elsevier B.V. 
Total:

$$
\mathrm{GeP}_{3}+4 \mathrm{Na}^{+}+4 \mathrm{e}^{-} \leftrightarrow \mathrm{NaGe}+\mathrm{Na}_{3} \mathrm{P}
$$

During Na-insertion, the layer structured $\mathrm{GeP}_{3}$ can be converted to $\mathrm{NaGe}$ and $\mathrm{Na}_{3} \mathrm{P}$. During Na-extraction, however, $\mathrm{Na}_{3} \mathrm{P}$ and NaGe are transformed into $\mathrm{a} \mathrm{Na}_{x} \mathrm{GeP}_{3}(x \leq 2.4)$ phase, which is then recovered to pristine $\mathrm{GeP}_{3}$ with a topotactictransition (Fig. 29a).

Recently, a layered GeP-black $\mathrm{P}$ composite $\left(\mathrm{Ge}_{2} \mathrm{P}_{3}\right)$ as a binary-phase anode for SIBs was prepared by a simple ball milling method ${ }^{264}$ and also showed an excellent Na storage performance. During the milling process, element Ge and commercial RP were converted into GeP and BP (black P); in the meantime, these two products were hybridized to form a layered GeP-BP composite (Fig. 29d and f). The authors proposed that the numerous heterointerfaces between layered GeP and BP could increase the number of reaction sites and enhance the Na-ion and electron transport capability. Coupled with the intrinsic excellent $\mathrm{Na}$ storage capability of GeP and $\mathrm{BP}$, this binary-phase anode showed a reversible capacity of $970 \mathrm{~mA} \mathrm{~h} \mathrm{~g}^{-1}$ at $50 \mathrm{~mA} \mathrm{~g}^{-1}$ with an initial coulombic efficiency of $88 \%$, and retained $890 \mathrm{~mA} \mathrm{~h} \mathrm{~g}^{-1}$ after 100 cycles (Fig. 29e). Moreover, it also exhibited a rate capacity of $275 \mathrm{~mA} \mathrm{~h} \mathrm{~g}^{-1}$ at $5 \mathrm{Ag}^{-1}$, which could recover back nearly to its initial value when the current density was changed back to the initial value of $50 \mathrm{~mA} \mathrm{~g}^{-1}$. This study shows a simple and cost-efficient strategy to prepare GeP and BP in one step, offering excellent possibility for application in practical SIBs. In another study, a GeP anode with a flexible layered structure was successfully synthesized by a simple mechanochemical method. ${ }^{197}$ When tested as the anode for a SIB, the GeP anode delivered an initial discharge/ charge capacity of $900 / 840 \mathrm{~mA} \mathrm{~h} \mathrm{~g}^{-1}$ with an initial coulombic efficiency of up to $93 \%$ and a rate capacity of $360 \mathrm{~mA} \mathrm{~h} \mathrm{~g}^{-1}$ at a current density of $5 \mathrm{~A} \mathrm{~g}^{-1}$. Similar to $\mathrm{GeP}_{3}$, GeP underwent a reversible Na-storage process that involved intercalation, conversion, and alloying. The peculiar self-healing phenomenon was derived from its ultra-low formation energy $(0.19 \mathrm{eV})$ for the reconstruction of the original layered structure, as confirmed by first-principles calculations. The low formation energy also enabled the formation of chemical bonding between layered GeP and graphite, thus achieving an excellent performance as an anode for SIBs.

Overall, germanium phosphides also attract much attention and show great potential as anode materials for SIBs. Despite the high cost of Ge, these Ge-P anodes may still be affordable for large scale application, especially $\mathrm{GeP}_{5}$ which has a low molar ratio of Ge. Although high performances of these $\mathrm{GeP}_{5}$ composite anodes have been achieved in terms of initial coulombic efficiency and specific capacity (especially for $\mathrm{GeP}_{5}$ / $\mathrm{CNT}$ ), up to now, all these $\mathrm{GeP}_{5}$ composites are prepared by the ball milling method and show a large particle size. The large particle size might be a major reason for their insufficient longcycle stability. In addition, the poor rate capability is also a concern for practical application. The $\operatorname{MGeP}_{x}(x \approx 1.6)$ composite reported by Tseng et $a .^{230}$ is the only case where a germanium phosphide anode was prepared by a solvothermal method. Due to the ultrafine nanostructure of this $\mathrm{MGeP}_{x}$, a better rate capability could be obtained. Although the $\mathrm{P}$ content in $\mathrm{GeP}_{3}$ is lower than that in $\mathrm{GeP}_{5}$, it was reported that a superior sodium storage performance could be achieved for $\mathrm{GeP}_{3}$ compared to $\mathrm{GeP}_{5}$ in terms of specific capacity and cycling stability. GeP and its composites also exhibit high performance for Na storage; however, the high molar ratio of Ge may increase the fabrication cost of these GeP anodes, and thus may hinder their practical application.

\subsection{Other metal phosphides}

Other binary metal phosphides have also been studied for SIB anodes. For example, Li et al. ${ }^{\mathbf{2 3 2}}$ synthesized a well-aligned $\mathrm{Zn}_{3} \mathrm{P}_{2}$ nanowire-assembly bundle/Ti foil integrated anode through a facile chemical vapor deposition method and reported that this anode showed high sodium storage performances, delivering a reversible capacity of $\sim 600 \mathrm{~mA} \mathrm{~h} \mathrm{~g}^{-1}$ at $100 \mathrm{~mA} \mathrm{~g}^{-1}$ and a high rate capability of $280 \mathrm{~mA} \mathrm{~h} \mathrm{~g}^{-1}$ at $5 \mathrm{~A} \mathrm{~g}^{-1}$. Huang et al. ${ }^{231}$ also successfully prepared molybdenum phosphide (MoP) nanorods wrapped within a thin carbon layer as a SIB anode material and reported that this MoP electrode exhibited high cycling performances with a discharge capacity of $398.4 \mathrm{~mA} \mathrm{~h} \mathrm{~g}^{-1}$ at a current density of $100 \mathrm{~mA} \mathrm{~g}^{-1}$ after 800 cycles and a remarkable rate capability of $104.5 \mathrm{~mA} \mathrm{~g}^{-1}$ at $1600 \mathrm{~mA} \mathrm{~h} \mathrm{~g}^{-1}$ after 10000 cycles. These low-cost metals such as $\mathrm{Zn}$ and Mo give a competitive option for metal phosphides in fabricating large-scale SIB anodes. In another study, Usui et $a .^{209}$ studied sodiation/desodiation reactions in indium phosphide (InP) anodes which were obtained by ball milling in ionic liquid electrolytes and found that InP could provide phase separation in the first sodiation to form elemental In and P, which could subsequently react with $\mathrm{Na}$ individually. And in the following desodiation process, Na-extraction of NaIn and $\mathrm{Na}_{3} \mathrm{P}$ occurred and a nanostructure of crystalline In nanoparticles dispersed in an amorphous-like P matrix was formed. Based on this Na storage mechanism, InP can provide a theoretical capacity of $730 \mathrm{~mA} \mathrm{~h} \mathrm{~g}^{-1}$ (Fig. 30a-c). This mechanism was also observed in $\mathrm{Sn}_{4} \mathrm{P}_{3}$ anodes. ${ }^{208}$ These researchers also reported that the In phase in this InP anode could relax strain induced by $\mathrm{P}$ volume change and prevent electrical isolation of active material layers, and in addition, the high conductivity could compensate for the poor electronic conductivity of $\mathrm{Na}_{3} \mathrm{P}$ phases created by $\mathrm{P}$ sodiation, allowing for a high capacity of $500 \mathrm{~mA} \mathrm{~h} \mathrm{~g}^{-1}$ after 100 cycles at a current of $50 \mathrm{~mA} \mathrm{~g}$ (Fig. 30d).

\section{Non-metal phosphides}

Many non-metal phosphides also possess the ability to store $\mathrm{Na}$ ions, such as $\mathrm{SiP}_{2}$ and $\mathrm{Se}_{4} \mathrm{P}_{4} \cdot{ }^{233,234}$ Duveau et al. ${ }^{233}$ prepared a $\mathrm{SiP}_{2}$ material through simple ball milling of silicon and phosphorus powders at room temperature and demonstrated potential as a novel anode for SIBs in which the corresponding anode provided a sustained capacity of $572 \mathrm{~mA} \mathrm{~h} \mathrm{~g}^{-1}$ after 15 cycles. Although the reversible capacity is much lower than the theoretical capacity of $1780 \mathrm{~mA} \mathrm{~h} \mathrm{~g}^{-1}$ (considering that $\mathrm{P}$ can 
a

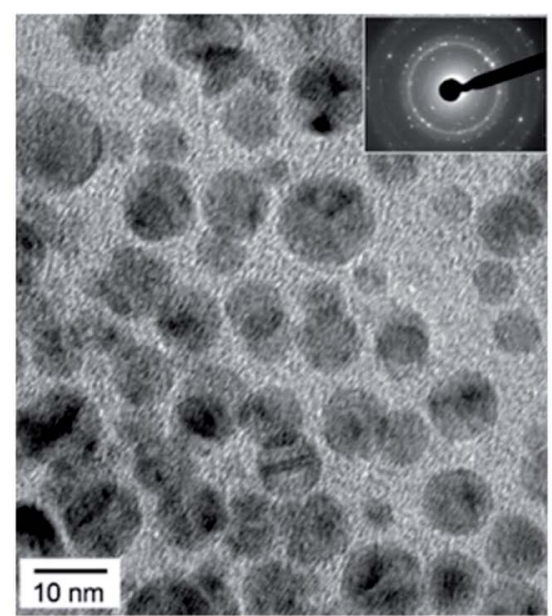

b

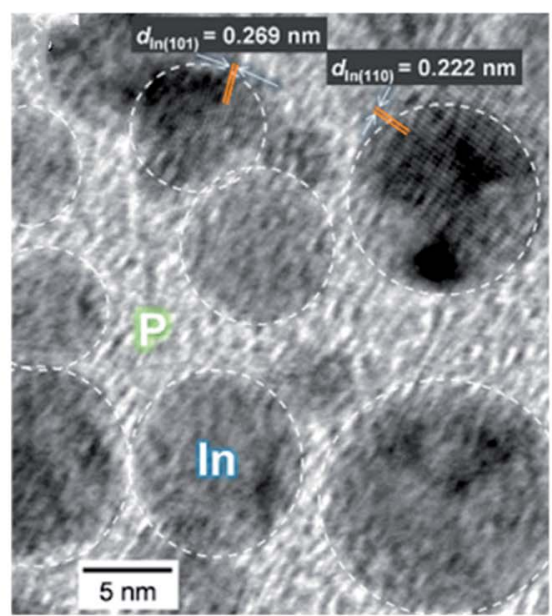

c

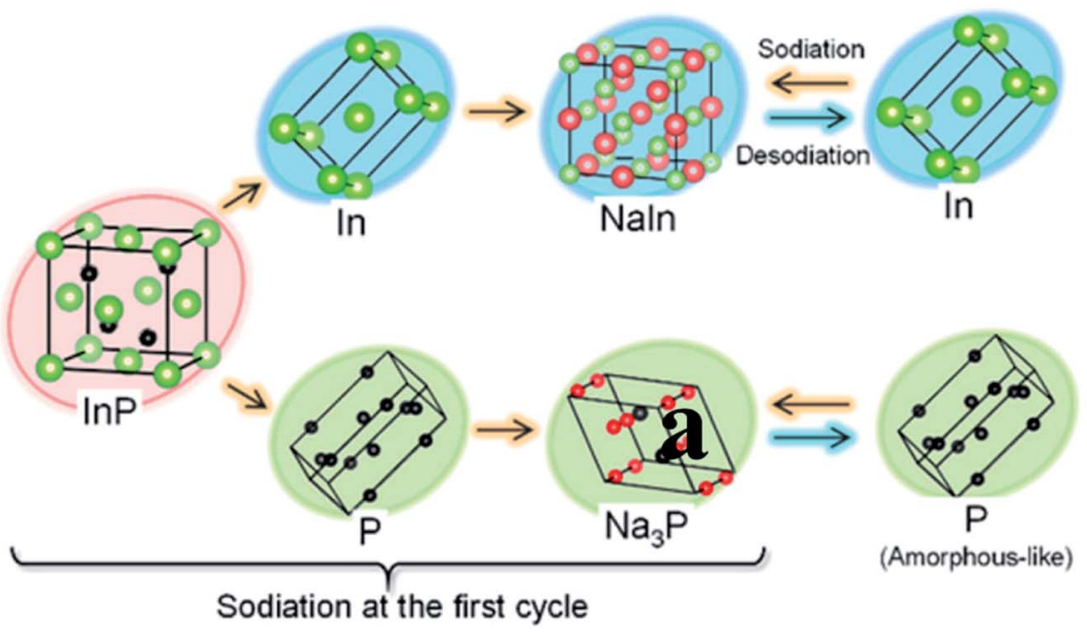

d

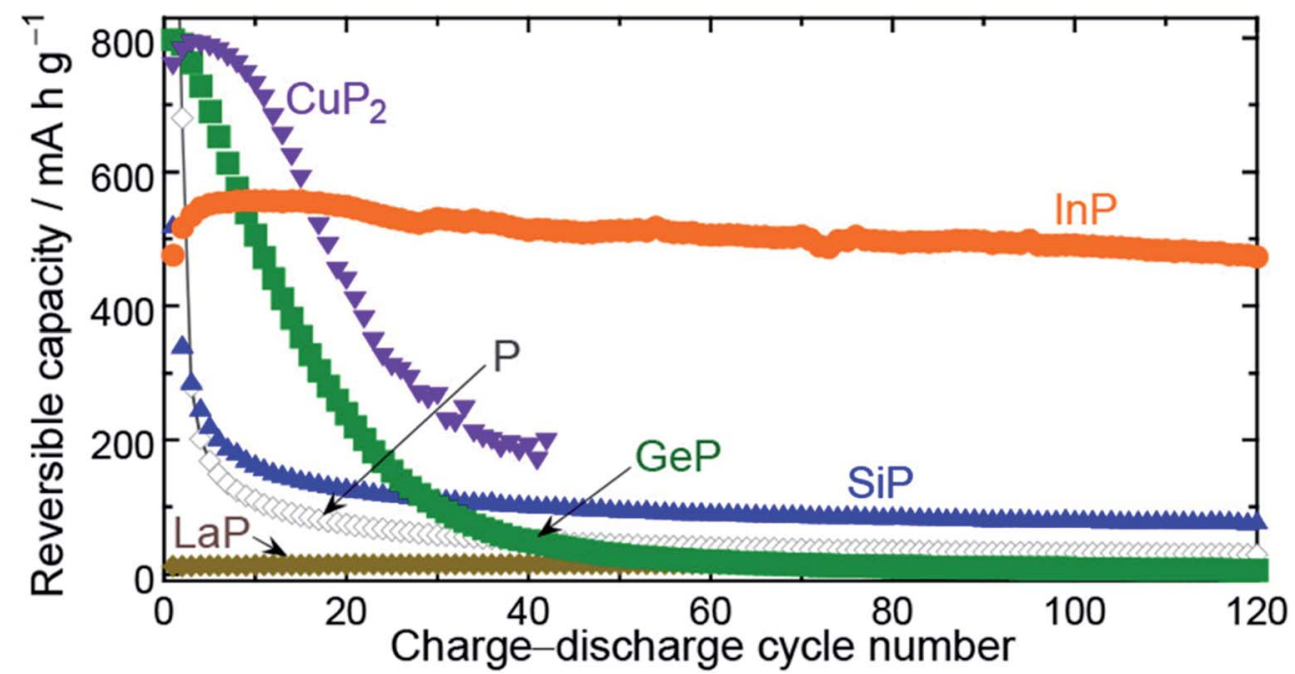

Fig. 30 (a) TEM image of $\operatorname{lnP}$ after the first desodiation. The particle size was $9.3 \pm 1.7 \mathrm{~nm}$. (b) High-magnification TEM image showing crystalline In nanoparticles dispersed in an amorphous-like P matrix. (c) Phase changes of InP in charge/discharge reactions. (d) Anode performances of various phosphide electrodes cycled at a current density of $50 \mathrm{~mA} \mathrm{~g}^{-1}$ in an ionic liquid electrolyte (NaFSA/Py13-FSA). For comparison, results are also shown for the electrode of $\mathrm{P}$ alone. Reproduced with permission. ${ }^{209}$ Copyright 2018, American Chemical Society. 
a

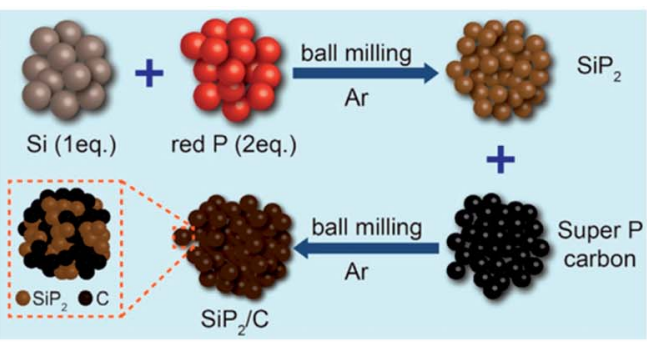

b
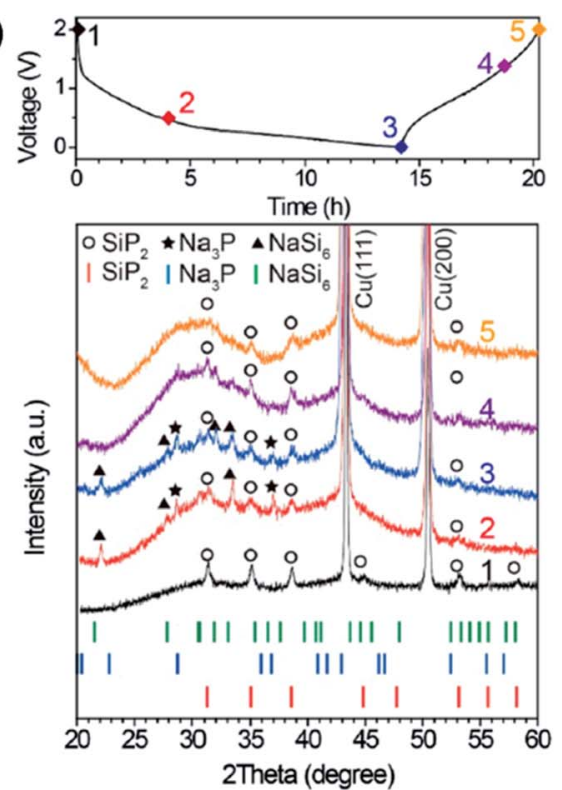
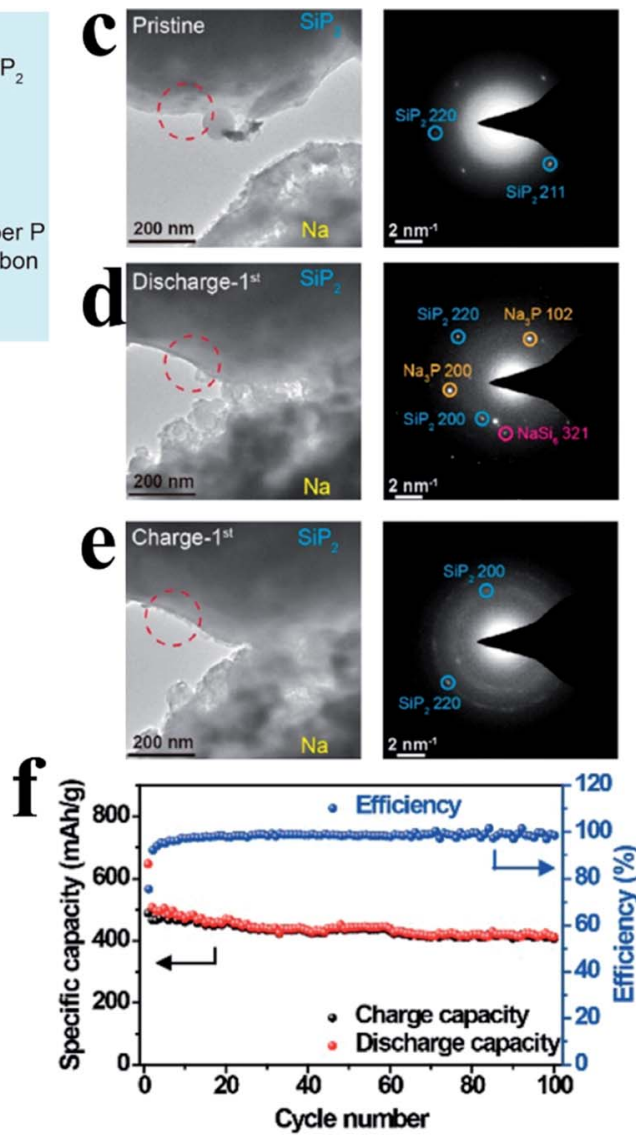

Fig. 31 (a) Schematic illustration of the synthesis process of the $\mathrm{SiP}_{2} / \mathrm{C}$ composite. (b) Ex situ XRD of the $\mathrm{SiP}_{2} / \mathrm{C}$ electrode in different discharge/ charge states in the first cycle. (c-e) In situ TEM investigation of a $\mathrm{SiP}_{2}-\mathrm{Na}$ nanobattery. TEM images of electrodes and the corresponding SAED patterns of the $\mathrm{SiP}_{2}$ electrode in selected regions acquired before battery working (c), when discharged at $-3 \mathrm{~V}(\mathrm{~d})$, and when further charged at $+3 \mathrm{~V}$ (e). (f) Cycle performance of the $\mathrm{SiP}_{2} / \mathrm{C}$ electrode acquired at a current density of $50 \mathrm{~mA} \mathrm{~g}^{-1}$. Reproduced with permission. ${ }^{266}$ Copyright 2019, American Chemical Society.

react with $3 \mathrm{Na}$ to form $\mathrm{Na}_{3} \mathrm{P}$ and that $\mathrm{Si}$ has no electrochemical activity toward sodium), ${ }^{265}$ this pioneering study demonstrates the great potential of $\mathrm{SiP}_{2}$ as a SIB anode material. Recently, Saddique et al. ${ }^{266}$ synthesized a $\mathrm{SiP}_{2} / \mathrm{C}$ composite by a facile ball milling method (Fig. 31a). The well-constructed composite comprised of uniformly distributed $\mathrm{SiP}_{2}$ nanocrystallites within a conductive carbon framework could greatly enhance the electrode conductivity and structural compatibility for repeated sodiation/desodiation conversions, demonstrating a high capacity of $410 \mathrm{~mA} \mathrm{~h} \mathrm{~g}^{-1}$ at $50 \mathrm{~mA} \mathrm{~g}^{-1}$ after 100 cycles (Fig. 31f), and a largely improved cyclability with $80 \%$ capacity retention for 500 cycles. Furthermore, the authors elucidated the reaction mechanism of $\mathrm{SiP}_{2}$ in SIBs by various investigation methods and found that $\mathrm{Si}$ could also electrochemically react with $\mathrm{Na}$, as expressed in the following equations:

$$
\begin{aligned}
\mathrm{SiP}_{2} & \rightarrow \mathrm{Na}_{6} \mathrm{Si}+\mathrm{Na}_{3} \mathrm{P} \text { (discharge) } \\
\mathrm{Na}_{6} \mathrm{Si}+\mathrm{Na}_{3} \mathrm{P} & \rightarrow\left(\mathrm{SiP}_{2}\right)_{\text {crystalline/amorphous }}+\mathrm{P}(\text { charge })
\end{aligned}
$$

This reaction mechanism was evidenced by the ex situ XRD and TEM images (Fig. 31b-e). During the first discharge process, crystalline $\mathrm{SiP}_{2}$ was gradually transformed into $\mathrm{Na}_{6} \mathrm{Si}$ and $\mathrm{Na}_{3} \mathrm{P}$ because of $\mathrm{Na}$ insertion. In the charge process, only parts of $\mathrm{Na}_{6} \mathrm{Si}$ and $\mathrm{Na}_{3} \mathrm{P}$ could reversibly form $\mathrm{SiP}_{2}$, resulting in amorphization of part of $\mathrm{SiP}_{2}$ after full charge. This could be evidenced by the XRD result where the $\mathrm{SiP}_{2}$ peaks could not recover their initial intensities after full charge (Fig. 31b). Although Na storage performance is insufficient, this study demonstrates that $\mathrm{SiP}_{2}$ can also reversibly react with $\mathrm{Na}$. And in view of the low cost and environmental friendliness of both $\mathrm{Si}$ and $\mathrm{P}$, these studies offer the possibility for scalable application of $\mathrm{SiP}_{2}$ or other silicides in practical SIBs.

$\mathrm{Se}_{4} \mathrm{P}_{4}$ is another attractive anode material for SIBs because selenium is active towards $\mathrm{Na}$ and possesses good electrical conductivity and $\mathrm{Se}_{4} \mathrm{P}_{4}$ provides a theoretical capacity of $1217 \mathrm{~mA} \mathrm{~h} \mathrm{~g}^{-1}$ in reactions with $20 \mathrm{Na}$ ions during sodiation. ${ }^{234,267}$ For example, Lu et al. ${ }^{234}$ synthesized an amorphous $\mathrm{Se}_{4} \mathrm{P}_{4}$ composite through a facile mechanical milling technique and reported that this $\mathrm{Se}_{4} \mathrm{P}_{4}$ anode exhibited a high reversible capacity of $1048 \mathrm{~mA} \mathrm{~h} \mathrm{~g}^{-1}$ at $50 \mathrm{~mA} \mathrm{~g}^{-1}$, good cycling stabilities of $804 \mathrm{~mA} \mathrm{~h} \mathrm{~g}^{-1}$ after 60 cycles and outstanding rate capabilities of $724 \mathrm{~mA} \mathrm{~h} \mathrm{~g}^{-1}$ at $500 \mathrm{~mA} \mathrm{~g}^{-1}$ and $332 \mathrm{~mA} \mathrm{~h} \mathrm{~g}^{-1}$ at $3000 \mathrm{~mA} \mathrm{~g}^{-1}$ respectively, which were superior to those of both $\mathrm{P}$ and Se. Furthermore, ex situ XRD, TEM and in situ Raman analysis 
revealed that the reaction mechanism during the charge/ discharge of $\mathrm{Se}_{4} \mathrm{P}_{4}$ was as follows:

$$
\mathrm{Se}_{4} \mathrm{P}_{4}+20 \mathrm{Na}^{+}+20 \mathrm{e}^{-} \leftrightarrow 4 \mathrm{Na}_{3} \mathrm{P}+\mathrm{Na}_{2} \mathrm{Se}
$$

$\mathrm{Se}_{4} \mathrm{P}_{4}$ was converted into $\mathrm{Na}_{2} \mathrm{Se}$ and $\mathrm{Na}_{3} \mathrm{P}$ after full discharge and subsequently reformed to amorphous $\mathrm{Se}_{4} \mathrm{P}_{4}$ in the subsequent charging process. Furthermore, a full cell with a $\mathrm{Se}_{4} \mathrm{P}_{4}$ anode and a $\mathrm{Na}_{3}\left(\mathrm{VO}_{0.5}\right)_{2}\left(\mathrm{PO}_{4}\right)_{2} \mathrm{~F}_{2} / \mathrm{C}$ cathode delivered a discharge capacity of $985 \mathrm{~mA} \mathrm{~h} \mathrm{~g}^{-1}$ (based on the mass of $\mathrm{Se}_{4} \mathrm{P}_{4}$ ) and an average output voltage of $\sim 2.5 \mathrm{~V}$. Cao et al. ${ }^{268}$ also successfully synthesized $\mathrm{P}_{4} \mathrm{Se}_{3}$ microparticles (higher $\mathrm{P}$ content as compared with $\mathrm{Se}_{4} \mathrm{P}_{4}$ ) through simple heating of selenium and amorphous RP at low temperatures (Fig. 32a and b) and reported that these orthorhombic-phase microparticles as a SIB anode could exhibit a high reversible capacity of $654 \mathrm{~mA} \mathrm{~h} \mathrm{~g}^{-1}$ at
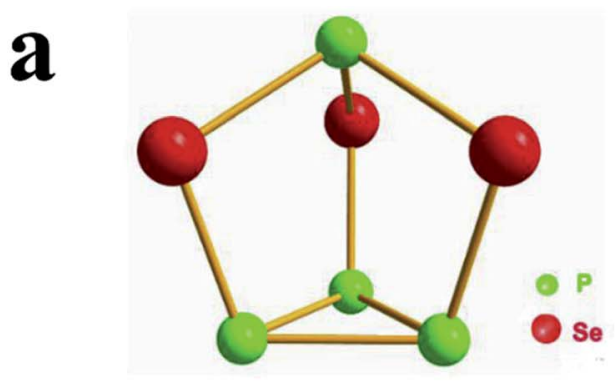

b
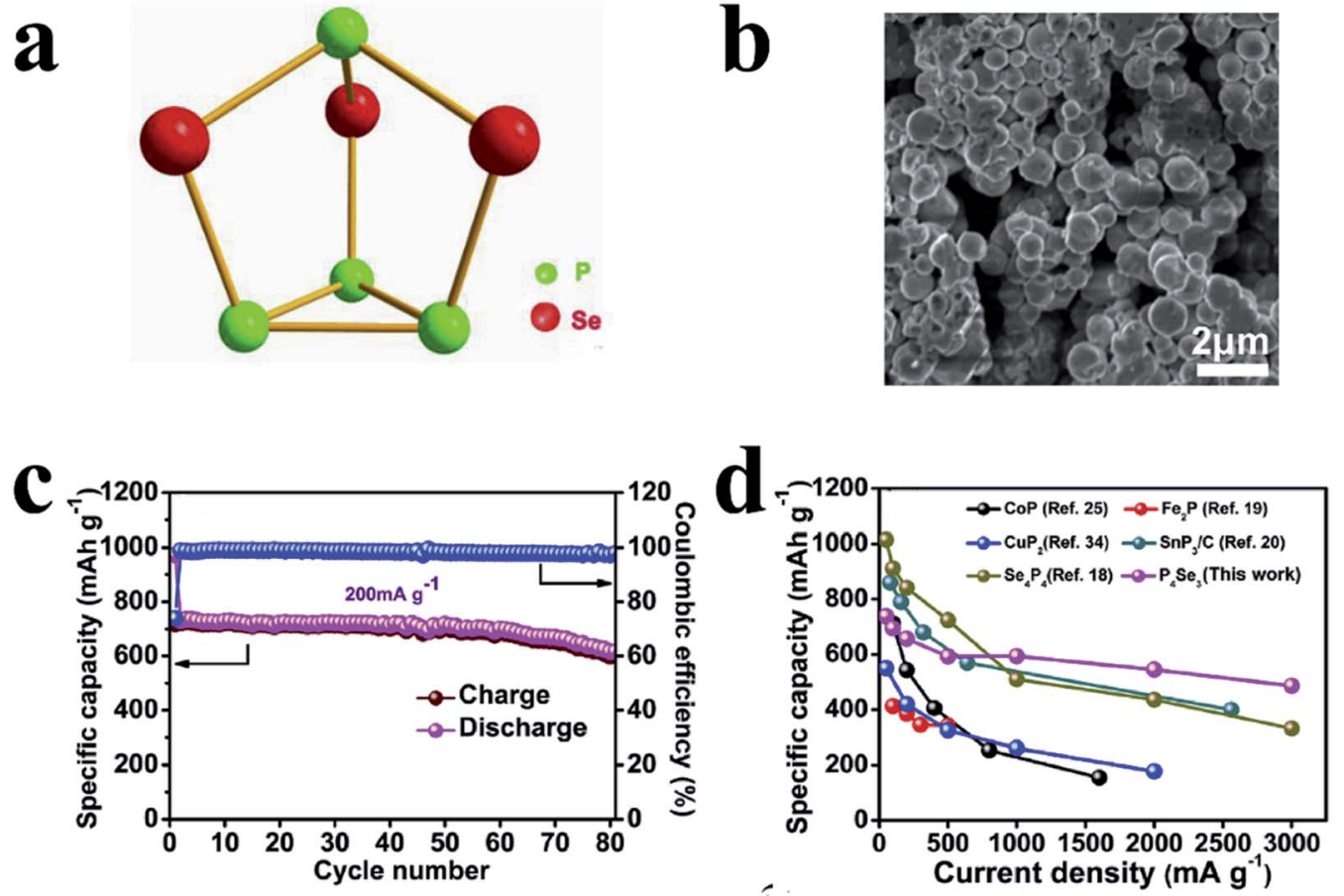

e
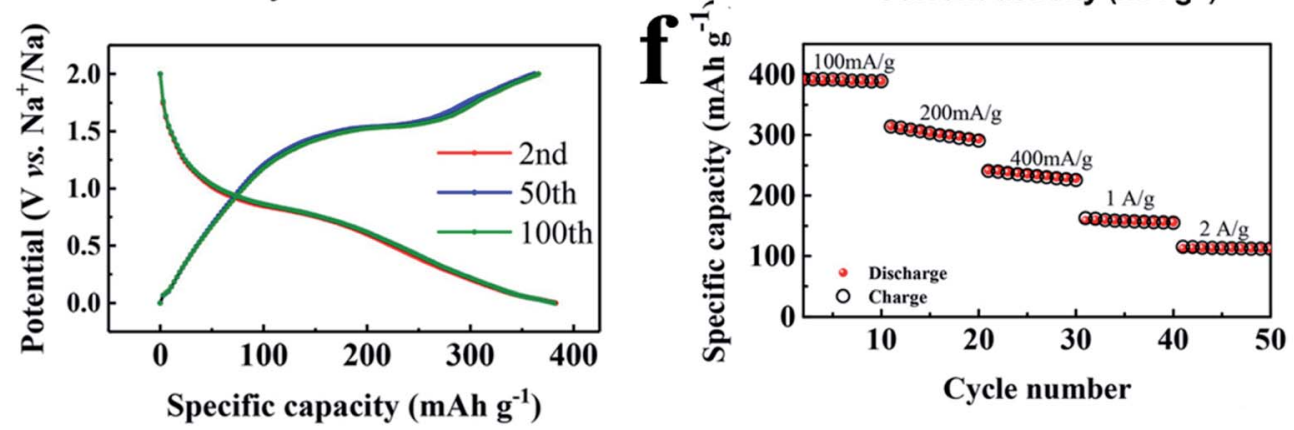

g

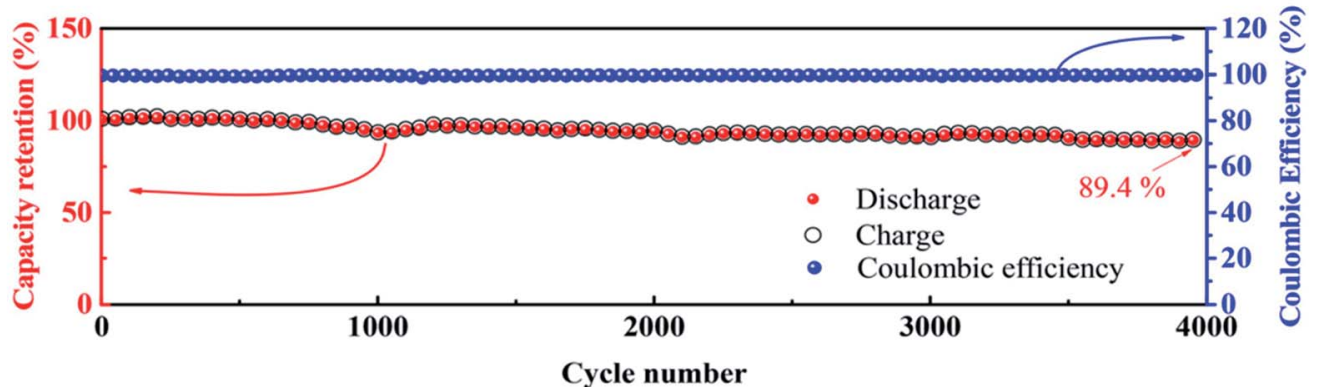

Fig. 32 (a) Illustration of the cage structure of $\mathrm{P}_{4} \mathrm{Se}_{3}$. (b) SEM image of $\mathrm{P}_{4} \mathrm{Se}_{3}$. (c) Cycling stability tested at $200 \mathrm{~mA} \mathrm{~g}^{-1}$ and coulombic efficiency of $\mathrm{P}_{4} \mathrm{Se}_{3}$ anodes. (d) Rate capability comparisons of reported studies and this study. Reproduced with permission. ${ }^{268}$ Copyright 2018 , Elsevier B.V. (e and f) Electrochemical performances of the $\mathrm{P}_{2} \mathrm{~S}_{5} / \mathrm{C}$ composite after 70 hours of ball milling. (e) Typical potential profiles of the second, fifth and 100th cycles. (f) Rate capability of the $\mathrm{P}_{2} \mathrm{~S}_{5} / \mathrm{C}$ composite. (g) Performance and coulombic efficiency at $2000 \mathrm{~mA} \mathrm{~g}^{-1}$. Reproduced with permission. ${ }^{235}$ Copyright 2017, American Chemical Society. 
$200 \mathrm{~mA} \mathrm{~g}^{-1}$ after 70 cycles and high rate capabilities with a reversible capacity of $486 \mathrm{~mA} \mathrm{~h} \mathrm{~g}^{-1}$ at $3 \mathrm{~A} \mathrm{~g}^{-1}$ (Fig. $32 \mathrm{c}$ and d). Here, the researchers attributed this high electrochemical performance to the formation of more conductive $\mathrm{Na}_{2} \mathrm{Se}$ and $\mathrm{Se}$ $\left(\sim 10^{-6}\right.$ and $\sim 10^{-5} \mathrm{~S} \mathrm{~cm}^{-1}$ ) during cycling and the dominance of capacitive behavior, all of which could accelerate kinetic behaviors.

In another example, Li et al. ${ }^{235}$ prepared a $\mathrm{P}_{2} \mathrm{~S}_{5} / \mathrm{C}$ composite using a simple and low-cost high energy ball milling method and investigated its reaction mechanisms with Na. Here, the researchers found that during the ball milling process, crystalline $\mathrm{P}_{2} \mathrm{~S}_{5}$ transformed into amorphous $\mathrm{P}_{2} \mathrm{~S}_{5}$ to form an amorphous $\mathrm{P}_{2} \mathrm{~S}_{5} / \mathrm{C}$ composite that could exhibit a safe average potential of $0.82 \mathrm{~V}$, and the reaction mechanism of the first discharge process may be based on conversion and alloying processes as follows:

Conversion:

$$
10 \mathrm{Na}^{+}+10 \mathrm{e}^{-}+\mathrm{P}_{2} \mathrm{~S}_{5} \rightarrow 5 \mathrm{Na}_{2} \mathrm{~S}+2 \mathrm{P}
$$

Alloying:

$$
6 \mathrm{Na}^{+}+6 \mathrm{e}^{-}+2 \mathrm{P} \rightarrow 5 \mathrm{Na}_{3} \mathrm{P}
$$

As a result, an anode of this $\mathrm{P}_{2} \mathrm{~S}_{5} / \mathrm{C}$ material delivered a high reversible capacity of $396 \mathrm{~mA} \mathrm{~h} \mathrm{~g}^{-1}$ at $100 \mathrm{~mA} \mathrm{~g}^{-1}$, a high capacity retention of $99.5 \%$ after 100 cycles at $100 \mathrm{~mA} \mathrm{~g}^{-1}$ and a moderate capacity of $114 \mathrm{~mA} \mathrm{~h} \mathrm{~g}^{-1}$ at $2 \mathrm{~A} \mathrm{~g}^{-1}$ at a high rate (Fig. 32e and f). In addition, a high capacity retention of $89.4 \%$ was achieved even after the amorphous $\mathrm{P}_{2} \mathrm{~S}_{5} / \mathrm{C}$ was cycled over 4000 times at $2 \mathrm{~A} \mathrm{~g}^{-1}$ (Fig. 32g). However, the initial coulombic efficiency (ICE) of this anode is not high $(<40 \%)$, which is insufficient for practical SIBs. Even so, the low cost and facile $\mathrm{P}_{2} \mathrm{~S}_{5}$ still shows significant potential for sodium storage if the issue of low ICE can be well addressed.

Theoretical calculations and predictions are also important in the search for new materials for SIB anode applications. For example, Zhao et al. $^{269}$ identified a hitherto unknown $\mathrm{P}_{3} \mathrm{C}$ monolayer with a puckered honeycomb structure using firstprinciples swarm-intelligence structural calculations in which they predicted that the theoretical capacity of $\mathrm{P}_{3} \mathrm{C}$ as a SIB anode could reach $1022 \mathrm{~mA} \mathrm{~h} \mathrm{~g}^{-1}$ and that the acceptable barrier energy and lower open-circuit voltage could ensure good rate capability and safety in practical applications. Here, the researchers attributed the high performances to the unique arrangement of two types of hexagon rings that could produce highly cohesive energy and thermodynamic stability, making $\mathrm{P}_{3} \mathrm{C}$ monolayers a promising $2 \mathrm{D}$ material for SIB applications.

\section{Ternary phosphides}

Ternary phosphides are a class of novel phosphide materials in which the synergistic effects of different elements may enhance electron/ion conductivity and mechanical stability, and provide richer redox reactions, or bring about other beneficial effects on SIB anode performances. ${ }^{270}$ For example, Liang et al. ${ }^{236}$ prepared $2 \mathrm{D} \mathrm{MPS}_{3}(\mathrm{M}=\mathrm{Fe}, \mathrm{Co}, \mathrm{Ni})$ nanosheets using an efficient solid- state method in which the $\mathrm{MPS}_{3}$ single-crystal nanosheets were exposed at the $(00 l)$ facet and possessed an average lateral size of $\approx 200 \mathrm{~nm}$ with an average thickness of $\approx 18 \mathrm{~nm}$. And due to the layered structure, good crystallinity, large surface area, excellent electrical conductivity and high pseudocapacitance from surface reactions, the $\mathrm{MPS}_{3}$ nanosheets provided superior performances as anode materials in SIBs; for example, $\mathrm{NiPS}_{3}$ nanosheets could deliver a high initial coulombic efficiency of $70 \%$ and a reversible capacity of 910 and $316 \mathrm{~mA} \mathrm{~h} \mathrm{~g}^{-1}$ at current densities of 0.05 and $5 \mathrm{Ag}^{-1}$, respectively, and a capacity retention of $88 \%$ over 200 cycles at $2.0 \mathrm{~A} \mathrm{~g}^{-1}$. In addition, the interlayer spacing of these $\mathrm{MPX}_{3}$ nanosheets could be expanded by intercalating guest propylamine molecules, leading to an improved $\mathrm{Na}$ storage performance (1090 and $536 \mathrm{~mA} \mathrm{~h} \mathrm{~g}^{-1}$ at 0.05 and $5.0 \mathrm{~A} \mathrm{~g}^{-1}$ respectively for intercalated $\mathrm{NiPS}_{3}$ nanosheets). These superior performances as well as the facile preparation method and the low cost of $\mathrm{Fe}, \mathrm{Ni}, \mathrm{P}$ and $\mathrm{S}$ indicate that these $2 \mathrm{D} \mathrm{MPS}_{3}(\mathrm{M}=\mathrm{Fe}, \mathrm{Co}, \mathrm{Ni})$ nanosheet composites are promising candidates for practical SIBs. In another example, Marino et al. ${ }^{271}$ synthesized a ternary $\mathrm{Ni}_{2} \mathrm{SnP}$ composite as an anode material for SIBs using a simple ball milling method and reported that $\mathrm{Ni}_{2} \mathrm{SnP}$ only exhibited a reversible specific charge capacity of $\sim 200 \mathrm{~mA} \mathrm{~h} \mathrm{~g}{ }^{-1}$ in SIBs, which was much lower than that of the corresponding Li-ion battery. The researchers found that in SIBs, only phosphorus was active in the electrochemical reaction, unlike in the case of binary Sn-based phosphides such as $\mathrm{Sn}_{3} \mathrm{P}_{4}$ (ref. 91) in which Sn was also active towards Na. Here, the researchers suggested that this reaction mechanism could explain the poor cyclability of anode materials for SIBs and that in particular, the low conductivity of $\mathrm{P}$ could result in the formation of only small proportions of $\mathrm{Na}_{3} \mathrm{P}$. The insufficient sodium storage performance of the $\mathrm{Ni}_{2} \mathrm{SnP}$ composite may hinder its application in SIBs; however, this study gives a suggestion that the total or partial recombination of the pristine phase is crucial to the electrochemical performance of ternary electrode materials. Lan et $a .^{237}$ prepared pure phase ternary phosphide-copper tin phosphide $\left(\mathrm{Cu}_{4} \mathrm{SnP}_{10}\right)$ nanowires by a solution-liquid-solid growth method and investigated the performance of these composites as SIB anodes. The researchers found that $\mathrm{Cu}$ incorporation could effectively alleviate $\mathrm{Sn}$ aggregation in anodes during charge/discharge cycles, as $\mathrm{Sn}$ aggregation was considered to be a major reason for the reduced cycling performances in $\mathrm{Sn}-\mathrm{P}$ compounds. And a composite of $\mathrm{Cu}_{4} \mathrm{SnP}_{10}$ nanowires combined with multiwalled carbon nanotubes delivered a stable capacity of $512 \mathrm{~mA} \mathrm{~h} \mathrm{~g}{ }^{-1}$ after 100 cycles at a current density of $100 \mathrm{~mA} \mathrm{~g}^{-1}$ and a rate capacity of $412 \mathrm{~mA} \mathrm{~h} \mathrm{~g}^{-1}$ at $1 \mathrm{~A} \mathrm{~g}^{-1}$. Furthermore, Liu et al. ${ }^{238}$ synthesized a ball milled $\mathrm{FeSi}_{4} \mathrm{P}_{4}$ composite as a SIB anode material and reported a reversible capacity of $180 \mathrm{~mA} \mathrm{~h} \mathrm{~g}^{-1}$ at $100 \mathrm{~mA} \mathrm{~g}^{-1}$ with a capacity retention of $99 \%$ after 100 cycles. Although the specific capacity is low, the high short-term cycle stability is quite surprising.

In another study, Wang et al. ${ }^{270}$ prepared a composite of holey-structured $2 \mathrm{D} \mathrm{Ni}_{1.5} \mathrm{Co}_{0.5} \mathrm{P}_{x}$ nanosheets as a SIB anode material through a simple solution method and a subsequent phosphorization process. Then these as-prepared 2D holeystructured $\mathrm{Ni}_{1.5} \mathrm{Co}_{0.5} \mathrm{P}_{x}$ nanosheets were subsequently 

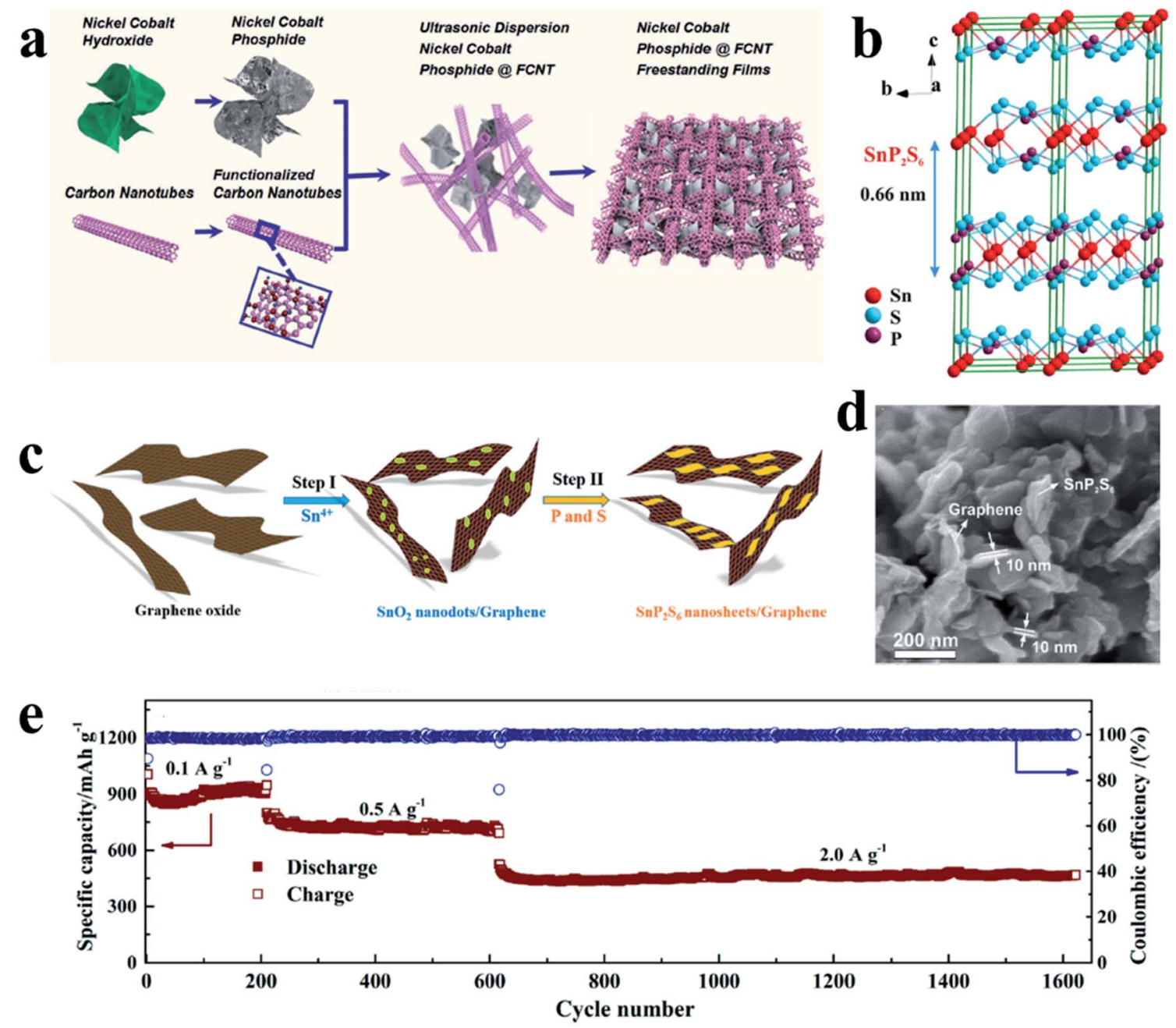

Fig. 33 (a) Schematic diagram of the synthesis of NCP@FCNT-FS free-standing films. Reproduced with permission. ${ }^{270}$ Copyright 2018 , WILEY$\mathrm{VCH}$. (b) Crystal model showing the asymmetric-layered structure of $\mathrm{SnP}_{2} \mathrm{~S}_{6}$. (c) Schematic illustration of the in situ growth of ultrathin $\mathrm{SnP}_{2} \mathrm{~S}_{6}$ nanosheets on graphene. (d) SEM image of the SPS/G hybrid. (e) Long-term cycling performance at current densities of $0.1,0.5$, and $2.0 \mathrm{~A} \mathrm{~g}^{-1}$. Reproduced with permission. Copyright 2018, American Chemical Society.

hybridized with surface-functionalized carbon nanotubes (CNTs) to form a lightweight, free-standing and binder-free integrated flexible electrode (Fig. 33a). The researchers reported that the synergistic effects of $\mathrm{Co}$ and $\mathrm{Ni}$ atoms could enhance charge transfer and promote the release of more capacity as compared with single metal phosphides. In addition, they also suggested that the connected CNT network could affect the formation of conversion reaction products by forming a film structure rather than big-sized microspheres, which could effectively alleviate volumetric changes. As a result, this flexible anode achieved a reversible capacity of $496.4 \mathrm{~mA} \mathrm{~h} \mathrm{~g}^{-1}$ at $0.5 \mathrm{C}$ and a good rate capacity of $276.1 \mathrm{~mA} \mathrm{~h} \mathrm{~g}^{-1}$ at $8 \mathrm{C}$. However the high cost of CNTs may increase the fabrication cost of this composite and thus hinder its practical application especially for large-scale energy storage systems. Nevertheless, the flexibility of this anode makes it very suitable for wearable products. In addition, this free-standing and binder-free integrated electrode is also beneficial to increasing the volumetric specific capacity and reducing the fabrication cost. Cheng et al. ${ }^{239}$ designed a strategy to in situ coat a tin-phosphorusoxygen (SnPO) composite with reduced graphene oxide (rGO) and reported that the coating protection could not only increase electrical conductivity, but also buffer volume expansion and suppress the pulverization of electrode materials during cycling. As a result, the $\mathrm{SnPO} / \mathrm{rGO}$ composite delivered an initial discharge/charge capacity of $843 \mathrm{~mA} \mathrm{~h} \mathrm{~g}^{-1} / 450 \mathrm{~mA} \mathrm{~h} \mathrm{~g}{ }^{-1}$ at a current density of $50 \mathrm{~mA} \mathrm{~g}{ }^{-1}$ and retained a reversible discharge capacity of $\sim 420 \mathrm{~mA} \mathrm{~h} \mathrm{~g}{ }^{-1}$ after 100 cycles with a rate performance with a capacity of $200 \mathrm{~mA} \mathrm{~h} \mathrm{~g}^{-1}$ at a current density of $2000 \mathrm{~mA} \mathrm{~g}^{-1}$.

Recently, a composite of $2 \mathrm{D}$ ternary tin thiophosphate $\left(\mathrm{SnP}_{2} \mathrm{~S}_{6}\right)$ nanosheets $(\sim 10 \mathrm{~nm}$ thickness) grown on graphene (denoted as the SPS/G hybrid) was also demonstrated as an intriguing anode for SIBs (Fig. 33b-d). ${ }^{272}$ Benefiting from the 2D hetero-structural nanojunction and compositional advantages, the SPS/G hybrid showed good electrical conductivity and mechanical resilience to realize rapid ion and electron transfer as well as accommodation of volume change during the 
Table 3 Advantages and disadvantages of different preparation methods for RP anodes

\begin{tabular}{|c|c|c|c|}
\hline Preparation methods & Advantages & Disadvantages & Reference \\
\hline Ball milling & $\begin{array}{l}\text { Simple/facile } \\
\text { Large-scale }\end{array}$ & Uneven/big particle size $(\sim \mu \mathrm{m})$ & 82 and 121 \\
\hline Vaporization-condensation & $\begin{array}{l}\text { Uniform/small size } \\
\text { Intimate contact with host } \\
\text { materials } \\
\text { Well-controlled nanostructure }\end{array}$ & $\begin{array}{l}\text { Low P loading ratio } \\
\text { Uncontrollable distribution }\end{array}$ & 76,85 and 131 \\
\hline $\begin{array}{l}\text { Novel methods (solution method and solvothermal } \\
\text { method } \\
\text { Carbothermic reduction) }\end{array}$ & $\begin{array}{l}\text { Controllable size } \\
\text { Refined nanostructure }\end{array}$ & $\begin{array}{l}\text { Simplex morphology (particle or } \\
\text { sphere) } \\
\text { Toxic reagent involved }\end{array}$ & $\begin{array}{l}87,127,144 \text { and } \\
145\end{array}$ \\
\hline
\end{tabular}

electrochemical process. As a result, the SPS/G hybrid anode exhibited a high reversible capacity $\left(1230 \mathrm{~mA} \mathrm{~h} \mathrm{~g}{ }^{-1}\right.$ at $\left.50 \mathrm{~mA} \mathrm{~g}^{-1}\right)$, superior rate capability $\left(200 \mathrm{~mA} \mathrm{~h} \mathrm{~g}{ }^{-1}\right.$ at $\left.15 \mathrm{~A} \mathrm{~g}^{-1}\right)$, and an exceptional capacity retention of $76 \%$ after 1000 cycles at $2.0 \mathrm{~A} \mathrm{~g}^{-1}$ (Fig. 33e). A full cell based on this anode also exhibited an excellent performance, affording a capacity of $470 \mathrm{~mA} \mathrm{~h} \mathrm{~g}^{-1}$ at $30 \mathrm{~mA} \mathrm{~g}^{-1}$ (on the basis of anode weight) and a good cycling capacity of $360 \mathrm{~mA} \mathrm{~h} \mathrm{~g}{ }^{-1}$ at $150 \mathrm{~mA} \mathrm{~g}^{-1}$ after 50 cycles corresponding to a retention of $90.6 \%$. Due to the superior sodium storage performance, the low-cost of Sn, P and S, and the facile and scalable solid-state preparation route, this SPS/G hybrid can have great potential for practical SIBs.

The combination of different kinds of metal phosphides is an interesting and effective strategy to improve performances as SIB anodes. For example, Li et al. ${ }^{75}$ synthesized a unique coreshell porous $\mathrm{FeP} @ \mathrm{CoP}$ phosphide microcube interconnected with reduced graphene oxide (RGO) nanosheets (RGO@CoP@FeP) through a solution method combined with a lowtemperature phosphorization process. The researchers reported that the FeP@CoP core-shell structure could provide enough cushion space for volume change and shorten $\mathrm{Na}^{+}$ diffusion paths. In addition, the interconnected RGO nanosheets and carbon layers wrapped on the FeP core cubes could build a conductive highway to enhance charge transfer kinetics, leading to a reversible capacity of $551.4 \mathrm{~mA} \mathrm{~h} \mathrm{~g}^{-1}$ in the first cycle and a capacity of $456.2 \mathrm{~mA} \mathrm{~h} \mathrm{~g}^{-1}$ maintained in the 200th cycle. In this study, the combination strategy enables facile preparation of this sophisticated core-shell structure, and thus provides an improved sodium storage performance. Zhang et al. ${ }^{273}$ ball milled a mixture of elementary $\mathrm{Sn}, \mathrm{Sb}, \mathrm{P}$, and $\mathrm{C}$, and obtained a $\mathrm{Sn}_{5} \mathrm{SbP}_{3} / \mathrm{C}$ powder composite which consisted of micrometric agglomerates of active $\mathrm{Sn}_{4} \mathrm{P}_{3}$, SnSb and Sn nanoparticles. Here, the researchers reported that the carbon in the composites not only acted as a conducting matrix, but also enhanced the ball milling efficiencies and extended electrode cycle lifespans. In addition, each of the active $\mathrm{Sn}_{4} \mathrm{P}_{3}, \mathrm{SnSb}$ and Sn phases in the composite could function mutually as a buffer for one another. And as a result, this ternary composite SIB anode delivered a capacity of $352 \mathrm{~mA} \mathrm{~h} \mathrm{~g}^{-1}$ at a current density of $2 \mathrm{~A} \mathrm{~g}^{-1}$, which was notably higher than that of binary $\mathrm{Sn}_{4} \mathrm{P}_{3} / \mathrm{C}$ and $\mathrm{SnSb} / \mathrm{C}$ composites produced under the same conditions. In another study, ${ }^{274}$ a self-supporting three-dimensional (3D) composite of $\mathrm{Cu}_{3} \mathrm{P}$ and $\mathrm{Co}_{2} \mathrm{P}$ interconnected by $\mathrm{N}$-doped $\mathrm{C}$ fibers $\left(\mathrm{Cu}_{3} \mathrm{P}-\mathrm{Co}_{2} \mathrm{P} / \mathrm{N}-\mathrm{C}\right)$ was prepared by a simple electrospinning method. The synergistic effects between $\mathrm{Cu}_{3} \mathrm{P}$, $\mathrm{Co}_{2} \mathrm{P}$, and $\mathrm{N}$-doped carbon could increase the electrical conductivity and active sites, ensuring more ion storage. The $\mathrm{Cu}_{3} \mathrm{P}-\mathrm{Co}_{2} \mathrm{P} / \mathrm{N}-\mathrm{C}$ anode for SIBs delivered high initial discharge/ charge capacities of $429.5 / 321.2 \mathrm{~mA} \mathrm{~h} \mathrm{~g}^{-1}$ accompanied by a high ICE of $74.8 \%$, as well as a stable capacity of around $166.4 \mathrm{~mA} \mathrm{~h} \mathrm{~g}^{-1}$ after 50 cycles. As the Na storage performance of this anode was inferior to its Li storage performance, it seemed to be more suitable for application in LIBs rather than in SIBs. Nevertheless, this novel nanostructure as well as the corresponding preparation method can still give inspiration for future design of SIB anode materials. Table 3 summarizes the advantages and disadvantages of different preparation methods for RP anodes. Table 4 summarizes some basic properties of RP, $\mathrm{BP}$ and metal phosphides, as well as the advantages and disadvantages of these P-based materials used as anodes for SIBs.

\section{Summary, challenges and future research directions}

\subsection{Summary}

Sodium-ion batteries are promising alternatives to lithium-ion batteries and have attracted considerable attention due to the abundant availability of sodium and similar electrochemical properties to lithium as well as their great potential to meet the increasing demand for large-scale energy storage systems. Recently, phosphorus-based materials such as red phosphorus and metal/nonmetal phosphides have been considered as the most promising candidates as anodes for SIBs and attracted much research effort. Therefore, to facilitate the further research and development of these materials, this review has comprehensively discussed the status of phosphorus-based materials as anodes for sodium-ion batteries, including red/ black phosphorus, phosphorene, metal/nonmetal-phosphides and ternary phosphides, in which the material design, synthesis strategy, structural/morphology characterization, sodium storage mechanism and electrochemical performance were analyzed. In general, the combination of red phosphorus with carbon or other materials is an effective approach to enhance the conductivity of the anode and to accommodate large volume change during charge/discharge cycles, thus leading to improved specific capacities, rate performances and 


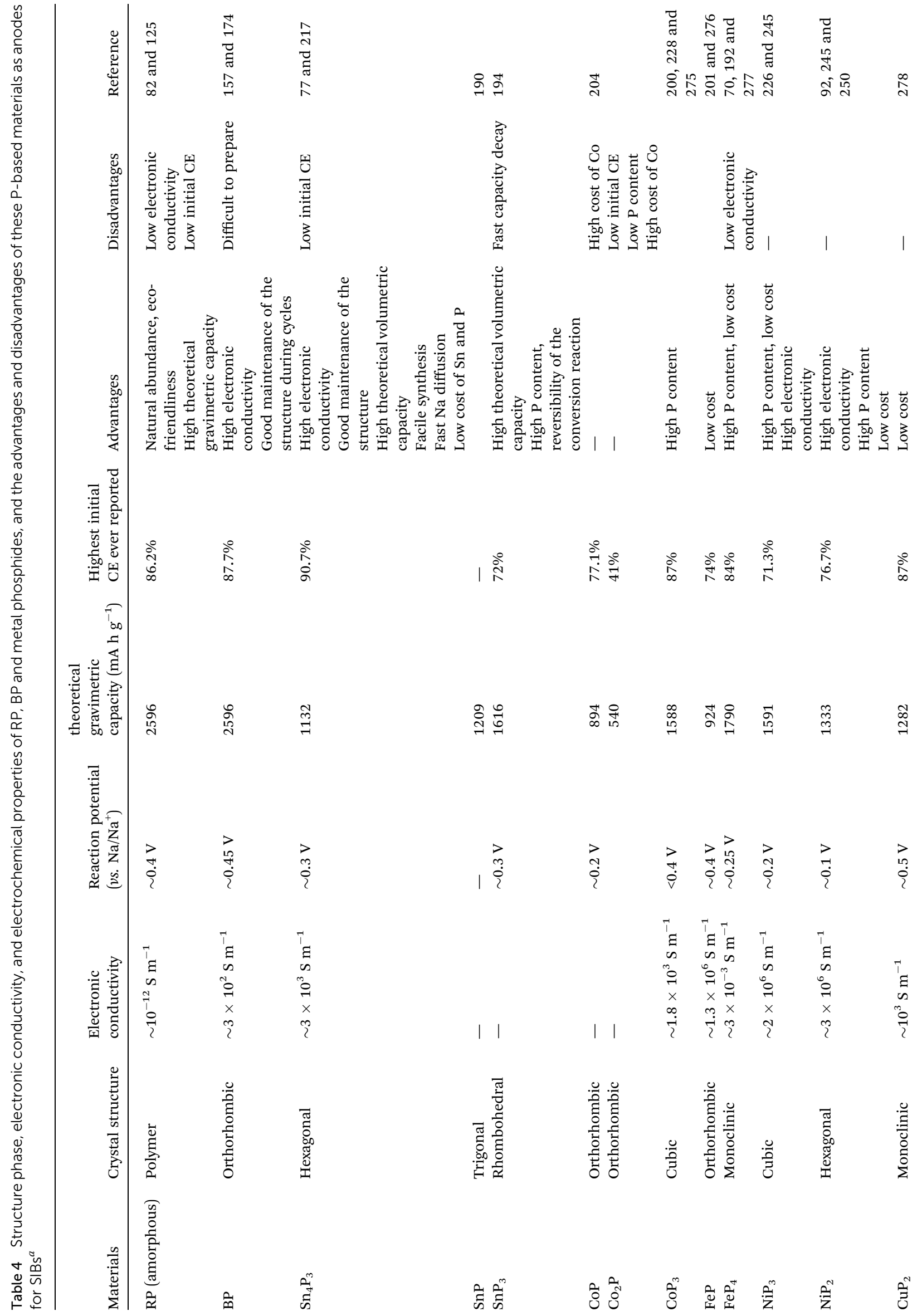




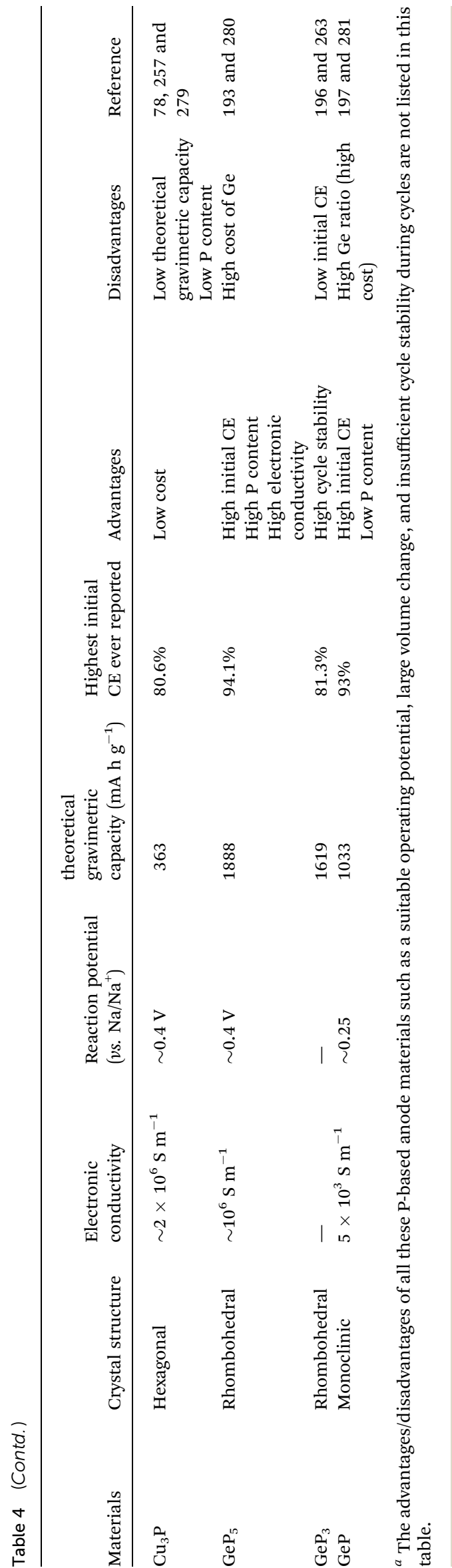

durability. Various red phosphorus nanostructures/composites can be obtained through conventional ball milling or vaporization/condensation techniques and new strategies such as solution-based methods with well-controlled sizes/ morphologies are emerging. Layer-structured black phosphorus and phosphorene also show great potential as anode materials as 2D materials, and many nanostructures/ composites of $\mathrm{BP} /$ phosphorene materials have been explored for sodium storage and a comprehensive Na storage mechanism of BP was presented. Metal phosphides show higher electronic conductivities than red phosphorus and are more available than $\mathrm{BP} /$ phosphorene. Many nanostructures/ composites of metal phosphides, including $\mathrm{Fe}-\mathrm{P}$, Co-P, Ni-P, $\mathrm{Sn}-\mathrm{P}, \mathrm{Cu}-\mathrm{P}$ and $\mathrm{Ge}-\mathrm{P}$, have been successfully synthesized and demonstrate excellent rate capabilities and cycle stabilities. Non-metal phosphides and ternary phosphides including metal-metal phosphides and metal-nonmetal phosphides have also been explored as anodes of sodium-ion batteries with some promising results obtained.

\subsection{Challenges and future research directions}

With the rapid advancement of different nanotechnologies, great progress has been achieved in the development of phosphorus-based composites as anode materials for sodiumion batteries. However, several challenges must be overcome before realizing their practical application, such as (1) fast degradation of sodium-ion batteries caused by large volume change of anode materials during charge and discharge; (2) low rate capability, low initial coulombic efficiency (60-85\%), and reversible capacity caused by the low electronic conductivity and/or poor diffusion kinetics of sodium ions in phosphorusbased materials.

To overcome these challenges, several possible research directions are proposed:

(1) Further exploration of new phosphorus-composited materials as well as corresponding synthetic methods to obtain novel nanostructures/composites to accommodate large volume change during charge/discharge cycles. Here, the optimization of the structure/morphology/size and the introduction of counter materials with high conductivity and mechanical strengthen are promising approaches.

(2) Further improvements to the rate performance of phosphorus-based anode materials by solving the issues of poor diffusion kinetics, slow reaction kinetics and low electronic conductivity through surface engineering, compositing strategies, doping and other methods/strategies. And further improving the initial coulombic efficiency through rational composition/structure/morphology design and particle surface modification.

(3) Increasing the P content in P-composite anodes to further improve their gravimetric/volumetric specific capacities. Enhancing the phosphorus content in the composite $(>70 \%)$ or constructing a self-supported anode (binder-/conductive additive-free anode) are all effective strategies to achieve this goal. In addition, fabricating P-based anodes for flexible SIBs is also interesting and meaningful; searching for large-scale, high 
yield and low-cost synthesis methods to prepare P-based anode materials is also important for practical applications.

(4) Combining experimental characterization with theoretical studies to obtain fundamental understandings of the relationship between the sodium storage performance and composition/structure as well as sodium storage mechanisms. This will allow for the prediction of new anode materials and guide the optimization of the design, synthesis and performance of phosphorus-composited materials for sodium-ion batteries.

(5) Further exploration of the degradation mechanisms of sodium-ion battery anode materials during charge and discharge through both theoretical and experimental approaches along with the development of mitigation strategies to enhance stability and durability.

(6) Further optimization of the design and fabrication of sodium-ion batteries using matching phosphorus-composited anodes, cathodes and electrolytes with respect to battery performance towards large-scale application in energy storage systems.

\section{Conflicts of interest}

There are no conflicts of interest to declare.

\section{Acknowledgements}

The authors acknowledge the support from the Shanghai Education Ministry and Shanghai University PhD Program, National Natural Science Foundation of China (51774251), the Hebei Science Foundation for Distinguished Young Scholars (B2017203313), the Hundreds of Innovative Talents in Hebei Province (SLRC2017057), and the opening project of the state key laboratory of Advanced Chemical Power Sources (SKL-ACPSC-11).

\section{References}

1 J. Lu, Z. Chen, F. Pan, Y. Cui and K. Amine, Electrochem. Energy Rev., 2018, 1, 35-53.

2 H. Zhang, H. Zhao, M. A. Khan, W. Zou, J. Xu, L. Zhang and J. Zhang, J. Mater. Chem. A, 2018, 6, 20564-20620.

3 M. S. Dresselhaus and I. L. Thomas, Nature, 2001, 414, 332337.

4 Y. Fang, L. Xiao, Z. Chen, X. Ai, Y. Cao and H. Yang, Electrochem. Energy Rev., 2018, 1, 294-296.

5 M. D. Slater, D. Kim, E. Lee and C. S. Johnson, Adv. Funct. Mater., 2013, 23, 947-958.

6 D. Tie, G. Gao, F. Xia, R. Yue, Q. Wang, R. Qi, B. Wang and Y. Zhao, ACS Appl. Mater. Interfaces, 2019, 11, 6978-6985.

7 J. Ding, Y.-C. Lin, J. Liu, J. Rana, H. Zhang, H. Zhou, I.-H. Chu, K. M. Wiaderek, F. Omenya, N. A. Chernova, K. W. Chapman, L. F. J. Piper, S. P. Ong and M. S. Whittingham, Adv. Energy Mater., 2018, 8, 1800221.

8 M. H. Han, E. Gonzalo, G. Singh and T. Rojo, Energy Environ. Sci., 2015, 8, 81-102.
9 Y. You and A. Manthiram, Adv. Energy Mater., 2018, 8, 1701785.

10 G. Gao, D. Tie, H. Ma, H. Yu, S. Shi, B. Wang, S. Xu, L. Wang and Y. Zhao, J. Mater. Chem. A, 2018, 6, 6675-6684.

11 J.-M. Tarascon, Nat. Chem., 2010, 2, 510.

12 R. Alcantara, J. M. J. Mateos and J. L. Tirado, J. Electrochem. Soc., 2002, 149, A201-A205.

13 W. B. Xing and J. R. Dahn, J. Electrochem. Soc., 1997, 144, 1195-1201.

14 D. A. Stevens and J. R. Dahn, J. Electrochem. Soc., 2000, 147, 1271-1273.

15 L. Xiao, H. Lu, Y. Fang, M. L. Sushko, Y. Cao, X. Ai, H. Yang and J. Liu, Adv. Energy Mater., 2018, 8, 1703238.

16 F. A. Soto, P. Yan, M. H. Engelhard, A. Marzouk, C. Wang, G. Xu, Z. Chen, K. Amine, J. Liu, V. L. Sprenkle, F. ElMellouhi, P. B. Balbuena and X. Li, Adv. Mater., 2017, 29, 1606860 .

17 Z. Zhu, F. Liang, Z. Zhou, X. Zeng, D. Wang, P. Dong, J. Zhao, S. Sun, Y. Zhang and X. Li, J. Mater. Chem. A, 2018, 6, 1513-1522.

18 S. Huang, Z. Li, B. Wang, J. Zhang, Z. Peng, R. Qi, J. Wang and Y. Zhao, Adv. Funct. Mater., 2018, 28, 1706294.

19 Y. Cao, L. Xiao, M. L. Sushko, W. Wang, B. Schwenzer, J. Xiao, Z. Nie, L. V. Saraf, Z. Yang and J. Liu, Nano Lett., 2012, 12, 3783-3787.

20 B. Jache and P. Adelhelm, Angew. Chem., Int. Ed., 2014, 53, 10169-10173.

21 Y. Wen, K. He, Y. Zhu, F. Han, Y. Xu, I. Matsuda, Y. Ishii, J. Cumings and C. Wang, Nat. Commun., 2014, 5, 40334042.

22 H. Kim, J. Hong, Y.-U. Park, J. Kim, I. Hwang and K. Kang, Adv. Funct. Mater., 2015, 25, 534-541.

23 Y. Wang, S. Chou, H. Liu and S. Dou, Carbon, 2013, 57, 202208.

24 N. A. Kumar, R. R. Gaddam, S. R. Varanasi, D. Yang, S. K. Bhatia and X. S. Zhao, Electrochim. Acta, 2016, 214, 319-325.

25 Y. Yan, Y.-X. Yin, Y.-G. Guo and L.-J. Wan, Adv. Energy Mater., 2014, 4, 1301584.

26 Y.-X. Wang, S.-L. Chou, H.-K. Liu and S.-X. Dou, Carbon, 2013, 57, 202-208.

27 X. Wang, G. Li, F. M. Hassan, J. Li, X. Fan, R. Batmaz, X. Xiao and Z. Chen, Nano Energy, 2015, 15, 746-754.

28 J. Xu, M. Wang, N. P. Wickramaratne, M. Jaroniec, S. Dou and L. Dai, Adv. Mater., 2015, 27, 2042-2048.

29 C. Wang, L. Wang, F. Li, F. Cheng and J. Chen, Adv. Mater., 2017, 29, 1702212.

30 L. Wu, X. Hu, J. Qian, F. Pei, F. Wu, R. Mao, X. Ai, H. Yang and Y. Cao, Energy Environ. Sci., 2014, 7, 323-328.

31 S. Liu, J. Feng, X. Bian, J. Liu and H. Xu, Energy Environ. Sci., 2016, 9, 1229-1236.

32 Z. Li, J. Ding and D. Mitlin, Acc. Chem. Res., 2015, 48, 16571665.

33 W. Tian, S. Zhang, C. Huo, D. Zhu, Q. Li, L. Wang, X. Ren, L. Xie, S. Guo, P. K. Chu, H. Zeng and K. Huo, ACS Nano, 2018, 12, 1887-1893. 
34 H. Ying, S. Zhang, Z. Meng, Z. Sun and W.-Q. Han, J. Mater. Chem. A, 2017, 5, 8334-8342.

35 N. Wang, Z. Bai, Y. Qian and J. Yang, Adv. Mater., 2016, 28, 4126-4133.

36 J. Pan, N. Wang, Y. Zhou, X. Yang, W. Zhou, Y. Qian and J. Yang, Nano Res., 2017, 10, 1794-1803.

37 Y. Liu, X. Fang, M. Ge, J. Rong, C. Shen, A. Zhang, H. A. Enaya and C. Zhou, Nano Energy, 2015, 16, 399-407.

38 K. Lee, S. Shin, T. Degen, W. Lee and Y. S. Yoon, Nano Energy, 2017, 32, 397-407.

39 W. Chen, K. Song, L. Mi, X. Feng, J. Zhang, S. Cui and C. Liu, J. Mater. Chem. A, 2017, 5, 10027-10038.

40 D. Ma, Y. Li, H. Mi, S. Luo, P. Zhang, Z. Lin, J. Li and H. Zhang, Angew. Chem., Int. Ed., 2018, 57, 8901-8905.

41 T. Li, A. Qin, L. Yang, J. Chen, Q. Wang, D. Zhang and H. Yang, ACS Appl. Mater. Interfaces, 2017, 9, 19900-19907.

42 D. Y. W. Yu, P. V. Prikhodchenko, C. W. Mason, S. K. Batabyal, J. Gun, S. Sladkevich, A. G. Medvedev and O. Lev, Nat. Commun., 2013, 4, 2922-2931.

43 X. Xiong, G. Wang, Y. Lin, Y. Wang, X. Ou, F. Zheng, C. Yang, J.-H. Wang and M. Liu, ACS Nano, 2016, 10, 10953-10959.

44 Y. Xiao, S. H. Lee and Y.-K. Sun, Adv. Energy Mater., 2017, 7, 1601329.

45 S. Wang, Y. Fang, X. Wang and X. W. D. Lou, Angew. Chem., Int. Ed., 2019, 58, 760-763.

46 F. Xie, L. Zhang, Q. Gu, D. Chao, M. Jaroniec and S.-Z. Qiao, Nano Energy, 2019, 60, 591-599.

47 D. Chao, B. Ouyang, P. Liang, T. T. T. Huong, G. Jia, H. Huang, X. Xia, R. S. Rawat and H. J. Fan, Adv. Mater., 2018, 30, 1804833.

48 H. Park, J. Kwon, H. Choi, D. Shin, T. Song and X. W. D. Lou, ACS Nano, 2018, 12, 2827-2837.

49 S. Yuan, Y. H. Zhu, W. Li, S. Wang, D. Xu, L. Li, Y. Zhang and X. B. Zhang, Adv. Mater., 2017, 29, 1602469.

50 F. Zhang, C. Xia, J. Zhu, B. Ahmed, H. Liang, D. B. Velusamy, U. Schwingenschlögl and H. N. Alshareef, Adv. Energy Mater., 2016, 6, 1601188.

51 K. Zhang, Z. Hu, X. Liu, Z. Tao and J. Chen, Adv. Mater., 2015, 27, 3305-3309.

52 Z. Ali, T. Tang, X. Huang, Y. Wang, M. Asif and Y. Hou, Energy Storage Mater., 2018, 13, 19-28.

53 H. Fan, H. Yu, Y. Zhang, J. Guo, Z. Wang, H. Wang, N. Zhao, Y. Zheng, C. Du, Z. Dai, Q. Yan and J. Xu, Energy Storage Mater., 2018, 10, 48-55.

54 X. Ou, C. Yang, X. Xiong, F. Zheng, Q. Pan, C. Jin, M. Liu and K. Huang, Adv. Funct. Mater., 2017, 27, 1606242.

55 L. Ji, M. Gu, Y. Shao, X. Li, M. H. Engelhard, B. W. Arey, W. Wang, Z. Nie, J. Xiao, C. Wang, J.-G. Zhang and J. Liu, Adv. Mater., 2014, 26, 2901-2908.

56 M. Walter, S. Doswald and M. V. Kovalenko, J. Mater. Chem. A, 2016, 4, 7053-7059.

57 L. Xiao, Y. Cao, J. Xiao, W. Wang, L. Kovarik, Z. Nie and J. Liu, Chem. Commun., 2012, 48, 3321-3323.

58 Y.-M. Lin, P. R. Abel, A. Gupta, J. B. Goodenough, A. Heller and C. B. Mullins, ACS Appl. Mater. Interfaces, 2013, 5, 82738277.
59 J.-H. Choi, C.-W. Ha, H.-Y. Choi, J.-W. Seong, C.-M. Park and S.-M. Lee, J. Power Sources, 2018, 386, 34-39.

60 J. Qin, T. Wang, D. Liu, E. Liu, N. Zhao, C. Shi, F. He, L. Ma and C. He, Adv. Mater., 2018, 30, 1704670.

61 W. Ma, K. Yin, H. Gao, J. Niu, Z. Peng and Z. Zhang, Nano Energy, 2018, 54, 349-359.

62 H. Gao, J. Niu, C. Zhang, Z. Peng and Z. Zhang, ACS Nano, 2018, 12, 3568-3577.

63 B. Farbod, K. Cui, W. P. Kalisvaart, M. Kupsta, B. Zahiri, A. Kohandehghan, E. M. Lotfabad, Z. Li, E. J. Luber and D. Mitlin, ACS Nano, 2014, 8, 4415-4429.

64 L. O. Vogt and C. Villevieille, J. Mater. Chem. A, 2017, 5, 3865-3874.

65 S. Wang, L. Wang, Z. Zhu, Z. Hu, Q. Zhao and J. Chen, Angew. Chem., Int. Ed., 2014, 53, 5892-5896.

66 C. Luo, G. L. Xu, X. Ji, S. Hou, L. Chen, F. Wang, J. Jiang, Z. Chen, Y. Ren, K. Amine and C. Wang, Angew. Chem., Int. Ed., 2018, 57, 2879-2883.

67 H. Zhu, J. Yin, X. Zhao, C. Wang and X. Yang, Chem. Commun., 2015, 51, 14708-14711.

68 C. Luo, J. Wang, X. Fan, Y. Zhu, F. Han, L. Suo and C. Wang, Nano Energy, 2015, 13, 537-545.

69 H. J. Lee, J. Shin and J. W. Choi, Adv. Mater., 2018, 30, 1705851.

70 W. Zhang, M. Dahbi, S. Amagasa, Y. Yamada and S. Komaba, Electrochem. Commun., 2016, 69, 11-14.

71 C. Zhang, X. Wang, Q. Liang, X. Liu, Q. Weng, J. Liu, Y. Yang, Z. Dai, K. Ding, Y. Bando, J. Tang and D. Golberg, Nano Lett., 2016, 16, 2054-2060.

72 J. Sun, H.-W. Lee, M. Pasta, H. Yuan, G. Zheng, Y. Sun, Y. Li and Y. Cui, Nat. Nanotechnol., 2015, 10, 980-986.

73 J. Song, Z. Yu, M. L. Gordin, S. Hu, R. Yi, D. Tang, T. Walter, M. Regula, D. Choi, X. Li, A. Maniyannan and D. Wang, Nano Lett., 2014, 14, 6329-6335.

74 J. Qian, Y. Xiong, Y. Cao, X. Ai and H. Yang, Nano Lett., 2014, 14, 1865-1869.

75 Z. Li, L. Zhang, X. Ge, C. Li, S. Dong, C. Wang and L. Yin, Nano Energy, 2017, 32, 494-502.

76 W. Li, S. Hu, X. Luo, Z. Li, X. Sun, M. Li, F. Liu and Y. Yu, Adv. Mater., 2017, 29, 1605820-1605827.

77 Y. Kim, Y. Kim, A. Choi, S. Woo, D. Mok, N.-S. Choi, Y. S. Jung, J. H. Ryu, S. M. Oh and K. T. Lee, Adv. Mater., 2014, 26, 4139-4144.

78 M. Fan, Y. Chen, Y. Xie, T. Yang, X. Shen, N. Xu, H. Yu and C. Yan, Adv. Funct. Mater., 2016, 26, 5019-5027.

79 J. Qian, X. Wu, Y. Cao, X. Ai and H. Yang, Angew. Chem., Int. Ed., 2013, 52, 4633-4636.

80 P. Extance and S. R. Elliott, Philos. Mag. B, 1981, 43, 469483.

81 Y. Fu, Q. Wei, G. Zhang and S. Sun, Adv. Energy Mater., 2018, 8, 1703058.

82 Y. Kim, Y. Park, A. Choi, N. S. Choi, J. Kim, J. Lee, J. H. Ryu, S. M. Oh and K. T. Lee, Adv. Mater., 2013, 25, 3045-3049.

83 N. Wu, H.-R. Yao, Y.-X. Yin and Y.-G. Guo, J. Mater. Chem. A, 2015, 3, 24221-24225.

84 M. Dahbi, N. Yabuuchi, M. Fukunishi, K. Kubota, K. Chihara, K. Tokiwa, X.-f. Yu, H. Ushiyama, 
K. Yamashita, J.-Y. Son, Y.-T. Cui, H. Oji and S. Komaba, Chem. Mater., 2016, 28, 1625-1635.

85 Y. Zhu, Y. Wen, X. Fan, T. Gao, F. Han, C. Luo, S.-C. Liou and C. Wang, ACS Nano, 2015, 9, 3254-3264.

86 S. Liu, J. Feng, X. Bian, J. Liu, H. Xu and Y. An, Energy Environ. Sci., 2017, 10, 1222-1233.

87 J. Zhou, X. Liu, W. Cai, Y. Zhu, J. Liang, K. Zhang, Y. Lan, Z. Jiang, G. Wang and Y. Qian, Adv. Mater., 2017, 29, 1700214.

88 A. Morita, Appl. Phys. A, 1986, 39, 227-242.

89 J. Wu, N. Mao, L. Xie, H. Xu and J. Zhang, Angew. Chem., Int. Ed., 2015, 54, 2366-2369.

90 D. Sun, X. Zhu, B. Luo, Y. Zhang, Y. Tang, H. Wang and L. Wang, Adv. Energy Mater., 2018, 8, 1801197.

91 J. Liu, P. Kopold, C. Wu, P. A. van Aken, J. Maier and Y. Yu, Energy Environ. Sci., 2015, 8, 3531-3538.

92 S. Shi, Z. Li, Y. Sun, B. Wang, Q. Liu, Y. Hou, S. Huang, J. Huang and Y. Zhao, Nano Energy, 2018, 48, 510-517.

93 J. M. Sangster, J. Phase Equilib. Diffus., 2009, 31, 62-67.

94 J. L. Zhang, S. Zhao, C. Han, Z. Wang, S. Zhong, S. Sun, R. Guo, X. Zhou, C. D. Gu, K. D. Yuan, Z. Li and W. Chen, Nano Lett., 2016, 16, 4903-4908.

95 J. Zhang, D. Zhao, D. Xiao, C. Ma, H. Du, X. Li, L. Zhang, J. Huang, H. Huang, C. L. Jia, D. Tomanek and C. Niu, Angew. Chem., Int. Ed., 2017, 56, 1850-1854.

96 Q. Peng, Z. Wang, B. Sa, B. Wu and Z. Sun, ACS Appl. Mater. Interfaces, 2016, 8, 13449-13457.

97 W. Roth, T. DeWitt and A. J. Smith, J. Am. Chem. Soc., 1947, 69, 2881-2885.

98 M. Ceppatelli, R. Bini, M. Caporali and M. Peruzzini, Angew. Chem., Int. Ed., 2013, 52, 2313-2317.

99 J. A. Young, J. Chem. Educ., 2004, 81, 945.

100 S. Zhang, H. J. Qian, Z. Liu, H. Ju, Z. Y. Lu, H. Zhang, L. Chi and S. Cui, Angew. Chem., Int. Ed., 2019, 58, 1659-1663.

101 J. Sun, H.-W. Lee, M. Pasta, Y. Sun, W. Liu, Y. Li, H. R. Lee, N. Liu and Y. Cui, Energy Storage Mater., 2016, 4, 130-136.

102 M. Scheer, G. Balazs and A. Seitz, Chem. Rev., 2010, 110, 4236-4256.

103 U. Braun and B. Schartel, Macromol. Chem. Phys., 2004, 205, 2185-2196.

104 K. Sladkova, J. Houska and J. Havel, Rapid Commun. Mass Spectrom., 2009, 23, 3114-3118.

105 B. Weber, S. Mahapatra, H. Ryu, S. Lee, A. Fuhrer, T. Reusch, D. Thompson, W. Lee, G. Klimeck and L. C. Hollenberg, Science, 2012, 335, 64-67.

106 F. Wang, W. K. H. Ng, C. Y. Jimmy, H. Zhu, C. Li, L. Zhang, Z. Liu and Q. Li, Appl. Catal., B, 2012, 111, 409-414.

107 W. L. Roth, T. W. DeWitt and A. J. Smith, J. Am. Chem. Soc., 1947, 69, 2881-2885.

108 H. Thurn and H. Krebs, Angew. Chem., Int. Ed., 1966, 78, 1101-1102.

109 H. Thurn and H. Krebs, Acta Crystallogr., Sect. B: Struct. Sci., 1969, 25, 125-135.

110 M. Ruck, D. Hoppe, B. Wahl, P. Simon, Y. Wang and G. Seifert, Angew. Chem., Int. Ed., 2005, 117, 7788-7792.

111 W. Li, Z. Yang, Y. Jiang, Z. Yu, L. Gu and Y. Yu, Carbon, 2014, 78, 455-462.
112 N. Yabuuchi, Y. Matsuura, T. Ishikawa, S. Kuze, J.-Y. Son, Y.-T. Cui, H. Oji and S. Komaba, ChemElectroChem, 2014, 1, 580-589.

113 R. Gusmao, Z. Sofer and M. Pumera, Angew. Chem., Int. Ed., 2017, 56, 8052-8072.

114 M. Sopicka-Lizer, High-Energy Ball Milling: Mechanochemical Processing of Nanopowders, Elsevier Science, Woodheam Publishing Limited, Great Abington, Cambridge, UK, 2010.

115 C. Marino, A. Debenedetti, B. Fraisse, F. Favier and L. Monconduit, Electrochem. Commun., 2011, 13, 346-349.

116 F. Yang, H. Gao, J. Chen and Z. Guo, Small Methods, 2017, 1, 1700216.

117 D. Liu, X. Huang, D. Qu, D. Zheng, G. Wang, J. Harris, J. Si, T. Ding, J. Chen and D. Qu, Nano Energy, 2018, 52, 1-10.

118 L. Wang, X. He, J. Li, W. Sun, J. Gao, J. Guo and C. Jiang, Angew. Chem., Int. Ed., 2012, 51, 9034-9037.

119 C. M. Park and H. J. Sohn, Adv. Mater., 2007, 19, 2465-2468.

120 J. Qian, D. Qiao, X. Ai, Y. Cao and H. Yang, Chem. Commun., 2012, 48, 8931-8933.

121 W. J. Li, S. L. Chou, J. Z. Wang, H. K. Liu and S. X. Dou, Nano Lett., 2013, 13, 5480-5484.

122 W. Liu, X. Yuan and X. Yu, Nanoscale, 2018, 10, 1667516682.

123 Y. Hu, B. Li, X. Jiao, C. Zhang, X. Dai and J. Song, Adv. Funct. Mater., 2018, 28, 1801010.

124 J. Song, Z. Yu, M. L. Gordin, X. Li, H. Peng and D. Wang, ACS Nano, 2015, 9, 11933-11941.

125 Q. Xu, J. K. Sun, F. S. Yue, J. Y. Li, G. Li, S. Xin, Y. X. Yin and Y. G. Guo, ACS Appl. Mater. Interfaces, 2018, 10, 3047930486.

126 M. Li, R. Carter, L. Oakes, A. Douglas, N. Muralidharan and C. L. Pint, J. Mater. Chem. A, 2017, 5, 5266-5272.

127 Y. Liu, N. Zhang, X. Liu, C. Chen, L.-Z. Fan and L. Jiao, Energy Storage Mater., 2017, 9, 170-178.

128 W. Li, Z. Yang, M. Li, Y. Jiang, X. Wei, X. Zhong, L. Gu and Y. Yu, Nano Lett., 2016, 16, 1546-1553.

129 G. Qin, J. Duan, Y. Yang and F. Liu, ACS Appl. Mater. Interfaces, 2018, 10, 6441-6452.

130 D. Lan and Q. Li, ACS Appl. Energy Mater., 2018, 2, 661-667. 131 H. Gao, T. Zhou, Y. Zheng, Y. Liu, J. Chen, H. Liu and Z. Guo, Adv. Energy Mater., 2016, 6, 1601037.

132 Y. Liu, A. Zhang, C. Shen, Q. Liu, X. Cao, Y. Ma, L. Chen, C. Lau, T. C. Chen, F. Wei and C. Zhou, ACS Nano, 2017, 11, 5530-5537.

133 Y. Liu, A. Zhang, C. Shen, Q. Liu, J. Cai, X. Cao and C. Zhou, Nano Res., 2018, 11, 3780-3790.

134 X. Sun, W. Li, X. Zhong and Y. Yu, Energy Storage Mater., 2017, 9, 112-118.

135 S. Yao, J. Cui, J. Huang, J.-Q. Huang, W. G. Chong, L. Qin, Y.-W. Mai and J.-K. Kim, Adv. Energy Mater., 2018, 8, 1702267.

136 Z. Yu, J. Song, D. Wang and D. Wang, Nano Energy, 2017, 40, 550-558.

137 J. Hanawalt, H. Rinn and L. Frevel, Ind. Eng. Chem., Anal. Ed., 1938, 10, 457-512. 
138 D. Yan, C. Yu, X. Zhang, J. Li, J. Li, T. Lu and L. Pan, Electrochim. Acta, 2017, 254, 130-139.

139 S.-O. Kim and A. Manthiram, Chem. Mater., 2016, 28, 59355942.

140 W. C. Chang, K. W. Tseng and H. Y. Tuan, Nano Lett., 2017, 17, 1240-1247.

141 I. T. Kim, E. Allcorn and A. Manthiram, J. Power Sources, 2015, 281, 11-17.

142 L.-C. Chin, Y.-H. Yi, W.-C. Chang and H.-Y. Tuan, Electrochim. Acta, 2018, 266, 178-184.

143 M. Walter, R. Erni and M. V. Kovalenko, Sci. Rep., 2015, 5, 8418-8424.

144 S. Liu, H. Xu, X. Bian, J. Feng, J. Liu, Y. Yang, C. Yuan, Y. An, R. Fan and L. Ci, ACS Nano, 2018, 12, 7380-7387.

145 S. Liu, H. Xu, X. Bian, J. Feng, J. Liu, Y. Yang, C. Yuan, Y. An, R. Fan and L. Ci, J. Mater. Chem. A, 2018, 6, 12992-12998.

146 G. Zeng, X. Hu, B. Zhou, J. Chen, C. Cao and Z. Wen, Nanoscale, 2017, 9, 14722-14729.

147 C.-M. Park and H.-J. Sohn, Adv. Mater., 2007, 19, 2465-2468.

148 N. S. G. Ralph Hultgren and B. E. Warren, J. Chem. Phys., 1935, 3, 351-355.

149 M. Huang, M. Wang, C. Chen, Z. Ma, X. Li, J. Han and Y. Wu, Adv. Mater., 2016, 28, 3481-3485.

150 L. Li, Y. Yu, G. J. Ye, Q. Ge, X. Ou, H. Wu, D. Feng, X. H. Chen and Y. Zhang, Nat. Nanotechnol., 2014, 9, 372377.

151 H. Liu, Y. Du, Y. Deng and P. D. Ye, Chem. Soc. Rev., 2015, 44, 2732-2743.

152 A. J. Mannix, B. Kiraly, M. C. Hersam and N. P. Guisinger, Nat. Rev. Chem., 2017, 1, 0014.

153 X. Ling, H. Wang, S. Huang, F. Xia and M. S. Dresselhaus, Proc. Natl. Acad. Sci., 2015, 112, 4523-4530.

154 S. R. Allan Brown, Acta Cryst., 1965, 19, 684-685.

155 J. C. Slater, G. F. Koster and J. H. Wood, Phys. Rev., 1962, 126, 1307-1317.

156 R. W. Keyes, Phys. Rev., 1953, 92, 580-584.

157 Y. Zhang, Y. Zheng, K. Rui, H. H. Hng, K. Hippalgaonkar, J. Xu, W. Sun, J. Zhu, Q. Yan and W. Huang, Small, 2017, 13, 1700661.

158 L. Li, Y. Zheng, S. Zhang, J. Yang, Z. Shao and Z. Guo, Energy Environ. Sci., 2018, 11, 2310-2340.

159 Y. Zhang, W. Sun, Z.-Z. Luo, Y. Zheng, Z. Yu, D. Zhang, J. Yang, H. T. Tan, J. Zhu, X. Wang, Q. Yan and S. X. Dou, Nano Energy, 2017, 40, 576-586.

160 M. Köpf, N. Eckstein, D. Pfister, C. Grotz, I. Krüger, M. Greiwe, T. Hansen, H. Kohlmann and T. Nilges, J. Cryst. Growth, 2014, 405, 6-10.

161 L.-Q. Sun, M.-J. Li, K. Sun, S.-H. Yu, R.-S. Wang and H.-M. Xie, J. Phys. Chem. C, 2012, 116, 14772-14779.

162 Y. Liu, Q. Liu, A. Zhang, J. Cai, X. Cao, Z. Li, P. D. Asimow and C. Zhou, ACS Nano, 2018, 12, 8323-8329.

163 Q. Jiang, L. Xu, N. Chen, H. Zhang, L. Dai and S. Wang, Angew. Chem., Int. Ed., 2016, 55, 13849-13853.

164 B. Tian, B. Tian, B. Smith, M. C. Scott, Q. Lei, R. Hua, Y. Tian and Y. Liu, Proc. Natl. Acad. Sci., 2018, 115, 43454350 .
165 V. Eswaraiah, Q. Zeng, Y. Long and Z. Liu, Small, 2016, 12, 3480-3502.

166 X. Li, B. Deng, X. Wang, S. Chen, M. Vaisman, S.-i. Karato, G. Pan, M. Larry Lee, J. Cha, H. Wang and F. Xia, 2D Mater., 2015, 2, 031002.

167 K. P. S. S. Hembram, H. Jung, B. C. Yeo, S. J. Pai, S. Kim, K.-R. Lee and S. S. Han, J. Phys. Chem. C, 2015, 119, 15041-15046.

168 L. E. Marbella, M. L. Evans, M. F. Groh, J. Nelson, K. J. Griffith, A. J. Morris and C. P. Grey, J. Am. Chem. Soc., 2018, 140, 7994-8004.

169 S. Mukherjee, L. Kavalsky and C. V. Singh, ACS Appl. Mater. Interfaces, 2018, 10, 8630-8639.

170 X. Liu, Y. Wen, Z. Chen, B. Shan and R. Chen, Phys. Chem. Chem. Phys., 2015, 17, 16398-16404.

171 L. Wang, Z. Jiang, W. Li, X. Gu and L. Huang, J. Phys. D: Appl. Phys., 2017, 50, 165501.

172 H. Liu, L. Tao, Y. Zhang, C. Xie, P. Zhou, H. Liu, R. Chen and S. Wang, ACS Appl. Mater. Interfaces, 2017, 9, 3684936856.

173 G. L. Xu, Z. Chen, G. M. Zhong, Y. Liu, Y. Yang, T. Ma, Y. Ren, X. Zuo, X. H. Wu, X. Zhang and K. Amine, Nano Lett., 2016, 16, 3955-3965.

174 S. Haghighat-Shishavan, M. Nazarian-Samani, M. Nazarian-Samani, H.-K. Roh, K.-Y. Chung, B.-W. Cho, S. F. Kashani-Bozorg and K.-B. Kim, J. Mater. Chem. A, 2018, 6, 10121-10134.

175 M. Li, N. Muralidharan, K. Moyer and C. L. Pint, Nanoscale, 2018, 10, 10443-10449.

176 R. Meng, J. Huang, Y. Feng, L. Zu, C. Peng, L. Zheng, L. Zheng, Z. Chen, G. Liu, B. Chen, Y. Mi and J. Yang, Adv. Energy Mater., 2018, 8, 1801514.

177 T. Song, H. Chen, Q. Xu, H. Liu, Y. G. Wang and Y. Xia, ACS Appl. Mater. Interfaces, 2018, 10, 37163-37171.

178 T. Song, H. Chen, Z. Li, Q. Xu, H. Liu, Y. Wang and Y. Xia, Adv. Funct. Mater., 2019, 1900535.

179 X. Ding, Y. Huang, G. Li, Y. Tang, X. Li and Y. Huang, Electrochim. Acta, 2017, 235, 150-157.

180 J. R. Brent, N. Savjani, E. A. Lewis, S. J. Haigh, D. J. Lewis and P. O'Brien, Chem. Commun., 2014, 50, 13338-13341.

181 A. Favron, E. Gaufres, F. Fossard, A. L. Phaneuf-L'Heureux, N. Y. Tang, P. L. Levesque, A. Loiseau, R. Leonelli, S. Francoeur and R. Martel, Nat. Mater., 2015, 14, 826-832.

182 P. Yasaei, B. Kumar, T. Foroozan, C. Wang, M. Asadi, D. Tuschel, J. E. Indacochea, R. F. Klie and A. SalehiKhojin, Adv. Mater., 2015, 27, 1887-1892.

183 Q. Zhou, Q. Chen, Y. Tong and J. Wang, Angew. Chem., Int. Ed., 2016, 55, 11437-11441.

184 R. Fei, A. Faghaninia, R. Soklaski, J. A. Yan, C. Lo and L. Yang, Nano Lett., 2014, 14, 6393-6399.

185 V. V. Kulish, O. I. Malyi, C. Persson and P. Wu, Phys. Chem. Chem. Phys., 2015, 17, 13921-13928.

186 Y. Zhao, H. Wang, H. Huang, Q. Xiao, Y. Xu, Z. Guo, H. Xie, J. Shao, Z. Sun, W. Han, X. F. Yu, P. Li and P. K. Chu, Angew. Chem., Int. Ed., 2016, 55, 5003-5007. 
187 C. R. Ryder, J. D. Wood, S. A. Wells, Y. Yang, D. Jariwala, T. J. Marks, G. C. Schatz and M. C. Hersam, Nat. Chem., 2016, 8, 597-602.

188 Z. Huang, H. Hou, Y. Zhang, C. Wang, X. Qiu and X. Ji, Adv. Mater., 2017, 29, 1702372.

189 F. Zhao, N. Han, W. Huang, J. Li, H. Ye, F. Chen and Y. Li, J. Mater. Chem. A, 2015, 3, 21754-21759.

190 J. Liu, S. Wang, K. Kravchyk, M. Ibáñez, F. Krumeich, R. Widmer, D. Nasiou, M. Meyns, J. Llorca, J. Arbiol, M. V. Kovalenko and A. Cabot, J. Mater. Chem. A, 2018, 6, 10958-10966.

191 J. Zhang, K. Zhang, J. Yang, G.-H. Lee, J. Shin, V. Wing-hei Lau and Y.-M. Kang, Adv. Energy Mater., 2018, 8, 1800283.

192 X. Wang, K. Chen, G. Wang, X. Liu and H. Wang, ACS Nano, 2017, 11, 11602-11616.

193 W. Li, L. Ke, Y. Wei, S. Guo, L. Gan, H. Li, T. Zhai and H. Zhou, J. Mater. Chem. A, 2017, 5, 4413-4420.

194 X. Fan, J. Mao, Y. Zhu, C. Luo, L. Suo, T. Gao, F. Han, S.-C. Liou and C. Wang, Adv. Energy Mater., 2015, 5, 1500174.

195 W. Li, S. L. Chou, J. Z. Wang, J. H. Kim, H. K. Liu and S. X. Dou, Adv. Mater., 2014, 26, 4037-4042.

196 K.-H. Nam, K.-J. Jeon and C.-M. Park, Energy Storage Mater., 2019, 17, 78-87.

197 W. Li, X. Li, J. Liao, B. Zhao, L. Zhang, Y. Liu, L. Huang, Y. Li and M. Liu, Energy Storage Mater., 2019, 20, 380-387.

198 M. Kong, H. Song and J. Zhou, Adv. Energy Mater., 2018, 8, 1801489.

199 J. Fullenwarth, A. Darwiche, A. Soares, B. Donnadieu and L. Monconduit, J. Mater. Chem. A, 2014, 2, 2050-2059.

200 W. Zhao, X. Ma, G. Wang, X. Long, Y. Li, W. Zhang and P. Zhang, Appl. Surf. Sci., 2018, 445, 167-174.

201 W. J. Li, S. L. Chou, J. Z. Wang, H. K. Liu and S. X. Dou, Chem. Commun., 2015, 51, 3682-3685.

202 Y. Wang, C. Wu, Z. Wu, G. Cui, F. Xie, X. Guo and X. Sun, Chem. Commun., 2018, 54, 9341-9344.

203 W.-J. Li, Q.-R. Yang, S.-L. Chou, J.-Z. Wang and H.-K. Liu, J. Power Sources, 2015, 294, 627-632.

204 X. Ge, Z. Li and L. Yin, Nano Energy, 2017, 32, 117-124.

205 X. Fan, T. Gao, C. Luo, F. Wang, J. Hu and C. Wang, Nano Energy, 2017, 38, 350-357.

206 K. A. Kovnir, Y. V. Kolen'ko, S. Ray, J. Li, T. Watanabe, M. Itoh, M. Yoshimura and A. V. Shevelkov, J. Solid State Chem., 2006, 179, 3756-3762.

207 S. C. Jung, J.-H. Choi and Y.-K. Han, J. Mater. Chem. A, 2018, 6, 1772-1779.

208 H. Usui, Y. Domi, K. Fujiwara, M. Shimizu, T. Yamamoto, T. Nohira, R. Hagiwara and H. Sakaguchi, ACS Energy Lett., 2017, 2, 1139-1143.

209 H. Usui, Y. Domi, R. Yamagami, K. Fujiwara, H. Nishida and H. Sakaguchi, ACS Appl. Energy Mater., 2018, 1, 306311.

210 Y. Ding, Z.-F. Li, E. V. Timofeeva and C. U. Segre, Adv. Energy Mater., 2018, 8, 1702134.

211 H. Usui, T. Sakata, M. Shimizu and H. Sakaguchi, Electrochem, 2015, 83, 810-812.
212 W. Wang, J. Zhang, D. Y. W. Yu and Q. Li, J. Power Sources, 2017, 364, 420-425.

213 Y. Xu, B. Peng and F. M. Mulder, Adv. Energy Mater., 2018, 8, 1701847.

214 F. Han, C. Y. J. Tan and Z. Gao, ChemElectroChem, 2016, 3, 1054-1062.

215 H. S. Shin, K. N. Jung, Y. N. Jo, M. S. Park, H. Kim and J. W. Lee, Sci. Rep., 2016, 6, 26195.

216 L. Ma, P. Yan, S. Wu, G. Zhu and Y. Shen, J. Mater. Chem. A, 2017, 5, 16994-17000.

217 J. Choi, W.-S. Kim, K.-H. Kim and S.-H. Hong, J. Mater. Chem. A, 2018, 6, 17437-17443.

218 Q. Li, Z. Li, Z. Zhang, C. Li, J. Ma, C. Wang, X. Ge, S. Dong and L. Yin, Adv. Energy Mater., 2016, 6, 1600376.

219 D. Lan, W. Wang, L. Shi, Y. Huang, L. Hu and Q. Li, J. Mater. Chem. A, 2017, 5, 5791-5796.

220 J. Gullman, J. Solid State Chem., 1990, 87, 202-207.

221 D.-H. Ha, L. M. Moreau, C. R. Bealing, H. Zhang, R. G. Hennig and R. D. Robinson, J. Mater. Chem., 2011, 21, 11498.

222 Q. Zhou, Z. Shen, C. Zhu, J. Li, Z. Ding, P. Wang, F. Pan, Z. Zhang, H. Ma, S. Wang and H. Zhang, Adv. Mater., 2018, 30, 1800140.

223 K. Zhang, M. Park, J. Zhang, G.-H. Lee, J. Shin and Y.-M. Kang, Nano Res., 2017, 10, 4337-4350.

224 D. Zhou and L.-Z. Fan, J. Mater. Chem. A, 2018, 6, 21392147.

225 C. Wu, P. Kopold, P. A. van Aken, J. Maier and Y. Yu, Adv. Mater., 2017, 29, 1604015.

226 M. Ihsan-Ul-Haq, H. Huang, J. Cui, S. Yao, J. Wu, W. G. Chong, B. Huang and J.-K. Kim, J. Mater. Chem. A, 2018, 6, 20184-20194.

227 C. Dong, L. Guo, Y. He, C. Chen, Y. Qian, Y. Chen and L. Xu, Energy Storage Mater., 2018, 15, 234-241.

228 S. Chen, F. Wu, L. Shen, Y. Huang, S. K. Sinha, V. Srot, P. A. van Aken, J. Maier and Y. Yu, ACS Nano, 2018, 12, 7018-7027.

229 Q. L. Ning, B. H. Hou, Y. Y. Wang, D. S. Liu, Z. Z. Luo, W. H. Li, Y. Yang, J. Z. Guo and X. L. Wu, ACS Appl. Mater. Interfaces, 2018, 10, 36902-36909.

230 K.-W. Tseng, S.-B. Huang, W.-C. Chang and H.-Y. Tuan, Chem. Mater., 2018, 30, 4440-4447.

231 Z. Huang, H. Hou, C. Wang, S. Li, Y. Zhang and X. Ji, Chem. Mater., 2017, 29, 7313-7322.

232 X. Li, W. Li, J. Yu, H. Zhang, Z. Shi and Z. Guo, J. Alloys Compd., 2017, 724, 932-939.

233 D. Duveau, S. S. Israel, J. Fullenwarth, F. Cunin and L. Monconduit, J. Mater. Chem. A, 2016, 4, 3228-3232.

234 Y. Lu, P. Zhou, K. Lei, Q. Zhao, Z. Tao and J. Chen, Adv. Energy Mater., 2017, 7, 1601973.

235 X. Li, S. Guo, K. Jiang, Y. Qiao, M. Ishida and H. Zhou, ACS Appl. Mater. Interfaces, 2018, 10, 16-20.

236 Q. Liang, Y. Zheng, C. Du, Y. Luo, J. Zhang, B. Li, Y. Zong and Q. Yan, Small Methods, 2017, 1, 1700304.

237 D. Lan, W. Wang and Q. Li, Nano Energy, 2017, 39, 506-512. 238 Q. Liu, J. Wang, Y. Luo, L. Miao, Y. Yan, L. Xue and W. Zhang, Electrochim. Acta, 2017, 247, 820-825. 
239 N. Cheng, L. Fan, Z. Liu, S. Chen, E. Zhang, J. Zhao, H. Yang, X. Yu and B. Lu, Mater. Today Energy, 2019, 11, 174-181.

240 R. Jin, X. Li, Y. Sun, H. Shan, L. Fan, D. Li and X. Sun, ACS Appl. Mater. Interfaces, 2018, 10, 14641-14648.

241 G. Cho, H. Kim, Y. S. Park, Y.-K. Hong and D.-H. Ha, Int. J. Hydrogen Energy, 2018, 43, 11326-11334.

242 H. Yan, Comp. Mater. Sci., 2015, 107, 204-209.

243 S. Boyanov, D. Zitoun, M. Ménétrier, J. C. Jumas, M. Womes and L. Monconduit, J. Phys. Chem. C, 2009, 113, 2144121452.

244 I. Shirotani, E. Takahashi, N. Mukai, K. Nozawa, M. Kinoshita, T. Yagi, K. Suzuki, T. Enoki and S. Hino, Jpn. J. Appl. Phys., 1993, 32, 294.

245 G. Samsonov, Y. B. Paderno, V. Lazorenko and P. Vityaz', Powder Metall. Met. Ceram., 1971, 10, 565-567.

246 Y. Lu and J.-p. Tu, CrystEngComm, 2012, 14, 8633-8641.

247 Q. Li, J. Ma, H. Wang, X. Yang, R. Yuan and Y. Chai, Electrochim. Acta, 2016, 213, 201-206.

248 J. Xiang, X. Wang, X. Xia, J. Zhong and J. Tu, J. Alloys Compd., 2011, 509, 157-160.

249 E. J. Popczun, J. R. McKone, C. G. Read, A. J. Biacchi, A. M. Wiltrout, N. S. Lewis and R. E. Schaak, J. Am. Chem. Soc., 2013, 135, 9267-9270.

250 H. Li, S. Hao, Z. Tian, Z. Zhao and X. Wang, Electrochim. Acta, 2019, 321, 134624.

251 H. Guo, C. Chen, K. Chen, H. Cai, X. Chang, S. Liu, W. Li, Y. Wang and C. Wang, J. Mater. Chem. A, 2017, 5, 2231622324.

252 S. O. Kim and A. Manthiram, Chem. Commun., 2016, 52, 4337-4340.

253 J. Duan, S. Deng, W. Wu, X. Li, H. Fu, Y. Huang and W. Luo, ACS Appl. Mater. Interfaces, 2019, 11, 12415-12420.

254 A. Zhou, B. Yang, W. Wang, X. Dai, M. Zhao, J. Xue, M. Han, C. Fan and J. Li, RSC Adv., 2016, 6, 26800-26808.

255 R. Wang, X. Y. Dong, J. Du, J. Y. Zhao and S. Q. Zang, Adv. Mater., 2018, 30, 1703711.

256 X. Y. Peilei He and X. Wen Lou, Angew. Chem., Int. Ed., 2017, 56, 3897-3900.

257 J. Zhu, Q. He, Y. Liu, J. Key, S. Nie, M. Wu and P. K. Shen, J. Mater. Chem. A, 2019, 7, 16999-17007.

258 X. Li, J. Liao, P. Shen, X. Lia, Y. Li, N. Li, Z. Li, Z. Shi, H. Zhang and W. Li, J. Alloys Compd., 2019, 803, 804-811.

259 W. Li, P. Shen, J. Liao, J. Yu, X. Li, Y. Liu, Y. Li, Z. Shi and H. Zhang, Mater. Lett., 2019, 253, 263-267.

260 Y. Liu, X. Xiao, X. Fan, M. Li, Y. Zhang, W. Zhang and L. Chen, J. Alloys Compd., 2018, 744, 15-22.

261 W. Li, H. Li, Z. Lu, L. Gan, L. Ke, T. Zhai and H. Zhou, Energy Environ. Sci., 2015, 8, 3629-3636.
262 S. Haghighat-Shishavan, M. Nazarian-Samani, M. Nazarian-Samani, H. K. Roh, K. Y. Chung, S. H. Oh, B. W. Cho, S. F. Kashani-Bozorg and K. B. Kim, ACS Appl. Mater. Interfaces, 2019, 11, 32815-32825.

263 D. Kim, K. Zhang, J.-M. Lim, G.-H. Lee, K. Cho, M. Cho and Y.-M. Kang, Mater. Today Energy, 2018, 9, 126-136.

264 X. Li, W. Li, P. Shen, L. Yang, Y. Li, Z. Shi and H. Zhang, Ceram. Int., 2019, 45, 15711-15714.

265 C.-Y. Chou, M. Lee and G. S. Hwang, J. Phys. Chem. C, 2015, 119, 14843-14850.

266 J. Saddique, X. Zhang, T. Wu, X. Wang, X. Cheng, H. Su, S. Liu, L. Zhang, G. Li, Y. Zhang and H. Yu, ACS Appl. Energy Mater., 2019, 2, 2223-2229.

267 A. Abouimrane, D. Dambournet, K. W. Chapman, P. J. Chupas, W. Weng and K. Amine, J. Am. Chem. Soc., 2012, 134, 4505-4508.

268 Y. Cao, M. K. Majeed, Y. Li, G. Ma, Z. Feng, X. Ma and W. Ma, J. Alloys Compd., 2019, 775, 1286-1292.

269 Z. Zhao, T. Yu, S. Zhang, H. Xu, G. Yang and Y. Liu, J. Mater. Chem. A, 2019, 7, 405-411.

270 X.-W. Wang, H.-P. Guo, J. Liang, J.-F. Zhang, B. Zhang, J.-Z. Wang, W.-B. Luo, H.-K. Liu and S.-X. Dou, Adv. Funct. Mater., 2018, 28, 1801016.

271 C. Marino, N. Dupré and C. Villevieille, J. Power Sources, 2017, 365, 339-347.

272 Q. Liang, Y. Zheng, C. Du, Y. Luo, J. Zhao, H. Ren, J. Xu and Q. Yan, ACS Nano, 2018, 12, 12902-12911.

273 W. Zhang, J. Mao, W. K. Pang, Z. Guo and Z. Chen, Electrochim. Acta, 2017, 235, 107-113.

274 J. Li, X. Li, P. Liu, X. Zhu, R. N. Ali, H. Naz, Y. Yu and B. Xiang, ACS Appl. Mater. Interfaces, 2019, 11, 1144211450.

275 A. W. J. Ackermann, J. Phys. Chem. Solids, 1977, 38, 10131016.

276 M. V. David Bellavance, B. Morris and A. Wold, J. Solid State Chem., 1969, 1, 82-87.

277 N. K. M. Sugitan and M. Koizumi, J. Solid State Chem., 1978, 26, 195-201.

278 S. S. J. P. Odile, C. A. Castro and A. Wold, Inorg. Chem., 1978, 17, 283-286.

279 G. S. D. S. Robertson and H. Webber, J. Mater. Sci., 1980, 15, 256-258.

280 H. S. Y. P. C. Donohue, J. Solid State Chem., 1970, 1, 143149.

281 H. Shen, Z. Ma, B. Yang, B. Guo, Y. Lyu, P. Wang, H. Yang, Q. Li, H. Wang, Z. Liu and A. Nie, J. Power Sources, 2019, 433, 126682. 